\title{
Serodiagnosis of Lyme borreliosis : in search of the holy grail
}

Citation for published version (APA):

Goossens, H. A. T. (2002). Serodiagnosis of Lyme borreliosis : in search of the holy grail. [Doctoral Thesis, Maastricht University]. Unigraphics. https://doi.org/10.26481/dis.20021211hg

Document status and date:

Published: 01/01/2002

DOI:

10.26481/dis.20021211hg

Document Version:

Publisher's PDF, also known as Version of record

\section{Please check the document version of this publication:}

- A submitted manuscript is the version of the article upon submission and before peer-review. There can be important differences between the submitted version and the official published version of record.

People interested in the research are advised to contact the author for the final version of the publication, or visit the DOI to the publisher's website.

- The final author version and the galley proof are versions of the publication after peer review.

- The final published version features the final layout of the paper including the volume, issue and page numbers.

Link to publication

\footnotetext{
General rights rights.

- You may freely distribute the URL identifying the publication in the public portal. please follow below link for the End User Agreement:

www.umlib.nl/taverne-license

Take down policy

If you believe that this document breaches copyright please contact us at:

repository@maastrichtuniversity.nl

providing details and we will investigate your claim.
}

Copyright and moral rights for the publications made accessible in the public portal are retained by the authors and/or other copyright owners and it is a condition of accessing publications that users recognise and abide by the legal requirements associated with these

- Users may download and print one copy of any publication from the public portal for the purpose of private study or research.

- You may not further distribute the material or use it for any profit-making activity or commercial gain

If the publication is distributed under the terms of Article $25 \mathrm{fa}$ of the Dutch Copyright Act, indicated by the "Taverne" license above, 
Serodiagnosis of Lyme borreliosis in search of the holy grail 
Book production

Unigraphics, Maastricht

Layout and cover design

Hans A. T. Goossens

(1) 2002, H.A.T. Goossens. All rights reserved.

All chapters previously published are reprinted with the permission of the original copyright holders.

Financial support by Genzyme Virotech GmbH (Germany) for publication of this thesis is gratefully acknowledged. Additional support was granted by : D-tek SA (Belgium). 


\section{Serodiagnosis of Lyme borreliosis in search of the holy grail}

Seradiagnostiek van Lyme borreliose, een zoektocht naar de heilige graal

\section{PROEFSCHRIFT}

Ter verkrijging van de graad van doctor aan de Universiteit Maastricht, op gezag van de Rector Magnificus, Prof. Dr. A.C. Nieuwenhuijzen Kruseman, volgens het besluit van het College van Decanen, in het openbaar te verdedigen op woensdag 11 december 2002 om 16.00 uur

door

Hans Achiel Tony Goossens 
Promotor

Prof. Dr. C.A. Bruggeman

Co-promotor

Dr. A.E.J.M. van den Bogaard

\section{Beoordelingscommissie}

Prof. Dr. P.G. Knipschild (voorzitter)

Prof. Dr. K.M.L. Leunissen

Prof. Dr. J.M.J.P. van der Linden

Prof. Dr. Dr. h.c. A. Rijnberk (Universiteit Utrecht)

Dr. J.F.P. Schellekens (Rijksinstituut voor Volksgezondheid en Milieu, Bilthoven) 




\section{Contents}

\section{Outline of the thesis}

\section{Chapter I}

General review and aims of the study.

\section{Chapter II}

A systematic evaluation of the methodological quality of performance testing of recently published EIA and WB tests for Lyme borreliosis in humans.

\section{Chapter III}

Evaluation of fifteen commercially available serological tests for diagnosis of Lyme borreliosis.

Correspondence Reduced specificity of combined IgM and IgG enzyme immunoassay testing for Lyme borreliosis.

Epstein-Barr virus and Cytomegalo virus infections cause false-positive results in IgM two-test protocol for early Lyme borreliosis.

\section{Chapter IV}

Serodiagnosis of Lyme borreliosis using detection of different immunoglobulin (sub)classes by enzyme-linked immunosorbent assay and Western blotting.

\section{Chapter V}

Dogs as sentinels for human Lyme borreliosis in the Netherlands.

\section{Chapter VI}

Development of a species independent EIA for the estimation of the prevalence of antibodies against B. burgdorferi in Dutch dogs.

\section{Chapter VII}

Prevalence of antibodies to Borrelia burgdorferi in humans and domestic animals in the Netherlands.

General discussion

Summary

Samenvatting

Acknowledgments

Curriculum vitae 



\section{Outline of the thesis}

This thesis attends to several aspects of the development, evaluation and use of enzyme immunoassays (EIAs) for the laboratory confirmation of clinical Lyme borreliosis (LB) and for the study of the epidemiology in humans and domestic animals.

In chapter I a review of the disease LB and its causative organism: Borrelia burgdorferi is presented. Special emphasis was given to the genetic variation in the genospecies $B$. burgdorferi sensu lato and the influence of host and culture conditions on the antigen expression and heterogenicity in relation to the performance of immunoassays.

In chapter II an analysis is presented of the validation of 59 recently published studies evaluating EIAs and Western blotting (WB) for the laboratory confirmation of clinical LB in humans.

In chapter III 11 commercially available EIAs, four WB tests and the EIA-WB two-test protocol, were evaluated. A total of 229 sera of which 39 confirmed LB patients were used as positive controls. Sera of 190 healthy persons or patients with infections mimicking LB or known to cross-react in LB serological assays were used as negative controls. In addition, the effect on the validity of combined IgM- and IgG-EIA testing for LB was analysed. The recommended two-test protocol was examined and searched how specificity could be improved for early LB. A patient group of 57 early Lyme and 256 patients with infections mimicking LB or known to cross-react in LB serological tests were used.

In chapter IV the prevalence of IgA, IgM, IgG and different subclasses of IgG: $\operatorname{IgG}_{14}$ against the various antigens of $B$. burgdorferi were investigated in a population of 40 clinically well defined early and 27 late LB patients, 62 healthy patients and 140 non-Lyme patients with disorders clinically mimicking LB and/or known to cause cross-reactivity in LB serology using WB. In addition to expand the comprehension of sub(class) detection in EIA, the sensitivity and specificity was investigated in EIAs with different antigens.
In chapter $\mathrm{V}$ the sera of 448 hunting dogs and 493 hunters were tested to investigate whether the risk for LB in humans can be deduced from the seroprevalence of the dog population in the same area and whether dogs in an area endemic for LB pose a risk for their owners to acquire LB. In addition the risk of regular outdoor activities in a Lyme endemic area and the persistence of specific antibodies in both man and dogs were examined.

In chapter VI the sera of 501 healthy dogs with different risks for LB and 676 dogs, presented in veterinary hospitals with clinical symptoms attributable to LB, were analyzed for antibodies to B. burgdorferi in order to test the performance and the value of diagnostic tests to support the diagnosis for LB. Furthermore the influence of antigenic heterogeneity on sensitivity of the tests was determined in dogs with clinical manifestations associated with infection by specific $B$.burgdorferi strains in humans.

In chapter VII the prevalence of antibodies against B. burgdorferi in sera of 1052 humans, 1177 dogs, 3919 cattle and 2288 sheep from different regions and biotopes in the Netherlands was determined in order to estimate the risk for humans and animals to become infected with $B$. burgdorferi in these regions and the influence of different biotopes. 

Chapter I

GENERAL REVIEW AND AIM OF THE STUDY 



\section{Serodiagnosis of Lyme Borreliosis In search of the holy grail}

\section{INTRODUCTION}

\section{LYME BORRELIOSIS AND BORRELIA BURGDORFERI}

\section{Infections in humans}

The discovery of the disease and cause of Lyme borreliosis is an exciting chapter in the history of modern medicine. It shows that in this high tech age, new discoveries are possible even with relatively simple tools like epidemiological methods and microscopy by prepared minds. The stimulant to search this bacterial infection was given by two women, Polly Murray and Judith Mensch who were concerned about the abnormal high occurrence of arthritis in the neighboring towns of Lyme and East Haddam. After a long period of lobbying and persistence, their suspicion that something unusual was occurring was accepted by the Connecticut State Health Department, which acquired the help from Dr. Allen Steere, who in 1975 started a retrospective study that led to the description of "Lyme arthritis" (280). Later on "Lyme arthritis" was changed to Lyme disease (277) and after the discovery of the causative agent into Lyme borreliosis (LB). LB is a complex multisystemic infection with protean clinical manifestations. However in Europe, many of its clinical manifestations had already been described in former centuries and were considered as distinct clinical entities.

In the late nineteenth century a diffuse skin atrophy: acrodermatitis chronica atrophicans (ACA) had been described by Buchwald $(47,140)$. Later, Kahle (159) and Grüneberg (125) discovered that ACA patients were seropositive against Treponema pallidum, which lead to the speculations that the disease was caused by a spirochete. In 1955, Lohel claimed that mice inoculated with blood from ACA patients developed antibodies against spirochetes (183), but his observations could not be confirmed by others and finally the hypothesis of ACA being a spirochetosis was rejected. After the discovery of Borrelia burgdorferi, Asbrink finally showed in 1984 that ACA was one of the clinical manifestations of LB (13). In addition, Afzelius had described in 1909 migrating ringlike skin lesions as a result of bites by
Lxodes ricinus ticks: erythema chronicum migrans (ECM) (4). In 1936 Askani concluded that ECM, after reviewing the significance of ticks as vectors of human and animal pathogens, was caused either by a toxin or by a living pathogen from the salivary glands of ticks (14). The discovery that ECM was caused by an infectious agent susceptible to penicillin was made by Binder and co-workers (34). In 1955 they succeeded in transmitting ECM by transplantation of pieces of skin among themselves, taken from the peripheral zone of a lesion of a patient with ECM, and successfully treated their lesions with penicillin. Although this was never been confirmed, the idea suggested by French scientists (112) that ECM is a rickettsial disease was again brought to attention by the electron microscopic demonstration of rickettsialike microorganisms in two ECM patients (250). In the Netherlands, ECM as a result of a bite of lxodes ricinus had been reported as early as 1925 (41) and in 1968 Thöne (291) suggested a bacterial origin since treatment with penicillin or tetracyclines was effective. In 1969 the first reports of ECM appeared in the United States and a cluster of four cases occurring in the midsummer of 1975 in southeastern Connecticut has been described.

In 1922, the French neurologists, Garin and Bujadoux reported a reddish skin lesion followed by a painful meningoradiculitis and speculated that a tickborne virus or spirochete might be the causative agent (112). Yet, the causative agent of ACA, ECM and meningoradiculitis remained elusive till the beginning of the 1980's. The discovery of the causative agent was a result of the investigation of the arthritis epidemic in the townships of Old Lyme and Lyme (Connecticut, USA) by Steere. He found that approximately $25 \%$ of the patients that had suffered from arthritis in the Lyme area, remembered to have recently being bitten by a tick and/or had suffered previously from an expanding skin lesion similar to ECM (280). Arthritis, however had not yet been described in association with ECM and therefore he believed that Lyme patients were suffering from an untill than unknown infection. In his search for the causative agent he focused on tickborne viruses and rickettsial agents (280), but all tests proved negative. 


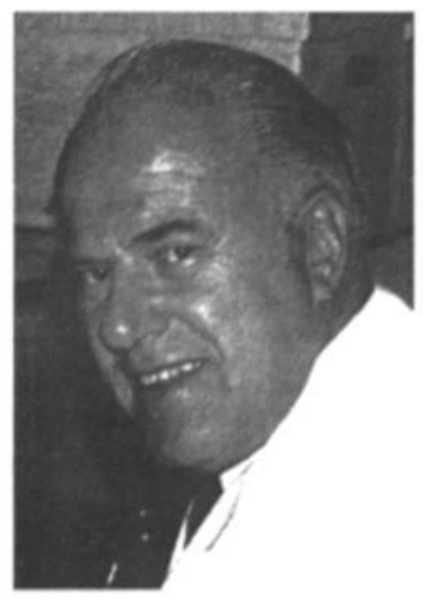

Figure I. Dr. W. Burgdorfer, National Institute of health, Rocky Mountain Laboratories, Hamilton / Montana (USA)

The discovery of the causative agent of LB, ECM and ACA came unexpectedly in 1981 when Willy Burgdorfer (Figure I) was searching for $R$. rickettsii in lxodes dammini-ticks. While checking these ticks, he observed irregularly coiled spirochetes in the midgut of some ticks. Being aware of Hellerströms paper on ECM in 1950 (138), Burgdorfer postulated that this spirochete could indeed be the long-sought-after causative agent of LB. First evidence was provided by the fact that sera of LB patients were positive in indirect immunofluorescence testing with cultured spirochetes. Next, Burgdorfer reexamined ticks he recently had collected in Switzerland. Also in these European Ixodes ricinus ticks he observed spirochetes morphologically identical to those found in Ixodes dammini and Ixodes pacificus from the USA. Soon Burgdorfer succeeded with the help of Barbour to culture the spirochetes in-vitro, which he isolated from the midgut of infected ticks (19). The spirochete was described in 1984 by Johnson et al. to be a new species belonging to the genus Borrelia and in honour of its discoverer the name Borrelia burgdorferi was proposed. Shortly after the reports of Burgdorfer (49-51) spirochetes were demonstrated in ECM lesions (31) and blood of ECM patients $(2,28,278)$.

In Europe, Ackermann (2) was the first to confirm the presence of the spirochete now known as B. burgdorferi in Ixodes ricinus ticks from two foci of the disease in Germany and he successfully treated LB patients with penicillin or tetracyclines. Also cases of LB were reported in the Netherlands $(141,311)$ and Belgium (32, 148). Later on, B. burgdorferi was isolated from Dutch patients (89) and Lxodes ricinus ticks $(33,157,217)$ in the Netherlands and Belgium.

Now LB is considered the most common tickbome disease in humans. Apart from the symptoms in the acute and early stages of the disease, various other clinical manifestations, such as lymphocytic meningoradiculitis (Bannwarth's syndrome) and ACA are now recognised as late stages of LB and to be the result of an infection by B. burgdorferi.

LB occurs in areas where with B.burgdorferi infected hard ticks of the genus Lxodes are endemic. This bacterium infects apart from humans a broad range of other vertebrate hosts, mainly mammals and birds. Several species of mice are the main reservoir of B. burgdorferi $(88,115,145,203,205)$. Transmission from the vertebrate reservoir to humans is done by Lxodes scapularis in the Eastern United States, Ixodes pacificus and Ixodes dammini in Western United States, while lxodes ricinus and Lxodes persulcatus are the primary vectors in Europe and Eurasia, respectively.

\section{Infections in animals}

The first observations in animals of B. burgdorferi infections have been reported in the 60's. In 1966, Hjelle described borrelia-like organisms in the urine sediment of sheep raised in the South of Norway. However, due to failure in culturing the micro-organisms Hjelle was unable to characterize them. In 1969, spirochetes were observed in blood smears from cattle of the Dutch island Ameland and presumptively identified as Borrelia theileri. The facts that; $B$. burgdorferi infected ticks are abundantly present on this island, Borrelia theileri infections never have been diagnosed in the Netherlands and no tick vector for this species has ever been found in the Netherlands, strongly suggests that the observed spirochetes in reality were B. burgdorferi. Soon after the findings of Burgdorfer (49$51), B$. burgdorferi or antibodies against this spirochete were reported in dogs (181), cats (9), sheep, cattle (144), horses $(56,196)$, domestic animals (296), wildlive (22, 38 ) and insects (188).

\section{The causative organism}

B. burgdorferi is a long, slender, and helix-shaped micro-aerophilic Gram-negative, bacterium (Figure II), 10 to $30 \mu \mathrm{m}$ long, 0.20 to $0.30 \mu \mathrm{m}$ wide, composed of 3-10 lose coils and has tapered ends. At each end 7 to 11 flagella are inserted. It is motile with corkscrew-like movements as can be seen using a dark-field or phasecontrast microscope. The organism can be stained according to Gram, Giemsa or with carbol fuchsin (21, 
TABLE 1. Overview of Borrelia burgdorferi proteins described in the litterature and relation to conditional expression factors.

\begin{tabular}{|c|c|c|c|c|c|c|c|}
\hline \multicolumn{3}{|c|}{ Borrelia burgdorferi proteins } & \multicolumn{4}{|c|}{ Conditional expression factors } & \multirow[b]{2}{*}{ Reference } \\
\hline Molecular weight $(\mathrm{kDa})$ & location & name & in vitro cultivation & nemen & 至 & 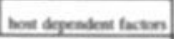 & \\
\hline $83 / 94$ & & & & & & & \\
\hline $\begin{array}{l}78 \\
n\end{array}$ & & & $\begin{array}{c}\text { lp } \\
\text { ap log }-\operatorname{stat} \text { - }\end{array}$ & & & & $\left(\begin{array}{ll}\infty \\
\ln \end{array}\right.$ \\
\hline 60 & & groel. & up & & & & $(20)$ \\
\hline 58 & outer \& inner membrane & & & & patai & & $6 n$ \\
\hline 54 & & & Ip & & & & $(\infty)$ \\
\hline 49 & inner membrane & & & & past & & (5) \\
\hline 45 & & & & & $\operatorname{sic} \theta x$ & & (6) \\
\hline 4 & & & Ip log-stat - & & & & an \\
\hline 435 & & & Ip log-sat 1 & & & & ans \\
\hline $\begin{array}{l}42 \\
41\end{array}$ & membrane & flaB, fapellin & Ip log-stat - & $3 \times \mathrm{C}$ & wast & & (67),2069) \\
\hline 39 & menbrase & BmpA & ip log 1 & & & & ann \\
\hline 38 & & & & $3 \mathrm{~s} ;$ & & & oas \\
\hline 37 & & & & $3 \mathrm{c} ;$ & & & owe \\
\hline 35 & & p3s & Ip stat 1 & $3 \mathrm{C} ;$ & $=18$. & & $(60,67,150,277,200,206$ \\
\hline $\begin{array}{c}35 \\
43.35\end{array}$ & coter surfece & vate & Ip & & & $\mathrm{v}$ & ois \\
\hline 34 & 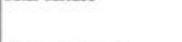 & & Ip log - stat - & & & 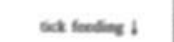 & 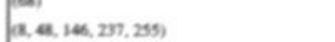 \\
\hline 33 & outer membrane & & Ip & & $=1+7 x$ & & (a) (es) \\
\hline 31-32 & outer surface & oape & Ip log-tate - & & $=1+\mathrm{v}$ & 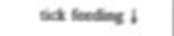 & a.,28, 106, 146, 27, 277, 316 \\
\hline $\begin{array}{l}29 \\
28\end{array}$ & octer surface & opp & Ip log $\operatorname{lota} \mid$ & & & & ans \\
\hline 28 & outer memitraxe & & lp og & & mas & & ess, sa, $2 \mathrm{~m}$ \\
\hline 27 & owter surface & oapp & Ip log-tax 1 & sxt & $\sin 2 \sin x$ & $=1$ & $00,271,201,200,231,36$ \\
\hline 26 & oster memibraxe & & lp & & & & ens \\
\hline 25 & & & & & mat & & (6) \\
\hline 24 & & & p & & & & (a) \\
\hline $23-24$ & outer surfiace & $\cos c$ & Ip log-tax 1 & 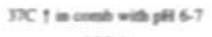 & sta: : & aximent? & 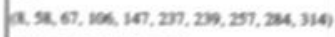 \\
\hline 22 & inner mentrine & & Ip log $-x=1$ & $\mathbf{s c}$ & mast & $\mathbf{s e v}$ & $\operatorname{lom}, 16,207, \operatorname{sen}, 316$ \\
\hline $\begin{array}{l}22 \\
21\end{array}$ & & pQ (ospf related) & 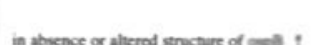 & & & it & $\operatorname{lom}$ \\
\hline 207 & & p21 & (2) & & & $=x$ & 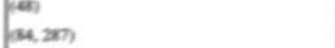 \\
\hline 20 & & & Ip & se: & & & ar.2an \\
\hline 19 & oveder sortice & oppe & 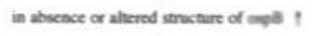 & & & & is \\
\hline 19 & oster serface & Decorrin binding proverims A & 甲 & $3 \mathbf{c}$ & & & las 206 \\
\hline 18.5 & & & & $3 \mathrm{C} ;$ & & nesed i & $\infty, 20,206$ \\
\hline 18 & outer memitrane & & & & & $=x$ & on \\
\hline 179 & & eppa (expented plusmid proteie A) & & 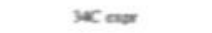 & 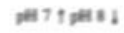 & sat inding $t$ & $\infty$ \\
\hline 179 & oveter membrime & RevA & Ip logetes ! & & & & $\mathrm{am}$ \\
\hline $\begin{array}{l}17 \\
165\end{array}$ & oster surface & Desorim tinding provetims B & 4 & $3 \times 1$ & & & ar:ase \\
\hline 16 & ineer \& cuter membrane & & Ip logetent 1 & & & & (2m) \\
\hline 15 & & & & & & & \\
\hline 14 & memerane & & $p=1$ & & & & (aso. $2 \mathrm{~m}$ \\
\hline $\begin{array}{l}12 \\
75\end{array}$ & & p75 & $1 p \log 1$ & & $=7$ & & (es) \\
\hline & Dembrane & $B=0$ & & & ent 70 & & $\sin$ \\
\hline
\end{tabular}


$142,232,275)$. The cell is surrounded by a highly fluid outer envelope, which contains outer surface proteins (osp's). Still, the presence of lipopolysaccharides in the outer envelope has been a matter of debate $(26,111,289)$ but it has now generally been accepted that the outer membrane of B. burgdorferi does not contain classic endotoxine: lipopolysaccharide (LPS) (289).

The genus Borrelia belongs to the spirochete phylum, which consists of six genera: Treponema, Spirochaeta, Borrelia, Serpulina and Leptospira (223). Borrelia spirochetes are obligate parasites which are transmitted by ticks and include at least seventeen pathogenic species $(21,173)$. For its growth $B$. burgdorferi requires $\mathrm{N}$-acetylglucosamine, a component of the chitin in arthropod cuticles which it uses as a building block for peptidoglycan (19), and ornithine as the diamino-acid to form the crosslinking peptidebonds of peptidoglycan (155). Consequently for isolation complex liquid media are needed like BSK-II (Barbour- Stoenner -Kelly) or one of its modifications $(19,198,292)$. In-vitro, virulence is lost after 10 to 15 passages in BSK but not in ESG (formerly BSKE) medium $(21,127)$. Also co-culturing of $B$. burgdorferi isolates with mammalian cells prevents loss of pathogenicity and protein expression (127). On solid media cultivation of $B$. burgdorferi is difficult but after subculturing, B. burgdorferi grows on adequate semi-solid media (171) in separate single colonies (233). The optimal incubation temperature is $30^{\circ} \mathrm{C}$ to $34^{\circ} \mathrm{C}$ (149) but when stored at $4^{\circ} \mathrm{C}$, cultures remain viable for months. Above $40^{\circ} \mathrm{C}$, the spirochete quickly loses its viability (19). The generation time of $B$. burgdorferi in-vitro varies from 12 to 24 hours depending on the culture conditions. In culture, strains tend to grow in large aggregates in concentrations of up to $10^{8}$ viable spirochetes per ml.

B. burgdorferi isolates show a large genotypic (restriction endonuclease patterns (175), DNA hybridisation $(175,258)$, and rRNA gene restriction patterns (3)) and phenotypic diversity (multi locus enzyme electrophoresis (37), fatty acid profiles (182), protein electrophoresis patterns and monoclonal antibody reactivity $(17,61,290$, 307-309)). Further analysis of this extraordinary genotypic and phenotypic variation within one species elucidated that what originally was considered as a single species $B$. burgdorferi in fact is a complex, that is now called " $B$. burgdorferi sensu lato" with the following assigned genomic groups: $B$. burgdorferi sensu stricto, B. garinii (former group 20047), B. afzelii (former group VS461), B. japonica (former group F63B), B. andersonii (former group 21123 also known as group 21038), B. valaisiana (former groups VS116 and M19), B. lusitaniae (former

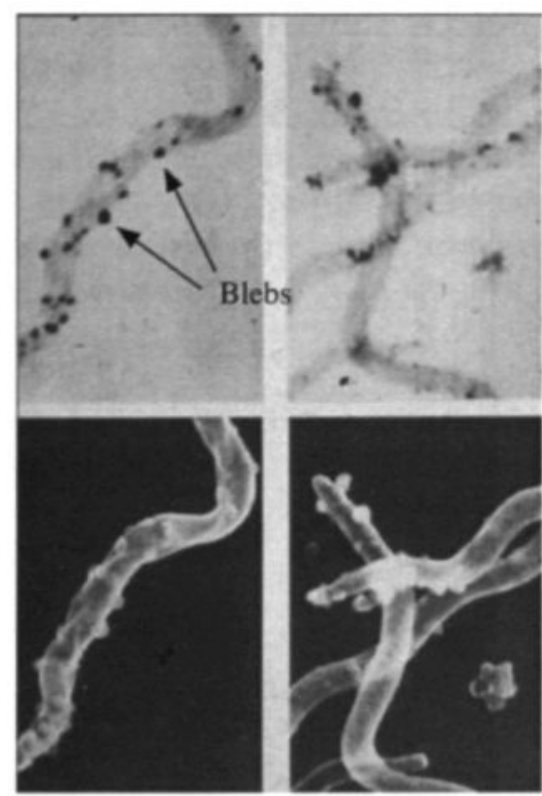

Figure II. B. burgdorferi, silver staining, transmission and scanning electron microscopy. (by Donward D. \& Grom C.)

group potiB2), B. bisettii (former group DN127). This classification into genomic groups explained the differences in clinical symptoms and natural history of LB observed between the USA and Europe. B. burgdorferi sensu stricto is mainly associated with arthritis and is the only genotype endemic in the USA where apart from EM, arthritis is the most pathognomonic symptom of LB. In Europe all genotypes are endemic and hence the observed pathology is much more diverse. Various studies present indirect evidence for the association of $B$. garinii with neurological symptoms, and B. afzelii with late chronic skin lesions ACA $(12,15,92)$. The pathogenicity of $B$. valaisiana and $B$. lusitaniae is still to be elucidated but $B$. japonica does not seem to cause any disease in humans or animals $(200,201)$.

\section{GENOMICS AND PROTEONOMICS}

The genome of B. burgdorferi is composed of a $910 \mathrm{~kb}$ linear chromosome and 21 different plasmids ( 9 circular and 12 linear) (70). Some of these may function as minichromosomes as seen in segmented genomes (20). Not all plasmids are required for in vitro growth, but most are essential for infectivity.

In addition $B$. burgdorferi contains multiple related genes termed paralogues (107) encoding for proteins with presumably similar functions. This might compensate for the loss of plasmids during infection. Moreover, this 
TABLE 2 Clinical manifestations of Lyme borreliosis*

\section{Early localized Lyme borreliosis:}

- Erythema migrans (50-70\%)

- Fatigue/malaise/lethargy

- Headache

- Myalgia

- Arthralgias

- Localized lymphadenopathy

Early disseminated Lyme borreliosis: (days to 10 months after the tick bite) (with or without prior features of localized LB)

- Carditis (8-10\% of untreated patients)

Conduction defects

Cardiomyopathy

- Neurological (10-12\% of untreated patients)

Meningitis

Encephalitis

Cranial neuropathy

Peripheral neuropathy/radiculopathy

Myelitis

- Musculoskeletal ( $\pm 50 \%$ of untreated patients)

Migratory polyarthritis and/or polyarthralgias

- Other rare manifestations

$\begin{array}{ll}\text { Cutaneous: } & \text { Lymphadenosis benigna cutis (Lymphocytoma) } \\ \text { Lymphadenopathy: } & \text { localized and/or generalized } \\ \text { Ophtalmologic: } & \text { Conjunctivits, iritis, choroiditis } \\ \text { Hepatic: } & \text { Liver function abnormalities, hepatitis } \\ \text { Renal: } & \text { Microhaematuria, proteinuria }\end{array}$

Late Lyme borreliosis: (months to years after the tick bite)

Musculoskeletal

$\pm 50 \%$ of untreated patients $>>$ migratory polyarthritis

$\pm 10 \%$ of untreated patients $->$ chronic monoarthritis of a knee

Neurological

Chronic, often subtle, encephalopathy

Chronic, often subtle, peripheral neuropathy

Ataxia, dementia, sleep disorder

\section{Cutaneous}

Acrodermatitis chronica atrophicans (ACA)

(Morphea/localized scleroderma-like lesions?)

*) modified according to $(101,266)$ 
genetic redundancy might provide the micro-organism with a battery of genes that code for antigenic variable proteins with compensatory functions, which are sequentially expressed via reversible phase variation or modified further by recombination. It is tempting to speculate that this two-component regulatory system of the genome may be involved in sensing and modulating gene expression in order to adapt to the host. Although antigenic variation in B. burgdorferi has been established, mechanisms mediating such a response in the tick, vertebrate and/or during cultivation, are unknown. Identification of such variable determinants may help to understand phenotypic variants that are selected to escape the host response and to explain the chronic infection associated with LB, tissue tropism and differences in clinical symptoms of LB.

Many B. burgdorferi surface, membrane, and cytoplasmic proteins, lipoproteins, lipids (156), and carbohydrates $(98,303)$ have been described. Prominent protein and lipoprotein antigens of B. burgdorferi are the outer surface proteins (osps) : ospA and ospB (21), ospC (309), ospD (238), ospE, ospF (172) and ospG (299); a 41-kDa flagellin (300) and a hook body protein which is part of the periplasmic flagellum encoded by flgE (158); $58 \mathrm{kDa}$ (131), $66 \mathrm{kDa}$, and other heat shock proteins (64); $22 \mathrm{kD}$ (268, 301), BmpA $39 \mathrm{kDa}(245), 55 \mathrm{kDa}(103), 66 \mathrm{kDa}$ (234), 66-73 kDa (184) and $93 \mathrm{kDa}(297)$ proteins; and a putative glyceraldehyde 3 phosphate dehydrogenase (7). OspC in B. burgdorferi (248) is encoded on a circular plasmid and analogous with the surface variable membrane proteins (Vmps) expressed by other Borrelia spp. (69, 96, 197). Different genospecies of Borrelia express similar but different surface proteins. Hence their presence may be genomic group specific, but, as described, the expression of many (lipo)proteins by B. burgdorferi is influenced by the environment in which

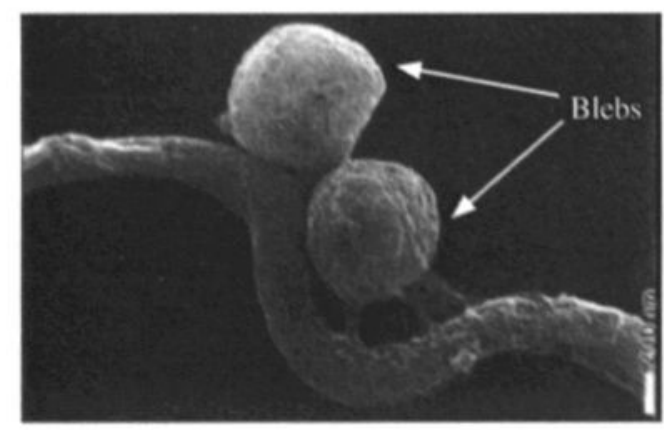

Figure III. naturally elaborated membrane blebs on the surface of cultured Borrelia burgdorferi. (by Dornuand $D$. \& Gron $C$ ). the micro-organism is grown: a tick, a mammal or bird, or in vitro. For instance, protein EppA (exported plasmid protein A), not expressed by $B$. burgdorferi in ticks has been retrieved from patient serum (71). Furthermore a decrease in ospA and an increase in the expression of ospC has been demonstrated $(57,91,106,257)$ in the last $12 \mathrm{hrs}$ of tick attachment and transmission of B. burgdorferi to the mammalian host. Further, experimental infections via tick bites induce antibodies against different antigens compared to injections (intracutaneous) of the same cultured $B$. burgdorferi-strain $(106,117)$. Several differences in environment and culture conditions which influence the expression of protein expression of $B$. burgdorferi are shown in Table 1.

An interesting finding is the production of membranebound blebs (Figure II and III) of B. burgdorferi, which detach from the parent organism, after being exposed to a mammalian host (264). These blebs contain DNA $(113,228)$ and have osps on their surface $(265,269,304)$. Therefore they might distract the hosts immune responses and help survival of B. burgdorferi in the host.

Since all borrelial species are host-propagated bacteria that shuttle between a vertebrate and an arthropod host, the survival of B. burgdorferi in tick and vertebrate hosts largely depends on their ability to quickly adapt to new environments. The dynamic genome arrangement, the significant plasticity and adaptability of the genome may be necessary for its survival in different environments as ticks and warm blooded animals (70). However details pertaining to the genetic and metabolic regulatory pathways that allow for this differential gene expression are unknown. Moreover, a shuttle between a vertebrate host might be an essential step in the natural history of LB, as it has been shown that repeated passages of $B$. burgdorferi through laboratory mice caused a decline in virulence and a modified protein expression $(116,256)$. After isolation of $B$. burgdorferi from mouse brain after experimental infection, the used B. burgdorferi strain showed a change in its plasmid content and was more resistant to antibiotics and less to complement-mediated killing (220). However in other studies no such changes in antigen expression (24) nor in plasmid profile (227) were seen. In addition the host immune response might also select for strains expressing or not expressing certain antigens. For example, the finding of only just an ospA variant in one of the subsequent samples of a patient's synovial fluid, suggests that during infection, host immune responses may also select for B. burgdorferi variants resistant to the antibodies produced (104).

It is clear that changes in protein expression is strongly 
correlated with environment adaptation and might influence virulence factors $(27,235,246,247)$. In addition the volatile antigen variety of $B$. burgdorferi poses many problems in the development of laboratory tests. The fact that many antigens (Table 1), that are either de-repressed or repressed in conjunction with (changes in) cultivation conditions and host adaptation, are also variable among different strains and genotypes of $\boldsymbol{B}$. burgdorferi makes it difficult to develop a single serological test with a high degree of specificity and sensitivity needed to provide adequate laboratory support for the diagnosis of the different forms and stages of LB.

Use of the knowledge and study of those variable antigens might lead to the identification of specific proteins that are expressed during different stages of infections and/or related with particular symptoms of LB, which might improve therapy and laboratory diagnosis.

\section{IMMUNE RESPONSE}

After an infection with B. burgdorferi the first humoral immune response is $\mathrm{IgM}$ production directed to various antigenic components of the invading $\boldsymbol{B}$. burgdorferi strain $(80,236)$. The maximum production of $\mathrm{IgM}$ is usually between week 3 and 6 after infection $(80,236)$. This IgM response is followed by the production of IgG, which reaches its maximum between week 4 and 6 after infection (80). Other isotype responses have been described: IgE against the $41-\mathrm{kD}$ protein (29) and IgA responses (243). Of IgG, several subclasses are produced: a prominent $\mathrm{IgG}_{1}$ and $\mathrm{IgG}_{3}$ response which in contrast to the $\mathrm{IgG}_{2}$ response were not absorbed out by Treponema phagadenis (136). In certain patients suffering from LB an apparently new $\mathrm{IgM}$ response to $\mathrm{OspB}(34 \mathrm{kD})$ has been observed during the late stages of the disease (80). The earliest specific antibody production found is directed against the $41-\mathrm{kD}$ flagelline protein (cross-reactive with Treponema pallidum), followed later on by a response to more antigens ( $15 \mathrm{kD}, 27 \mathrm{kD}, 66 \mathrm{kD}$ and $83 \mathrm{kD})$, and months or years later to still others $(17 \mathrm{kD}, 29 \mathrm{kD}, 31 \mathrm{kD}$ ospA, $34 \mathrm{kD}-\mathrm{ospB}, 60 \mathrm{kD}$ and $75 \mathrm{kD})(80)$.

Cross-reactivity also occurs because of shared antigenic determinants of the $41-\mathrm{kD}$ antigen of B. burgdorferi with cardiac muscle lipids (1) and neural tissue (267) but may also be provoked by other Borrelia spp. and Treponema spp. $(44,81)$. In certain instances reactivity to B. burgdorferi antigen components might also be caused by nonspecific polyclonal B cell stimulations which are the result of an infection with a T-independent B cell stimulating virus like Epstein-Barr virus $(87,137,162)$.
Early, even inadequate, antibiotic treatment can prevent the production of antibodies against $B$. burgdorferi and render patients permanently seronegative (86). Other patients, do not seroconvert until eight weeks after an infection with $B$. burgdorferi and some seroconvert not at all (275). Although an explanation for this phenomenon is not known, it has been postulated that these produced antibodies are sequestered in immune complexes (253, 254). Such immune complexes containing $B$. burgdorferi antigens have been found in the spinal fluid of patients with LB (77-79). Seropositivity, including IgM seropositivity, may persist for long periods after the patient has recovered $(6,163)$. The cellular immunity consists of a T-cell response including suppressor cells which can shut off or tune down the humoral response. The suppressor activity may be specific for particular antigens, or may be more global and limit the response to a number of antigens. The micro-organism B. burgdorferi has profound effects on T cells as well in vitro and in vivo. The dynamic relationship between specific helper and suppressor cells, just as the different temporal exposure of the immune system to particular antigens during a $B$. burgdorferi infection, might explain the variability in humoral immune response and the variation in the course of $\mathrm{LB}$ between different patients.

\section{CLINICAL SYMPTOMS OF LB IN MAN}

In Europe, the chance of developing clinical LB for humans after a bite of an infected tick is $2 \%$ to $4 \%$ (102, 224,252 ). The risk of human infection mainly derives from the nymphal stage of the vector tick because larva are rarely infected and the adult tick is large enough to be noticed and promptly removed. Given that the spirochetal infection rate in Europe of the nymphal stage is 18\% (204) results in a risk of acquiring clinical LB after a tick bite to be lower than $1 \%$. Apart from the low risk of getting LB after a tick bite, many B. burgdorferi infections most likely do not cause any clinical symptoms as might be concluded from the numbers of seropositive individuals that are found in healthy populations like blooddonors or risk groups such as hunters, and those who had not suffered from symptoms of LB $(102,170,218)$.

As shown in Table $2(101,266)$, the clinical symptoms of LB, which can affect a variety of organ systems, i.e. skin, joints, heart, and nervous system, can be divided into early localized LB, early disseminated LB and late (chronic) LB. Early localized LB infection is often limited to a mild 'flu-like' illness or general malaise with or without erythema migrans (EM). EM is an annular 
skin rash that begins days to weeks after and on the spot of a tick bite. It expands gradually with a whitening of its center. Borrelial lymphocytoma is a very uncommon form of early localized LB, which is usually seen on the earlobe (especially in children), nipple or scrotum. It usually appears as an intense bluish-red localized painless patch of skin. The patient may not recall a tick bite, but will have a history of recent exposure to ticks. Histological examination shows very dense lymphocyte infiltrates.

In early disseminated LB, the organism can spread through the bloodstream and lymphatics to other tissues, such as other parts of the skin, nervous system, muscles and heart. The wide variation of clinical symptoms, that can develop from a few weeks to over a year after the initial infection with $B$. burgdorferi depends on the organ systems infected. Worsening of clinical symptoms and/or swelling of the lymph nodes (glands) of the area affected by EM, development of multiple erythema migrans, severe arthralgia, myalgia, headache or neck stiffness, indicates dissemination of the infection. Other clinical symptoms that occur usually months rather than weeks after initial infection are radiculopathy recurrent arthritis with effusion: carditis with conduction defects (usuallv partial heart block); early neuroborreliosis (facial palsy, other cranial nerve palsies, meningitis, encephalitis and peripheral neuritis). Other rare manifestations of early disseminated LB are anterior and posterior uveitis, panophthalmitis, hepatitis, myositis and orchitis. Like in syphilis, during the early stages of LB, relatively large numbers of B. burgdorferi can be found in the affected organs or blood. However, the numbers of spirochetes present in the late stages of the disease are low and clinical symptoms might be largely due to the reaction of the host to the causative micro-organism.

Late (chronic) LB causes clinical symptoms years after the initial infection and may involve the joints (chronic Lyme arthritis), skin (acrodermatitis chronica atrophicans) or, rarely, chronic neurological syndromes like Lyme encephalopathy. The fact that chronic Lyme arthritis is diagnosed more commonly in North America compared to Europe is most likely because the only $B$. burgdorferi genotype that is endemic in the USA (B. burgdorferi sensu stricto) has an affinity for the joints (276). Lyme arthritis typically manifests itself as an intermittent or chronic mono- or oligoarthritis of the large joints, especially the knees, and rarely with erosions of cartilage or bone, or tendinitis. Sometimes it develops in patients who have during earlier stages of the infection suffered from intermittent arthralgias or oligoarthritis. Gradually these symptoms progress into continuous chronic arthitis. Even without treatment these patients may recover fter several years, but in severe cases affected joints mght have been damaged beyond repair. There are indicatons that genetic predisposition also plays a role in chnnic Lyme arthritis, particularly in patients with treatnentresistant arthritis $(242,260,279)$.

In Europe acrodermatitis chronica atrophicans (ACA), an unusual progressive fibrosing skin infection vith B. burgdorferi, is the common manifestation of ate LB. Viable B. burgdorferi have been isolated from kin biopsies of ACA patients as long as 10 years after prinary infection. It usually affects the lower limbs of elerly people, starting with a bluish discolouration of the kin, followed by gradual epidermal atrophy. A rare form of ate LB and a chronic infection with $B$. burgdorferi is chrnic Lyme encephalopathy with memory loss, depresion, sensory polyneuropathy and/or spastic paraparesis. The chronic fatigue syndrome (CFS) or fibromyalgia has ben associated with late Lyme encephalopathy $(99,114,393$. 294). This later condition may have been triggered ly a preceding $B$. burgdorferi infection (amongst many oher possible triggers), but no active $B$. burgdorferi infecion is,ncesent

ACA and Lyme encephalomyelitis are more common in Europe and Asia but are infrequent among patients in North America $(207,213,276)$. In Europe, along with $B$. burgdorferi sensu stricto also other genotypes like B. afzelii, B. garinii and B. valensiae are endemic and infections with $B$. afzelii has been associated with ACA. However, all genospecies can cause erythema migrans and neuroborreliosis.

\section{CLINICAL SYMPTOMS OF LB IN DOMESTIC ANIMALS}

In contrast to human LB, where the clinical picture is heterogeneous but relatively well defined $(213,273)$, clinical symptoms of LB in animals are not clearly characterised and reports of clinical LB in animals are much less common and often controversial. A variety of clinical symptoms in cattle have been attributed to infections with $B$. burgdorferi. Fever, lameness, single or multiple swollen joints, arthritis, weight loss and diminished milk production are the most common clinical symptoms in cattle $(52,54,180,302)$. A warm hypersensitive hyperaemic skin lesion resembling the erythema migrans rash in humans has been observed on the udders of infected cows (180). B. burgdorferiinfections have also been blamed for occurrence of 
chronic weight loss, laminitis and abortions in cattle (63). In sheep the clinical symptoms attributed to LB are similar to those described in cattle $(59,74,108,144$, 210). In dogs the most typical clinical symptom of LB is considered lameness combined with malaise (122, 151). The malaise may be caused by fever resulting in listlessness and/or lack of appetite (151). Experimental infestations of dogs with $\boldsymbol{B}$. burgdorferi-infected ticks caused fever and lameness in one or more legs within 210 days after challenge in all exposed animals (60). Other clinical manifestations in dogs are lethargy, lymphadenopathy, and heart block $(169,176,190)$. In addition a proliferative glomerulonephritis with tubulonecrosis and lymphoplasmatic infiltration caused by a $B$. burgdorferi infection has been described $(83,121)$ and the presence of spirochetes have also been observed in silver stained liver sections from dogs with chronic active hepatitis (35). Also in horses LB has mainly been associated with lameness $(43,53,55,76,222)$. Other clinical signs associated with $B$. burgdorgfer in horses include arthritis $(55,76)$, uveitis (55), encephalitis (56), limb edema (76), dermatitis (76) and foal mortality (53).

\section{LABORATORY DIAGNOSIS}

Since the discovery of $B$. burgdorferi as the agent of LB, many laboratory tests have been developed to support the clinical diagnosis of LB. Every test has its inherent advantages and limitations. Direct laboratory tests are isolation of the causative micro-organism, its detection by staining or demonstration of specific nucleic acid sequences and antigens. Indirect laboratory tests are based on the detection of antibodies against B. burgdorferi in serum and other body fluids. Currently, the diagnosis of LB is mainly established on clinical symptoms and epidemiological grounds: stay in an endemic area, exposure to ticks, a tick bite, presence of clinical symptoms consistent with LB, exclusion of other diseases that cause similar symptoms, a positive response to antibiotic therapy. Still, laboratory test should only be used for confirmation of a clinical diagnosis of LB (270).

\section{Culture}

Isolation of B. burgdorferi from biopsies of affected organ systems or blood is the "golden standard" for the diagnosis of human LB. It has been used successfully for skin biopsy or cutaneous lavage specimens from patients with EM lesions and blood from patients with symptoms of early-disseminated LB. Positive culture rates of nearly $90 \%$ for secondary EM lesions, $50 \%$ for primary EM lesions, and $48 \%$ for large-volume $(\geq 9 \mathrm{ml})$ blood or plasma specimens from non treated patients with early LB have been reported $(208,211,259,313)$. Isolation of B. burgdorferi from other sites, such as cerebrospinal fluid and synovial fluid has much lower recovery rates. This probably reflects the small number of viable organisms present in those anatomic locations and in general during the late stage of the LB. Furthermore isolation is time consuming, expensive and not available in most clinical situations. Isolation can therefore not be adviced for routine testing for LB. However isolation could be considered to confirm the diagnosis of LB in untreated patients having lesions suspected to be primary EM, particularly as these appear atypical. Although histopathology of LB lesions is not specific, it is useful for excluding other diseases. However in most cases EM can be easily recognised and is so pathognomonic for LB that no laboratory confirmation of the clinical diagnosis is required.

\section{Polymerase chain reaction (PCR)}

Because of the low sensitivity of isolation or antigen detection of B. burgdorferi, PCR tests have been developed in an attempt to increase sensitivity without losing specificity and to decrease the time required for laboratory confirmation of LB. These assays are based on the amplification of specific $B$. burgdorferi sensu lato nucleic acid sequences present in biopsy specimens or body fluids. Both single-stage and nested PCR assays have been developed (251). Detection methods vary from gel electrophoresis and Southern hybridization to real-time PCR with quantitation of product (251). Both plasmid and chromosomal targets have been used (251). Targets carried on plasmids, such as genes that code for ospA, ospC, and vlsE, are present in multiple copies within each bacterium, resulting in a higher sensitivity than use of single-copy chromosomal targets (251). Before the appearance of serum antibodies and without the delay associated with culture isolation, PCR can be used to confirm detection of $B$. burgdorferi in EM lesions (259). A recent meta-analysis of PCR detection of B. burgdorferi in EM biopsies showed an overall sensitivity of $68 \%$ (range: $59 \%-84 \%$ ) and a specificity of $100 \%(95)$. In contrast with isolation, the detection of B. burgdorferi in blood or plasma of patients with early-disseminated LB with PCR has been disappointing. The sensitivity in patients with primary EM and secondary EMs was $9.5 \%$ and $40 \%$ respectively (259). However, sensitivities which varied from $59 \%$ - $88 \%(40,174,212,259,298)$ have also been reported in patients with EM. 
PCR has been used successfully to identify B. burgdorferi nucleic acids in a high percentage of synovial fluids from patients with untreated Lyme arthritis (215). A meta-analysis of similar studies revealed an overall sensitivity of $73 \%$ and specificity of at least $99 \%$ (95). Untreated patients have been found to have ospA coding DNA in the synovial fluid of their affected joints, while patients with persistent arthritis after antimicrobial therapy are unlikely to have any detectable plasmid or chromosomal DNA. This finding supports an immune response-mediated etiology for persistent arthritis rather than an active infection requiring additional antimicrobial therapy (279). The results using CSF are highly variable. The overall sensitivity was only $20 \%(95)$, but this is higher than the isolation rate of B. burgdorferi from CSF, which is relatively rare $(229,241)$. Neuroborreliosis patients are in nearly all cases seropositive and antibodies to B. burgdorferi can be detected in $\operatorname{CSF}(213,276)$. However, for the few patients that are seronegative despite having a significant clinically likelihood of neural LB or for patients showing a particularly confusing array of neurological symptoms, additional testing is indicated. In those cases PCR of CSF could be used.

A controversial area for molecular testing is the detection of specific B. burgdorferi antigens or nucleic acids in urine. Still, a Lyme antigen test for urine has been evaluated and was not found to have sufficient reproducibility to be useful in clinical practice (168). Furthermore, several PCR assays have been developed for testing of urine specimens but sensitivities varied from $13 \%$ to $100 \%$ (95) and positive PCR results for urine did not correlate with clinical disease.

\section{IMMUNE-DIAGNOSIS}

B. burgdorferi induces a humoral and cellular immune response where the initial immune response is mediated by T-cells. The T-cell response is followed by the production of specific antibodies by B-cells (85). Thus, demonstration of an immune response to $B$. burgdorferi sensu lato is possible either by T-cell proliferation assay or serology. Methods for the detection of antibodies to $B$. burgdorferi sensu lato include immune complextest, detection of borreliacidal antibodies, immune fluorescence assay (IFA), indirect hemagglutination assay (IHA), enzyme immuno assay (EIA) and Western blotting.

\section{T-cell test}

Despite that patients treated early after infection may fail to develop detectable antibodies, they usually will show an active T-cell proliferation response to $B$. burg. dorferi (85). Laboratory tests of T-lymphocyte recognition of B. burgdorferi are relatively complicated and are therefore not readily available in clinical practice. Furthermore, reports of the specificity $(87 \%-99 \%)$ and sensitivity ( $30 \%$ to $60 \%$ ), show that the T-cell assay, is not an improvement over most other laboratory tests $(94,213)$.

\section{Detection of antibodies Immune complex-test}

Detection of circulating immune complexes (IC) has been advocated as an approach to find specific antibodies during very early stages of LB, when excess B. burgdorferi antigens bind to IgM antibodies, making them undetectable by more commonly used tests. Since IC formation requires ongoing $B$.burgdorferi antigen availability, IC-based assays might be useful in distinguishing positive serology associated with active infection from residual antibodies from a prior infection (45).

\section{Detection of borreliacidal antibodies}

Borreliacidal antibodies are produced early in the course of LB and are able to immobilize B. burgdorferi which can be detected by a flow cytometry based assay (143). The reported sensitivity is $72 \%$ for patients with early LB. It has been claimed that this test might be useful in differentiating between acute and convalescent LB as it can distinguish positive serology associated with active infection from the residual antibodies from a prior infection.

\section{Indirect hemagglutination antibody assay (IHA)}

The $B$. burgdorferi IHA is procedurally very similar to one of the passive hemagglutination techniques (39, 274) that were originally developed $40-50$ years ago for detection of specific antibodies. In this technique red blood cells (RBC) from sheep are coated with cell components of $B$. burgdorferi. In the presence of reactive antibodies, antigen coated RBC will agglutinate or clump. Antibody levels are quantitated to an endpoint titer by diluting the serum sample until little or no agglutination of sensitized RBC visually can be seen. The test is easy to use but cross-reactions with other bacterial species or high titer heterophile antibodies can occur $(82,206,216)$. A disadvantage of the IHA is that in case of reaction of the patients serum against the carrier material, erythrocytes 
from an other species than sheep are needed. Although the IHA showed an overall lower sensitivity compared to IFA or $\operatorname{EIA}(82,206,216)$, recent reports list a higher sensitivity for IHA compared to ElA (225) and demonstrated IHA to be an interesting tool for the detection of an acute Lyme infection because of its high sensitivity for IgM antibodies (119). However the contradictory foundings in the previous reports $(82,206,216)$, compared to the report of Pavia (225), probably are the result of a low number of clinical defined ELB patients searched. Furthermore with the current knowledge of $\boldsymbol{B}$. burgdorferi specific proteins, the use of purified or recombinant-derived proteins in IHA could prove to be a valuable laboratory procedure for aiding in the diagnosis of LB. In addition, the versatility of this visually read immunoassay includes its ready adaptability with minimal modifications for rapidly detecting borrelial antibodies present in various body fluids such as synovial and cerebrospinal fluid, as well as in the sera of virtually any mammalian species, especially dogs. The latter seem to be almost equally susceptible to some of the pathological complications of LB as man, thereby making the IHA test potentially of great value for veterinary diagnostic purposes (119). Furthermore IHA testing is relatively inexpensive and simple to perform, requires minimal technician time or expertise, and does not need any additional major equipment. IHA can be reported in a semi-quantitative format and could possible be used for screening $(110,130,271)$.

\section{Enzyme immuno assay (EIA) /}

Immune fluorescence assay (IFA)

EIA and IFA are the most commonly used tests for the serological diagnosis of infectious dieases including LB. These tests are ideal for high-volume testing, only need a small sample volume to test and provide reproducible objective results. Despite the fact that EIA and IFA tests are the most commonly used tests for the laboratory confirmation of LB, there is little or no standardization among the numerous commercial kits for LB diagnosis available on the market (42). When results from different laboratories for well-characterized proficiency samples are compared, significant differences in the sensitivities and specificities of EIA and IFA have been observed (16). One of the reasons could be that as earlier mentioned, B. burgdorferi sensu lato, is a complex bacterium with numerous antigens on its surface and in its outer membrane as well as within the cytoplasm. Moreover the expression of these antigens is variable and not only genotype and strain dependent but also influenced by the environmental and culture conditions in which an isolate is grown. These antigens offer a wide array of potential targets for immuno serologic testing in humans as well as in animals. Among the most important antigens are the outer surface proteins ospA to - G, the 41-kDa flagellin protein, and a number of heat shock proteins $(44,306)$. The $23 \mathrm{kDa}$ ospC lipoprotein is a highly immunogenic antigen which demonstrates considerable variation, a situation analogous to the variable membrane proteins expressed by other Borrelia spp. $(69,96,197)$.

Although the different genospecies of B. burgdorferi sensu lato express generally similar antigens, significant differences do occur. These differences complicate development of a single immunoserologic assay for laboratory testing for LB in patients, which can be infected with any of the genospecies $(18,213,276)$. This might explain differences in test performance observed with different patient populations and between results of different tests using the same serum panel. In addition in order to improve sensitivity and specificity some immunoserologic tests with whole-cell preparations of B. burgdorferi are modified. Modifications can include; an adsorption step to block cross-reacting antibodies (100); single use or enrichment of the antigen source with flagellin, $\mathrm{p} 39$, or other B. burgdorferi sensu lato-specific antigens $(132,134,135,137,152,160,164,167,178,189$, $191,193,202,214,216,221,240,272$ ); fractionation of the $B$. burgdorferi sensu lato antigen source (72) or the use of an antibody capture step in EIA $(30,46,315)$.

Despite the improvements made in EIAs and IFAs they still have the drawback of lacking sensitivity for early disease. Therefore, for patients who have been exposed to ticks in endemic areas and present with EM which is pathognomonic for early LB, additional laboratory testing is not indicated. In clinical practice the vast majority of patients with extracutaneous LB are found to have detectable serum antibodies. However, occasionally seronegative patients present with a history of tick exposure and rheumatologic or neurological symptoms indicative for LB. In these cases localized intrathecal or synovial production of specific antibodies can be detected. However, specific antibody synthesis in the CSF or joint fluid can only be indicated by an antibody index defined as the ratio between the CSF or joint fluid / serum quotient for specific antibodies and the quotient of total IgG or IgM concentrations in CSF or joint fluid and serum (161, $293,295)$. The decision of whether or not to perform laboratory testing for patients who present without EM but with other clinical symptoms, indicative for LB requires a certain probability that the illness is actually LB $(36,42,312)$. The American College of Physicians 
(ACP) recommends serologic testing for patients with objective clinical signs that have a pretest probability of LB in the range of 0.20 to 0.80 (11). Patients with vague subjective complaints such as headache, fatigue, and myalgia are considered to have a low pretest probability of LB $(\leq 0.20)$. A positive EIA result in such setting very likely represents a false-positive result and can lead to misdiagnosis as well as unnecessary use of antibiotics for therapy. Because LB incidence rates and vector abundance vary widely between different geographic areas, it can be difficult for physicians to have sufficient information to allow accurate assessment of pretest probability of LB for individual patients. Exaggerated perceptions of LB risk by patients and health care providers results in unnecessary testing and a significant increase of false positive results resulting in antibiotic misuse and other associated expense (18). Still, EIA currently is the most favoured test for serological as well as epidemiological studies $(23,120,128,129,218,226,230,231,249,252$, $282,285,317)$.

\section{Immunoblotting allows detection of antibodies} to individual antigens of B.burgdorferi sensu lato. Antigens can be derived from whole-cell preparations of B. burgdorferi sensu lato or from expressed proteins taken from recombinant DNA. Both IgM and IgG immunoblotting kits are available but $\mathrm{IgM}$ is less specific than $\operatorname{IgG}$ immunoblotting, and patients with symptoms lasting longer than 4 weeks should have only IgG antibody testing done (93). In the USA, the Centers for Disease Control and Prevention (CDC) recommends that all serum specimens for LB diagnosis have to be evaluated in a two-step process (154). The first step consists of a sensitive serologic test, such as EIA or IFA. Specimens found to be negative are not tested further. All specimens with positive or questionable results are to be confirmed by immunoblotting, using standardized criteria for interpretation. When immunoblotting is used in the first 4 weeks after the onset of disease, both IgM and IgG immunoblotting should be performed. Most LB patients will seroconvert within this 4-week period. When a patient is suspected to have early LB and has a negative serology a second serum sample should be taken and both the paired acute- and convalescent-phase samples should be tested. Since specific IgG antibodies are present in nearly all untreated patients 1 month after infection, detection of IgM antibodies cannot be considered to support the diagnosis and may represent a false-positive result (10). An IgM immunoblot result is considered positive if any
2 of 3 bands (the 23-, 39-, and 41-kDa bands, with the $23-\mathrm{kDa}$ band representing ospC) are present (10). An IgC immunoblot result is considered positive if any 5 of 10 bands (the 18-, 23-, 28-, 30-, 39-, 41-, 45-, 58-, 66-, and 93-kDa bands, with the 23-kDa band representing ospC) are present (10). Furthermore when immunoblotting results are interpreted, the evolution of the immune response in LB should be taken into consideration (6). Fo: example, IgG immunoblotting with an acute-phase serum sample that reveals no bands might be followed severa weeks later i.e. during the convalescent-phase by a serum sample that shows four of the five diagnostic bands ir the IgG immunoblot. According to CDC criteria, both IgG test results should be considered negative. However, the results are strongly suggestive of a forthcoming sero-conversion. In the proper clinical context, this IgG response can be supportive of a clinical diagnosis of LB (10). In Europe and Asia, the development of a uniform approach for the immunoserologic evaluation of LB is complicated by the presence of three genospecies of the B. burgdorferi sensu lato genogroup and by significant antigenic variation within each genospecies (306). Despite European efforts to standardize immunoblotting methodologies and interpretive criteria, no consensus has been reached yet. In Europe it may be necessary to develop immunoserologic assays with antigens originating from the endemic genotypes of the B. burgdorferi sensu lato genogroup to improve performance $(133,244)$. Other immunologic assays have been developed to aid in the clinical diagnosis of LB, but have not been evaluated as thoroughly as EIA, IFA, and immunoblot assay (11). However, in the USA none of the assays currently used for the testing of LB in blood, plasma and serum samples for CSF or joint fluid testing have been approved by the USA Food and Drug Administration (FDA) (42).

\section{Laboratory testing in vaccinated individuals}

In 1998 the FDA approved a recombinant ospA vaccine for use in patients (age range, 15 to 70 years) at risk of acquiring LB (281). Since the protection provided by the vaccine after three doses is approximately $80 \%$, there is still a chance that vaccinated individuals develop LB after natural infection. EIAs and IFA assays utilizing ospAproducing strains of $\boldsymbol{B}$. burgdorferi will not discriminate between vaccinated and naturally infected individuals. Therefore, the CDC two-step algorithm is not applicable to vaccinated patients and only immunoblotting can be used for serologic confirmation of infection. The development of ELAs or other first-line assays using a nonospA-producing B. burgdorferi strains or recombinant 
borrelial antigens other than ospA as antigens $(118,168$, 178 ) has been suggested as a way to solve this problem, but the observation that some vaccinated patients produce antibodies that bind to various borrelial proteins, might make interpretation of test results of vaccinated patients very difficult if not impossible (5).

Laboratory testing in domestic animals.

Currently, serology is the only practical laboratory aid available for the diagnosis of LB in animals. The fact that clinical symptoms of LB in animals are much less common and not clearly characterized compared to human LB $(213,273)$ diagnosis is frequently solely based on serological tests. Although IFA was initially used to detect antibodies in animals, the EIA used for human LB serology is adapted for the detection of $\operatorname{dog}(105,123$, $124,126,165,177,179,190,192,195,262,263,286$, $305,310)$, sheep $(73,75,108,109,185,209)$, horse $(62$, $97,105,186,194)$ or other animal antibodies $(139,153$, $166,187,199,288$ ) to $B$. burgdorferi sensu lato antigens. The use of EIA facilitated the testing of numerous serum samples by diagnostic laboratories.

\section{CONCLUSIONS}

LB is a newly discovered infectious disease, that is prevalent where the Ixodes tick is endemic. Man and other animals can easily become infected. If not adequately treated, LB can have serious sequelae, but the disease responds especially in its early stages good to antibiotic therapy. The diagnosis of LB is primarily a clinical diagnosis supported by epidemiological data and confirmation by laboratory testing. Despite these shortcommings, EIAs are still the most commonly used tests for detecting antibodies to B. burgdorferi. Due to their reproducible objective results and need for only small sample volumes EIAs are well suited for highvolume testing. EIAs also are the test system of choice in the search for purified native proteins, subunits, recombinant osp's or recombinant chimeric proteins that combine critical epitopes from several immunodominant antigens for the improvement of sensitivity en specificity of LB serology as shown in Table 3. However few of the commercially available and newly developed EIAs show the reported sensitivity and specificity in real clinical laboratory situation. Reasons of these discrepancies could be, apart from differences in antigens used for the production of EIAs, the case definitions used for LB (golden standard), the selection criteria applied for the sera of LB patients and the control groups that were used for the test-evaluation. Control groups should not only consist of sera from healthy individuals, but should also contain sera of patients with diseases mimicking LB and from patients with diseases that are known to cause crossreactions in LB serology.

\section{AIMS OF THE STUDY}

The diagnosis "Lyme borreliosis" (LB) is generally based on clinical and epidemiological grounds. Especially in the early stages of the disease, the final diagnosis LB can be made on the typical clinical symptoms in combination with epidemiological anamnestic data. However, LB is a multi-system disease that can affect many organ systems and therefore its clinical symptomes can also be protean. Hence in patients suspected of LB with atypical symptoms or not residing in an endemic area, laboratory confirmation of a clinical diagnosis is indicated. Since culture, detection (molecular) or direct vizualization of the causative organism, B. burgdorferi, is difficult and often insensitive, serology still is the most used laboratory tool for confirmation of infection with B. burgdorferi. Currently for LB, EIA is the most used serological test and the only practical candidate for epidemiological research to estimate the prevalence of B. burgdorferi infections in a certain region. Before the application of a laboratory test, usually the performance is analysed by comparison to a reference test (i.e. a gold standard). Unfortunately for LB no such gold standard is available. Therefore other methods for test evaluation have to be applied, but as shown in chapter 2 this is often neglected.

The following studies were done to evaluate and, if possible, to improve the performance of commercial available EIA tests for the diagnosis of LB in humans. In addition an EIA test for the diagnosis of B. burgdorferi infections in animals was developed and evaluated.

1. Evaluation of the validity and performance of various commercially available EIA tests in Europe for diagnosis of LB in humans.

2. Improvement of the test-protocol currently used for LB serology.

3. Improvement of the validity and performance of LB EIAs by detection of specific subclasses of immunoglobulins and/or adaptation of the test protocol.

4. Development and evaluation of an EIA test for the use in domestic animals and assessment of the prevalence of $B$. burgdorferi infections in different 
populations of dogs in the Netherlands

5. To investigate wether the prevalence of antibodies against $B$. burgdorferi in dogs can be used to estimate the LB risk for humans.

6. To determin the prevalence of $B$. burgdorferi infections in humans and domestic animals in different regions of the Netherlands.

\section{REFERENCES}

1. Aberer, E., C. Brunner, G. Suchanek, H. Klade, A. Barbour, G. Stanek, and H. Lassmann. 1989. Molecular mimicry and Lyme borreliosis: a shared antigenic determinant between Borrelia burgdorferi and human tissue. Ann Neurol 26:732-7.

2. Ackerman, R. 1984. Spirochalten-Aetiologie der Erythema-chronicum-migrans Krankheit. Dtsch Med Wochenschr 109:92.

3. Adam, T., G. S. Gassmann, C. Rasiah, and U. B. Gobel. 1991. Phenotypic and genotypic analysis of Borrelia burg. dorferi isolates from various sources. Infect Immun 59: 2579-85.

4. Afzelius, A. 1910. Verhandlungen der Dermatologischen Gesellschaft zu Stockholm. Arch Derm Syph 101:404.

5. Aguero Rosenfeld, M. E., J. Roberge, C. A. Carbonaro, J. Nowakowski, R. B. Nadelman, and G. P. Wormser. 1999. Effects of OspA vaccination on Lyme disease serologic testing. J Clin Microbiol 37:3718-21.

6. Aguero-Rosenfeld, M. E., J. Nowakowski, S. Bittker, D. Cooper, R. B. Nadelman, and G. P. Wormser. 1996. Evolution of the serologic response to Borrelia burgdorferi in treated patients with culture-confirmed erythema migrans. J Clin Microbiol 34:1-9.

7. Anda, P., P. B. Backenson, J. L. Coleman, and J. L. Benach. 1994. Epitopes shared by unrelated antigens of Borrelia burgdorferi. Infect Immun 62:1070-8.

8. Anguita, J., S. Samanta, B. Revilla, K. Suk, S. Das, S. W. Barthold, and E. Fikrig. 2000. Borrelia burgdorferi gene expression in vivo and spirochete pathogenicity. Infect Immun 68:1222-30.

9. Angulo, A. B. 1986. Lyme disease in cats. SW Vet 37:100109.

10. Anonymous. 1995. From the Centers for Disease Control and Prevention. Recommendations for test performance and interpretation from the Second National Conference on Serologic Diagnosis of Lyme Disease. JAMA 274: 937.

11. Anonymous. 1997. Guidelines for laboratory evaluation in the diagnosis of Lyme disease. American College of Physicians. Ann Intern Med 127:1106-8.

12. Anthonissen, F. M., M. De Kesel, P. P. Hoet, and G. H. Bigaignon. 1994. Evidence for the involvement of different genospecies of Borrelia in the clinical outcome of Lyme disease in Belgium. Res Microbiol 145:327-31.
13. Asbrink, E., A. Hovmark, and B. Hederstedt. 1984 The spirochetal etiology of acrodermatitis chronica atrophicans Herxheimer. Acta Derm Venereol 64:506-12.

14. Askani, H. 1936. Zur Ätiologie des Erythema chronicum migrans. Dermatol Wochenschr 102:125.

15. Assous, M. V., D. Postic, G. Paul, P. Nevot, and G. Baranton. 1993. Western blot analysis of sera from Lyme borreliosis patients according to the genomic species of the Borrelia strains used as antigens. Eur J Clin Microbiol Infect Dis 12:261-8.

16. Bakken, L. L., S. M. Callister, P. J. Wand, and R. F. Schell. 1997. Interlaboratory comparison of test results for detection of Lyme disease by 516 participants in the Wisconsin State Laboratory of Hygiene/College of American Pathologists Proficiency Testing Program. J Clin Microbiol 35:537-43.

17. Baranton, G., D. Postic, I. Saint Girons, P. Boerlin, J. C. Piffaretti, M. Assous, and P. A. Grimont. 1992. Delineation of Borrelia burgdorferi sensu stricto, Borrelia garinii sp. nov., and group VS461 associated with Lyme borreliosis. Int J Syst Bacteriol 42:378-83.

18. Barbour, A. G. 1998. Fall and rise of Lyme disease and other Ixodes tick-borne infections in North America and Europe. Br Med Bull 54:647-58.

19. Barbour, A. G. 1984. Isolation and cultivation of Lyme disease spirochetes. Yale J Biol Med 57:521-5.

20. Barbour, A. G. 1993. Linear DNA of Borrelia species and antigenic variation. Trends Microbiol 1:236-9.

21. Barbour, A. G., and S. F. Hayes. 1986. Biology of Borrelia species. Microbiol Rev 50:381-400.

22. Barker, I. K., G. A. Surgeoner, S. A. McEwen, and H. Artsob. 1989. Distribution of the Lyme disease agent in wildlife reservoirs in Ontario. Can Dis Wkly Rep 15:1412.

23. Barker, T. L., A. L. Richards, E. Laksono, J. L. Sanchez, B. H. Feighner, W. Z. McBride, M. V. Rubertone, and K. C. Hyams. 2001. Serosurvey of Borrelia burgdorferi infection among U.S. military personnel: a low risk of infection. Am J Trop Med Hyg 65:804-9.

24. Barthold, S. W. 1993. Antigenic stability of Borrelia burgdorferi during chronic infections of immunocompetent mice. Infect Immun 61:4955-61.

25. Barthold, S. W., E. Fikrig, L. K. Bockenstedt, and D. H. Persing. 1995. Circumvention of outer surface protein A immunity by host-adapted Borrelia burgdorferi. Infect Immun 63:2255-61.

26. Beck, G., G. S. Habicht, J. L. Benach, and J. L. Coleman. 1985. Chemical and biologic characterization of a lipopolysaccharide extracted from the Lyme disease spirochete (Borrelia burgdorferi). J Infect Dis 152:108-17.

27. Belisle, J. T., M. E. Brandt, J. D. Radolf, and M. V. Norgard. 1994. Fatty acids of Treponema pallidum and Borrelia burgdorferi lipoproteins. J Bacteriol 176:2151-7.

28. Benach, J. L., E. M. Bosler, J. P. Hanrahan, J. L. Coleman, G. S. Habicht, T. F. Bast, D. J. Cameron, J. L. Ziegler, A. G. Barbour, W. Burgdorfer, R. Edelman, and R. A. Kaslow. 1983. Spirochetes isolated from the blood of two patients with Lyme disease. N Engl J Med 
308:740-2.

29. Benach, J. L., B. L. Gruber, J. L. Coleman, G. S Habicht, and M. G. Golightly. 1986. An IgE response to spirochete antigen in patients with Lyme disease. Zentralbl Bakteriol Mikrobiol Hyg [A] 263:127-32.

30. Berardi, V. P., K. E. Weeks, and A. C. Steere. 1988. Serodiagnosis of early Lyme disease: analysis of $\mathrm{IgM}$ and IgG antibody responses by using an antibody-capture enzyme immunoassay. J Infect Dis 158:754-60.

31. Berger, B. W., O. J. Clemmensen, and A. B. Ackerman. 1983. Lyme disease is a spirochetosis. A review of the disease and evidence for its cause. Am J Dermatopathol 5: 111-24.

32. Bigaignon, G., P. Goubau, J. Desmyter, and J. Vandepitte. 1987. Lyme borreliosis in Belgium. Lancet 1:557.

33. Bigaignon, G., P. Martin, J. P. Tomasi, M. Gonzalez, E. Lozes, P. Gillion, and A. Fain. 1989. Lyme disease in Belgium: presence of the spirochete Borrelia burgdorferi in Ixodes ricinus ticks recovered from the Meuse River region. Rev Med Liege 44:489-93.

34. Binder, E., R. Doepfmer, and O. Hornstein. 1955. Experimentelle Öbertragung des Erythema chronicum migrans von Mensch zu Mensch. Hautarzt 6:494.

35. Bishop, L., J. D. Strandberg, R. J. Adams, D. G. Brownstein, and R. Patterson. 1979. Chronic active hepatitis in dogs associated with leptospires. Am J Vet Res 40:839-844.

36. Blaauw, I., L. Nohlmans, T. van den Bogaard, and S. van der Linden. 1992. Diagnostic tools in Lyme borreliosis: clinical history compared with serology. J Clin Epidemiol 45:1229-36.

37. Boerlin, P., O. Peter, A. G. Bretz, D. Postic, G. Baranton, and J. C. Piffaretti. 1992. Population genetic analysis of Borrelia burgdorferi isolates by multilocus enzyme electrophoresis. Infect Immun 60:1677-83.

38. Bosler, E. M., B. G. Ormiston, J. L. Coleman, J. P. Hanrahan, and J. L. Benach. 1984. Prevalence of the Lyme disease spirochete in populations of white-tailed deer and white-footed mice. Yale J Biol Med 57:651-9.

39. Boyden, S. V. 1951. The absorption of proteins on erythrocytes treated with tannic acid and subsequent hemagglutination by antiprotein sera. J Exp Med 93:107-120.

40. Brettschneider, S., H. Bruckbauer, N. Klugbauer, and H. Hofmann. 1998. Diagnostic value of PCR for detection of Borrelia burgdorferi in skin biopsy and urine samples from patients with skin borreliosis. J Clin Microbiol 36:2658-65.

41. Broers, J. H. 1925. Over de door Lxodes ricinus, hondeteek, veroorzaakte huidaandoeningen. Ned Tijdschr Geneeskd 69:1824-1826.

42. Brown, S. L., S. L. Hansen, and J. J. Langone. 1999. Role of serology in the diagnosis of Lyme disease. JAMA 282:62-6.

43. Browning, A., S. D. Carter, A. Barnes, C. May, and D. Bennett. 1993. Lameness associated with Borrelia burgdorferi infection in the horse. Vet Rec 132:610-1.

44. Bruckbauer, H. R., V. Preac-Mursic, R. Fuchs, and B. Wilske. 1992. Cross-reactive proteins of Borrelia burg- dorferi. Eur J Clin Microbiol Infect Dis 11:224-32,

45. Brunner, M., and L. H. Sigal. 2001. Use of serum immune complexes in a new test that accurately confirms early Lyme disease and active infection with Borrelia burgdorferi. J Clin Microbiol 39:3213-21.

46. Brunner, M., S. Stein, P. D. Mitchell, and L. H. Sigal. 1998. Immunoglobulin M capture assay for serologic confirmation of early Lyme disease: analysis of immune complexes with biotinylated Borrelia burgdorferi sonicate enhanced with flagellin peptide epitope. J Clin Microbiol 36:1074-80.

47. Buchwald, A. 1883. Ein fall von diffuser idiopathischer Hautatrophie. Derm Vierteljahresschr 10:553.

48. Bundec, V. G., and A. G. Barbour. 1989. Clonal polymorphisms of outer membrane protein OspB of Borrelia burgdorferi. Infect Immun 57:2733-41.

49. Burgdorfer, W., A. G. Barbour, S. F. Hayes, J. L. Benach, E. Grunwaldt, and J. P. Davis. 1982. Lyme disease-a tick-borne spirochetosis? Science 216:1317-9.

50. Burgdorfer, W., A. G. Barbour, S. F. Hayes, O. Peter, and A. Aeschlimann. 1983. Erythema chronicum migrans--a tickborne spirochetosis. Acta Trop 40:79-83.

51. Burgdorfer, W., R. S. Lane, A. G. Barbour, R. A. Gresbrink, and J. R. Anderson. 1985. The western black-legged tick, Ixodes pacificus: a vector of Borrelia burgdorferi. Am J Trop Med Hyg 34:925-30.

52. Burgess, E. C. 1988. Borrelia burgdorferi infection in Wisconsin horses and cows. Ann N Y Acad Sci 539:23543.

53. Burgess, E. C., A. Gendron Fitzpatrick, and M. Mattison. 1988. Foal mortality associated with natural infection of pregnant mares with Borrelia burgorferi. Proc 5th Int Conf Equine Infect Dis:217-219.

54. Burgess, E. C., A. Gendron Fitzpatrick, and W. O. Wright. 1987. Arthritis and systemic disease caused by Borrelia burgdorferi infection in a cow. J Am Vet Med Assoc 191: 1468-70.

55. Burgess, E. C., D. Gillette, and J. P. Pickett. 1986. Arthritis and panuveitis as manifestations of Borrelia burgdorferi infection in a Wisconsin pony. J Am Vet Med Assoc 189:1340-2.

56. Burgess, E. C., and M. Mattison. 1987. Encephalitis associated with Borrelia burgdorferi infection in a horse. $\mathbf{J}$ Am Vet Med Assoc 191: 1457-8.

57. Burkot, T. R., J. Piesman, and R. A. Wirtz. 1994. Quantitation of the Borrelia burgdorferi outer surface protein A in Ixodes scapularis: fluctuations during the tick life cycle, doubling times, and loss while feeding. J Infect Dis 170: 883-9.

58. Busch, U., G. Will, C. Hizo-Teufel, B. Wilske, and V. Preac-Mursic. 1997. Long-term in vitro cultivation of Borrelia burgdorferi sensu lato strains: influence on plasmid patterns, genome stability and expression of proteins. Res Microbiol 148:109-18.

59. Cabannes, A., J. C. Hernandez, F. Lucchese, M. Appriou, and J. Tribouleyduret. 1997. Epidemiology of Lyme-Disease in Cattle and Sheep, in Gironde (France). Med Mal Infect 27:878-883. 
60. Callister, S. M., D. A. Jobe, R. F. Schell, S. D. Lovrich, K. L. Onheiber, and J. B. Korshus. 2000. Detection of borreliacidal antibodies in dogs after challenge with Borrelia burgdorferi-infected Ixodes scapularis ticks. J Clin Microbiol 38:3670-3674.

61. Canica, M. M., F. Nato, L. du Merle, J. C. Mazie, G. Baranton, and D. Postic. 1993. Monoclonal antibodies for identification of Borrelia afzelii sp. nov, associated with late cutaneous manifestations of Lyme borreliosis. Scand J Infect Dis 25:441-8.

62. Caputa, A. C., M. P. Murtaugh, R. F. Bey, and K. I. Loken. 1991. 110-kilodalton recombinant protein which is immunoreactive with sera from humans, dogs, and horses with Lyme borreliosis. J Clin Microbiol 29:2418-23.

63. Carlomagne, G., V. Luksa, G. Candussi, G. M. Rizzi, and G. Trevisan. 1988. Lyme Borrelia positive serology associated with spontaneous abortion in an endemic Italian area. Acta Eur Fertil 19:279-81.

64. Carreiro, M. M., D. C. Laux, and D. R. Nelson. 1990. Characterization of the heat shock response and identification of heat shock protein antigens of Borrelia burgdorferi. Infect Immun 58:2186-91.

65. Carroll, J. A., R. M. Cordova, and C. F. Garon. 2000. Identification of $11 \mathrm{pH}$-regulated genes in Borrelia burg. dorferi localizing to linear plasmids. Infect Immun 68: 6677-84.

66. Carroll, J. A., N. El-Hage, J. C. Miller, K. Babb, and B. Stevenson. 2001. Borrelia burgdorferi RevA antigen is a surface-exposed outer membrane protein whose expression is regulated in response to environmental temperature and $\mathrm{pH}$. Infect Immun 69:5286-93.

67. Carroll, J. A., C. F. Garon, and T. G. Schwan. 1999. Effects of environmental $\mathrm{pH}$ on membrane proteins in Borrelia burgdorferi. Infect Immun 67:3181-7.

68. Carroll, J. A., and F. C. Gherardini. 1996. Membrane protein variations associated with in vitro passage of Borrelia burgdorferi. Infect Immun 64:392-8.

69. Carter, C. J., S. Bergstrom, S. J. Norris, and A. G. Barbour. 1994. A family of surface-exposed proteins of 20 kilodaltons in the genus Borrelia. Infect Immun 62:2792 9.

70. Casjens, S., N. Palmer, R. van Vugt, W. M. Huang, B. Stevenson, P. Rosa, R. Lathigra, G. Sutton, J. Peterson, R. J. Dodson, D. Haft, E. Hickey, M. Gwinn, O. White, and C. M. Fraser. 2000. A bacterial genome in flux: the twelve linear and nine circular extrachromosomal DNAs in an infectious isolate of the Lyme disease spirochete Borrelia burgdorferi. Mol Microbiol 35:490-516.

71. Champion, C. I., D. R. Blanco, J. T. Skare, D. A. Haake, M. Giladi, D. Foley, J. N. Miller, and M. A. Lovett. 1994. A 9.0-kilobase-pair circular plasmid of Borrelia burgdorferi encodes an exported protein: evidence for expression only during infection. Infect Immun 62:2653-61.

72. Christenson, V. D., and D. H. White. 1991. Evaluation of four commercially available ELISA assays for the serologic diagnosis of Lyme disease. J Clin Lab Anal 5:340-3.

73. Ciceroni, L., A. Bartoloni, S. Ciarrocchi, A. Pinto, P. Guglielmetti, C. Valdez Vasquez, H. Gamboa Bara- hona, M. Roselli, and F. Paradisi. 1997. Serologic survey for antibodies to Borrelia burgdorferi in sheep, goats and dogs in Cordillera Province, Bolivia. Zentralbl Veterinarmed (B) 44:133-7.

74. Ciceroni, L., J. Simeoni, A. I. Pacetti, S. Ciarrocchi, and B. Cacciapuoti. 1996. Antibodies to Borrelia burgdorferi in sheep and goats. Alto Adige-South Tyrol, Italy. New Microbiol 19:171-174.

75. Ciceroni, L., J. Simeoni, A. I. Pacetti, S. Ciarrocchi, and B. Cacciapuoti. 1996. Antibodies to Borrelia burgdorferi in sheep and goats. Alto Adige-South Tyrol, Italy. New Microbiol 19:171-4.

76. Cohen, D., E. M. Bosler, W. Bernard, D. Meirs, 2nd, R. Eisner, and T. L. Schulze. 1988. Epidemiologic studies of Lyme disease in horses and their public health significance. Ann N Y Acad Sci 539:244-57.

77. Coyle, P. K., Z. Deng, S. E. Schutzer, A. L. Belman, J. Benach, L. B. Krupp, and B. Luft. 1993. Detection of Borrelia burgdorferi antigens in cerebrospinal fluid. Neurology 43:1093-8.

78. Coyle, P. K., S. E. Schutzer, A. L. Belman, L. B. Krupp, and M. G. Golightly. 1990. Cerebrospinal fluid immune complexes in patients exposed to Borrelia burgdorferi: detection of Borrelia-specific and -nonspecific complexes. Ann Neurol 28:739-44.

79. Coyle, P. K., S. E. Schutzer, Z. Deng, L. B. Krupp, A. L. Belman, J. L. Benach, and B. J. Luft. 1995. Detection of Borrelia burgdorferi-specific antigen in antibody-negative cerebrospinal fluid in neurologic Lyme disease. Neurology 45:2010-5.

80. Craft, J. E., D. K. Fischer, G. T. Shimamoto, and A. C. Steere. 1986. Antigens of Borrelia burgdorferi recognized during Lyme disease. Appearance of a new immunoglobulin $\mathrm{M}$ response and expansion of the immunoglobulin $\mathrm{G}$ response late in the illness. J Clin Invest 78:934-9.

81. Craft, J. E., R. L. Grodzicki, and A. C. Steere. 1984. Antibody response in Lyme disease: evaluation of diagnostic tests. J Infect Dis 149:789-95.

82. Cutler, S. J., and D. J. Wright. 1990. Evaluation of three commercial tests for Lyme disease. Diagn Microbiol Infect Dis 13:271-2.

83. Dambach, D. M., C. A. Smith, R. M. Lewis, and T. J. Vanwinkle. 1997. Morphologic, immunohistochemical, and ultrastructural characterization of a distinctive renal lesion in dogs putatively associated with Borrelia burgdorferi infection: 49 cases (1987-1992). Vet Path 34:85-96.

84. Das, S., S. W. Barthold, S. S. Giles, R. R. Montgomery, S. R. Telford, 3rd, and E. Fikrig. 1997. Temporal pattern of Borrelia burgdorferi p21 expression in ticks and the mammalian host. J Clin Invest 99:987-95.

85. Dattwyler, R. J., D. J. Volkman, J. J. Halperin, B. J. Luft, J. Thomas, and M. G. Golightly. 1988. Specific immune responses in Lyme borreliosis. Characterization of $\mathrm{T}$ cell and B cell responses to Borrelia burgdorferi. Ann N Y Acad Sci 539:93-102.

86. Dattwyler, R. J., D. J. Volkman, B. J. Luft, J. J. Halperin, J. Thomas, and M. G. Golightly. 1988. Seronegative Lyme disease. Dissociation of specific T- and B-lym- 
phocyte responses to Borrelia burgdorferi. N Engl J Med 319:1441-6.

87. Davidson, M. M., C. L. Ling, S. M. Chisholm, A. D. Wiseman, A. W. Joss, and D. O. Ho-Yen. 1999. Evidence-based diagnosis of Lyme disease. Eur J Clin Microbiol Infect Dis 18:484-9.

88. De Boer, R., K. E. Hovius, M. K. Nohlmans, and J. S Gray. 1993. The woodmouse (Apodemus sylvaticus) as a reservoir of tick-transmitted spirochetes (Borrelia burgdorferi) in The Netherlands. Zentralbl Bakteriol 279:404 16.

89. De Koning, J., R. B. Bosma, and J. A. Hoogkamp-Korstanje. 1987. Demonstration of spirochaetes in patients with Lyme disease with a modified silver stain. J Med Microbiol 23:261-7.

90. de Silva, A. M., and E. Fikrig. 1997. Arthropod- and host-specific gene expression by Borrelia burgdorferi. J Clin Invest 99:377-9.

91. de Silva, A. M., S. R. Telford, 3rd, L. R. Brunet, S. W. Barthold, and E. Fikrig. 1996. Borrelia burgdorferi OspA is an arthropod-specific transmission-blocking Lyme disease vaccine. J Exp Med 183:271-5.

92. Dressler, F., R. Ackermann, and A. C. Steere. 1994. Antibody responses to the three genomic groups of Borrelia burgdorferi in European Lyme borreliosis. J Infect Dis 169:313-8

93. Dressler, F., J. A. Whalen, B. N. Reinhardt, and A. C. Steere. 1993. Western blotting in the serodiagnosis of Lyme disease. J Infect Dis 167:392-400.

94. Dressler, F., N. H. Yoshinari, and A. C. Steere. 1991. The T-cell proliferative assay in the diagnosis of Lyme disease. Ann Intern Med 115:533-9.

95. Dumler, J. S. 2001. Molecular diagnosis of Lyme disease: review and meta-analysis. Mol Diagn 6:1-11.

96. Dykhuizen, D. E., D. S. Polin, J. J. Dunn, B. Wilske, V. Preac-Mursic, R. J. Dattwyler, and B. J. Luft. 1993. Borrelia burgdorferi is clonal: implications for taxonomy and vaccine development. Proc Natl Acad Sci U S A 90: 10163-7.

97. Egenvall, A., P. Franzen, A. Gunnarsson, E. O. Engvall, I. Vagsholm, U. B. Wikstrom, and K. Artursson. 2001. Cross-sectional study of the seroprevalence to Borrelia burgdorferi sensu lato and granulocytic Ehrlichia spp. and demographic, clinical and tick-exposure factors in Swedish horses. Prev Vet Med 49:191-208.

98. Eiffert, H., H. Lotter, K. Jarecki-Khan, and R. Thomssen. 1991. Identification of an immunoreactive non-proteinaleous component in Borrelia burgdorferi. Med Microbiol Immunol (Berl) 180:229-37.

99. Elkins, L. E., D. A. Pollina, S. R. Scheffer, and L. B. Krupp. 1999. Psychological states and neuropsychological performances in chronic Lyme disease. Appl Neuropsychol 6:19-26.

100. Engel, W., A. Vogt, and S. R. Batsford. 2000. Validity of prior absorption of serum samples with Reiter's spirochetes in serological diagnosis of Borrelia burgdorferi infections. Eur J Clin Microbiol Infect Dis 19:960-3.

101. EUCALB. Clinical manifestations of Lyme disease. http:
Wvie.dis.strath.ac.uk/vie/LymeEU/disease-overview_ $2 \mathrm{html}$.

102. Fahrer, H., S. M. van der Linden, M. J. Sauvain, L. Gern, E. Zhioua, and A. Aeschlimann. 1991. The prevalence and incidence of clinical and asymptomatic Lyme borreliosis in a population at risk. J Infect Dis 163:30510.

103. Feng, S., S. W. Barthold, S. R. Telford, 3rd, and E. Fikrig. 1996. P55, an immunogenic but nonprotective 55kilodalton Borrelia burgdorferi protein in murine Lyme disease. Infect Immun 64:363-5.

104. Fikrig, E., B. Liu, L. L. Fu, S. Das, J. I. Smallwood, R. A. Flavell, D. H. Persing, R. T. Schoen, S. W. Barthold, and S. E. Malawista. 1995. An ospA frame shift, identified from DNA in Lyme arthritis synovial fluid, results in an outer surface protein $A$ that does not bind protective antibodies. J Immunol 155:5700-4.

105. Fikrig, E., L. A. Magnarelli, M. Chen, J. F. Anderson, and R. A. Flavell. 1993, Serologic analysis of dogs, horses, and cottontail rabbits for antibodies to an antigenic flagellar epitope of Borrelia burgdorferi. J Clin Microbiol 31:2451-5.

106. Fingerle, V., U. Hauser, G. Liegl, B. Petko, V. PreacMursic, and B. Wilske. 1995. Expression of outer surface proteins $\mathrm{A}$ and $\mathrm{C}$ of Borrelia burgdorferi in Ixodes ricinus. J Clin Microbiol 33:1867-9.

107. Fraser, C. M., S. Casjens, W. M. Huang, G. G. Sutton, R. Clayton, R. Lathigra, O. White, K. A. Ketchum, R. Dodson, E. K. Hickey, M. Gwinn, B. Dougherty, J. F. Tomb, R. D. Fleischmann, D. Richardson, J. Peterson, A. R. Kerlavage, J. Quackenbush, S. Salzberg, M. Hanson, R. van Vugt, N. Palmer, M. D. Adams, J. Gocayne, J. C. Venter, and et al. 1997. Genomic sequence of a Lyme disease spirochaete, Borrelia burgdorferi. Nature 390:580-6.

108. Fridriksdottir, V., L. L. Nesse, and R. Gudding. 1992. Seroepidemiological studies of Borrelia burgdorferi infection in sheep in Norway. J Clin Microbiol 30:1271-7.

109. Fridriksdottir, V., G. Overnes, and S. Stuen. 1992. Suspected Lyme borreliosis in sheep. Vet Rec 130:323-4.

110. Fujita, H., T. Sato, Y. Ohara, and M. Homma. 1991. An indirect microhemagglutination test for Lyme disease. Microbiol Immunol 35:589-92.

111. Fumarola, D., I. Munno, and G. Miragliotta. 1983. "Endotoxicity" of the Lyme disease spirochete. Infection 11:345.

112. Garin, C., and C. Bujadoux. 1922. Paralysie par les tiques. J Med Lyon 71:765.

113. Garon, C. F., D. W. Dorward, and M. D. Corwin. 1989. Structural features of Borrelia burgdorferi--the Lyme disease spirochete: silver staining for nucleic acids. Scanning Microsc Suppl 3:109-15.

114. Gaudino, E. A., P. K. Coyle, and L. B. Krupp. 1997. Post-Lyme syndrome and chronic fatigue syndrome. Neuropsychiatric similarities and differences. Arch Neurol 54: 1372-6.

115. Gern, L., M. Siegenthaler, C. M. Hu, S. Leuba-Garcia, P. F. Humair, and J. Moret. 1994. Borrelia burgdorferi 
in rodents (Apodemus flavicollis and A. sylvaticus): duration and enhancement of infectivity for Ixodes ricinus ticks. Eur J Epidemiol 10:75-80.

116. Golde, W. T., and M. C. Dolan. 1995. Variation in antigenicity and infectivity of derivatives of Borrelia burgdorferi, strain B31, maintained in the natural, zoonotic cycle compared with maintenance in culture. Infect Immun 63: 4795-801.

117. Golde, W. T., K. J. Kappel, G. Dequesne, C. Feron, D. Plainchamp, C. Capiau, and Y. Lobet. 1994. Tick transmission of Borrelia burgdorferi to inbred strains of mice induces an antibody response to P39 but not to outer surface protein A. Infect Immun 62:2625-7.

118. Gomes Solecki, M. J., J. J. Dunn, B. J. Luft, J. Castillo, D. E. Dykhuizen, X. Yang, J. D. Glass, and R. J. Dattwyler. 2000. Recombinant chimeric Borrelia proteins for diagnosis of Lyme disease. J Clin Microbiol 38:2530-5.

119. Goossens, H. A. 2002. Prevalence of Lyme borreliosis in Dutch dogs. submitted.

120. Goossens, H. A., A. E. van den Bogaard, and M. K. Nohlmans. 2001. Dogs as sentinels for human Lyme borreliosis in The Netherlands. J Clin Microbiol 39:844-8.

121. Grauer, G. F., E. C. Burgess, A. J. Cooley, and J. H. Hagee. 1988. Renal lesions associated with Borrelia burgdorferi infection in a dog. J Am Vet Med Assoc 193:2379.

122. Greene, R. T. 1990. An update on the serodiagnosis of canine Lyme borreliosis. J Vet Intern Med 4:167-71.

123. Greene, R. T., J. F. Levine, E. B. Breitschwerdt, R. L. Walker, H. A. Berkhoff, J. Cullen, and W. L. Nicholson. 1988. Clinical and serologic evaluations of induced Borrelia burgdorferi infection in dogs. Am J Vet Res 49:752-7.

124. Greene, R. T., R. L. Walker, W. L. Nicholson, and J. F. Levine. 1991. Comparison of an enzyme-linked immunosorbent assay to an indirect immunofluorescence assay for the detection of antibodies to Borrelia burgdorferi in the dog. Vet Microbiol 26:179-90.

125. Grüneberg, T. 1954. Auffalige serologische Befunde bei Akrodermatitis chronica atrophicans Herxheimer. Klin Wochenschr 32:935.

126. Guerra, M. A., E. D. Walker, and U. Kitron. 2000. Quantitative approach for the serodiagnosis of canine Lyme disease by the immunoblot procedure. J Clin Microbiol 38:2628-32.

127. Guner, E. S. 1994. Retention of B. burgdorferi pathogenicity and infectivity after multiple passages in a coculture system. Experientia 50:54-9.

128. Gutierrez, J., M. Guerrero, F. Nunez, M. J. Soto, G. Piedrola, and M. C. Maroto. 2000. Antibodies to Borrelia burgdorferi in European populations. J Clin Lab Anal 14:20-6.

129. Hajek, T., B. Paskova, D. Janovska, R. Bahbouh, P. Hajek, J. Libiger, and C. Hoschl. 2002. Higher prevalence of antibodies to Borrelia burgdorferi in psychiatric patients than in healthy subjects. Am J Psychiatry 159: 297-301.

130. Hamann-Brand, A., M. Flondor, and V. Brade. 1994. Evaluation of a passive hemagglutination assay as screen- ing test and of a recombinant immunoblot as confirmatory test for serological diagnosis of Lyme disease. Eur J Clin Microbiol Infect Dis 13:572-5.

131. Hansen, K., J. M. Bangsborg, H. Fjordvang, N. S. Pedersen, and P. Hindersson. 1988. Immunochemical characterization of and isolation of the gene for a Borrelia burgdorferi immunodominant 60 -kilodalton antigen common to a wide range of bacteria. Infect Immun 56: 2047-53.

132. Hansen, K., P. Hindersson, and N. S. Pedersen. 1988 Measurement of antibodies to the Borrelia burgdorferi flagellum improves serodiagnosis in Lyme disease. J Clin Microbiol 26:338-46.

133. Hauser, U., G. Lehnert, R. Lobentanzer, and B. Wilske. 1997. Interpretation criteria for standardized Western blots for three European species of Borrelia burgdorferi sensu lato. J Clin Microbiol 35:1433-44.

134. Hauser, U., G. Lehnert, and B. Wilske. 1998. Diagnostic value of proteins of three Borrelia species (Borrelia burgdorferi sensu lato) and implications for development and use of recombinant antigens for serodiagnosis of Lyme borreliosis in Europe. Clin Diagn Lab Immunol 5:456-62.

135. Hauser, U., and B. Wilske. 1997. Enzyme-linked immunosorbent assays with recombinant internal flagellin fragments derived from different species of Borrelia burgdorferi sensu lato for the serodiagnosis of Lyme neuroborreliosis. Med Microbiol Immunol (Berl) 186:145-51.

136. Hechemy, K. E., H. L. Harris, M. J. Duerr, J. L. Benach, and C. B. Reimer. 1988. Immunoglobulin G subclasses specific to Borrelia burgdorferi in patients with Lyme disease. Ann N Y Acad Sci 539:162-9.

137. Heikkila, T., I. Seppala, H. Saxen, J. Panelius, M. Peltomaa, T. Julin, S. A. Carlsson, and P. Lahdenne. 2002. Recombinant BBK32 protein in serodiagnosis of early and late Lyme borreliosis. J Clin Microbiol 40:1174-80.

138. Hellerström, S. 1950. Erythema chronicum migrans Afzelius with meningitis. South Med J 43:330.

139. Henke, S. E., D. B. Pence, S. Demarais, and J. R. Johnson. 1990. Serologic survey of selected zoonotic disease agents in black-tailed jack rabbits from western Texas. J Wildl Dis 26:107-11.

140. Herxheimer, K., and K. Hartman. 1902. Uber Acrodermatitis chronica atrophicans. Arch Derm Syph 61:57.

141. Houwerzijl, J., J. J. Root, and A. A. Hoogkamp-Korstanje. 1984. A case of Lyme disease with cardiac involvement in the Netherlands. Infection 12:538.

142. Hovind-Hougen, K. 1984. Ultrastructure of spirochetes isolated from Ixodes ricinus and Ixodes dammini. Yale $\mathbf{J}$ Biol Med 57:543-8.

143. Hovius, J. W., K. E. Hovius, A. Oei, D. J. Houwers, and A. P. van Dam. 2000. Antibodies against specific proteins of and immobilizing activity against three strains of Borrelia burgdorferi sensu lato can be found in symptomatic but not in infected asymptomatic dogs. J Clin Microbiol 38:2611-21.

144. Hovmark, A., E. Asbrink, O. Schwan, B. Hederstedt, and D. Christensson. 1986. Antibodies to Borrelia spi- 
rochetes in sera from Swedish cattle and sheep. Acta Vet Scand 27:479-85.

145. Hovmark, A., T. G. Jaenson, E. Asbrink, A. Forsman, and E. Jansson. 1988. First isolations of Borrelia burgdorferi from rodents collected in northern Europe. Apmis 96:917-20.

146. Hu, C. M., L. Gern, and A. Aeschlimann. 1992. Changes in the protein profile and antigenicity of different Borrelia burgdorferi strains after reintroduction to Ixodes ricinus ticks. Parasite Immunol 14:415-27.

147. Hu, C. M., M. Simon, M. D. Kramer, and L. Gern. 1996. Tick factors and in vitro cultivation influence the protein profile, antigenicity and pathogenicity of a cloned Borrelia garinii isolate from Ixodes ricinus hemolymph. Infection 24:251-7.

148. Huaux, J. P., C. Sindic, H. Meunier, J. Sonnet, G. Bigaignon, P. Hantson, and P. Collard. 1987. Lyme arthritis in Belgium. Report of three cases. Clin Rheumatol 6:399-402.

149. Hubalek, Z., J. Halouzka, and M. Heroldova. 1998 Growth temperature ranges of Borrelia burgdorferi sensu lato strains. J Med Microbiol 47:929-32.

150. Indest, K. J., R. Ramamoorthy, M. Sole, R. D. Gilmore, B. J. Johnson, and M. T. Philipp. 1997. Cell-density-dependent expression of Borrelia burgdorferi lipoproteins in vitro. Infect Immun 65:1165-71.

151. Jacobson, R. H., Y. F. Chang, and S. J. Shin. 1996. Lyme-Disease - Laboratory Diagnosis of Infected and Vaccinated Symptomatic Dogs. Seminars in Veterinary Medicine and Surgery Small Animal 11:172-182.

152. Jauris-Heipke, S., B. Rossle, G. Wanner, C. Habermann, D. Rossler, V. Fingerle, G. Lehnert, R. Lobentanzer, I. Pradel, B. Hillenbrand, U. Schulte-Spechtel, and B. Wilske. 1999. Osp17, a novel immunodominant outer surface protein of Borrelia afzelii: recombinant expression in Escherichia coli and its use as a diagnostic antigen for serodiagnosis of Lyme borreliosis. Med Microbiol Immunol (Berl) 187:213-9.

153. Ji, B., C. B. Thomas, and M. T. Collins. 1994. Evaluation of an enzyme-linked immunosorbent assay that uses the 41-kd flagellin as the antigen for detection of antibodies to Borrelia burgdorferi in cattle. Am J Vet Res 55:12139.

154. Johnson, B. J., K. E. Robbins, R. E. Bailey, B. L. Cao, S. L. Sviat, R. B. Craven, L. W. Mayer, and D. T. Dennis. 1996. Serodiagnosis of Lyme disease: accuracy of a two-step approach using a flagella-based ELISA and immunoblotting. J Infect Dis 174:346-53.

155. Johnson, R. C., F. W. Hyde, and C. M. Rumpel. 1984. Taxonomy of the Lyme disease spirochetes. Yale J Biol Med 57:529-37.

156. Jones, J. D., K. W. Bourell, M. V. Norgard, and J. D. Radolf. 1995. Membrane topology of Borrelia burgdorferi and Treponema pallidum lipoproteins. Infect Immun 63:2424-34.

157. Jongejan, F., and S. Rijpkema. 1989. Borrelia burgdorferi from Ixodes ricinus ticks on Ameland. Tijdschr Diergeneeskd 114:1195-7.
158. Jwang, B., P. Dewing, E. Fikrig, and R. A. Flavell. 1995. The hook protein of Borrelia burgdorferi, encoded by the flgE gene, is serologically recognized in Lyme disease. Clin Diagn Lab Immunol 2:609-15.

159. Kahle, R. H. 1942. Pallidareaktion bei peripheren Durchblutungsstōrungen der Haut, insbesondere bei Akrodermatitis atrophicans. dissertation Halle.

160. Kaiser, R., and S. Rauer. 1999. Advantage of recombinant borrelial proteins for serodiagnosis of neuroborreliosis. J Med Microbiol 48:5-10.

161. Kaiser, R., and S. Rauer. 1998. Analysis of the intrathecal immune response in neuroborreliosis to a sonicate antigen and three recombinant antigens of Borrelia burg. dorferi sensu stricto. Eur J Clin Microbiol Infect Dis 17: 159-66.

162. Kaiser, R., and S. Rauer. 1999. Serodiagnosis of neuroborreliosis: comparison of reliability of three confirmatory assays. Infection 27:177-82.

163. Kalish, R. A., G. McHugh, J. Granquist, B. Shea, R. Ruthazer, and A. C. Steere. 2001. Persistence of immunoglobulin $\mathrm{M}$ or immunoglobulin $\mathrm{G}$ antibody responses to Borrelia burgdorferi 10-20 years after active Lyme dis. ease. Clin Infect Dis 33:780-5

164. Karlsson, M., G. Stiernstedt, M. Granstrom, E. Asbrink, and B. Wretlind. 1990. Comparison of flagellum and sonicate antigens for serological diagnosis of Lyme borreliosis. Eur J Clin Microbiol Infect Dis 9:169-77.

165. Kasbohrer, A., G. Liebisch, A. Schonberg, and A. Liebisch. 1994. Serodiagnosis of Lyme borreliosis: development and evaluation of a test system for epidemiological studies in the dog. Dtsch Tierarztl Wochenschr 101:476 81 .

166. Kasbohrer, A., and A. Schonberg. 1990. Serologic studies of the occurrence of Borrelia burgdorferi in domestic animals in Berlin (West). Berl Munch Tierarztl Wochen schr 103:374-8

167. Kawabata, M., N. Kubo, Y. Arashima, M. Yoshida, and K. Kawano. 1991. Serodiagnosis of Lyme disease by ELISA using Borrelia burgdorferi flagellum antigen. Rinsho Byori 39:891-4.

168. Klempner, M. S., C. H. Schmid, L. Hu, A. C. Steere, G. Johnson, B. McCloud, R. Noring, and A. Weinstein. 2001. Intralaboratory reliability of serologic and urine testing for Lyme disease. Am J Med 110:217-9.

169. Kornblatt, A. N., P. H. Urband, and S. A. C. 1985. Arthritis caused by Borrelia burgdorferi in dogs. J Am Vet Med Assoc 186:960-4.

170. Kuiper, H., A. P. van Dam, A. W. Moll van Charante, N. P. Nauta, and J. Dankert. 1993. One year follow-up study to assess the prevalence and incidence of Lyme borreliosis among Dutch forestry workers. Eur J Clin Microbiol Infect Dis 12:413-8.

171. Kurtti, T. J., U. G. Munderloh, R. C. Johnson, and G. G. Ahlstrand. 1987. Colony formation and morphology in Borrelia burgdorferi. J Clin Microbiol 25:2054-8.

172. Lam, T. T., T. P. Nguyen, R. R. Montgomery, F. S. Kantor, E. Fikrig, and R. A. Flavell. 1994. Outer surface proteins $\mathrm{E}$ and $\mathrm{F}$ of Borrelia burgdorferi, the agent of Lyme 
disease. Infect Immun 62:290-8.

173. Lane, R. S., W. Burgdorfer, S. F. Hayes, and A. G. Barbour. 1985. Isolation of a spirochete from the soft tick, Ornithodoros coriaceus: a possible agent of epizootic bovine abortion. Science 230:85-7.

174. Lebech, A. M., K. Hansen, F. Brandrup, O. Clemmensen, and L. Halkier-Sorensen. 2000. Diagnostic value of PCR for detection of Borrelia burgdorferi DNA in clinical specimens from patients with erythema migrans and Lyme neuroborreliosis. Mol Diagn 5:139-50.

175. LeFebvre, R. B., G. C. Perng, and R. C. Johnson. 1989. Characterization of Borrelia burgdorferi isolates by restriction endonuclease analysis and DNA hybridization. J Clin Microbiol 27:636-9.

176. Levy, S. A., and L. A. Magnarelli. 1992. Relationship between development of antibodies to Borrelia burgdorferi in dogs and the subsequent development of limb/joint borreliosis. J Am Vet Med Assoc 200:344-7.

177. Liang, F. T., R. H. Jacobson, R. K. Straubinger, A. Grooters, and M. T. Philipp. 2000. Characterization of a Borrelia burgdorferi VIsE invariable region useful in canine Lyme disease serodiagnosis by enzyme-linked immunosorbent assay. J Clin Microbiol 38:4160-6.

178. Liang, F. T., A. C. Steere, A. R. Marques, B. J. Johnson, J. N. Miller, and M. T. Philipp. 1999. Sensitive and specific serodiagnosis of Lyme disease by enzyme-linked immunosorbent assay with a peptide based on an immunodominant conserved region of Borrelia burgdorferi vlsE. J Clin Microbiol 37:3990-6.

179. Lindenmayer, J., M. Weber, J. Bryant, E. Marquez, and A. Onderdonk. 1990. Comparison of indirect immunofluorescent-antibody assay, enzyme-linked immunosorbent assay, and Western immunoblot for the diagnosis of Lyme disease in dogs. J Clin Microbiol 28:92-6.

180. Lischer, C. J., C. M. Leutenegger, U. Braun, and H. Lutz. 2000. Diagnosis of Lyme disease in two cows by the detection of Borrelia burgdorferi DNA. Vet Rec 146: 497-499.

181. Lissmann, B. A., E. M. Bosler, H. Camay, B. B. Ormiston, and J. L. Benach. 1984. Spirochete-associated arthritis (Lyme disease) in a dog. J Am Vet Med Ass 185:219-220.

182. Livesley, M. A., I. P. Thompson, L. Gern, and P. A. Nuttall. 1993. Analysis of intra-specific variation in the fatty acid profiles of Borrelia burgdorferi. J Gen Microbiol 139 ( Pt 9):2197-201.

183. Lohel, H. 1955. Tierexperimentelle Untersuchungen zur Ätiologie der Acrodermatitis chronica atrophicans Herxheimer. Klin Wochenschr 33:185.

184. Luft, B. J., P. D. Gorevic, W. Jiang, P. Munoz, and R. J. Dattwyler. 1991. Immunologic and structural characterization of the dominant 66- to 73-kDa antigens of Borrelia burgdorferi. J Immunol 146:2776-82.

185. Maggs, A. F., and D. J. Veale. 1994. Lyme disease in Scotland. Scott Med J 39:99-100.

186. Magnarelli, L. A., and J. F. Anderson. 1989. Class-specific and polyvalent enzyme-linked immunosorbent assays for detection of antibodies to Borrelia burgdorferi in equids. J Am Vet Med Assoc 195:1365-8.

187. Magnarelli, L. A., J. F. Anderson, C. S. Apperson, D. Fish, R. C. Johnson, and W. A. Chappell. 1986. Spirochetes in ticks and antibodies to Borrelia burgdorferi in white-tailed deer from Connecticut, New York State, and North Carolina. J Wildl Dis 22:178-88.

188. Magnarelli, L. A., J. F. Anderson, and A. G. Barbour. 1986. The etiologic agent of Lyme disease in deer flies, horse flies, and mosquitoes. J Infect Dis 154:355-8.

189. Magnarelli, L. A., J. F. Anderson, R. C. Johnson, R. B. Nadelman, and G. P. Wormser. 1994. Comparison of different strains of Borrelia burgdorferi sensu lato used as antigens in enzyme-linked immunosorbent assays. J Clin Microbiol 32:1154-8.

190. Magnarelli, L. A., J. F. Anderson, A. B. Schreier, and C. M. Ficke. 1987. Clinical and serologic studies of canine borreliosis. J Am Vet Med Assoc 191:1089-94.

191. Magnarelli, L. A., E. Fikrig, R. Berland, J. F. Anderson, and R. A. Flavell. 1992. Comparison of whole-cell antibodies and an antigenic flagellar epitope of Borrelia burgdorferi in serologic tests for diagnosis of Lyme borreliosis. J Clin Microbiol 30:3158-62.

192. Magnarelli, L. A., R. A. Flavell, S. J. Padula, J. F. Anderson, and E. Fikrig. 1997. Serologic diagnosis of canine and equine borreliosis: use of recombinant antigens in enzyme-linked immunosorbent assays. J Clin Microbiol 35:169-73.

193. Magnarelli, L. A., J. W. Ijdo, S. J. Padula, R. A. Flavell, and E. Fikrig. 2000. Serologic diagnosis of Lyme borreliosis by using enzyme-linked immunosorbent assays with recombinant antigens. J Clin Microbiol 38:1735-9.

194. Magnarelli, L. A., J. W. Ijdo, A. E. Van Andel, C. Wu, S. J. Padula, and E. Fikrig. 2000. Serologic confirmation of Ehrlichia equi and Borrelia burgdorferi infections in horses from the northeastern United States. J Am Vet Med Assoc 217:1045-50.

195. Magnarelli, L. A., S. A. Levy, J. W. Ijdo, C. Wu, S. J. Padula, and E. Fikrig. 2001. Reactivity of dog sera to whole-cell or recombinant antigens of Borrelia burgdorferi by ELISA and immunoblot analysis. J Med Microbiol 50:889-95,

196. Marcelis, L., P. de Marneffe, E. Chaidron, G. Bigaignon, P. Kageruka, and P. Goubau. 1987. Horse reservoir for Borrelia burgdorferi? Lancet 1:977.

197. Marconi, R. T., D. S. Samuels, T. G. Schwan, and C. F. Garon. 1993. Identification of a protein in several Borrelia species which is related to OspC of the Lyme disease spirochetes. J Clin Microbiol 31:2577-83.

198. Marques, A. R., F. Stock, and V. Gill. 2000. Evaluation of a new culture medium for Borrelia burgdorferi. J Clin Microbiol 38:4239-41.

199. Martinez, A., A. Salinas, F. Martinez, A. Cantu, and D. K. Miller. 1999. Serosurvey for selected disease agents in white-tailed deer from Mexico. J Wildl Dis 35:799-803.

200. Masuzawa, T., T. Kurita, H. Kawabata, K. Muramatsu, K. Uchikawa, and Y. Yanagihara. 1994. Infectivity and early antibody response to Borrelia burgdorferi sensu lato isolated in Japan in outbred mice. Microbiol Immunol 
38:621-7.

201. Masuzawa, T., Y. Okada, Y. Beppu, T. Oku, F. Kawamori, and Y. Yanagihara. 1991. Immunological properties of Borrelia burgdorferi isolated from the Ixodes ovatus in Shizuoka, Japan. Microbiol Immunol 35:913-9.

202. Mathiesen, M. J., M. Christiansen, K. Hansen, A. Holm, E. Asbrink, and M. Theisen. 1998. Peptide-based OspC enzyme-linked immunosorbent assay for serodiagnosis of Lyme borreliosis. J Clin Microbiol 36:3474-9.

203. Matuschka, F. R., H. Eiffert, A. Ohlenbusch, and A. Spielman. 1994. Amplifying role of edible dormice in Lyme disease transmission in central Europe. J Infect Dis 170:122-7.

204. Matuschka, F. R., P. Fischer, M. Heiler, S. Blumcke, and A. Spielman. 1992. Stage-associated risk of transmission of the Lyme disease spirochete by European Ixodes ticks. Parasitol Res 78:695-8.

205. Matuschka, F. R., P. Fischer, M. Heiler, D. Richter, and A. Spielman. 1992. Capacity of European animals as reservoir hosts for the Lyme disease spirochete. J Infect Dis 165:479-83.

206. Melby, K., M. Steinbakk, M. Jensenius, and K. J. Figenschau. 1990. Detection of serum antibodies against Borrelia burgdorferi with some commercially available serological tests. NIPH Ann 13:37-44.

207. Melski, J. W. 2000. Lyme borreliosis. Semin Cutan Med Surg 19:10-8.

208. Melski, J. W., K. D. Reed, P. D. Mitchell, and G. D. Barth. 1993. Primary and secondary erythema migrans in central Wisconsin. Arch Dermatol 129:709-16.

209. Mitchell, G. B., and I. W. Smith. 1993. Lyme disease in Scotland: results of a serological study in sheep. Vet Rec 133:66-7.

210. Mitchell, G. B. B., and I. W. Smith. 1993. Lyme-Disease in Scotland - Results of a Serological Study in Sheep. Vet Rec 133:66-67.

211. Mitchell, P. D., K. D. Reed, M. F. Vandermause, and J. W. Melski. 1993. Isolation of Borrelia burgdorferi from skin biopsy specimens of patients with erythema migrans. Am J Clin Pathol 99:104-7.

212. Moter, S. E., H. Hofmann, R. Wallich, M. M. Simon, and M. D. Kramer. 1994. Detection of Borrelia burgdorferi sensu lato in lesional skin of patients with erythema migrans and acrodermatitis chronica atrophicans by ospAspecific PCR. J Clin Microbiol 32:2980-8.

213. Nadelman, R. B., and G. P. Wormser. 1998. Lyme borreliosis. Lancet 352:557-65.

214. Nilsson, I., and I. A. von Rosen. 1996. Serum antibodies against Borrelia afzelii, Borrelia burgdorferi sensu stricto and the 41-kiloDalton flagellin in patients from a Lyme borreliosis endemic area: analysis by EIA and immunoblot. Apmis 104:907-14.

215. Nocton, J. J., F. Dressler, B. J. Rutledge, P. N. Rys, D. H. Persing, and A. C. Steere. 1994. Detection of Borrelia burgdorferi DNA by Polymerase Chain Reaction in Synovial Fluid from Patients with Lyme Arthritis. New England Journal of Medicine 330:229-234.

216. Nohlmans, M. K., A. A. Blaauw, A. E. van den Bogaard, and C. P. van Boven. 1994. Evaluation of nine serological tests for diagnosis of Lyme borreliosis. Eur J Clin Microbiol Infect Dis 13:394-400.

217. Nohlmans, M. K., R. de Boer, A. E. van den Bogaard, A. A. Blaauw, and C. P. van Boven. 1990. Occurrence of Borrelia burgdorferi in Ixodes ricinus in The Netherlands. Ned Tijdschr Geneeskd 134:1300-3.

218. Nohlmans, M. K., A. E. van den Bogaard, A. A. Blaauw, and C. P. van Boven. 1991. Prevalence of Lyme borreliosis in The Netherlands. Ned Tijdschr Geneeskd 135:228892.

219. Norris, S. J., C. J. Carter, J. K. Howell, and A. G. Barbour. 1992. Low-passage-associated proteins of Borrelia burgdorferi B31: characterization and molecular cloning of OspD, a surface-exposed, plasmid-encoded lipoprotein. Infect Immun 60:4662-72.

220. Pachner, A. R., and A. Itano. 1990. Borrelia burgdorferi infection of the brain: characterization of the organism and response to antibiotics and immune sera in the mouse model. Neurology 40: 1535-40.

221. Padula, S. J., F. Dias, A. Sampieri, R. B. Craven, and R. W. Ryan. 1994. Use of recombinant OspC from Borrelia burgdorferi for serodiagnosis of early Lyme disease. J Clin Microbiol 32:1733-8.

222. Parker, J. L., and K. K. White. 1992. Lyme borreliosis in cattle and horses: a review of the literature. Cornell Vet 82:253-74

223. Paster, B. J., F. E. Dewirst, W. G. Weisburg, L. S. Tordorff, G. J. Fraser, R. B. Hespell, T. B. Stanton, L. Zahlen, L. Mandelco, and C. R. Woese. 1991. Phylogenetic analysis of the spirochetes. J Bacteriol 173:61016109.

224. Paul, H., H. J. Gerth, and R. Ackermann. 1987. Infectiousness for humans of Ixodes ricinus containing Borrelia burgdorferi. Zentralbl Bakteriol Mikrobiol Hyg (A) 263: 473-6.

225. Pavia, C. S., G. P. Wormser, S. Bittker, and D. Cooper. 2000. An indirect hemagglutination antibody test to detect antibodies to Borrelia burgdorferi in patients with Lyme disease. J Microbiol Methods 40:163-73.

226. Pawelczyk, A., and E. Sinski. 2000. Prevalence of IgG antibodies response to Borrelia burgdorferi s.I. in populations of wild rodents from Mazury lakes district region of Poland. Ann Agric Environ Med 7:79-83.

227. Persing, D. H., D. Mathiesen, D. Podzorski, and S. W. Barthold. 1994. Genetic stability of Borrelia burgdorferi recovered from chronically infected immunocompetent mice. Infect Immun 62:3521-7.

228. Persing, D. H., B. J. Rutledge, P. N. Rys, D. S. Podzorski, P. D. Mitchell, K. D. Reed, B. Liu, E. Fikrig, and S. E. Malawista. 1994. Target imbalance: disparity of Borrelia burgdorferi genetic material in synovial fluid from Lyme arthritis patients. J Infect Dis 169:668-72.

229. Peter, O., A. G. Bretz, R. Zenhausern, H. Roten, and E. Roulet. 1993. Isolation of Borrelia burgdorferi in the cerebrospinal fluid of 3 children with neurological involvement. Schweiz Med Wochenschr 123:14-9.

230. Poljak, I., B. Troselj-Vukic, B. Miletic, M. Morovic, E. 
Ruzic-Sabljic, A. Vucemilovic, and E. Materljan. 2000. Low sero-prevalence of Lyme borreliosis in the forested mountainous area of Gorski Kotar, Croatia. Croat Med J 41:433-6.

231. Postic, D., M. V. Assous, P. A. Grimont, and G. Baranton. 1994. Diversity of Borrelia burgdorferi sensu lato evidenced by restriction fragment length polymorphism of $\mathrm{rf}$ (5S)-rrl (23S) intergenic spacer amplicons. Int J Syst Bacteriol 44:743-52.

232. Preac-Mursic, V., and B. Wilske. 1993. Biology of Borrelia burgdorfer In: Weber K, Burgdorfer W. Aspects of Lyme borreliosis. Springer-Verlag Berlin Heidelberg:4458.

233. Preac-Mursic, V., B. Wilske, and S. Reinhardt. 1991. Culture of Borrelia burgdorferi on six solid media. Eur J Clin Microbiol Infect Dis 10:1076-9,

234. Probert, W. S., K. M. Allsup, and R. B. LeFebvre. 1995. Identification and characterization of a surface-exposed, 66-kilodalton protein from Borrelia burgdorferi. Infect Immun 63:1933-9.

235. Radolf, J. D., M. S. Goldberg, K. Bourell, S. I. Baker, J. D. Jones, and M. V. Norgard. 1995. Characterization of outer membranes isolated from Borrelia burgdorferi, the Lyme disease spirochete. Infect Immun 63:2154-63.

236. Rahn, D. W. 1991. Lyme disease: clinical manifestations, diagnosis, and treatment. Semin Arthritis Rheum 20:20118.

237. Ramamoorthy, R., and M. T. Philipp. 1998. Differential expression of Borrelia burgdorferi proteins during growth in vitro. Infect Immun 66:5119-24.

238. Ramamoorthy, R., L. Povinelli, and M. T. Philipp. 1996. Molecular characterization, genomic arrangement, and expression of bmpD, a new member of the bmp class of genes encoding membrane proteins of Borrelia burgdorferi. Infect Immun 64: 1259-64.

239. Ramamoorthy, R., and D. Scholl-Meeker. 2001. Borrelia burgdorferi proteins whose expression is similarly affected by culture temperature and $\mathrm{pH}$. Infect Immun 69: 2739-42.

240. Rauer, S., N. Spohn, C. Rasiah, U. Neubert, and A. Vogt. 1998. Enzyme-linked immunosorbent assay using recombinant $\mathrm{OspC}$ and the internal $14-\mathrm{kDa}$ flagellin fragment for serodiagnosis of early Lyme disease. J Clin Microbiol 36:857-61.

241. Rawlings, J. A., P. V. Fournier, and G. J. Teltow. 1987. Isolation of Borrelia spirochetes from patients in Texas. J Clin Microbiol 25:1148-50.

242. Reveille, J. D. 1993. The interplay of nature versus nurture in predisposition to the rheumatic diseases. Rheum Dis Clin North Am 19:15-27.

243. Roberg, M., P. Forsberg, A. Tegnell, and K. Ekerfeldt. 1995. Intrathecal production of specific IgA antibodies in CNS infections. J Neurol 242:390-7.

244. Robertson, J., E. Guy, N. Andrews, B. Wilske, P. Anda, M. Granstrom, U. Hauser, Y. Moosmann, V. Sambri, J. Schellekens, G. Stanek, and J. Gray. 2000. A European multicenter study of immunoblotting in serodiagnosis of lyme borreliosis. J Clin Microbiol 38:2097-102.
245. Roessler, D., U. Hauser, and B. Wilske. 1997. Heterogeneity of BmpA (P39) among European isolates of Borrelia burgdorferi sensu lato and influence of interspecies variability on serodiagnosis. J Clin Microbiol 35:2752-8.

246. Sadziene, A., A. G. Barbour, P. A. Rosa, and D. D. Thomas. 1993. An OspB mutant of Borrelia burgdorferi has reduced invasiveness in vitro and reduced infectivity in vivo. Infect Immun 61:3590-6.

247. Sadziene, A., D. D. Thomas, and A. G. Barbour. 1995. Borrelia burgdorferi mutant lacking Osp: biological and immunological characterization. Infect Immun 63:157380.

248. Sadziene, A., B. Wilske, M. S. Ferdows, and A. G. Barbour. 1993. The cryptic ospC gene of Borrelia burgdorferi B31 is located on a circular plasmid. Infect Immun 61: 2192-5.

249. Salinas-Melendez, J. A., R. Avalos-Ramirez, V. M. Riojas-Valdez, and A. Martinez-Munoz. 1999. Serological survey of canine borreliosis. Rev Latinoam Microbiol 41: 1-3.

250. Sandbank, M., and E. F. Feuermann. 1979. Ultrastructural observation of rickettsia-like bodies in erythema chronicum migrans. J Cutan Pathol 6:253.

251. Schmidt, B. L. 1997. PCR in laboratory diagnosis of human Borrelia burgdorferi infections. Clin Microbiol Rev 10:185-201.

252. Schmutzhard, E., G. Stanek, M. Pletschette, A. M. Hirschl, A. Pallua, R. Schmitzberger, and R. Schlogl. 1988. Infections following tickbites. Tick-borne encephalitis and Lyme borreliosis--a prospective epidemiological study from Tyrol. Infection 16:269-72.

253. Schutzer, S. E., P. K. Coyle, A. L. Belman, M. G. Golightly, and J. Drulle. 1990. Sequestration of antibody to Borrelia burgdorferi in immune complexes in seronegative Lyme disease. Lancet 335:312-5.

254. Schutzer, S. E., P. K. Coyle, J. J. Dunn, B. J. Luft, and M. Brunner. 1994. Early and specific antibody response to OspA in Lyme Disease. J Clin Invest 94:454-7.

255. Schwan, T. G., W. Burgdorfer, and C. F. Garon. 1988. Changes in infectivity and plasmid profile of the Lyme disease spirochete, Borrelia burgdorferi, as a result of in vitro cultivation. Infect Immun 56:1831-6.

256. Schwan, T. G., R. H. Karstens, M. E. Schrumpf, and W. J. Simpson. 1991. Changes in antigenic reactivity of Borrelia burgdorferi, the Lyme disease spirochete, during persistent infection in mice. Can J Microbiol 37:450-4.

257. Schwan, T. G., J. Piesman, W. T. Golde, M. C. Dolan, and P. A. Rosa. 1995. Induction of an outer surface protein on Borrelia burgdorferi during tick feeding. Proc Natl Acad Sci U S A 92:2909-13.

258. Schwan, T. G., W. J. Simpson, M. E. Schrumpf, and R. H. Karstens. 1989. Identification of Borrelia burgdorferi and $\mathrm{B}$. hermsii using DNA hybridization probes. J Clin Microbiol 27:1734-8.

259. Schwartz, I., G. P. Wormser, J. J. Schwartz, D. Cooper, P. Weissensee, A. Gazumyan, E. Zimmermann, N. S. Goldberg, S. Bittker, G. L. Campbell, and et al. 1992. Diagnosis of early Lyme disease by polymerase chain re- 
action amplification and culture of skin biopsies from erythema migrans lesions. J Clin Microbiol 30:3082-8.

260. Segura-Porta, F., and J. L. Benach. 1992. Etiopathogenic aspects of Lyme disease. Enferm Infece Microbiol Clin 10:302-7.

261. Seshu, J., and J. T. Skare. 2000. The many faces of Borrelia burgdorferi. J Mol Microbiol Biotechnol 2:463-72.

262. Sheets, J. T., C. A. Rossi, B. J. Kearney, and G. E. Moore. 2000. Evaluation of a commercial enzyme-linked immunosorbent assay for detection of Borrelia burgdorferi exposure in dogs. J Am Vet Med Assoc 216:1418-22.

263. Shin, S. J., Y. F. Chang, R. H. Jacobson, E. Shaw, T. L. Lauderdale, M. J. Appel, and D. H. Lein. 1993. Crossreactivity between $\mathbf{B}$. burgdorferi and other spirochetes affects specificity of serotests for detection of antibodies to the Lyme disease agent in dogs. Vet Microbiol 36:161-74.

264. Shoberg, R. J., and D. D. Thomas. 1995. Borrelia burgdorferi vesicle production occurs via a mechanism independent of immunoglobulin $\mathrm{M}$ involvement. Infect Immun 63:4857-61.

265. Shoberg, R. J., and D. D. Thomas. 1993. Specific adherence of Borrelia burgdorferi extracellular vesicles to human endothelial cells in culture. Infect Immun 61:3892. 900.

266. Sigal, L. H. 1997. Lyme disease: a review of aspects of its immunology and immunopathogenesis. Annu Rev Immunol 15:63-92.

267. Sigal, L. H., and A. H. Tatum. 1988. Lyme disease patients' serum contains IgM antibodies to Borrelia burgdorferi that cross-react with neuronal antigens. Neurology 38: 1439-42.

268. Simpson, W. J., M. E. Schrumpf, S. F. Hayes, and T. G. Schwan. 1991. Molecular and immunological analysis of a polymorphic periplasmic protein of Borrelia burgdorferi. J Clin Microbiol 29:1940-8.

269. Skare, J. T., E. S. Shang, D. M. Foley, D. R. Blanco, C. I. Champion, T. Mirzabekov, Y. Sokolov, B. L. Kagan, J. N. Miller, and M. A. Lovett. 1995. Virulent strain associated outer membrane proteins of Borrelia burgdorferi. J Clin Invest 96:2380-92.

270. Smouha, E. E., P. K. Coyle, and S. Shukri. 1997. Facial nerve palsy in Lyme disease: evaluation of clinical diagnostic criteria. Am J Otol 18:257-61.

271. Stanek, G. 1991. Laboratory diagnosis and seroepidemiology of Lyme borreliosis. Infection 19:263-7.

272. Stanek, G., F. Breier, G. Menzinger, B. Schaar, M. Hafner, and H. Partsch. 1999. Erythema migrans and serodiagnosis by enzyme immunoassay and immunoblot with three borrelia species. Wien Klin Wochenschr 111:951-6.

273. Stanek, G., S. O'Connell, M. Cimmino, and e. al. 1996. European Union concerted action on risk assessment in Lyme borreliosis: clinical case definition for Lyme borreliosis. Wien Klin Wochenschr 108:741-747.

274. Stavitsky, A. B. 1954. Micromethods for the study of proteins and antibodies. I. Procedure and general applications of hemagglutination-inhibition reactions with tannica acid and protein-treated red blood cells. J Immunol 72:360368.
275. Steere, A. C. 1989. Lyme disease. N Engl J Med 321:58696.

276. Steere, A. C. 2001. Lyme disease. N Engl J Med 345:115. 25.

277. Steere, A. C., and e. al. 1977. Erythema chronicum migrans and Lyme arthritis: the enlarging clinical spectrum. Ann Intern Med 86:685

278. Steere, A. C., R. L. Grodzicki, A. N. Kornblatt, J. E. Craft, A. G. Barbour, W. Burgderfer, G. P. Schmid, E. Johnson, and S. E. Malawista. 1983. The spirochetal etiology of Lyme disease. N Engl J Med 308:733-40.

279. Steere, A. C., D. Gross, A. L. Meyer, and B. T. Huber. 2001. Autoimmune mechanisms in antibiotic treatmentresistant lyme arthritis. J Autoimmun 16:263-8.

280. Steere, A. C., S. E. Malawista, D. R. Syndman, and e. al. 1977. Lyme arthritis: An epidemic of oligoarthritis in children and adults in three Connecticut communities. Arthritis Rheum 20:7-17.

281. Steere, A. C., V. K. Sikand, F. Meurice, D. L. Parenti, E. Fikrig, R. T. Schoen, J. Nowakowski, C. H. Schmid, S. Laukamp, C. Buscarino, and D. S. Krause. 1998. Vaccination against Lyme disease with recombinant Borrelia burgdorferi outer-surface lipoprotein A with adjuvant. Lyme Disease Vaccine Study Group. N Engl J Med 339: 209-15.

282. Stefancikova, A., B. Pet'ko, I. Rezicka, N. Salyova, and D. Ohlasova. 2001. Epidemiological survey of human borreliosis diagnosed in Eastern Slovakia. Ann Agric Environ Med 8: 171-5.

283. Stevenson, B., J. L. Bono, T. G. Schwan, and P. Rosa. 1998. Borrelia burgdorferi erp proteins are immunogenic in mammals infected by tick bite, and their synthesis is inducible in cultured bacteria. Infect Immun 66:2648-54 .

284. Stevenson, B., T. G. Schwan, and P. A. Rosa. 1995. Temperature-related differential expression of antigens in the Lyme disease spirochete, Borrelia burgdorferi. Infect Immun 63:4535-9.

285. Sugiyama, Y., N. Minamoto, and T. Kinjo. 1998. Serological surveillance of Lyme borreliosis in wild Japanese serows (Capricornis crispus). J Vet Med Sci 60:745-7.

286. Sugiyama, Y., F. Sugiyama, and K. Yagami. 1993. Comparative study on cross-reaction of leptospiral antibodies in several serological tests to detect antibodies to Borrelia burgdorferi in dogs. J Vet Med Sci 55:149-51.

287. Suk, K., S. Das, W. Sun, B. Jwang, S. W. Barthold, R. A. Flavell, and E. Fikrig. 1995. Borrelia burgdorferi genes selectively expressed in the infected host. Proc Natl Acad Sci U S A 92:4269-73.

288. Takahashi, K., E. Isogai, H. Isogai, T. Takagi, K. Sasaki, N. Fujii, and K. Kimura. 1993. Serological survey for Borrelia burgdorferi infection in cattle in southern Hokkaido. J Vet Med Sci 55:921-4.

289. Takayama, K., R. J. Rothenberg, and A. G. Barbour. 1987. Absence of lipopolysaccharide in the Lyme disease spirochete, Borrelia burgdorferi. Infect Immun 55:2311-3.

290. Theisen, M., B. Frederiksen, A. M. Lebech, J. Vuust, and K. Hansen. 1993. Polymorphism in ospC gene of Borrelia burgdorferi and immunoreactivity of OspC pro- 
tein: implications for taxonomy and for use of OspC protein as a diagnostic antigen. J Clin Microbiol 31:2570-6.

291. Thöne, A. W. 1968. Ixodes ricinus und Erythema chronicum migrans (Afzelius). Dermatologica (Basel) 136:57.

292. Tilton, R. C., D. Barden, and M. Sand. 2001. Culture Borrelia burgdorferi. J Clin Microbiol 39:2747.

293. Treib, J., A. Fernandez, A. Haass, M. T. Grauer, G. Holzer, and R. Woessner. 1998. Clinical and serologic follow-up in patients with neuroborreliosis. Neurology 51: 1489-91.

294. Treib, J., M. T. Grauer, A. Haass, J. Langenbach, G. Holzer, and R. Woessner. 2000. Chronic fatigue syndrome in patients with Lyme borreliosis. Eur Neurol 43: 107-9.

295. Treib, J., R. Woessner, G. Dobler, A. Fernandez, G. Holzer, and K. Schimrigk. 1997. Clinical value of specific intrathecal production of antibodies. Acta Virol 41: 27-30.

296. van den Bogaard, A. E., and M. K. Nohlmans. 1990. Lyme borreliosis in domestic animals; the situation in the Netherlands. Vet quarterly:56S-58S.

297. Volkman, D. J., B. J. Luft, P. D. Gorevic, J. Schultz, and L. Padovano. 1991. Characterization of an immunoreactive 93-kDa core protein of Borrelia burgdorferi with a human IgG monoclonal antibody. J Immunol 146:3177. 82.

298. von Stedingk, L. V., I. Olsson, H. S. Hanson, E. Asbrink, and A. Hovmark. 1995. Polymerase chain reaction for detection of Borrelia burgdorferi DNA in skin lesions of early and late Lyme borreliosis. Eur J Clin Microbiol Infect Dis 14:1-5.

299. Wallich, R., C. Brenner, M. D. Kramer, and M. M. Simon. 1995. Molecular cloning and immunological characterization of a novel linear-plasmid-encoded gene, pG, of Borrelia burgdorferi expressed only in vivo. Infect Immun 63:3327-35.

300. Wallich, R., S. E. Moter, M. M. Simon, K. Ebnet, A. Heiberger, and M. D. Kramer. 1990. The Borrelia burgdorferi flagellum-associated 41-kilodalton antigen (flagellin): molecular cloning, expression, and amplification of the gene. Infect Immun 58:1711-9.

301. Wallich, R., M. M. Simon, H. Hofmann, S. E. Moter, U. E. Schaible, and M. D. Kramer. 1993. Molecular and immunological characterization of a novel polymorphic lipoprotein of Borrelia burgdorferi. Infect Immun 61: 4158-66.

302. Wells, S. J., A. M. Trent, R. A. Robinson, K. S. Knutson, and R. F. Bey. 1993. Association between clinical lameness and Borrelia burgdorferi antibody in dairy cows. Am J Vet Res 54:398-405.

303. Wheeler, C. M., J. C. Garcia Monco, J. L. Benach, M. G. Golightly, G. S. Habicht, and A. C. Steere. 1993. Nonprotein antigens of Borrelia burgdorferi. J Infect Dis 167:665-74,

304. Whitmire, W. M., and C. F. Garon. 1993. Specific and nonspecific responses of murine B cells to membrane blebs of Borrelia burgdorferi. Infect Immun 61:1460-7.

305. Wieler, L. H., C. Szattelberger, R. Weiss, R. Bauer- feind, P. Kutzer, K. Failing, and G. Baljer. 1999. Serum antibodies against particular antigens of Borrelia burgdorferi sensu stricto and their potential in the diagnosis of canine Lyme borreliosis. Berl Munch Tierarztl Wocherschr 112:465-71.

306. Wilske, B., A. G. Barbour, S. Bergstrom, N. Burman, B. I. Restrepo, P. A. Rosa, T. Schwan, E. Soutschek, and R. Wallich. 1992. Antigenic variation and strain heterogeneity in Borrelia spp. Res Microbiol 143:583-96.

307. Wilske, B., S. Jauris-Heipke, R. Lobentanzer, I. Pradel, V. Preac-Mursic, D. Rossler, E. Soutschek, and R. C. Johnson. 1995. Phenotypic analysis of outer surface protein $\mathrm{C}(\mathrm{OspC})$ of Borrelia burgdorferi sensu lato by monoclonal antibodies: relationship to genospecies and OspA serotype. J Clin Microbiol 33:103-9.

308. Wilske, B., V. Preac-Mursic, U. B. Gobel, B. Graf, S. Jauris, E. Soutschek, E. Schwab, and G. Zumstein. 1993. An OspA serotyping system for Borrelia burgdorferi based on reactivity with monoclonal antibodies and OspA sequence analysis. J Clin Microbiol 31:340-50.

309. Wilske, B., V. Preac-Mursic, S. Jauris, A. Hofmarn, I. Pradel, E. Soutschek, E. Schwab, G. Will, and G. Wanner. 1993. Immunological and molecular polymorphisms of OspC, an immunodominant major outer surface prctein of Borrelia burgdorferi. Infect Immun 61:2182-91.

310. Wittenbrink, M. M., K. Failing, and H. Krauss. 1996. Enzyme-linked immunosorbent assay and immuncblot analysis for detection of antibodies to Borrelia burgdorferi in dogs. The impact of serum absorption with homologous and heterologous bacteriae. Vet Microbiol 48:257-68.

311. Wokke, J. H., J. A. Vanneste, M. Vermeulen, A. A. Op de Coul, H. C. Overbeek, R. M. Janssen, and R. Brouwers. 1984. Lymphocytic meningoradiculitis following insect bites (Bannwarth' syndrome). Ned Tijdschr Geneeskd 128:1796-9.

312. Wormser, G. P., M. E. Aguero Rosenfeld, and R. B. Nadelman. 1999. Lyme disease serology: problems and opportunities. JAMA 282:79-80.

313. Wormser, G. P., S. Bittker, D. Cooper, J. Nowakowski, R. B. Nadelman, and C. Pavia. 2001. Yield of large-volume blood cultures in patients with early Lyme disease. J Infect Dis 184:1070-2.

314. Yang, X., M. S. Goldberg, T. G. Popova, G. B. Schoeler, S. K. Wikel, K. E. Hagman, and M. V. Norgard. 2000. Interdependence of environmental factors influencing reciprocal patterns of gene expression in virulent Borrelia burgdorferi. Mol Microbiol 37:1470-9.

315. Yu, Z., J. M. Carter, L. H. Sigal, and S. Stein. 1996. Multi-well ELISA based on independent peptide antigens for antibody capture. Application to Lyme disease serodiagnosis. J Immunol Methods 198:25-33.

316. Zhang, J. R., and S. J. Norris. 1998. Kinetics and in vivo induction of genetic variation of vlsE in Borrelia burgdorferi. Infect Immun 66:3689-97.

317. Zhioua, E., F. Rodhain, P. Binet, and C. Perez-Eid. 1997. Prevalence of antibodies to Borrelia burgdorferi in forestry workers of Ile de France, France. Eur J Epidemiol 13:959-62. 


Chapter II

\section{A SYSTEMATIC EVALUATION OF THE METHODOLOGICAL QUALITY OF RECENTLY PUBLISHED PERFORMANCE TESTING OF ENZYME IMMUNO ASSAYS AND WESTERN IMMUNOBLOT TESTS FOR LYME BORRELIOSIS IN HUMANS}

H.A.T. Goossens and A.E. van den Bogaard

Department of Medical Microbiology, University Maastricht 



\title{
A SYSTEMATIC EVALUATION OF THE METHODOLOGICAL QUALITY OF RECENTLY PUBLISHED PERFORMANCE TESTING

\author{
OF ENZYME IMMUNO ASSAYS
} \\ AND WESTERN IMMUNOBLOT TESTS \\ FOR LYME BORRELIOSIS \\ IN HUMANS
}

\author{
H.A.T. Goossens, A.E. van den Bogaard (*) \\ Department of Medical Microbiology, University of Maastricht, \\ NL-6200 MD Maastricht, The Netherlands
}

\begin{abstract}
In total 59 articles that described the performance of enzyme immuno assays and Western blot tests for Lyme borreliosis in humans were evaluated for the methodological quality of performance testing. A scoring method was developed to rank the articles evaluated. Six score groups were used. Each with a maximum number of points related to the importance of the information presented. The evaluation showed that the choice and number of patient sera and control sera do not reflect the real laboratory situation. Therefore, especially the expansion of the non-Lyme patient control group in future studies is needed in panels of sera used for the evaluation of diagnostic tests for Lyme borreliosis.
\end{abstract}

Systematic reviews of research evidence are important tools in medicine to improve quality of provided health services. Furthermore it also aids in the design and justification of controlled clinical trials and education of health professionals and lay people (14-16, 32-35, 42, $54,57,62)$. However, most meta-analytic studies so far have dealt with the effects of therapeutic interventions and relatively few laboratory diagnostic methods have been covered by systematic reviews. The demand for systematic reviews vastly exceeds the capacity of those who are prepared to commit themselves. The preparation of such reviews implies that acceptable scientific standards must be met and that these reviews have to be maintained for a long time as new evidence and criticisms emerge. Therefore reviewing existing evidence should

\footnotetext{
- Corresponding author. Mailing address: Department of Medical Microbiology, University of Maastricht, P.O. Box 616, NL-6200 MD Maastricht, The Netherlands. Phone: $+31 .(0) 43.388$.10.15. Fax; +31.(0)43.388.41.61. E-mail: A.vandenBogaard@cpv.unimaas.nl
}

be considered as advanced clinical research and metaanalytic approaches should be used in cases where it is appropriate and possible. For the laboratory confirmation of the clinical diagnosis of Lyme borreliosis (LB) in humans, serological tests such as the enzyme linked immunoassay (EIA) and Western blotting (WB) are the most used and advised tests. Consequently many LB EIAs and WBs have been developed either for in-house use or to be made commercially available. The results of performance testing of many of these EIAs and WBs, each with their own characteristics have been published. Out of this overwhelming amount of data it is difficult to decide which specific test to use and how to interpret the results. For responsible decision-making it is necessary to assess the overall value and performance of a test and compare it to others. A crucial step in this evaluation is the assessment of diagnostic accuracy. This is the ability of the test to determine correctly the presence or absence of the disease of interest, by comparing the test results with those obtained using a "golden standard". Because 
Table 1 Weighting of information listed in articles assesing EIA and/or WB test(s) used in the seradiagnosis of human LB

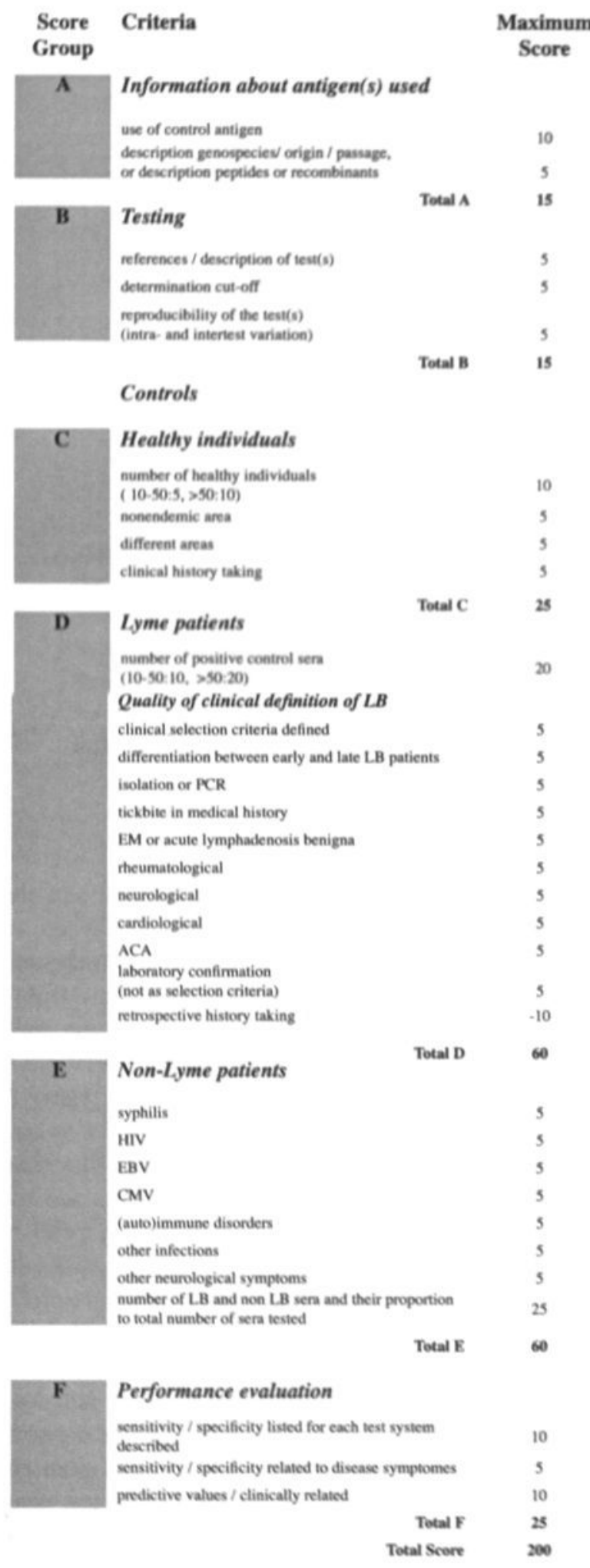

of the chosen "golden standard", tests may falsely appear to perform better compared to others. Other factors like the number and the definitions of patients do not allow generalization of the estimated diagnostic accuracy When too few patients are used, no precise estimates can be made and in case of selected populations a bias is introduced. Therefore an analysis of the results in the published literature might be useful for assessing diagnostic accuracy of the described tests.

The aim of this study was:

1. to present a summary of the literature listed in Medline $^{\mathrm{TM}}$ between $1990-2002$ about the performance of EIA and WB tests for the laboratory confirmation of the clinical diagnosis of LB in humans.

2. to evaluate the provided information on test characteristics and determination of test performance.

\section{RELEVANT LITERATURE}

A Medline ${ }^{\mathrm{TM}}$ search of English publications between $1990-2002$ was performed using the following key words: Borrelia burgdorferi, B. burgdorferi, Lyme borreliosis or disease, EIA, ELISA, WB, comparison, performance, evaluation, human, serology. All publications with the main purpose to present only sero-epidemiologic data were excluded. In the analysis, only articles describing EIA(s) or WB(s) or comparing (one of) these tests with another serological test were included.

\section{ASSESSMENT OF THE PUBLISHED STUDIES}

Diagnostic tests for LB are used against the background of clinical information that is available before testing. Hence, a test may appear useful if its information is carried by data that are already available to the clinician. As previously shown (Chapter 1, Table 2), the clinical spectrum of LB is diverse. Therefore to assess the validity of a laboratory test for confirmation of $\mathrm{LB}$, it is imperative that a patient population with a variety of clinical symptoms characteristic for LB as well as the different stages of the disease is tested. In addition, for the determination of the specificity of the test(s), not only sera of healthy individuals, but also sera of patients with diseases clinically mimicking LB or known to cause false positive results in LB serology should be included in a non-Lyme patient control group. This approach should be used as this reflects the clinical setting in which these tests will be used.

A scoring method, as shown in Table 1, was developed 
by using a modification of the methodological criteria for evaluating diagnostic tests $(9,14-16,32-34,42$, 54, 57, 62). Each article was assessed for six aspects (A.-F.). Every aspect was given a certain maximum number of points. Factors like: the type of antigen(s) used, description of how the tests were performed, the method(s) of performance-evaluation, the choice, composition, numbers of the positive and negative control sera and the applied clinical definitions were scored. The importance of each aspect was reflected by the maximum number of points granted. All studies were scored independently a second time by a second reviewer. Disagreement was resolved by consensus.

Aspect A. concerned the description of the antigen(s) used, and was granted maximum 15 points $(7.5 \%)$ out of the total scoring of 200 points. With respect to the additional value of a 'reference' which facilitates the comparisson to other tests, a total of 10 points was given to the articles describing a reference antigen. The other 5 points could be gained when detailed information was given concerning the origin, genospecies and the passage number (in case of whole cell extracts). Generally, most articles provide information about the used antigens, but this is not always complete. In case of in-house tests, detailed information is required to allow repetition of the test results. Also when commercially available tests are evaluated, a description of the antigen composition is needed because adaptation of used antigens occurs without changing the name of the test kit.

For aspect B. (test execution) a total of $7.5 \%$ of the total score $(15 / 200)$ could be earned when information was provided on: the calculation and the used cut-off value, intra- and intertest variation and test parameters. Although the information scored in A. and B. does not affect the performance of a test, they were included because of their importance for comparison of test systems and explanation of differences in test results. In fact the aspect A. and B. contain information that should be provided in the material and methods section of each paper about EIA and WB test, but is often missing or incomplete. Therefore a total of $30 / 200$ points $(15 \%)$ for A. or B. together was allocated.

Most serological tests for infectious diseases only differentiate between infected and non-infected individuals irrespective of clinical disease or symptoms. This means in case of LB that the prevalence of positive, recovered or subclinically infected individuals with B. burgdorferi in a population, defines the maximum performance limit of a serological LB test. Therefore inclusion of a control group of healthy individuals is important and was granted 25 points. However, because in a clinical laboratory situation the sera of patients suspected of LB are tested, the score for aspect C. was set considerably less than aspect D. (Lyme patient sera) and E. (non-Lyme patient sera).

In the clinical laboratory situation, the prevalence of LB is low and patients with diseases known to crossreact with LB tests or patients with diseases clinically mimicking LB represent the major part of patients tested for LB. Therefore, aspect D. and E. are granted the highest score: 60 points each. To estimate the value of the control

Table 2 Antigens described in evaluated articles assessing EIA and/or WB test(s) used in the seradiagnosis of human LB.

\begin{tabular}{|c|c|}
\hline Strains & $\begin{array}{c}\text { Antigen } \\
\text { code }\end{array}$ \\
\hline $\begin{array}{l}\text { B. burgdorferi sensu stricto } \\
\text { B. burgdorferi sensu stricto, }\end{array}$ & 1 \\
\hline flagellin enriched & 2 \\
\hline Borrelia afzelii & 3 \\
\hline Borrelia garinii & 4 \\
\hline Borrelia bissettii & 5 \\
\hline native purified flagellin & 6 \\
\hline $\begin{array}{l}\text { BBK } 32 * \\
\text { chimeric* flaA-B-C, C-93, C2- }\end{array}$ & 7 \\
\hline $\begin{array}{l}\text { C12, C1-C10 } \\
\text { chimeric* ospA, ospB, ospC, }\end{array}$ & 8 \\
\hline flaA, p93 & 9 \\
\hline $\mathrm{p} 83 / 100^{*}$ & 10 \\
\hline p58* & 11 \\
\hline p41 flagellin* & 12 \\
\hline p41-G* & 13 \\
\hline p4li* & 14 \\
\hline p39* & 15 \\
\hline p37* & 16 \\
\hline ospB* & 17 \\
\hline ospA* & 18 \\
\hline ospC* & 19 \\
\hline ospF* & 20 \\
\hline ospE* & 21 \\
\hline $\mathrm{DpA}^{*}$ & 22 \\
\hline p22* & 23 \\
\hline p17* & 24 \\
\hline p14* & 25 \\
\hline p83 (peptide) & 26 \\
\hline C10 (peptide) & 27 \\
\hline C6 (VLSE-peptide) & 28 \\
\hline flagellin (peptide) & 29 \\
\hline ospA (peptide) & 30 \\
\hline peptide-screen & 31 \\
\hline
\end{tabular}


Table 3 Ranking of articles evaluating EIA and/or WB for human LB.

\begin{tabular}{|c|c|c|c|c|c|c|c|c|c|c|c|}
\hline \multirow[b]{2}{*}{ Ref } & \multirow{2}{*}{$\begin{array}{l}\text { Author, } \\
\text { publication year }\end{array}$} & \multicolumn{2}{|c|}{ Test systems } & \multirow{2}{*}{$\begin{array}{l}\text { Antigen(s) used } \\
\text { (code cfr. Table 2) }\end{array}$} & \multicolumn{6}{|c|}{ Score groups (max score) } & \multirow{2}{*}{$\frac{\text { Rating }}{\text { A-F (200) }}$} \\
\hline & & EIA & WB & & $A(15)$ & $\mathrm{B}(15)$ & $\mathrm{C}(25)$ & $\mathrm{D}(60)$ & $\mathrm{E}(60)$ & $\mathrm{F}(25)$ & \\
\hline 12 & Cutler, 1993 & & $x^{\prime}$ & $\%$ & 0 & 5 & 0 & 0 & 0 & 0 & 5 \\
\hline 2 & Arzouni, 1993 & & $x$ & 1 & 0 & 5 & 10 & 0 & 2 & 0 & 17 \\
\hline 72 & Wormser, 2000 & $x$ & $x$ & $?$ & 0 & 1 & 10 & 0 & 4 & 5 & 20 \\
\hline 64 & Rose, 1991 & $x$ & $\mathrm{x}$ & 1 & 0 & 5 & 0 & 20 & 5 & 0 & 30 \\
\hline 52 & Melby, 1990 & 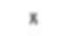 & $x$ & $3,6,7$ & 13 & 5 & 0 & 15 & 0 & 0 & 33 \\
\hline 66 & Stanek, 1999 & 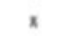 & $x$ & $1,3,4$ & 10 & 5 & 10 & 0 & 8 & 0 & 33 \\
\hline 10 & Cretella, 1995 & $x$ & $x$ & 1,13 & 13 & 3 & 0 & 20 & 3 & 0 & 39 \\
\hline 46 & Lin, 1991 & $\mathbf{x}$ & $x$ & 1,2 & 13 & 3 & 15 & 0 & 9 & 0 & 40 \\
\hline 6 & Burken, 1996 & $x$ & & $3,10,14$ & 14 & 8 & 10 & 0 & 4 & 5 & 40 \\
\hline 43 & Kourmitcheva, 2001 & $x$ & & 31 & 5 & 7 & 0 & 20 & 12 & 0 & 44 \\
\hline 58 & Pachner, 1992 & $x$ & $\mathbf{x}$ & 1 & 0 & 10 & 5 & 15 & 15 & 0 & 45 \\
\hline 1 & Aguero-Rosenfeld, 1993 & $x$ & $\mathrm{x}$ & 1,7 & 10 & 5 & 0 & 25 & 2 & 8 & so \\
\hline 47 & Magnarelli, 1994 & $x$ & & $1,3,4,5$ & 10 & 10 & 0 & 15 & 12 & 5 & 52 \\
\hline 11 & Cutler, 1900 & $x$ & & 7 & 10 & 0 & $\mathbf{0}$ & 30 & 14 & 1 & 55 \\
\hline 5 & Brunner, 1998 & $x$ & $\mathrm{x}$ & 1. 29 & 15 & 8 & 1 & 23 & 3 & 8 & 57 \\
\hline 67 & Steere, 1990 & s & & 1,7 & 10 & 10 & 0 & 30 & 3 & 6 & 59 \\
\hline 13 & Davidson, 1999 & $x$ & $\mathbf{x}$ & 1.7 & 13 & 5 & 0 & 0 & 26 & 15 & 59 \\
\hline 4 & Brunner, 2001 & $\mathrm{x}$ & & 1 & 0 & 10 & 0 & 20 & 20 & 10 & 60 \\
\hline 21 & Fawcett, 1998 & & $\mathrm{x}$ & $6,10,15,19$ & 14 & 5 & 10 & 15 & 11 & 7 & 61 \\
\hline 38 & Kaiser, 1998 & 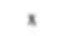 & & 1. 10, 19.25 & 14 & 10 & 0 & 25 & 14 & 0 & 62 \\
\hline s & Christenson, 1991 & $x$ & $x$ & 1,7 & 10 & 0 & 0 & 20 & 25 & 8 & 62 \\
\hline 44 & Ledve, 1996 & $x$ & $x$ & 1 & 0 & 8 & 5 & 20 & 23 & 8 & 63 \\
\hline 20 & Fawcett, 1995 & $x$ & & 1,7 & 10 & 5 & 0 & 25 & 18 & 7 & 65 \\
\hline$n$ & Fikrie. 1992 & $x$ & 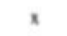 & $1,12,13,17,18$ & 14 & 8 & 5 & 20 & 12 & 7 & 66 \\
\hline 65 & Simpson, 1990 & & $\mathrm{x}$ & 1 & 10 & 5 & 5 & 25 & 19 & 2 & 66 \\
\hline 40 & Karlsson, 1990 & $x$ & $x$ & 3,6 & 14 & 5 & 0 & 25 & 12 & 12 & 68 \\
\hline 70 & Wilske, 1994 & & $\mathrm{x}$ & $3,4,10,12,14,18,19$ & 14 & 5 & 5 & 20 & 14 & 15 & 72 \\
\hline 45 & Liang. 1999 & $\mathrm{x}$ & & 28 & 5 & 5 & 15 & 15 & 26 & 10 & 76 \\
\hline 55 & Nilsson, 1996 & $x$ & $\mathbf{x}$ & $1,3,6$ & 14 & 15 & 10 & 25 & 11 & 5 & 80 \\
\hline 19 & Fawcett, 1991 & $x$ & $\mathbf{x}$ & 1 & 0 & 5 & 15 & 20 & 25 & 15 & 80 \\
\hline 63 & Robertson, 2000 & & $x$ & $1,3,4$ & 10 & 5 & 15 & 35 & 16 & 0 & 81 \\
\hline 37 & Kaiser, 1999 & $\mathbf{x}$ & & $1,10,19,25$ & 14 & 10 & 10 & 25 & 8 & 15 & 81 \\
\hline 59 & Panelius, 2001 & $\mathbf{x}$ & $\mathbf{x}$ & 12 & 14 & 8 & 5 & 23 & 28 & 6 & 83 \\
\hline 73 & $\mathrm{Yu}, 1996$ & $x$ & & $26,29,30$ & 14 & 5 & 5 & 35 & 9 & 15 & 84 \\
\hline 18 & Engstrom, 1995 & $x$ & $\mathbf{x}$ & 1 & 0 & 10 & 10 & 15 & 35 & 15 & 84 \\
\hline 74 & Zoller, 1991 & & $x$ & 1.4 & 10 & 10 & 5 & 40 & 18 & 2 & 85 \\
\hline 51 & Mathiesen, 1996 & $\mathbf{x}$ & $x$ & $1,3,4$ & 10 & 10 & 10 & 30 & 19 & 11 & 90 \\
\hline 49 & Magnarelli, 2000 & $x$ & $x$ & $\begin{array}{c}1,13,15,16,17,19 \\
20,21,23\end{array}$ & 14 & 3 & 10 & 15 & 34 & 15 & 90 \\
\hline 31 & Heikkila, 2002 & $x$ & $x$ & 3,22 & 15 & 8 & 1 & 29 & 27 & 13 & 92 \\
\hline 39 & Kaiser, 1999 & $x$ & $x$ & $1,10,19,25$ & 13 & 8 & 10 & 25 & 22 & 15 & 92 \\
\hline 17 & Dressler, 1993 & $x$ & $x$ & 1 & 0 & 8 & 0 & 35 & 36 & 14 & 92 \\
\hline 29 & Hauser, 1997 & $x$ & & $1,3,4,14$ & 15 & 10 & 10 & 31 & 13 & 15 & 94 \\
\hline 48 & Magnarelli, 1992 & $x$ & & 1,13 & 14 & 10 & 5 & 30 & 20 & 15 & 94 \\
\hline 61 & Rauer, 1998 & $\mathbf{x}$ & & $3,19,25$ & 14 & 4 & 15 & 35 & 29 & 0 & 96 \\
\hline 30 & Heikkila, 2002 & $x$ & $\mathbf{x}$ & 7,3 & 14 & 10 & 5 & 28 & 26 & 15 & 98 \\
\hline 56 & Nohlmans, 1994 & $x$ & & 1,3 & 10 & 13 & 10 & 25 & 26 & 15 & 99 \\
\hline 36 & Jauris-Heipke, 1999 & & $x$ & 3,24 & 13 & 5 & 0 & 40 & 26 & 15 & 99 \\
\hline 23 & Gomes-Solecki, 2001 & $x$ & $x$ & 9,7 & 13 & 11 & 10 & 22 & 31 & 13 & 99 \\
\hline 41 & Karlsson, 1990 & $x$ & & 1.6 & 14 & 10 & 0 & 35 & 29 & 15 & 103 \\
\hline$n$ & Wilske, 1999 & & $x$ & $3,10,11,14,15,19,24$ & 13 & 0 & 10 & 40 & 26 & 15 & 104 \\
\hline 26 & Hansen, 1991 & $x$ & & 6 & 4 & 10 & 10 & 35 & 31 & 15 & 105 \\
\hline 27 & Hauser, 1998 & $x$ & & $1,3,4$ & 10 & 15 & 15 & 35 & 16 & 15 & 106 \\
\hline 3 & Bergstrom, 1991 & $x$ & & 1.6 & 14 & 10 & 10 & 31 & 31 & 13 & 109 \\
\hline 24 & Gomes-Solecki, 2002 & $x$ & & 8,7 & 13 & 9 & 10 & 43 & 26 & 11 & 110 \\
\hline 28 & Hauser, 1997 & & $\mathrm{x}$ & $1,3,4$ & 10 & 10 & 10 & 40 & 26 & 15 & 111 \\
\hline 25 & Goossens, 1999 & $\mathrm{x}$ & $\mathbf{x}$ & $1,3,4,19,25$ & 13 & 5 & 5 & 30 & 41 & 20 & 114 \\
\hline so & Mathiesen, 1998 & $x$ & & 6.19 .27 & 13 & 10 & 10 & 35 & 36 & 12 & 116 \\
\hline 69 & Wilske, 1993 & $x$ & $x$ & $3,12,14,18,19$ & 14 & 8 & 10 & 40 & 31 & 15 & 117 \\
\hline$\omega$ & Rauer, 1995 & $\mathbf{x}$ & & 10 & 14 & 10 & 10 & 40 & 31 & 13 & 118 \\
\hline
\end{tabular}

*? no information provided 


\section{METHODOLOGICAL QUALITY OF PERFORMANCE TESTING OF EIA AND WB}

groups used in the literature, the scores were split up for Lyme patients and non-Lyme patients. As shown in Table 1 , the score system of the Lyme and non-Lyme patients was not only made dependent on the number of patients tested but also on the quality of clinical definitions and heterogeneity of symptoms and disease stages. In case of retrospective clinical history taking, that inevitably ignore false negative results, 10 points were subtracted. Because even in case of careful patient selection in the clinical situation more non-Lyme than Lyme patient sera will be submitted, an additional 25 points were given if the non-Lyme patient group was larger than the Lyme patient group. However, not only the absolute numbers of Lyme and non-Lyme patients were taken into account for this score, but also the different disease stages of LB and the range of diseases in the non-Lyme patient group. The calculation was performed as followed: $\mathrm{n} \mathrm{LB}<50: 0,78$; 50-100: 1,56 ; $>100: 3,13$; n non-LB $<50: 0,78$; $50-100$; 1,56 ; $>100: 3,13$; $\mathrm{LB}$ groups $<3: 1,56 ; \geq 3: 3,13$; n nonLB groups $\langle 3 ; 0,78 ; 3-5 ; 1,56 ; 25 ; 3,13 ; n$ LB/n non-LB $>0,4: 3,13 ; 0,2-0,4: 6,25 ; 0,1-0,2: 12,5$.

For aspect $F$. a total of 25 points was granted. When the sensitivity and specificity was listed for all tests described, 10 points could be eamed. In case where the predictive values were described in clinical defined groups an additional 10 points were granted. When the sensitivity and specificity of the tests was calculated in relation to the different diseases, 5 points could be earned.

\section{RESULTS}

In total 59 articles that fulfilled the selection criteria were found. Based on the criteria listed in Table 1, scores were allocated. As shown in Table 3, the total of each score group is listed and the articles ranked in ascending order according to the total rating obtained. Of these, 22 described only EIA tests, 10 only WBs and 27 described EIAs as well as WBs. As listed in Table 2, the antigens used for LB EIA and/or WB were very heterogeneous. Of the 27 articles, testing both EIA and WB, native and recombinant antigens were described in respectively 16 and 2 of the articles, whereas 9 articles described both native and recombinant antigens. Of the 22 articles describing only EIAs, native and recombinant antigens were used in respectively 10 and 4 test systems, whereas 8 compared native with recombinant antigens. Of the 10 articles evaluating only WB, 4 articles documented the use of both native as well as recombinant antigens.

For aspect A., 46 of the evaluated articles scored at least 10 points with a mean of 12 (SD 2) and three had a maximum of 15 . Thirteen articles scored lower than 10 because no control antigen had been used. In articles using native antigens an additional reason for a low scoring rate was the failure to report the number of passages of the $B$, burgdorferi isolate used.

With respect to aspect B., only two articles $(4,23)$ mentioned blinding of the tested sera, whereas only in 5 articles $(23,24,43,55,56)$ information about the intraand/or inter-test variation was provided. The mean score for aspect B. was 7 (SD 3) and the maximum score of 15 was obtained by two articles.

With respect to aspect $\mathrm{C}_{1}$, blood donors were used in 41 articles, of which two articles described the clinical anamnesis and three articles indicated that the blood donors originated from a non-endemic area. The mean score for aspect C. was 9 (SD 6) and the highest seore was 15.

The numbers of Lyme (aspect D.) and non-Lyme controls (aspect E.) was higher than 50 in respectively 29 and 26 of the articles. In respect to the quality of the clinical definition of LB patients, only 6 articles defined the clinical selection criteria for all Lyme patients used in the article, 8 differentiated between early and late LB, 5 described isolation or PCR and only one article listed a tickbite in the anamnesis. In the Lyme control group, patients with erythema migrans or acute lymphadenosis benigna were listed in 35 followed by 29 with neurological symptoms and 24 with rheumatological disorders caused by a $B$. burgdorferi infection and 15 with acrodermatitis chronica migrans. Cardiological disorders related to B. burgdorferi infection were only described in two articles. Laboratory confirmation of LB clinic was performed in 9 articles and a retrospective inquiry of the clinic for subjects showing positive reaction in LB serology was done in one article. The mean score in group D. was 24 (SD 12) and the highest score was 43. Seven articles scored higher then or equal to $40(24,28,36,60,69,71$, 74). For the patient control group, syphilis was listed in 34 articles followed by patients with auto-immune disorders (26/59), patients with EBV (16/59) and patients with other infections (11/59). Patients with other neurological disorders or HIV infection were only listed in 4 of the 59 articles. Only one article listed patients with CMV in the patient control group (25). The proportion of the numbers of Lyme and non-Lyme sera varied from $0,1-0,5$ in 13 articles, from $0,5-1$ in 17 articles and $\geq 1$ in 20 articles. The mean score for aspect E. was 19 (SD 12). For aspect E. ten articles scored 30 points or more $(3,17,18,23,25,26$, $49,50,60,69)$ and the highest score obtained was 41.

For the performance parameters (aspect F.), results 
about sensitivity and specificity were given in 47 articles of which 24 only listed data of all tests described. Of 21 from the 39 articles, sensitivity and specificity was related to all clinical Lyme symptoms listed. Predictive values (clinically related) were only given in one article (25). The mean score for aspect F. was 16 and the highest score was 20.

Of the EIA articles with total scores higher than 100 , 4 articles $(3,26,27,41)$ described EIA tests with only native antigen and one with a recombinant antigen (60), whereas three articles described a comparison of EIAs using recombinant and native antigen(s) $(24,25,50)$. In WB articles scoring higher than 100 , native $(69,71)$ as well as recombinant antigen $(28,69)$ were evaluated. Of the 59 evaluated articles the total score of 12 articles ranged from $90-100 ; 4$ of these described $\operatorname{EIA}(29,48,56$, $61)$, one evaluated WB (36) and 7 tested EIA as well as WB $(17,23,30,31,39,49,51)$.

\section{DISCUSSION}

Most measures of diagnostic accuracy are based on the comparison of the test with a reference or so called "golden standard" that determines the presence or absence of the disease of interest. An ideal diagnostic test discriminates between diseased and non-diseased individuals without error. However for infectious diseases, most serological tests only can differentiate between infected and noninfected individuals, irrespective of clinical disease or symptoms.

Tests can be characterized by various measures. The two most commonly reported measures are sensitivity: the probability that a test result is positive in patients with the disease of interest, and specificity: the probability that the test result is negative in patients without the disease of interest. These measures rely on a single threshold (cutoff, or positive criterion) for classifying a test result as positive. Changing the threshold to increase sensitivity decreases specificity and vice versa. This trade-off between sensitivity and specificity makes it imperative that they be considered jointly. An alternative to reporting a single pair of sensitivity and specificity estimates is the report of a range of pairs, which is obtained as the threshold criterion is varied. Such a range of pairs is often reported as a receiver operating characteristic (ROC) curve, which is a graph of the sensitivity (true-positive rate) on the vertical axis against the false-positive rate (1-specificity) on the horizontal axis $(7,53)$. One overall measure of the test's accuracy is the area under the ROC

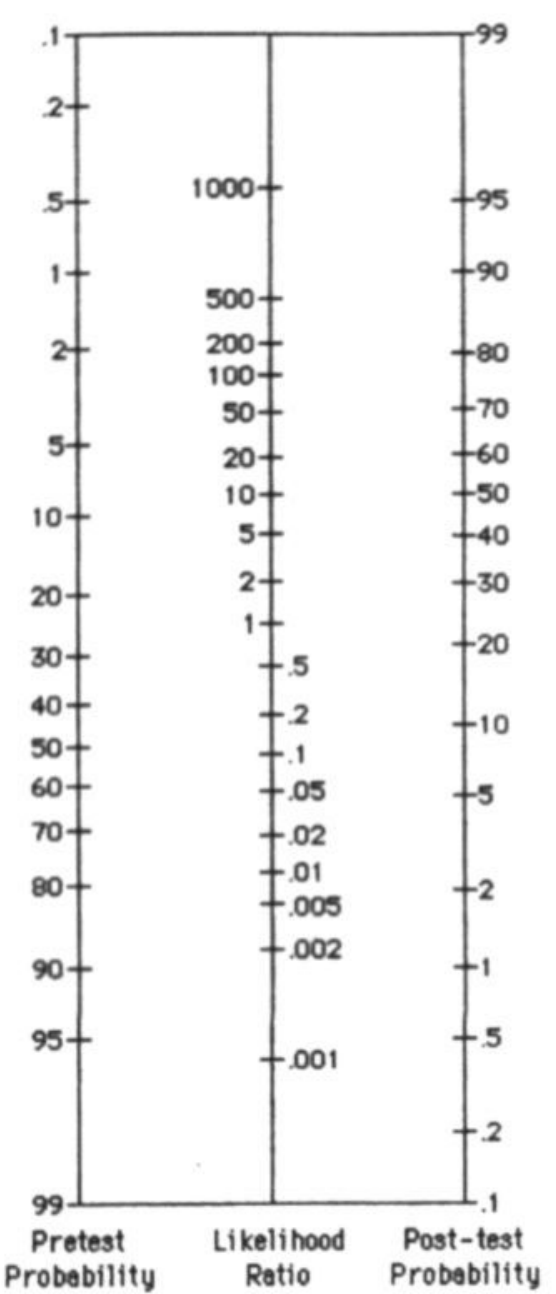

Figure 1 Nomogram for Bayes' theorem. (Fagan, U., N Engl J Med 293 (1975), letter)

curve. A value of 0.5 is obtained if the test does no better than chance and value 1 is obtained if the test is perfect. However in this evaluation only three articles $(17,27,50)$ were found who reported the ROC.

Another measure of test performance is the likelihood ratio, defined as the ratio of the probability of a particular test result in people with disease to the probability of the same test result in people without disesase. A likelihood ratio at each possible value of a multi-category or continuous test to get a result specific likelihood ratio can be estimated. This avoids the need to decide on a single threshold for dichotomising a test as positive or negative. More importantly, it avoids the loss of information that the dichotomy causes, where a test result just above the threshold is not differentiated from a test result well above the threshold. However in none of the articles listed, this measure was used. Furthermore, likelihood ratios can be 


\section{METHODOLOGICAL QUALITY OF PERFORMANCE TESTING OF EIA AND WB}

used to compute the post-test odds of disease (positive predictive value) with a known or estimated pre-test odds by using a version of Bayes' theorem (33): post-test odds of disease $=($ pre-test odds of disease) $\mathbf{x}$ (likelihood ratio). In the articles evaluated in this study, only one study used the likelihood ratios of dichotomy data for the calculation of positive and negative predictive values (25). By using a nomogram (Figure 1) and likelihood ratios, pre-test probabilities of an illness can simply be converted into significant post-test probabilities (positive predictive values). However, the reliability of the predictive results strongly depends on the quality of the patient selection.

In reviewing the literature on EIA and WB used in the serodiagnosis for LB, there are major drawbacks resulting in contradictory results in the laboratory situation compared to the results listed in literature. The cause of these discrepancies are caused by the lack of an acceptable number of good clinical defined Lyme patients with various clinical pictures as well as the limited number of non-Lyme patients with heterogeneous clinical symptoms mimicking LB. Ideally the number of non-Lyme patient control sera should be at least a factor 5 higher than the number of Lyme patient sera, which is in agreement with the clinical situation where patients to be tested for LB are carefully selected. In this review only 23 of the 59 papers scored higher than 90 on the maximum scale of 200 points. In our opinion such a score could be improved by: 1. more detailed description of antigens used, 2. listing of clinical related sensitivity/ specificity, 3. expansion and variation of Lyme, especially non-Lyme patient controls to improve the predictive value which is needed in the clinical setting.

The value of a meta-analysis in summarizing the results of the accuracy of diagnostic tests is still under debate and several appropriate and flexible methods for metaanalysing data on test accuracy have been developed or are under development $(32,33,68)$. The major constraint to valid meta-analysis of EIA and WB tests for the detection of LB is not the absence of appropriate statistical techniques but the insufficient quality of primary studies as could be demonstrated by the low number of articles with an acceptable scoring found.

Ideally the relative accuracy of several LB EIAs and or WBs should be compared by applying all the tests to each of the patient groups listed in Table 1 or by randomly assigning tests to patients in each primary study. However obtaining diagnostic accuracy information for different tests from different primary studies is a weak design; differences in diagnostic ac-curacy may reflect differences in study characteristics that are unlikely to be adequately controlled by attempting to adjust for them in the meta-analysis.

Unfortunately, at present for LB, test systems for serodiagnosis must be selected on the basis of imperfect studies. So it is better that clinicians are not only aware of the test characteristics but also of the quality of the literature. However, also patient characteristics determine the accuracy of the final test result. Furthermore one should be aware that the patient selection for LB testing influences the post-test probability substantially and that the specificity can never outdo the prevalence or incidence found in healthy controls as a result of subclinical infections.

In conclusion, the systemic evaluation of the performance testing of serodiagnostic tests for Lyme borreliosis in humans shows clearly that the main deficient factor is the choice and number of patient groups and control groups which is not a reflection of the real laboratory situation. Therefore expanding especially the non-Lyme patient control group in future studies as listed in Table 1 would improve the pre-clinical evaluation of serological tests for LB considerably.

\section{REFERENCES}

1. Aguero-Rosenfeld, M. E., J. Nowakowski, D. F. McKenna, C. A. Carbonaro, and G. P. Wormser. 1993. Serodiagnosis in early Lyme disease. J Clin Microbiol 31: 3090-5.

2. Arzouni, J. P., M. Laveran, J. Beytout, O. Ramousse, and D. Raoult. 1993. Comparison of western blot and microimmunofluorescence as tools for Lyme disease seroepidemiology. Eur J Epidemiol 9:269-73.

3. Bergstrom, S., A. Sjostedt, L. Dotevall, B. Kaijser, B. Ekstrand-Hammarstrom, C. Wallberg, G. Skogman, and A. G. Barbour. 1991. Diagnosis of Lyme borreliosis by an enzyme immunoassay detecting immunoglobulin $\mathrm{G}$ reactive to purified Borrelia burgdorferi cell components. Eur J Clin Microbiol Infect Dis 10:422-7.

4. Brunner, M., and L. H. Sigal. 2001. Use of serum immune complexes in a new test that accurately confirms early Lyme disease and active infection with Borrelia burgdorferi. J Clin Microbiol 39:3213-21.

5. Brunner, M., S. Stein, P. D. Mitchell, and L. H. Sigal. 1998. Immunoglobulin M capture assay for serologic confirmation of early Lyme disease: analysis of immune complexes with biotinylated Borrelia burgdorferi sonicate enhanced with flagellin peptide epitope. J Clin Microbiol 36:1074-80.

6. Burkert, S., D. Rossler, P. Munchhoff, and B. Wilske. 1996. Development of enzyme-linked immunosorbent 
assays using recombinant borrelial antigens for serodiagnosis of Borrelia burgdorferi infection. Med Microbiol Immunol (Berl) 185:49-57.

7. Chan, D. W. 1987. Immunoassay. A practical guide. Academic Press, London:53-5.

8. Christenson, V. D., and D. H. White. 1991. Evaluation of four commercially available ELISA assays for the serologic diagnosis of Lyme disease. J Clin Lab Anal 5: 340-3.

9. Cochrane Methods Group on Sereening and Diagnostic Tests. Recommended methods. [http://www,cochrane.org/ cochrane/sadt.html.

10. Cretella, S., S. Gordon, R. A. Flavell, and E. Fikrig. 1995. Evaluation of a Lyme disease enzyme immunoassay using the 41-G fragment of flagellin. Eur J Clin Microbiol Infect Dis 14:609-13.

11. Cutler, S. J., and D. J. Wright. 1990. Evaluation of three commercial tests for Lyme disease. Diagn Microbiol Infect Dis 13:271-2.

12. Cutler, S. J., D. J. Wright, and V. H. Luckhurst. 1993. Simplified method for the interpretation of immunoblots for Lyme borreliosis. FEMS Immunol Med Microbiol 6: 281-5.

13. Davidson, M. M., C. L. Ling, S. M. Chisholm, A. D. Wiseman, A. W. Joss, and D. O. Ho-Yen. 1999. Evidencebased diagnosis of Lyme disease. Eur J Clin Microbiol Infect Dis 18:484-9.

14. Deeks, J. J. 2001. Systematic reviews in health care: Systematic reviews of evaluations of diagnostic and screening tests. Bmj 323:157-62.

15. Deville, W. L., P. D. Bezemer, and L. M. Bouter. 2000. Publications on diagnostic test evaluation in family medicine journals: an optimal search strategy. J Clin Epidemiol 53:65-9.

16. Deville, W. L., F. Buntinx, L. M. Bouter, V. M. Montori, H. C. De Vet, D. A. Van Der Windt, and P. Bezemer. 2002. Conducting systematic reviews of diagnostic studies: didactic guidelines. BMC Med Res Methodol 2:9.

17. Dressler, F., J. A. Whalen, B. N. Reinhardt, and A. C. Steere. 1993. Western blotting in the serodiagnosis of Lyme disease. J Infect Dis 167:392-400.

18. Engstrom, S. M., E. Shoop, and R. C. Johnson. 1995. Immunoblot interpretation criteria for serodiagnosis of early Lyme disease. J Clin Microbiol 33:419-27.

19. Fawcett, P. T., K. M. Gibney, C. D. Rose, J. D. Klein, and R. A. Doughty. 1991. Adsorption with a soluble E. coli antigen fraction improves the specificity of ELISA tests for Lyme disease. J Rheumatol 18:705-8.

20. Fawcett, P. T., C. D. Rose, and K. M. Gibney. 1995. Comparative evaluation of adsorption with E. coli on ELISA tests for Lyme borreliosis. J Rheumatol 22:684-8.

21. Fawcett, P. T., C. D. Rose, K. M. Gibney, and R. A. Doughty. 1998. Comparison of immunodot and western blot assays for diagnosing Lyme borreliosis. Clin Diagn Lab Immunol 5:503-6.
22. Fikrig, E., E. D. Huguenel, R. Berland, D. W. Rahn, J. A. Hardin, and R. A. Flavell. 1992. Serologic diagnosis of Lyme disease using recombinant outer surface proteins A and B and flagellin. J Infect Dis 165:1127-32.

23. Gomes-Solecki, M. J., G. P. Wormser, D. H. Persing, B. W. Berger, J. D. Glass, X. Yang, and R. J. Dattwyler. 2001. A first-tier rapid assay for the serodiagnosis of Borrelia burgdorferi infection. Arch Intern Med 161:201520.

24. Gomes-Solecki, M. J., G. P. Wormser, M. Schriefer, G. Neuman, L. Hannafey, J. D. Glass, and R. J. Dattwyler. 2002. Recombinant assay for serodiagnosis of Lyme disease regardless of OspA vaccination status. J Clin Microbiol 40:193-7.

25. Goossens, H. A., A. E. van den Bogaard, and M. K. Nohlmans. 1999. Evaluation of fifteen commercially available serological tests for diagnosis of Lyme borreliosis. Eur J Clin Microbiol Infect Dis 18:551-60.

26. Hansen, K., K. Pii, and A. M. Lebech. 1991. Improved immunoglobulin $\mathrm{M}$ serodiagnosis in Lyme borreliosis by using a mu-capture enzyme-linked immunosorbent assay with biotinylated Borrelia burgdorferi flagella. J Clin Microbiol 29:166-73.

27. Hauser, U., H. Krahl, H. Peters, V. Fingerle, and B. Wilske. 1998. Impact of strain heterogeneity on Lyme disease serology in Europe: comparison of enzyme-linked immunosorbent assays using different species of Borrelia burgdorferi sensu lato. J Clin Microbiol 36:427-36.

28. Hauser, U., G. Lehnert, R. Lobentanzer, and B. Wilske. 1997. Interpretation criteria for standardized Western blots for three European species of Borrelia burgdorferi sensu lato. J Clin Microbiol 35:1433-44.

29. Hauser, U., and B. Wilske. 1997. Enzyme-linked immunosorbent assays with recombinant internal flagellin fragments derived from different species of Borrelia burgdorferi sensu lato for the serodiagnosis of Lyme neuroborreliosis. Med Microbiol Immunol (Berl) 186:14551.

30. Heikkila, T., I. Seppala, H. Saxen, J. Panelius, M. Peltomaa, T. Julin, S. A. Carlsson, and P. Lahdenne. 2002. Recombinant BBK32 protein in serodiagnosis of early and late Lyme borreliosis. J Clin Microbiol 40:117480.

31. Heikkila, T., I. Seppala, H. Saxen, J. Panelius, H. Yrjanainen, and P. Lahdenne. 2002. Species-specific serodiagnosis of Lyme arthritis and neuroborreliosis due to Borrelia burgdorferi sensu stricto, B. afzelii, and B. garinii by using decorin binding protein A. J Clin Microbiol 40: 453-60.

32. Irwig, L., P. Macaskill, P. Glasziou, and M. Fahey. 1995. Meta-analytic methods for diagnostic test accuracy. J Clin Epidemiol 48:119-30; discussion 131-2.

33. Irwig, L., A. N. Tosteson, C. Gatsonis, J. Lau, G. Colditz, T. C. Chalmers, and F. Mosteller. 1994. Guidelines for meta-analyses evaluating diagnostic tests. Ann Intern Med 


\section{0:667-76.}

34. Jaeschke, R., G. Guyatt, and D. L. Sackett. 1994. Users' guides to the medical literature. III. How to use an article about a diagnostic test. A. Are the results of the study valid? Evidence-Based Medicine Working Group. Jama 271:389-91.

35. Jaeschke, R., G. H. Guyatt, and D. L. Sackett. 1994. Users' guides to the medical literature. III. How to use an article about a diagnostic test. B. What are the results and will they help me in caring for my patients? The EvidenceBased Medicine Working Group. Jama 271:703-7.

36. Jauris-Heipke, S., B. Rossle, G. Wanner, C. Habermann, D. Rossler, V. Fingerle, G. Lehnert, R. Lobentanzer, I. Pradel, B. Hillenbrand, U. Schulte-Spechtel, and B. Wilske. 1999. Osp17, a novel immunodominant outer surface protein of Borrelia afzelii: recombinant expression in Escherichia coli and its use as a diagnostic antigen for serodiagnosis of Lyme borreliosis. Med Microbiol Immunol (Berl) 187:213-9.

37. Kaiser, R., and S. Rauer. 1999. Advantage of recombinant borrelial proteins for serodiagnosis of neuroborreliosis. J Med Microbiol 48:5-10.

38. Kaiser, R., and S. Rauer. 1998. Analysis of the intrathecal immune response in neuroborreliosis to a sonicate antigen and three recombinant antigens of Borrelia burgdorferi sensu stricto. Eur J Clin Microbiol Infect Dis 17:159-66.

39. Kaiser, R., and S. Rauer. 1999. Serodiagnosis of neuroborreliosis: comparison of reliability of three confirmatory assays. Infection 27:177-82.

40. Karlsson, M. 1990. Western immunoblot and flagellum enzyme-linked immunosorbent assay for serodiagnosis of Lyme borreliosis. J Clin Microbiol 28:2148-50.

41. Karlsson, M., G. Stiernstedt, M. Granstrom, E. Asbrink, and B. Wretlind. 1990. Comparison of flagellum and sonicate antigens for serological diagnosis of Lyme borreliosis. Eur J Clin Microbiol Infect Dis 9:169-77.

42. Knottnerus, J. A., C. van Weel, and J. W. Muris. 2002. Evaluation of diagnostic procedures. Bmj 324:477-80.

43. Kouzmitcheva, G. A., V. A. Petrenko, and G. P. Smith. 2001. Identifying diagnostic peptides for lyme disease through epitope discovery. Clin Diagn Lab Immunol 8: 150-60.

44. Ledue, T. B., M. F. Collins, and W. Y. Craig. 1996. New laboratory guidelines for serologic diagnosis of Lyme disease: evaluation of the two-test protocol. J Clin Microbiol 34:2343-50.

45. Liang, F. T., A. C. Steere, A. R. Marques, B. J. Johnson, J. N. Miller, and M. T. Philipp. 1999. Sensitive and specific serodiagnosis of Lyme disease by enzymelinked immunosorbent assay with a peptide based on an immunodominant conserved region of Borrelia burgdorferi vlsE. J Clin Microbiol 37:3990-6.

46. Lin, T. M., C. M. Schubert, F. F. Shih, P. Ahmad, M. Lopez, and H. Horst. 1991. Use of flagellin-enriched antigens in a rapid, simple and specific quantitative enzyme immunoassay for Lyme disease antibodies in human serum samples. J Immunoassay 12:325-46.

47. Magnarelli, L. A., J. F. Anderson, R. C. Johnson, R. B. Nadelman, and G. P. Wormser. 1994. Comparison of different strains of Borrelia burgdorferi sensu lato used as antigens in enzyme-linked immunosorbent assays. J Clin Microbiol 32:1154-8.

48. Magnarelli, L. A., E. Fikrig, R. Berland, J. F. Anderson, and R. A. Flavell. 1992. Comparison of whole-cell antibodies and an antigenic flagellar epitope of Borrelia burgdorferi in serologic tests for diagnosis of Lyme borreliosis. J Clin Microbiol 30:3158-62.

49. Magnarelli, L. A., J. W. Ijdo, S. J. Padula, R. A. Flavell, and E. Fikrig. 2000. Serologic diagnosis of Lyme borreliosis by using enzyme-linked immunosorbent assays with recombinant antigens. J Clin Microbiol 38:1735-9.

50. Mathiesen, M. J., M. Christiansen, K. Hansen, A. Holm, E. Asbrink, and M. Theisen. 1998. Peptide-based OspC enzyme-linked immunosorbent assay for serodiagnosis of Lyme borreliosis. J Clin Microbiol 36:3474-9.

51. Mathiesen, M. J., K. Hansen, N. Axelsen, L. HalkierSorensen, and M. Theisen. 1996. Analysis of the human antibody response to outer surface protein $\mathrm{C}(\mathrm{OspC})$ of Borrelia burgdorferi sensu stricto, B. garinii, and B. afzelii. Med Microbiol Immunol (Berl) 185:121-9.

52. Melby, K., M. Steinbakk, M. Jensenius, and K. J. Figenschau. 1990. Detection of serum antibodies against Borrelia burgdorferi with some commercially available serological tests. NIPH Ann 13:37-44.

53. Midgette, A. S., T. A. Stukel, and B. Littenberg. 1993. A meta-analytic method for summarizing diagnostic test performances: receiver-operating-characteristic-summary point estimates. Med Decis Making 13:253-7.

54. Mulrow, C. D., W. D. Linn, M. K. Gaul, and J. A. Pugh. 1989. Assessing quality of a diagnostic test evaluation. J Gen Intern Med 4:288-95.

55. Nilsson, I., and I. A. von Rosen. 1996. Serum antibodies against Borrelia afzelii, Borrelia burgdorferi sensu stricto and the 41-kiloDalton flagellin in patients from a Lyme borreliosis endemic area: analysis by EIA and immunoblot. Apmis 104:907-14.

56. Nohlmans, M. K., A. A. Blaauw, A. E. van den Bogaard, and C. P. van Boven. 1994. Evaluation of nine serological tests for diagnosis of Lyme borreliosis. Eur J Clin Microbiol Infect Dis 13:394-400.

57. Oosterhuis, W. P., R. W. Niessen, and P. M. Bossuyt. 2000. The science of systematic reviewing studies of diagnostic tests. Clin Chem Lab Med 38:577-88.

58. Pachner, A. R., and N. S. Ricalton. 1992. Western blotting in evaluating Lyme seropositivity and the utility of a gel densitometric approach. Neurology 42:2185-92.

59. Panelius, J., P. Lahdenne, H. Saxen, T. Heikkila, and I. Seppala. 2001. Recombinant flagellin A proteins from Borrelia burgdorferi sensu stricto, B. afzelii, and B. garinii in serodiagnosis of Lyme borreliosis. J Clin Microbiol 39: 
4013-9.

60. Rauer, S., M. Kayser, U. Neubert, C. Rasiah, and A. Vogt. 1995. Establishment of enzyme-linked immunosorbent assay using purified recombinant 83-kilodalton antigen of Borrelia burgdorferi sensu stricto and Borrelia afzelii for serodiagnosis of Lyme disease. J Clin Microbiol 33:2596600.

61. Rauer, S., N. Spohn, C. Rasiah, U. Neubert, and A. Vogt. 1998. Enzyme-linked immunosorbent assay using recombinant OspC and the internal $14-\mathrm{kDa}$ flagellin fragment for serodiagnosis of early Lyme disease. J Clin Microbiol 36:857-61.

62. Reid, M. C., M. S. Lachs, and A. R. Feinstein. 1995. Use of methodological standards in diagnostic test research. Getting better but still not good. Jama 274:645-51.

63. Robertson, J., E. Guy, N. Andrews, B. Wilske, P. Anda, M. Granstrom, U. Hauser, Y. Moosmann, V. Sambri, J. Schellekens, G. Stanek, and J. Gray. 2000. A European multicenter study of immunoblotting in serodiagnosis of lyme borreliosis. J Clin Microbiol 38:2097-102.

64. Rose, C. D., P. T. Fawcett, B. H. Singsen, S. B. Dubbs, and R. A. Doughty. 1991. Use of western blot and enzymelinked immunosorbent assays to assist in the diagnosis of Lyme disease. Pediatrics 88:465-70.

65. Simpson, W. J., M. E. Schrumpf, and T. G. Schwan. 1990. Reactivity of human Lyme borreliosis sera with a 39 kilodalton antigen specific to Borrelia burgdorferi. J Clin Microbiol 28:1329-37.

66. Stanek, G., F. Breier, G. Menzinger, B. Schaar, M. Hafner, and H. Partsch. 1999. Erythema migrans and serodiagnosis by enzyme immunoassay and immunoblot with three borrelia species. Wien Klin Wochenschr 111: 951-6.

67. Steere, A. C., V. P. Berardi, K. E. Weeks, E. L. Logigian, and R. Ackermann. 1990. Evaluation of the intrathecal antibody response to Borrelia burgdorferi as a diagnostic test for Lyme neuroborreliosis. J Infect Dis 161:1203-9.

68. Walter, S. D., L. Irwig, and P. P. Glasziou. 1999. Metaanalysis of diagnostic tests with imperfect reference standards. J Clin Epidemiol 52:943-51.

69. Wilske, B., V. Fingerle, P. Herzer, A. Hofmann, G. Lehnert, H. Peters, H. W. Pfister, V. Preac-Mursic, E. Soutschek, and K. Weber. 1993. Recombinant immunoblot in the serodiagnosis of Lyme borreliosis. Comparison with indirect immunofluorescence and enzyme-linked immunosorbent assay. Med Microbiol Immunol (Berl) 182:255-70.

70. Wilske, B., V. Fingerle, V. Preac-Mursic, S. JaurisHeipke, A. Hofmann, H. Loy, H. W. Pfister, D. Rossler, and E. Soutschek. 1994. Immunoblot using recombinant antigens derived from different genospecies of Borrelia burgdorferi sensu lato. Med Microbiol Immunol (Berl) 183:43-59.

71. Wilske, B., C. Habermann, V. Fingerle, B. Hillenbrand, S. Jauris-Heipke, G. Lehnert, I. Pradel, D. Rossler, and
U. Schulte-Spechtel. 1999. An improved recombinant IgG immunoblot for serodiagnosis of Lyme borreliosis. Med Microbiol Immunol (Berl) 188:139-44.

72. Wormser, G. P., C. Carbonaro, S. Miller, J. Nowakowski, R. B. Nadelman, S. Sivak, and M. E. Aguero-Rosenfeld. 2000. A limitation of 2-stage serological testing for Lyme disease: enzyme immunoassay and immunoblot assay are not independent tests. Clin Infect Dis 30:545-8.

73. Yu, Z., J. M. Carter, L. H. Sigal, and S. Stein. 1996. Multi-well ELISA based on independent peptide antigens for antibody capture. Application to Lyme disease serodiagnosis. J Immunol Methods 198:25-33.

74. Zoller, L., S. Burkard, and H. Schafer. 1991. Validity of western immunoblot band patterns in the serodiagnosis of Lyme borreliosis. J Clin Microbiol 29:174-82. 




\title{
Chapter III
}

\section{EVALUATION OF FIFTEEN COMMERCIALLY AVAILABLE SEROLOGICAL TESTS FOR DIAGNOSIS OF LYME BORRELIOSIS}

\author{
and \\ Correspondence
}

REDUCED SPECIFICITY OF COMBINED IGM AND IGG ENZYME IMMUNOASSAY TESTING FOR LYME BORRELIOSIS

EPSTEIN-BARR VIRUS AND CYTOMEGALOVIRUS INFECTIONS CAUSE FALSE-POSITIVE RESULTS IN IGM TWO-TEST PROTOCOL FOR EARLY LYME BORRELIOSIS 



\title{
Chapter IIIa
}

\section{EVALUATION OF FIFTEEN COMMERCIALLY AVAILABLE SEROLOGICAL TESTS FOR DIAGNOSIS OF \\ LYME BORRELIOSIS}

\author{
H.A.T. Goossens' ${ }^{1}$ A.E. van den Bogaard', M.K.E. Nohlmans ${ }^{2}$ \\ ' Department of Medical Microbiology, University Maastricht; \\ ${ }^{2}$ Department of Medical Microbiology, General Hospital Arnhem, The Netherlands
}

Reprinted by permission of Eur J Clin Microbiol Infect Dis (1999) 18:551-560. 



\title{
Article
}

\section{Evaluation of Fifteen Commercially Available Serological Tests for Diagnosis of Lyme Borreliosis}

\author{
H.A.T. Goossens, A.E. van den Bogaard, M.K.E. Nohlmans
}

\begin{abstract}
The performance of 11 commercially available enzyme immunoassays (EIA) and four Western blot (WB) tests for the detection of IgM and IgG antibodies against Borrelia burgdorferi were compared. A total of 229 serum specimens were used: 26 from patients with early Lyme borreliosis, 13 from patients with late Lyme borreliosis, 62 from healthy controls and 128 from patients with disorders clinically mimicking Lyme borreliosis and/or known to cause cross-reactivity in Lyme borreliosis serological tests (patient control group). In specimens from patients with early Lyme borreliosis, the sensitivity of the individual tests ranged from 35 to $81 \%$ for detection of IgM. In late Lyme borreliosis, sensitivity of the tests ranged from 46 to $92 \%$. In healthy controls the specificity of the tests ranged from 89 to $100 \%$ and from 82 to $97 \%$ for IgM and IgG tests, respectively. In the patient control group, specificity of the tests ranged from 75 to $90 \%$ for $\mathrm{IgM}$ and from 84 to $100 \%$ for $\mathrm{IgG}$ tests. The Behring (Germany) and Genzyme Virotech (Germany) IgM EIA tests showed the best performance in detecting early Lyme borreliosis. For the detection of late Lyme borreliosis, the Dako (Denmark) IgG test was the best despite its low sensitivity. The maximum sensitivity of Western blotting for detecting $\mathrm{IgM}$ in patients with early Lyme borreliosis and IgG in patients with late Lyme borreliosis was 50 and $46 \%$, respectively. The use of an EIA-WB two-test protocol improved the specificity and positive predictive values of the EIA results but caused a significant loss in sensitivity. Patients with Epstein-Barr virus or cytomegalovirus infection who had a positive reaction in the IgM EIA could not be discriminated from patients with early Lyme borreliosis with the help of Western blotting. Hence, positive and negative predictive values in combination with sensitivity and specificity values indicated that the exclusion of these infections was more relevant than the confirmation of a positive IgM EIA with Western blot.
\end{abstract}

\section{Introduction}

Since the discovery in 1982 of Borrelia burgdorferi as the causative agent of Lyme borreliosis (LB) [1] and the subsequent awareness of the extended distribution of this infection [2], the development of serological tests to aid the diagnosis of LB has received much

H.A.T. Goossens, A.E. van den Bogaard (ब)

Department of Medical Microbiology, University of Maastricht, PO Box 616, NL-6200 MD Maastricht, The Netherlands

M.K.E. Nohlmans

Department of Medical Microbiology, General Hospital

Arnhem, PO Box 9025, NL-6800 EG Arnhem, The Netherlands attention. Several factors have contributed to this development. Firstly, LB is a multisystemic disorder that may affect several organ systems such as the skin, nervous system, joints and/or heart. By virtue of its wide range of clinical manifestations, LB may mimick several other diseases $[3,4]$. Hence, diagnosing the disease purely on clinical grounds may be difficult, especially in the absence of erythema migrans (EM) or a tick bite in the anamnesis. Moreover, EM only occurs in about $60 \%$ of patients $[3,4]$. Secondly, the classical methods for confirming the diagnosis of a bacterial infection, i.e., isolation or direct visualization of the causative agent [5-7], and newer methods such as antigen detection, T-lymphocyte assay or polymerase chain reaction are either not sensitive enough or not readily available in clinical practice [8-23]. 
Currently, enzyme immunosorbent assays (EIAs) are the most reliable and readily available laboratory tests for LB. However, there are several problems in the serodiagnosis of LB. False-negative results in serological tests can be attributed to the slow antibody response in LB; IgM antibodies may not be detectable until 6 weeks after disease onset, and production of $\mathrm{IgG}$ antibodies may follow within a few weeks but may not reach a peak until months after disease onset [4]. Antibiotic therapy given during early Lyme borreliosis (ELB) may prevent the development of antibodies [4]. Moreover, while the incidence of seronegative LB cases remains controversial, it has been estimated to be as high as $5 \%[24,25]$. False-positive results may occur due to cross-reactivity with antibodies against other microorganisms, or due to the presence of aspecific antibodies in various viral and autoimmune syndromes [4]. Furthermore, the occurrence of asymptomatic LB with positive test results in healthy controls is well documented $[26,27]$.

To improve sensitivity, especially in the early stages of the disease, and to reduce cross-reactivity, several methods have been advocated. These include the use of purified outer membrane, flagella or recombinant antigens and the preadsorption of sera with Treponema phagedenis or other bacterial antigens [28]. However, experience thus far has been variable. None of the currently available diagnostic methods including immunofluorescent antibody assays, EIA, hemagglutination assays and Western blot (WB), have been standardized with regard to performance, relevance, techniques, antigen preparations, reagents or even the definition of what constitutes a positive result $[28,29]$. Despite these shortcomings, many laboratories follow the guidelines established by the Association of State and Territorial Public Health Laboratory Directors (ASTPHLD) and the U.S. Centers for Disease Control and Prevention (CDC), who recommend the use of a two-test protocol for the serodiagnosis of LB. The two-test protocol consists of screening with an IgM and/or IgG EIA followed by the use of $\mathrm{IgM}$ and/or $\mathrm{IgG}$ immunoblotting for reactive sera as a confirmatory test. Immunoblotting makes it feasible to visualize the immune response against individual Borrelia proteins.

Unfortunately, in many studies interpretation of immunoblot patterns has been subjective, which has resulted in diverse criteria for positivity [30-33]. Moreover, in most studies tests are evaluated based solely on sensitivity and specificity, which only characterize the validity of the test. Positive and negative predictive values are more relevant for clinical decision-making because they take into account the prevalence of the disease in a certain population.

In the present study, we evaluated 11 commercially available EIA tests, four Western blot (WB) tests and the EIA-WB two-test protocol using sera of confirmed
LB patients as positive controls and sera of healthy persons as well as of patients with infections mimicking LB or known to cross-react in LB serological tests as negative controls.

\section{Materials and Methods}

Sera. Two hundered twenty-nine serum samples were collected in the Netherlands during a period of 1 year. Using clinical criteria, they were divided into three major groups according to their origin. The Lyme patient group consisted of 26 patients with early Lyme borreliosis who had presented with an erythema migrans and had a history of a tick bite and/or isolation of Borrelia burgdorferi from their skin lesions (ELB group) and 13 patients with late Lyme borreliosis (LLB group), four with acrodermatitis chronica atrophicans and nine with neuroborreliosis. All Lyme patients were included in the study irrespective of the results obtained in serological tests and all recovered after adequate antibiotic therapy. There was no occurrence of relapse in the group. The healthy control group consisted of 62 healthy controls with no history of LB and tick exposure. The patient control group consisted of 128 persons: 24 with Epstein-Barr virus (EBV) infection, 12 with acute cytomegalovirus (CMV) infection, 24 with rheumatoid factor-positive rheumatoid arthritis (RF), 24 with antinuclear antibodies (ANA), 23 with syphilis (TP) and 21 which were seropositive for the human immunodeficiency virus (HIV).

All Lyme patients had negative test results for RF (Eurogenetics, Belgium), ANA (immunofluorescent assay with Hep-2 cells, internal house test), EBV (Paul en Bunell, internal house test, and EBV-EIA, IgM, Genzyme Virotech, Germany), CMV (Abbott, USA), HIV (Abbott, USA) and specific syphilis antibodies (Fujirebio, Japan).

IgM and IgG Enzyme Immunoassays. The following 11 commercially available EIA tests were evaluated: Behring (Germany) IgM and IgG EIA, Boehringer (Germany) IgM and IgG EIA, Dako (Denmark) IgM and IgG EIA, Genzyme Virotech (Germany) IgM and IgG EIA, IBL (Germany) IgM and IgG EIA, and Milenia (Germany) IgM + IgG EIA. All kits were purchased at the same time and were lot consistent. All systems were used according to the instructions of the manufacturers. Test characteristics and types of antigens used are shown in Table 1. All samples were tested in duplicate. For the calculation of sensitivity and specificity, borderline results were considered positive. For further comparison of the EIAs, WBs and EIA-WB two-test protocol, indexes and predictive values for positive and negative results were calculated. The predictive values were derived from the likelihood-ratio using Baye's theorem [34] and listed for the IgM and IgG tests with a $20 \%$ prevalence of, respectively, ELB and LLB in the population combined with healthy controls (population I), non-Lyme patient controls (population II) and non-Lyme patient controls eliminated from the EBV and CMV control group (population III). The postulated $20 \%$ prevalence of LB in this study was based on the prevalence of infection with Borrelia burgdorferi in patients tested for LB in north and central Europe [35]. The prevalence varied from $15 \%$ (Poland) to $28 \%$ (Netherlands). Because of earlier findings that CMV and EBV infections cause false-positive results in IgM EIA-WB two-test protocols for ELB, the CMV and EBV control group was excluded in population III. For the calculation of intra-assay precision, the deviation of the duplicate values within $25 \%$ of the mean baseline was used as described in [36].

IgM and $\operatorname{Ig} G$ Western Blots. Additionally, four commercially available WBs were tested: Genzyme Virotech (Germany) IgM and IgG and MRL (USA) IgM and IgG. All kits were purchased at the same time and were lot consistent. The $93 / 83 \mathrm{kDa}, 41 \mathrm{kDa}$ (Fla), $34 \mathrm{kDa}(\mathrm{OspB}), 31 \mathrm{kDa}(\mathrm{OspA})$ and $23 \mathrm{kDa}(\mathrm{OspC})$ bands 
Table 1 Main characteristics of 11 enzyme immunoassay (EIA) kits and four Western blot (WB) kits for the detection of lgM and/or IgG antibodies for Lyme borreliosis

\begin{tabular}{|c|c|c|c|c|c|}
\hline Test & Assay design & $\begin{array}{l}\text { B. burgdorferi } \\
\text { strain }\end{array}$ & $\begin{array}{l}\text { Antigen } \\
\text { preparation }\end{array}$ & $\begin{array}{l}\text { Preabsorption } \\
\text { of sera }\end{array}$ & $\begin{array}{l}\text { Total incubation } \\
\text { time (min) }\end{array}$ \\
\hline Behring EIA & indirect EIA ${ }^{a b b}$ & Pko & $\begin{array}{l}100 \mathrm{kDa}, 41 \mathrm{kDa} \\
\text { OspC. } 17 \mathrm{kDa}\end{array}$ & yes & 90 \\
\hline Bochringer ELA & indirect $\mathrm{ELA}^{\mathrm{ab} b}$ & Pko & 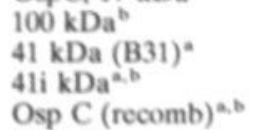 & recommended & 100 \\
\hline Dako EIA & $\begin{array}{l}\mu \text { capture } \\
\text { indirect EIA }\end{array}$ & $\begin{array}{l}\text { DK } \\
\text { DK }\end{array}$ & $\begin{array}{l}41 \mathrm{kDa} \\
41 \mathrm{kDa}\end{array}$ & $\begin{array}{l}\text { no } \\
\text { no }\end{array}$ & $\begin{array}{l}130 \\
130\end{array}$ \\
\hline Genzyme Virotech EIA & indirect EIA & 2591 & total sonicate & recommended & 90 \\
\hline IBL, EIA & indirect EIA ${ }^{a, b}$ & unknown & $14 \mathrm{kDa}$ (recomb) & yes & 100 \\
\hline Milenia EIA & indirect EIA ${ }^{a, b}$ & B. afzelii & total sonicate & no & 70 \\
\hline Genzyme Virotech WB & WB $^{2-b}$ & 2591 & total sonicate & recommended & 100 \\
\hline MRL WB & WB $^{a, b}$ & B. garinii & total sonicate & no & 95 \\
\hline
\end{tabular}

$\operatorname{Ig} \mathrm{M}$

- Absorption with Treponema phagedenis

${ }^{b} \mathrm{IgG}$

Recomb, recombinant, serum, conjugate and substrate incubation

were identified with monoclonal antibodies (Dr Kramer, University Heidelberg. Department of Immunology. Heidelberg. Germany). For the identification of OspC in the MRL WB, a monospecific chicken IgY was used. With the exception of the band evaluation, the tests were performed according to the instructions of the manufacturers.

To ensure an objective band detection, a densitometrical approach was used. All blots were scanned with a 600 dpi flatbed scanner (E6; Microtek, Germany) and band intensities were integrated with the Gel-Pro Analyzer densitometrical software (Media Cybernetics, USA). The software generated Gaussian curves for each peak, and the contribution of one peak to a nearby peak was measured. After molecular weights were indicated, the software identified molecular weight, maximum optical density and area under the curve of each peak. Using the described protocol, band areas were determined for all bands in increments of $1 \mathrm{kDa}$. Intrablot variation was checked by comparing band areas of a seropositive patient [reactive to p93/ 83, p41 (Fla), p39 (BmpA), p34 (OspB), p31 (OspA) and p23 (OspC) antigens] performed at the start and end position of the blot kit. Blot kits with an intrablot variation higher than $15 \%$, which occurred once in the MRL WB, were discarded and samples were retested. Interblot variation of band areas were corrected by applying a correction factor. The band area ratio of a reference band and corresponding band of strip 1 was used as a kit-specific correction factor. The reference band was defined as follows: a strip was incubated with the serum of a positive patient (the same as that used for the intrablot variation test), and a band with band area in the linear range of the densitometer was used as the reference. A kit-independent baseline value for positive band interpretation was applied. Baseline was set at a band area resulting in a maximum number of positive reactive ELB and LLB in IgM and IgG, respectively, and a minimum number of positive reactive healthy controls. For the calculations of sensitivity and specificity, borderline results were considered positive. The Genzyme Virotech IgM and IgG WB was interpreted as borderline when one and positive when minimum two of the following proteins were recognized: $83 \mathrm{kDa}, 39 \mathrm{kDa}, 34 \mathrm{kDa}$ (OspB), $31 \mathrm{kDa}(\mathrm{OspA}), 25 \mathrm{kDa}, 22 \mathrm{kDa}(\mathrm{OspC}), 20 \mathrm{kDa}$ or $18 \mathrm{kDa}$.

The MRL IgM WB was positive when reactivity to the $23 \mathrm{kDa}$ (OspC) and/or the $39 \mathrm{kDa}$ was observed. The IgG MRL WB was positive when four or more of the $93 \mathrm{kDa}, 45 \mathrm{kDa}, 41 \mathrm{kDa}$, $39 \mathrm{kDa}, 37 \mathrm{kDa}, 23 \mathrm{kDa}(\mathrm{OspC})$ and $21 \mathrm{kDa}$ proteins showed reactivity.
For the calculation of the predictive values of the different tests, the sera were clustered in three populations. Population I consisted of the sera of LB patients and healthy control patients. population II contained the sera of L.B patients and non-LB control patients, and population III consisted of the sera of LB patients and non-LB control patients with exclusion of EBV- and CMV-positive sera. The predictive values listed were derived from the likelihood-ratio using Baye's theorem [34] for an LB prevalance of $20 \%$, as can be expected in clinical laboratory situations.

\section{Results}

Performance of Enzyme Immunoassays. Sensitivity and specificity data of the six EIA tests for the detection of $\mathrm{IgM}$ and $\mathrm{IgG}$ antibodies for LB are listed in Tables 2 and 3 , respectively. Positive and negative predictive values for the detection of IgM antibodies in ELB and IgG antibodies in LLB, both calculated under an assumption of an LB prevalence of $20 \%$, are presented in Table 4. Intra-assay variances of the six EIAs for the detection of IgM and IgG antibodies to Lyme borreliosis are listed in Table 5.

IgM Enzyme Immunassay. As shown in Table 2, sensitivity for the detection of IgM antibodies by EIA in ELB ranged from 81 to $31 \%$. Sensitivity for detection of LLB varied from 69 to $46 \%$. Specificity ranged from 100 to $90 \%$ in the 62 healthy controls and from 89 to $75 \%$ in the patient control group. A drop in specificity in the non-Lyme patient controls was caused mainly by the false-positive results of sera from EBV and CMV patients, except for the Dako test, where a decrease in specificity occurred only in the EBV control group. Other non-Lyme groups in which the specificity was lower than $90 \%$ were HIV patients in the Genzyme Virotech test and syphilis patients in the IBL and Milenia tests. Excluding EBV- and CMV-positive sera from the non-Lyme patient control group resulted in a 
Table 2 Sensitivity and specificity (\%) of six enzyme immunoassays (EIAs) and two Western blots (WBs) for the detection of IgM antibodies for Lyme borreliosis

\begin{tabular}{|c|c|c|c|c|c|c|c|c|c|c|c|}
\hline \multirow[t]{3}{*}{ Test } & \multicolumn{2}{|c|}{$\begin{array}{l}\text { Percent } \\
\text { sensitivity }\end{array}$} & \multicolumn{9}{|c|}{$\begin{array}{l}\text { Percent } \\
\text { specificity }\end{array}$} \\
\hline & \multirow{2}{*}{$\begin{array}{l}\text { ELB } \\
(n=26\end{array}$} & \multirow{2}{*}{$\begin{array}{l}\text { LLB } \\
(n=13)\end{array}$} & \multirow{2}{*}{$\begin{array}{l}\text { Healthy } \\
\text { controls } \\
(n=62)\end{array}$} & \multicolumn{8}{|c|}{ Non-Lyme patients controls } \\
\hline & & & & $\begin{array}{l}(1-6) \\
\text { Non-Lyme } \\
\text { patients } \\
(n=128)\end{array}$ & $\begin{array}{l}(3-6) \\
\text { Non-Lyme } \\
\text { patients } \\
\text { without } \\
\text { EBV/CMV } \\
(n=92)\end{array}$ & $\begin{array}{l}(1) \\
\text { EBV } \\
(n=24)\end{array}$ & $\begin{array}{l}(2) \\
\text { CMV } \\
(n=12)\end{array}$ & $\begin{array}{l}(3) \\
\mathrm{RF} \\
(n=24)\end{array}$ & $\begin{array}{l}\text { (4) } \\
\text { ANA } \\
(n=24)\end{array}$ & $\begin{array}{l}(5) \\
\text { TP } \\
(n=23)\end{array}$ & $\begin{array}{l}(6) \\
\text { HIV } \\
(n=21)\end{array}$ \\
\hline Behring EIA & 77 & 62 & 98 & 85 & 98 & 38 & 83 & 96 & 100 & 100 & 95 \\
\hline Bochringer EIA & 35 & 46 & 100 & 89 & 99 & 58 & 75 & 100 & 100 & 100 & 95 \\
\hline Dako EIA & 65 & 69 & 95 & 88 & 99 & 46 & 92 & 100 & 100 & 100 & 95 \\
\hline Genzyme Virotech EIA & 81 & 62 & 98 & 81 & 92 & 42 & 67 & 96 & 96 & 91 & 86 \\
\hline IBL EIA & 65 & 62 & 90 & 75 & 89 & 33 & 50 & 92 & 96 & 78 & 90 \\
\hline Milenia EIA" & 31 & 69 & 95 & 88 & 88 & 92 & 83 & 96 & 96 & 70 & 90 \\
\hline Genzyme Virotech WB & 50 & 62 & 89 & 80 & 82 & 58 & 58 & 88 & 96 & 78 & 95 \\
\hline MRL WB & 46 & 54 & 98 & 90 & 98 & 83 & 42 & 92 & 100 & 100 & 100 \\
\hline
\end{tabular}

" IgM + IgG; ELB, early Lyme borreliosis; LLB late lyme borreliosis; EBV, Epstein-Barr virus; CMV, cytomegalovirus; RF, rheumatoid factor-positive rheumatoid arthritis; ANA, antinuclear antibodies; TP, syphilis

Table 3 Sensitivity and specificity (\%) of six enzyme immunoassays (EIAs) and two Westem blots (WBs) for the detection of IgG antibodies for Lyme borreliosis

\begin{tabular}{|c|c|c|c|c|c|c|c|c|c|c|c|}
\hline \multirow[t]{3}{*}{ Test } & \multicolumn{2}{|c|}{$\begin{array}{l}\text { Percent } \\
\text { sensitivity }\end{array}$} & \multicolumn{9}{|c|}{$\begin{array}{l}\text { Percent } \\
\text { specificity }\end{array}$} \\
\hline & \multirow{2}{*}{$\begin{array}{l}\text { ELB } \\
(n=26\end{array}$} & \multirow{2}{*}{$\begin{array}{l}\text { LLB } \\
(n=13)\end{array}$} & \multirow{2}{*}{$\begin{array}{l}\text { Healthy } \\
\text { controls } \\
(n=62)\end{array}$} & \multicolumn{8}{|c|}{ Non-Lyme patients controls } \\
\hline & & & & $\begin{array}{l}(1-6) \\
\text { Non-Lyme } \\
\text { patients } \\
(n=128)\end{array}$ & $\begin{array}{l}(3-6) \\
\text { Non-Lyme } \\
\text { patients } \\
\text { without } \\
\text { EBV/CMV } \\
(n=92)\end{array}$ & $\begin{array}{l}(1) \\
\mathrm{EBV} \\
(n=24)\end{array}$ & $\begin{array}{l}(2) \\
\text { CMV } \\
(n=12)\end{array}$ & $\begin{array}{l}(3) \\
\text { RF } \\
(n=24)\end{array}$ & $\begin{array}{l}(4) \\
\text { ANA } \\
(n=24)\end{array}$ & $\begin{array}{l}(5) \\
\text { TP } \\
(n=23)\end{array}$ & $\begin{array}{l}(6) \\
\text { HIV } \\
(n=21)\end{array}$ \\
\hline Behring EIA & 69 & 92 & 85 & 84 & 86 & 79 & 75 & 83 & 96 & 78 & 86 \\
\hline Bochringer EIA & 38 & 54 & 89 & 89 & 97 & 88 & 100 & 92 & 96 & 78 & 86 \\
\hline Dako EIA & 50 & 77 & 97 & 98 & 98 & 100 & 92 & 96 & 100 & 100 & 95 \\
\hline Genzyme Virotech EIA & 54 & 92 & 94 & 92 & 89 & 96 & 100 & 100 & 92 & 70 & 95 \\
\hline IBL EIA & 46 & 69 & 87 & 86 & 78 & 88 & 92 & 92 & 92 & 87 & 67 \\
\hline Milenia EIA" & 31 & 69 & 95 & 88 & 88 & 92 & 83 & 96 & 96 & 70 & 90 \\
\hline Genzyme Virotech WB & 27 & 46 & 82 & 91 & 89 & 100 & 83 & 88 & 96 & 96 & 76 \\
\hline MRL WB & 4 & 46 & 97 & 100 & 100 & 100 & 100 & 100 & 100 & 100 & 100 \\
\hline
\end{tabular}

" IgM + IgG; ELB, early Lyme borreliosis; LLB late lyme borreliosis; EBV, Epstein-Barr virus; CMV, cytomegalovirus; RF, rheumatoid factor-positive rheumatoid arthritis; ANA, antinuclear antibodies; TP, syphilis

specificity higher than $90 \%$ for all tests except the IBL and Milenia tests.

As shown in Tables 2 and 4 , the two tests with the highest sensitivity for detection of ELB, i.e. Genzyme Virotech (81\%) and Behring ( $77 \%)$, had a positive and negative predictive value higher than $90 \%$ in population I (healthy controls and an ELB prevalence of $20 \%$ ). In population II (control patients with disorders other than LB with an ELB prevalence of $20 \%$ ), Behring and Genzyme Virotech tests showed a positive predictive value of $56 \%$ and $52 \%$, respectively. Excluding CMV and EBV patients from the non-Lyme patient controls (group III, Table 4) increased the positive predictive value to $91 \%$ and $72 \%$ for the Behring and Genzyme Virotech tests, respectively. In all control groups, mean index values for positive results were more than twice the baseline, except for the Milenia IgM EIA, which scored less than twice the baseline in the EBV, ANA, RF and TP control groups. The Dako IgM EIA scored more than four times the baseline in the scored groups and more than 12 times the baseline for the LLB group.

As shown in Table 5, the intra-assay precision was higher than $90 \%$ for all IgM EIAs tested. 
Table 4 Positive and negative predictive values of six enzyme immunoassays (ElAs) and two Western blots (WBs) for the detection of IgM or IgG antibodies in early Lyme borreliosis (ELB) and late Lyme borreliosis (LLB) in three different populations. Predictive value is calculated for a prevalence of $20 \%$ early Lyme borreliosis and $20 \%$ late Lyme borreliosis in the population tested in IgM and $\lg G$, respectively

\begin{tabular}{|c|c|c|c|c|c|c|c|}
\hline & & \multicolumn{2}{|c|}{ Population $\mathrm{I}^{*}$} & \multicolumn{2}{|c|}{ Population $11^{6}$} & \multicolumn{2}{|c|}{ Population III ${ }^{e}$} \\
\hline & & PPV $\%$ & NPV $\%$ & PPV \% & NPV $\%$ & PPV $\%$ & NPV $\%$ \\
\hline \multirow[t]{2}{*}{ Behring EIA } & IgM & 92 & 94 & 56 & 94 & 91 & 94 \\
\hline & $\lg G$ & 61 & 98 & 59 & 98 & 62 & 98 \\
\hline \multirow[t]{2}{*}{ Boehringer EIA } & $\lg M$ & 100 & 86 & 44 & 84 & 90 & 86 \\
\hline & $\lg G$ & 54 & 88 & 55 & 89 & 82 & 89 \\
\hline \multirow{2}{*}{ Dako EIA } & $\mathrm{IgM}$ & 77 & 92 & 58 & 91 & 94 & 92 \\
\hline & IgG & 86 & 94 & 91 & 94 & 91 & 94 \\
\hline \multirow[t]{2}{*}{ Genzyme Virotech EIA } & $\lg M$ & 93 & 95 & 52 & 94 & 72 & 95 \\
\hline & IgG & 78 & 98 & 74 & 98 & 68 & 98 \\
\hline \multirow[t]{2}{*}{ IBL EIA } & $\lg M$ & 63 & 91 & 40 & 90 & 60 & 91 \\
\hline & IgG & 57 & 92 & 55 & 92 & 44 & 91 \\
\hline \multirow[t]{2}{*}{ Milenia ElA ${ }^{d}$} & ELLB & 61 & 85 & 39 & 84 & 39 & 84 \\
\hline & LLB & 78 & 92 & 59 & 92 & 59 & 92 \\
\hline \multirow[t]{2}{*}{ Genzyme Virotech WB } & IgM & 53 & 88 & 38 & 86 & 41 & 87 \\
\hline & IgG & 39 & 86 & 56 & 87 & 51 & 87 \\
\hline \multirow[t]{2}{*}{ MRL WB } & $\lg M$ & 85 & 88 & 53 & 87 & 85 & 88 \\
\hline & IgG & 79 & 88 & 100 & 88 & 100 & 88 \\
\hline
\end{tabular}

- Lyme borreliosis and healthy control group

${ }^{b}$ Lyme borreliosis and non-Lyme patient control group

' Lyme borreliosis and non-Lyme patient control group without cytomegalovirus and Epstein-Barr virus patient controls

Table 5 Comparison of intra-assay precision of six enzyme immunoassays (EIAs) for the detection of antibodies to Borrelia burgdorferi

\begin{tabular}{lrlll}
\hline EIA & \multicolumn{2}{l}{$\begin{array}{l}\text { No. (\%) of IgG } \\
\text { tested }\end{array}$} & \multicolumn{2}{l}{$\begin{array}{l}\text { No. (\%) of IgM } \\
\text { tested }\end{array}$} \\
\hline Behring & 17 & $(96)$ & 41 & $(98)$ \\
Boehringer & 24 & $(95)$ & 45 & $(96)$ \\
Dako & 9 & $(93)$ & 14 & $(93)$ \\
Genzyme Virotech & 20 & $(91)$ & 33 & $(98)$ \\
IBL & 41 & $(97)$ & 36 & $(97)$ \\
Milenia & 49 & $(96)$ & 49 & $(96)$ \\
\hline
\end{tabular}

a $\mathrm{IgM}+\mathrm{IgG}$

IgG Enzyme Immunoassay. As shown in Table 3, sensitivity for the detection of $\mathrm{IgG}$ antibodies by EIA in ELB ranged from 69 to $31 \%$. For LLB, sensitivity ranged from 92 to $54 \%$. Specificity in the 62 healthy controls ranged from 97 to $85 \%$. For the 128 non-Lyme patient control sera, specificity ranged from 98 to $84 \%$. The two EIAs with a specificity higher than $90 \%$ in healthy controls as well as in all non-Lyme patients were the Dako and Genzyme Virotech tests. The presence of EBV, CMV, RF, TP or HIV (but not ANA) contributed to the low specificity of the other EIAs. In Table 4, the positive predictive value in patient population I (LLB sera combined with sera of healthy controls), with an LLB prevalence of $20 \%$, was the highest for the Dako test $(86 \%)$, with a sensitivity of $77 \%$ and a specificity of $97 \%$ (Table 3), followed by the Genzyme Virotech test (78\%), with a sensitivity of $92 \%$
${ }^{d} \lg \mathrm{M}+\lg \mathrm{Ig}$

PPV, positive predictive value; NPV, negative predictive value and a specificity of $94 \%$ (Table 3 ). Of all IgG EIAs, the Dako test scored the highest positive predictive value ( $91 \%$ ) in population II (LLB sera and sera from nonLyme patient controls) and population III (94\%) (LLB sera combined with sera of non-Lyme patient controls, with EBV and CMV patient controls excluded), both with an LLB prevalence of $20 \%$ (Table 4).

Table 4 shows clearly that the low positive predictive value in the EIAs tested is not caused solely by the CMV and EBV sera. Mean index values of positive results in the ELB, LLB and healthy control groups were more than twice the baseline for all EIAs. Positive-reacting TP and HIV sera gave indexes more than twice the baseline for the Behring, Boehringer, Genzyme Virotech and IBL tests. Positive-reacting RF sera gave indexes more than twice the baseline in the Behring, Dako and IBL tests. ANA sera that scored more than twice the baseline were detected with the Genzyme Virotech and IBL IgG EIAs. CMV sera resulting in a positive EIA scored more than twice the baseline in the Behring, IBL and Milenia tests and more than four times the baseline in the Dako test. Positive-reacting EBV sera scored higher than two times the baseline in the Behring, Genzyme Virotech and IBL tests. As shown in Table 5, the intra-assay precision was higher than $90 \%$ for all IgG EIAs tested.

Performance of Western Blots. Sensitivity and specificity of the two WBs for the detection of IgM and IgG antibodies for Lyme borreliosis are listed in Tables 2 
and 3 , respectively. Predictive values for positive and negative results for the detection of $\mathrm{IgM}$ antibodies in ELB and IgG antibodies in LLB are listed in Table 4.

IgM Western Blot. Sensitivity varied from 50 to $46 \%$ in the 26 ELB patients and from 62 to $54 \%$ in the 13 LLB patients (Table 2). In the healthy control group, Genzyme Virotech and MRL WBs showed a specificity of $89 \%$ and $98 \%$, respectively. As seen in Table 2 , specificity of the test was the highest for the MRL WB in all patient groups except the CMV group. Low specificity caused by EBV and CMV was due to reactivity to OspC. The positive predictive value of $\mathrm{IgM}$ WB results in all patient populations was the highest for the MRL WB (Table 4). Excluding EBV and CMV positive sera from the patient control group increased the positive predictive value of the $\mathrm{IgM}$ WB results in the MRL WB from $53 \%$ up to $85 \%$. (Table 4 , population III).

$\operatorname{Ig} G$ Western Blot. The sensitivity of the IgG Western blots in the ELB group varied form 27 to $4 \%$ (Table 3 ). In the LLB group, sensitivity for the immunoblots was $46 \%$ for both WBs.

In the healthy control group, specificity varied from 97 to $82 \%$. In the non-Lyme patient control group, Genzyme Virotech showed a specificity lower than $90 \%$ in the CMV, RF and HIV control group. The MRL WB showed a specificity of $100 \%$ in all nonLyme groups. As shown in Table 4, among all IgG WBs, the positive predictive value was highest for MRL WB and was not affected by the non-Lyme patient control group. Excluding the EBV and CMV positive sera from the patient population afforded no apparent increase in the positive predictive value of the Genzyme Virotech IgG WB (Table 4).

IgM Enzyme Immunoassay-Western Blot Two-Test Protocol. The sensitivity and specificity of an EIA-WB two-test protocol for the detection of IgM antibodies in ELB and LLB sera is presented in Table 6. Predictive values for positive and negative results of the EIA-WB two-test protocol for the detection of $\mathrm{IgM}$ antibodies in ELB are listed in Table 7. As seen in Table 6, the IgM EIA-WB two-test combination with the highest sensitivity for detecting ELB was the Genzyme Virotech EIA and WB combination (50\%). The specificity of the most sensitive two-test combination was $100 \%$ for the healthy control group and $97 \%$ for the non-Lyme patient control group when EBV and CMV were excluded. The second best in sensitivity was the Behring EIA in combination with either the Genzyme Virotech or the MRL WB, the IBL EIA with the MRL WB, and the Genzyme Virotech EIA with the MRL WB. Specificity for the second best tests in sensitivity was $100 \%$ for the healthy control group and $99 \%$ or $100 \%$ for the non-Lyme patient control group when EBV and CMV patients were excluded. In Table 7, the positive predictive value of IgM results in the two-test protocol for population I (ELB + healthy controls) with a prevalence of $20 \%$ ELB patients was $100 \%$ for all test combinations except for the IBL EIA-Genzyme Virotech WB (74\%) and the Milenia EIA-MRL or Genzyme Virotech WB test combination $(25 \%$ and $38 \%$, respectively). If CMV-and EBV-positive patients were excluded from the patient population, the positive predictive value of the results was $100 \%$ for all EIA-

Table 6 Comparison of sensitivity and specificity of enzyme immunoassay (EIA) - Western blot (WB) two-test protocol combinations for the detection of $\mathrm{IgM} / \mathrm{IgG}$ antibodies for Lyme borreliosis

\begin{tabular}{|c|c|c|c|c|c|c|c|c|c|c|c|}
\hline \multirow[b]{3}{*}{ Test } & & \multicolumn{4}{|c|}{ Percent sensitivity } & \multicolumn{6}{|c|}{ Percent specificity } \\
\hline & & \multicolumn{2}{|c|}{$\begin{array}{l}\text { ELB } \\
(n=26)\end{array}$} & \multicolumn{2}{|c|}{$\begin{array}{l}\text { LLB } \\
(n=13)\end{array}$} & \multicolumn{2}{|c|}{$\begin{array}{l}\text { Healthy } \\
\text { controls } \\
(n=62)\end{array}$} & \multicolumn{2}{|c|}{$\begin{array}{l}\text { Non-Lyme } \\
(n=128)\end{array}$} & \multicolumn{2}{|c|}{$\begin{array}{l}\text { Non-Lyme } \\
\text { without } \\
\text { EBV/CMV } \\
(n=92)\end{array}$} \\
\hline & & $\lg M$ & $\lg G$ & $\operatorname{Ig} M$ & $\operatorname{IgG}$ & $\operatorname{IgM}$ & IgG & $\operatorname{Ig} M$ & IgG & IgM & IgG \\
\hline \multirow[t]{2}{*}{ Behring EIA } & + GV WB & 46 & 23 & 38 & 46 & 100 & 94 & 92 & 99 & 99 & 99 \\
\hline & + MRL WB & 46 & 4 & 46 & 38 & 100 & 97 & 95 & 100 & 100 & 100 \\
\hline \multirow[t]{2}{*}{ Bochringer EIA } & + GV WB & 31 & 15 & 31 & 46 & 100 & 94 & 93 & 98 & 100 & 98 \\
\hline & + MRL WB & 35 & 4 & 46 & 38 & 100 & 97 & 94 & 100 & 100 & 100 \\
\hline \multirow[t]{2}{*}{ Dako EIA } & + GV WB & 35 & 19 & 38 & 38 & 100 & 97 & 95 & 99 & 100 & 99 \\
\hline & + MRL WB & 42 & 4 & 46 & 38 & 100 & 97 & 96 & 100 & 100 & 100 \\
\hline \multirow[t]{2}{*}{ Genzyme Virotech ElA } & + GV WB & 50 & 19 & 38 & 38 & 100 & 95 & 88 & 99 & 97 & 99 \\
\hline & + MRL WB & 46 & 4 & 46 & 38 & 100 & 97 & 94 & 100 & 100 & 100 \\
\hline \multirow[t]{2}{*}{ IBL EIA } & + GV WB & 35 & 15 & 31 & 31 & 97 & 94 & 88 & 97 & 97 & 97 \\
\hline & + MRL WB & 46 & 4 & 38 & 31 & 100 & 97 & 92 & 100 & 100 & 100 \\
\hline \multirow{2}{*}{ Milenia ElA* } & + GV WB & 12 & 12 & 46 & 46 & 95 & 95 & 99 & 99 & 99 & 99 \\
\hline & + MRL WB & 4 & 4 & 46 & 46 & 97 & 97 & 100 & 100 & 100 & 100 \\
\hline
\end{tabular}

" $\lg M+\lg G$

GV WB, Genzyme Virotech Western blot; MRL WB, MRL Western blot: ELB, early Lyme borreliosis; LLB, late Lyme borreliosis; EBV, Epstein-Barr virus; CMV, cytomegalovirus 
Table 7 Comparison of positive and negative predictive values of enzyme immunoassay (EIA) - Western blot two-test protocol combinations for the detection of $\mathrm{IgM} / \mathrm{IgG}$ antibodies for Lyme borreliosis. Predictive value is calculated for a prevalence of $20 \%$ early Lyme borreliosis and $20 \%$ late Lyme borreliosis tested in IgM and IgG populations, respectively

\begin{tabular}{|c|c|c|c|c|c|c|c|}
\hline \multirow[t]{2}{*}{ Test } & & \multicolumn{2}{|c|}{ Population $\mathrm{I}^{*}$} & \multicolumn{2}{|c|}{ Population $11^{b}$} & \multicolumn{2}{|c|}{ Population $\mathrm{III}^{e}$} \\
\hline & & PPV (\%) & NPV $(\%)$ & PPV (\%) & NPV $(\%)$ & PPV $(\%)$ & NPV $(\%)$ \\
\hline \multicolumn{8}{|l|}{ IgM test } \\
\hline \multirow{2}{*}{ Behring EIA } & + GV WB & 100 & 88 & 59 & 87 & 92 & 88 \\
\hline & + MRL WB & 100 & 88 & 70 & 88 & 100 & 88 \\
\hline \multirow[t]{2}{*}{ Boehringer EIA } & + GV WB & 100 & 85 & 53 & 84 & 100 & 85 \\
\hline & + MRL WB & 100 & 86 & 59 & 85 & 100 & 86 \\
\hline \multirow[t]{2}{*}{ Dako EIA } & + GV WB & 100 & 86 & 64 & 85 & 100 & 86 \\
\hline & + MRL WB & 100 & 87 & 72 & 87 & 100 & 87 \\
\hline \multirow[t]{2}{*}{ Genzyme Virotech EIA } & + GV WB & 100 & 89 & 51 & 88 & 81 & 89 \\
\hline & + MRL WB & 100 & 88 & 66 & 87 & 100 & 88 \\
\hline \multirow[t]{2}{*}{ IBL EIA } & + GV WB & 74 & 86 & 42 & 84 & 74 & 86 \\
\hline & + MRL WB & 100 & 88 & 59 & 87 & 100 & 88 \\
\hline \multirow{2}{*}{ Milenia EIA ${ }^{d}$} & + GV WB & 38 & 81 & 75 & 82 & 75 & 82 \\
\hline & +MRL WB & 25 & 80 & 100 & 81 & 100 & 81 \\
\hline \multicolumn{8}{|l|}{ IgG test } \\
\hline \multirow[t]{2}{*}{ Behring EIA } & + GV WB & 66 & 87 & 92 & 88 & 92 & 88 \\
\hline & + MRL WB & 76 & 86 & 100 & 87 & 100 & 87 \\
\hline \multirow[t]{2}{*}{ Bochringer EIA } & +GV WB & 66 & 87 & 85 & 88 & 85 & 88 \\
\hline & + MRL WB & 76 & 86 & 100 & 87 & 100 & 87 \\
\hline \multirow[t]{2}{*}{ Dako EIA } & + GV WB & 76 & 86 & 90 & 86 & 90 & 86 \\
\hline & + MRL WB & 76 & 86 & 100 & 87 & 100 & 87 \\
\hline \multirow[t]{2}{*}{ Genzyme Virotech EIA } & $+\mathrm{GV} \mathrm{WB}$ & 66 & 86 & 90 & 86 & 90 & 86 \\
\hline & + MRL WB & 76 & 86 & 100 & 87 & 100 & 87 \\
\hline \multirow[t]{2}{*}{ IBL EIA } & + GV WB & 56 & 84 & 72 & 85 & 72 & 85 \\
\hline & + MRL WB & 72 & 85 & 100 & 85 & 100 & 85 \\
\hline \multirow[t]{2}{*}{ Milenia EIA ${ }^{d}$} & + GV WB & 70 & 88 & 92 & 88 & 92 & 88 \\
\hline & + MRL WB & 79 & 88 & 100 & 88 & 100 & 88 \\
\hline
\end{tabular}

ayme borreliosis and healthy control group

${ }^{b}$ Lyme borreliosis and non-Lyme patient control group

${ }^{c}$ Lyme borreliosis and non-Lyme patient control group without

cytomegalovirus and Epstein-Barr virus patient controls

${ }^{d} \mathrm{IgM}+\mathrm{IgG}$

GV WB, Genzyme Virotech Western blot; MRL WB, MRL Western blot; PPV, positive predictive value; NPV, negative predictive value
MRL WB test combinations. The Genzyme EIA-WB test combination gave a positive predictive value for IgM results of $81 \%$ when EBV and CMV patients were excluded from the non-Lyme patient controls. The Boehringer and the Dako EIAs in combination with Genzyme Virotech or MRL WB both gave a positive predictive value of $100 \%$ for IgM results when EBV and CMV patients were excluded.

The EIA and WB two-test combinations with the highest sensitivity, specificity and positive predictive values for IgM results are the Behring, Dako, Genzyme Virotech or IBL EIA in combination with the MRL WB.

As shown in Table 6, a maximum sensitivity of $46 \%$ for the detection of LLB was found with the Behring or Boehringer EIA in combination with the Genzyme Virotech WB and with the Milenia EIA in combination with the Genzyme Virotech or the MRL WB. Specificity in the healthy control group and nonLyme patients controls ranged from 94 to $100 \%$ for all test combinations. As shown in Table 7, the Milenia EIA - MRL WB test combination, with a sensitivity of
$46 \%$, gave the maximum positive predictive value (79\%) for IgG results in the two-test protocol for population I (LLB + healthy control group) with an LLB prevalence of $20 \%$. The Behring, Boehringer, Dako and Genzyme Virotech EIA in combination with MRL WB gave for the same population a positive predictive value of $76 \%$ for $\mathrm{IgG}$ results. The Dako EIA showed no difference for population $I$ in the positive predictive value of $\mathrm{IgG}$ results $(76 \%)$ for both WBs used in the two-test combination. Exclusion of EBV and CMV from the patient control group did not increase the predictive value of all two-test combinations.

\section{Discussion}

Of the 11 EIAs tested, the Behring and Genzyme Virotech IgM tests were superior to the others with respect to sensitivity, specificity and predictive value of detecting ELB when EBV and CMV patients were excluded but showed unacceptably low positive predictive values for the IgG test results. The Dako IgG test, which yielded a lower sensitivity in detecting LLB, showed the highest positive predictive value in a population of LLB patients that included either healthy 
controls or non-Lyme patient controls. Overall, low specificity in IgM EIA was mainly observed in the EBV IgM- and CMV IgM-positive sera group.

The derived index values showed clearly that sera of EBV and CMV patients who reacted positively in EIA were significantly higher than the baseline. Because laboratory testing for LB is mainly used to confirm the clinical diagnosis, the sensitivity in combination with the predictive values of positive and negative results are the most important. Accordingly, we compared in this study the results in populations consisting of LB patients with healthy controls and non-Lyme patients. In contrast to most studies, the non-Lyme patient group contained sera positive for EBV, CMV, RF, ANA, TP and HIV. Results indicated that EBV and CMV are the main causes of false-positive reactions in IgM EIAs and can only be discriminated from ELB with an additional test for EBV and CMV. This was clearly shown by the finding that the specificity and positive predictive value in population II increased substantially after exclusion of the CMV- and EBVpositive sera. The predictive value of positive results in a patient population consisting of LLB either with healthy controls or non-Lyme patient controls was lower than $80 \%$ for all IgG EIAs except for the Dako IgG EIA. However, 5-10\% of asymptomatic seropositive LB cases are commonly found in a healthy population and have also been reported from the Netherlands $[27,37]$.

For WB, the observer-independent interpretation helped considerably in the quantification of faint bands that posed interpretation difficulties on visual examination. Compared to the visual scoring, our quantitative approach scored a higher specificity without losing sensitivity (data not presented). Instead of using band values expressed as percentages of a fixed reference band performed by Pachner et al. [38], we used a correction method that could provide additional information on inter- and intra-blot variation.

The reason for the low sensitivity of IgM and IgG WB was probably due to very weak bands or the total lack of specific bands. For the Genzyme Virotech IgG WB, specificity in healthy controls increased from 82 to $97 \%$, without loss of sensitivity, when OspA or OspB was excluded from the criteria. for a positive blot interpretation, as recommended by Hauser et al. [29] for WBs using Borrelia burgdorferi sensu stricto as antigen. As indicated by others [39], antibodies against OspA and OspB proteins were rarely detected in LLB patients. Although the detection of antibodies against the OspA and OspB proteins may not be crucial for the diagnosis in terms of sensitivity, Leung et al. [40] indicated these proteins to be very specific markers of LLB when they are detected in tandem.

In our study, reactions to both OspA and OspB were only seen in $15 \%$ of the LLB. A very low specificity was found when we used the criteria resulting in a positive $\mathrm{IgG}$ blot with at least one band of p83, p58, p56, OspC, p21 or p17, as recommended by Hauser et al. [29] for blots using the sensu stricto strain. This was caused by the appearance of the p56 band in the control group. In the MRL WB the criteria recommended by Hauser et al. [29] for WBs using Borrelia garinii as antigen gave a lower specificity compared to the criteria of the manufacturer. The recommended criteria for IgM blots, where a strong reaction to p41 (flagellin) increases sensitivity without significant loss of specificity, could not be confirmed in our study. In all control groups, cross-reactive IgM responses, particularly with the $41 \mathrm{kDa}$ flagellar antigen, occurred more frequently in the Genzyme Virotech WB compared to the MRL WB but did not affect the evaluation when the manufacturer's criteria were strictly followed. Low specificity in IgM WB was mainly observed in the EBV- and CMV-positive sera. In these sera, WB showed a predominant reaction with the highly specific OspC, which hampered differentiation of these non-Lyme sera by WB. Changing the criteria for positive IgM WB interpretation in the MRL WB to two bands of $41 \mathrm{kDa}, 39 \mathrm{kDa}$ or $23 \mathrm{kDa}$ (OspC) improved neither sensitivity nor specificity.

Several technical problems of Western blotting using sonicated Borrelia burgdorferi cells have been mentioned in the literature [31]. Still, information about data such as (a) strain-dependent molecular weights of similar / identical proteins of the spirochete; (b) comigration of multiple proteins to the same area; (c) use of monoclonal antibodies for protein identification and (d) 2-D mapping, which might indicate a comigration of different proteins, are often not provided by the manufacturers. Therefore, a false-positive reaction in Lyme Western blotting for EBV-and CMV-positive sera caused by an OspC co-migrating protein cannot be ruled out.

The findings of Hauser et al. [29] that the use of a WB with a European strain gave a higher sensitivity for a European serum panel than the WB with an American isolate for detecting early or late Lyme borreliosis in, respectively, IgM and IgG was not confirmed by our results. Although the use of a European strain in WB showed a higher positive predictive value, specificity of the WB in RF-, TP- and HIV-positive sera was lower when an American strain was used. The cross-reaction with Borrelia burgdorferi of sera positive for TP or HIV has been reported [41], but we had no trouble differentiating such sera from the sera of patients with LB in the WB test. Preabsorption with RF and Reiter antigens to improve specificity was not performed in our WB testing as these were not standard antigens included in the test kits. However, in our study, preabsorption would not have affected the overall performance of the WB kits. The observed percentages of positive reactions in the healthy control group of $3 \%$ for 
the MRL and the Genzyme Virotech IgG WBs (when excluding OspA and OspB in the interpretation criteria from the Genzyme Virotech WB) are of the same size as of the $5 \%$ asymptomatic healthy controls found positive $[27,37]$ in a Dutch population and are therefore most likely a result of previous asymptomatic infections. In contrast to the findings of Dressler et al. [31] and the recommendations of ASTPHLD and CDC to use a two-step protocol where WB is used to increase specificity, we found that, with the IgM EIAs tested, performing an additional EBV and, if indicated, a CMV test is a more effective way of increasing the specificity without a significant loss in sensitivity in case of ELB.

This study showed clearly that not only sera of healthy controls but, preferably, sera of patients with a similar differential diagnosis as LB should be used for the evaluation of the serodiagnostic tests for LB. As positive and negative predictive values are the most relevant parameters for clinical decision making, not only sensitivity and specificity but also the predictive values for positive and negative results should be compared. The two tests presenting the best results for detecting ELB in a population without EBV and CMV patients were the Behring IgM EIA followed by the Genzyme Virotech IgM EIA. Despite its relatively low sensitivity in detecting LLB, the positive predictive value in the populations studied was the highest for the Dako IgG EIA. It should be realized, however, that a specificity and positive predictive value of $100 \%$ can never be expected because of possible previous asymptomatic infections that can result in a positive result in LB serological tests. The use of a WB test as a confirmatory test gave some improvement over IgG EIA results alone, but for positive IgM EIA results in a geographical region where the LB prevalence is $20 \%$ or lower, the exclusion of an EBV infection and, if indicated, a CMV infection, seems more advisable.

\section{References}

1. Burgdorfer W, Barbour AG, Hayes SF, Benach JL, Grunwaldt E, Davis JP: Lyme disease: a tickborne spirochetosis? Science (1982) 216:1317-1319

2. Liu HH: Lyme disease epidemiology, diagnosis, and management. Delaware Medical Journal (1990) 62:1351-1360

3. Steere AC: Lyme disease. New England Journal of Medicine (1989) 321:586-596

4. Rahn DW: Lyme disease clinical manifestations, diagnosis, and treatment. Seminars in Arthritis and Rheumatism (1991) 20:201-218

5. Nadelman RB, Pavia CS, Magnarelli LA, Wormser GP: Isolation of Borrelia burgdorferi from the blood of seven patients with Lyme disease. American Journal of Medicine (1990) $88: 21-26$

6. De Koning J, Bosma RB, Hoogkamp Korstanje JA: Demonstration of spirochaetes in patients with Lyme disease with a modified silver stain. Journal of Medical Microbiology (1987) 23:261-267
7. Valesova M, Trnavsky K. Hulinska D, Alusik S, Janousek J, Jirous J: Detection of Borrelia in the synovial tissue from a patient with Lyme borreliosis by electron microscopy. Journal of Rheumatology (1989) 16:1502-1505

8. Dattwyler RJ, Volkman DJ, Halperin JJ, Luft BJ, Thomas J, Golightly MG: Specific immune responses in Lyme borreliosis. Characterization of $\mathrm{T}$ cell and $\mathrm{B}$ cell responses to Borrelia burgdorferi. Annals of the New York Academy of Sciences (1988) 539:93-102

9. Huycke MM, D'Alessio DD, Marx JJ: Prevalence of antibody to Borrelia burgdorferi by indirect fluorescent antibody assay, ELISA, and Western immunoblot in healthy adults in Wisconsin and Arizona. Journal of Infectious Discases (1992) $165: 1133-1137$

10. Craft JE, Grodzicki RL, Shrestha M, Fischer DK, Garcia Blanco M. Steere AC. The antibody response in Lyme disease. Yale Journal of Biology and Medicine (1984) 57:561-565

11. Weber K, Schierz G, Wilske B, Preac Mursic V: European erythema migrans disease and related disorders. Yale Journal of Biology and Medicine (1984) 57:463-471

12. Melby K, Steinbakk M, Jensenius M, Figenschau KJ: Detection of serum antibodies against Borrelia burgdorferi with some commercially available serological tests. NIPH Annals (1990) 13:37-44

13. Cutler SJ, Wright DJ: Evaluation of three commercial tests for Lyme disease. Diagnostic Microbiology and Infectious Discase (1990) 13:271-272

14. Stiernstedt G, Granstrom M: Borrelia arthritis in Sweden. Zentralblatt für Bakteriologie und Hygiene (1986) $263: 285-287$

15. Coleman JL. Benach JL: Isolation of antigenic components from the Lyme discase spirochete their role in early diagnosis. Journal of Infectious Discases (1987) 155:756-765

16. Grodzicki RL, Steere AC: Comparison of immunoblotting and indirect enzyme-linked immunosorbent assay using different antigen preparations for diagnosing early Lyme disease. Journal of Infectious Diseases (1988) 157:790-797

17. Magnarelli LA, Anderson JF, Barbour AG: Enzyme-linked immunosorbent assays for Lyme disease reactivity of subunits of Borrelia burgdorferi. Journal of Infectious Diseases (1989) $159: 43-49$

18. Hansen K, Hindersson P, Pedersen NS: Measurement of antibodies to the Borrelia burgdorferi flagellum improves serodiagnosis in Lyme disease. Journal of Clinical Microbiology (1988) 26:338-346

19. Fister RD, Weymouth LA, McLaughlin JC, Ryan RW, Tilton RC: Comparative evaluation of three products for the detection of Borrelia burgdorferi antibody in human serum. Journal of Clinical Microbiology (1989) 27:2834-2837

20. Putzker M, Mertes T, Faulde M, Sobe D: Gegenüberstellung der Exoproteinmuster dreier europäischer Isolate von Borrelia burgdorferi. Vergleich von 14 kommerziell erhältlichen und einem selbst entwickelten und evaluierten Elisa für die serologische Diagnostik der Lyme-Borreliose. Laboratoriums-Medizin (1990) 14:397-403

21. Christenson VD, White DH: Evaluation of four commercially available ELISA assays for the serologic diagnosis of Lyme disease. Journal of Clinical Laboratory Analysis (1991) 5:340-343

22. Luger SW, Krauss E: Serologic tests for Lyme disease. Interlaboratory variability. Archives of Internal Medicine (1990) $150: 761-763$

23. Schwartz BS, Goldstein MD, Ribeiro JM, Schulze TL, Shahied SI: Antibody testing in Lyme discase. A comparison of results in four laboratories. JAMA (1989) 262:3431-3434

24. Dattwyler RJ, Volkman DJ, Luft BJ, Halperin JJ, Thomas J, Golightly MG: Seronegative Lyme disease. Dissociation of specific T- and B-lymphocyte responses to Borrelia burgdorferi. New England Journal of Medicine (1988) $319: 1441-1446$ 
25. Schutzer SE, Coyle PK, Belman AL, Golightly MG, Drulle J: Sequestration of antibody to in immune complexes in seronegative Lyme disease. Lancet (1990) 335:312-315

26. Fahrer H, Sauvain MJ, v.d. Linden S, Zhioua E, Gern L, Aeschlimann A: Prevalence of Lyme borreliosis in a Swiss population at risk. Schweizerische Medizinische Wochenschrift (1988) 118:65-69

27. Nohlmans MK, van den Bogaard AE, Blaauw AA, van Boven CP: Prevalence of Lyme borreliosis in Netherlands. Nederlands Tijdschrift voor Geneeskunde (1991) $135: 2288-2292$

28. Stiernstedt G, Dattwyler R, Duray PH, Hansen K, Jirous J, Johnson RC, Karlsson M, Preac Mursic V, Schwan TG: Diagnostic tests in Lyme borreliosis. Scandinavian Journal of Infectious Diseases (1991) 77:136-142

29. Hauser U, Lehnert G, Lobentanzer R, Wilske B: Interpretation criteria for standardized Western blots for three european species of Clinical Microbiology (1997) 35:1433-1444

30. Cutler SJ, Wright DJ, Luckhurst VH: Simplified method for the interpretation of immunoblots for Lyme borreliosis. FEMS Immunology and Medical Microbiology (1993) 6:281-285

31. Dressler F, Whalen JA, Reinhardt BN, Steere AC: Western blotting in the serodiagnosis of Lyme disease. Journal of Infectious Diseases (1993) 167:392-400

32. Engstrom SM, Shoop E, Johnson RC: Immunoblot interpretation criteria for serodiagnosis of early Lyme disease. Journal of Clinical Microbiology (1995) 33:419-427
33. Kowal K, Weinstein A: Western blot band intensity analysis. Application to the diagnosis of Lyme arthritis. Arthritis and Rheumatism (1994) 37:1206-1211

34. Fagan TJ: Nomogram for Bayes's theorem. New England Journal of Medicine (1975) 293:257

35. Santino I, Dastoli F, Sessa R, Del Piano M: Geographical incidence of infection with Panminerva Medicine (1997) 39:208-214

36. Chan DW: Immunoassay. A practical guide. Academic Press, London (1987) pp 53-55

37. Kuiper H, van Dam AP, Moll van Charante AW, Nauta NP, Dankert J: One year follow-up study to assess the prevalence and incidence of Lyme borreliosis among Dutch forestry workers. European Journal of Clinical Microbiology \& Infectious Diseases (1993) 12:413-418

38. Pachner AR, Ricalton NS: Western blotting in evaluating Lyme seropositivity and the utility of a gel densitometric approach. Neurology (1992) 42:2185-2192

39. Zoller L, Burkard S, Schafer H: Validity of Western immunoblot band patterns in the serodiagnosis of Lyme borreliosis. Journal of Clinical Microbiology (1991) 29:174-182

40. Ma B, Christen B, Leung D, Vigo Pelfrey C: Serodiagnosis of Lyme borreliosis by Western immunoblot reactivity of various significant antibodies against Journal of Clinical Microbiology (1992) 30:370-376

41. Raoult D, Hechemy KE, Branton G: Cross-reaction with antigen of sera from patients with human immunodeficiency virus infection, syphilis, and leptospirosis. Journal of Clinical Microbiology (1989) 27:2152-2155 



\section{Chapter IIIb}

\section{REDUCED SPECIFICITY OF COMBINED IGM AND IGG ENZYME IMMUNOASSAY TESTING FOR LYME BORRELIOSIS}

H.A.T. Goossens ${ }^{1}$, A.E. van den Bogaard', M.K.E. Nohlmans ${ }^{2}$

' Department of Medical Microbiology, University Maastricht;

${ }^{2}$ Department of Medical Microbiology, General Hospital Arnhem, The Netherlands

Reprinted by permission of Eur J Clin Microbiol Infect Dis Letter (2000) 19:400-402. 

regardless of the stage of disease or the symptoms observed. The decision whether to determine total immunoglobulins or class-specific antibodies to Borrelia burgdorferi depends on tradition, laboratory preference, physicians' demands and budgetary restrictions. In a recently published study [1], we observed that the only polyvalent assay included performed poorly compared to the class-specific assays tested. Subsequently, we were asked what results we would have expected had the results of the IgM and IgG EIAs been combined. Because of the importance of the results for clinical practice, we present here - in addition to the data of the previously published study - the combined results of the IgG and IgM ElAs and an additional patient test group: Lyme borreliosis (LB) patients $(n=39)$, consisting of both the early Lyme borreliosis (ELB) patients and the late Lyme borreliosis (LLB) patients from the former study.

In our previous study we evaluated 11 commercially available EIA tests (Table 1). Briefly, a total of 229 sera obtained from three patient groups and a healthy control group were investigated. The healthy control group consisted of 62 sera of healthy individuals with no history of LB or tick exposure. The three patient groups consisted of 26 confirmed ELB patients, 13 LLB patients and a patient control group of 128 persons: 24 with Epstein-Barr virus (EBV) infection, 12 with acute cytomegalovirus (CMV) infection, 24 with rheumatoid factor-positive rheumatoid arthritis, 24 with antinuclear antibodies, 23 with syphilis and 21 who were seropositive for human immunodeficiency virus.

\section{Reduced Specificity of Combined IgM and IgG Enzyme Immunoassay Testing for Lyme Borreliosis}

\author{
H.A.T. Goossens, A.E. van den Bogaard, \\ M.K.E. Nohlmans
}

Polyvalent assays are sometimes preferred for routine screening of large numbers of serum samples in clinical laboratories because they are cost-effective In many laboratories, however, two separate enzyme immunoassays (EIAs) are routinely used to test sera from patients suspected to have Lyme borreliosis for the presence of IgM and IgG against Borrelia burgdorferi,

H.A.T. Goossens, A.E. van den Bogaard ( $(\mathbb{Z})$

Department of Medical Microbiology, University of Maastricht, PO Box 616, 6200 MD Maastricht, The Netherlands e-mail: A.vandenBogaard@cpv.unimaas.nl

M.K.E. Nohlmans

Department of Medical Microbiology, General Hospital Arnhem, PO Box 9025, 6800 EG Arnhem, The Netherlands
The results are shown in Table 1 and Table 2. To test the significance of differences between tests and populations, the McNemar and chi-square tests were used. The differences between EIAs detecting IgM or/and IgG antibodies to Borrelia burgdorferi and the combined results of specific IgG and IgM tests on the sensitivity and specificity are presented in Table 1. Positive and negative predictive values for patient populations in which the prevalence of LB was $20 \%$ (estimated rate for laboratories testing sera for LB) are shown in Table 2. Apart from CMV, other illnesses included in the non-LB patient group mimic LB and represent a population that might be encountered in the clinical laboratory. As the proportion of potentially cross-reacting sera may vary, especially with respect to the prevalence of acute EBV and CMV infections, the positive predictive value in this study might appear lower than that in other clinical laboratory situations.

As shown in Table 1, the use of the combined IgM and IgG test results significantly improved the sensitivity for detection of LB in the LB group $(P<0.05)$ compared to the use of the test results of all EIAs individually. Although IgM antibodies normally do not persist, a spontaneous resurgence of $\mathrm{IgM}$ antibodies in 
Table 1 Percent sensitivity and specificity of six enzyme immunoassays (EIAs) for the detection of $\operatorname{IgM}$ or $\operatorname{IgG}$ antibodies to Borrelia burgdorferi, calculated on the basis of the EIA results individually and combined

\begin{tabular}{|c|c|c|c|c|c|c|c|}
\hline \multirow[t]{3}{*}{ EIA test } & \multirow{3}{*}{$\begin{array}{l}\text { Antibody } \\
\text { response }\end{array}$} & \multicolumn{3}{|c|}{ Sensitivity (\%) } & \multicolumn{3}{|c|}{ Specificity $(\%)$} \\
\hline & & \multirow{2}{*}{$\begin{array}{l}\text { ELB } \\
\text { patients }\end{array}$} & \multirow{2}{*}{$\begin{array}{l}\text { LLB } \\
\text { patients } \\
(n=13)\end{array}$} & \multirow{2}{*}{$\begin{array}{l}\text { Total LB } \\
\text { patients } \\
(n=39)\end{array}$} & \multirow{2}{*}{$\begin{array}{l}\text { Healthy } \\
\text { controls }\end{array}$} & \multicolumn{2}{|c|}{ Non-LB patient controls } \\
\hline & & & & & & $\begin{array}{l}\text { Non-LB } \\
\text { patients } \\
(n=128)\end{array}$ & $\begin{array}{l}\text { Non-LB patients } \\
\text { without EBV/CMV } \\
(n=92)\end{array}$ \\
\hline \multirow[t]{3}{*}{ Behring (Germany) } & IgM & 77 & 62 & 72 & 98 & 85 & 98 \\
\hline & $\operatorname{Ig} G$ & 69 & 92 & 77 & 85 & 84 & 86 \\
\hline & $\operatorname{IgM}$ or $\operatorname{IgG}$ & 85 & 100 & 90 & 84 & 70 & 84 \\
\hline \multirow[t]{3}{*}{ Boehringer (Germany) } & IgM & 35 & 46 & 38 & 100 & 89 & 99 \\
\hline & $\mathrm{IgG}$ & 38 & 54 & 44 & 89 & 89 & 88 \\
\hline & IgM or IgG & 62 & 77 & 67 & 89 & 80 & 88 \\
\hline \multirow[t]{3}{*}{ Dako (Denmark) } & IgM & 65 & 69 & 67 & 95 & 88 & 99 \\
\hline & $\operatorname{IgG}$ & 50 & 77 & 59 & 97 & 98 & 98 \\
\hline & IgM or IgG & 85 & 85 & 85 & 92 & 86 & 97 \\
\hline \multirow[t]{3}{*}{ Genzyme Virotech (Germany) } & IgM & 81 & 62 & 74 & 98 & 81 & 92 \\
\hline & $\operatorname{IgG}$ & 54 & 92 & 67 & 94 & 92 & 89 \\
\hline & $\operatorname{Ig} \mathrm{M}$ or $\operatorname{Ig} \mathrm{G}$ & 92 & 92 & 92 & 92 & 73 & 83 \\
\hline \multirow[t]{3}{*}{ IBL (Germany) } & IgM & 65 & 62 & 64 & 90 & 75 & 89 \\
\hline & IgG & 46 & 69 & 54 & 87 & 86 & 78 \\
\hline & $\operatorname{Ig} M$ or IgG & 85 & 85 & 85 & 79 & 64 & 75 \\
\hline Milenia (Germany) & $\mathrm{IgM}+\mathrm{IgG}$ & 31 & 69 & 44 & 95 & 88 & 88 \\
\hline
\end{tabular}

Table 2 Positive and negative predictive values (PPV and NPV) of six enzyme immunoassays for the detection of $\mathrm{IgM}$ or $\mathrm{IgG}$ antibodies indicating early Lyme borreliosis (ELB) and late Lyme borreliosis (LLB) in two different patient populations. Predictive

\begin{tabular}{|c|c|c|c|c|c|}
\hline \multirow[t]{2}{*}{ EIA test } & \multirow{2}{*}{$\begin{array}{l}\text { Antibody } \\
\text { response }\end{array}$} & \multicolumn{2}{|c|}{ Population I* } & \multicolumn{2}{|c|}{ Population II $^{\mathrm{b}}$} \\
\hline & & $\begin{array}{l}\text { PPV } \\
(\%)\end{array}$ & $\begin{array}{l}\text { NPV } \\
(\%)\end{array}$ & $\begin{array}{l}\text { PPV } \\
(\%)\end{array}$ & $\begin{array}{l}\text { NPV } \\
(\%)\end{array}$ \\
\hline \multirow[t]{3}{*}{ Behring (Germany) } & IgM & 64 & 94 & 91 & 94 \\
\hline & $\lg G$ & 59 & 98 & 62 & 98 \\
\hline & IgM or IgG & 47 & 97 & 58 & 97 \\
\hline \multirow[t]{3}{*}{ Boehringer (Germany) } & $\lg M$ & 55 & 85 & 90 & 85 \\
\hline & IgG & 55 & 88 & 55 & 88 \\
\hline & IgM or IgG & 50 & 91 & 58 & 91 \\
\hline \multirow[t]{3}{*}{ Dako (Denmark) } & $\lg M$ & 62 & 91 & 84 & 91 \\
\hline & $\operatorname{lgG}$ & 90 & 94 & 90 & 94 \\
\hline & $\lg M$ or $\lg G$ & 64 & 96 & 81 & 96 \\
\hline \multirow[t]{3}{*}{ Genzyme Virotech (Germany) } & IgM & 61 & 95 & 80 & 95 \\
\hline & $\lg G$ & 77 & 98 & 72 & 98 \\
\hline & IgM or IgG & 52 & 98 & 64 & 98 \\
\hline \multirow[t]{3}{*}{ IBL (Germany) } & IgM & 45 & 90 & 62 & 90 \\
\hline & IgG & 55 & 92 & 49 & 92 \\
\hline & $\lg M$ or $\lg G$ & 41 & 95 & 48 & 95 \\
\hline \multirow[t]{3}{*}{ Milenia $\left(\right.$ Germany) ${ }^{\mathrm{e}}$} & ELB & 44 & 84 & 46 & 84 \\
\hline & LLB & 63 & 92 & 66 & 92 \\
\hline & LB & 52 & 86 & 55 & 86 \\
\hline
\end{tabular}

"LB healthy control group and non-LB patient control group

'LB healthy control group and non-LB patient control group without cytomegalovirus and Epstein-Barr virus patient controls

' $\operatorname{Ig} M+\operatorname{Ig} G$

LLB patients, which has been observed previously [2], could explain the improvement of sensitivity in our LLB patient group. However, due to cross-reacting IgG and $\mathrm{IgM}$ antibodies (mostly nonpaired), the use of combined IgM and IgG test results caused a significant value is calculated for a prevalence of $20 \%$ ELB, $20 \%$ LLB and $20 \%$ Lyme borreliosis (LB) in the populations tested for IgM, $\operatorname{IgG}$ and $\operatorname{IgM}$ or $\operatorname{IgG}$, respectively 
patient group after EBV and CMV patients were excluded. The Genzyme Virotech EIA and the Dako EIA showed positive predictive values of $64 \%$ and $81 \%$, respectively, using the combined $\mathrm{IgM}$ and $\mathrm{IgG}$ test results obtained in a population consisting of $20 \%$ (estimated) LB patients, healthy controls and non-LB patients with infections known to cause cross-reactions in serological tests for LB and/or with infections that mimic the clinical symptoms of LB, without the CMV and EBV patient controls.

The Dako EIA had the highest sensitivity, specificity and positive and negative predictive values when the IgM and IgG test results were combined. Compared to the other tests, the Dako EIA showed a significantly higher positive predictive value $(P<0.05)$ in a population of LB patients, healthy controls and patient controls, when CMV and EBV patients were excluded. The prevalence of LB patients in this population was $20 \%$ (estimated). This confirmed the conclusion of our original study, namely that the exclusion of EBV and, if indicated, CMV infections improves the precision of LB EIA test results significantly.
In conclusion, the use of combined IgM and IgG EIA test results for laboratory confirmation of the diagnosis of LB improves sensitivity at the cost of lower specificity, which results in a lower positive predictive value for most tests. In our study the performance of only one test system was improved by the use of combined IgM and IgG test results. Therefore, the use of classspecific IgM or IgG antibody detection to confirm a diagnosis of ELB or LLB, respectively, seems preferable for most EIA systems tested.

\section{References}

1. Goossens HAT, van den Bogaard AE, Nohlmans MKE: Evaluation of fifteen commercially available serological tests for diagnosis of Lyme borreliosis. European Journal of Clinical Microbiology \& Infectious Diseases (1999) 18:551-560

2. Craft JE, Fischer DK, Shimamoto GT, Steere AC: Antigens of Borrelia burgdorferi recognized during Lyme disease, appearance of a new immunoglobulin $M$ response and expansion of the immunoglobulin $\mathrm{G}$ response late in the illness. Journal of Clinical Investigation (1986) 78:934-939 



\title{
Chapter IIIc
}

\section{EPSTEIN-BARR VIRUS AND CYTOMEGALOVIRUS INFECTIONS CAUSE FALSE-POSITIVE RESULTS IN IGM TWO-TEST PROTOCOL FOR EARLY LYME BORRELIOSIS}

\author{
H.A.T. Goossens', A.E. van den Bogaard', M.K.E. Nohlmans ${ }^{2}$ \\ ' Department of Medical Microbiology, University Maastricht; \\ ${ }^{2}$ Department of Medical Microbiology, General Hospital Arnhem. The Netherlands
}

Reprinted by permission of Infection Letter (1999) 27 (3) 231 . 



\section{Epstein-Barr Virus and Cytomegalovirus Infections Cause False-Positive Results in IgM Two-Test Protocol for Early Lyme Borreliosis}

Serological testing is important for the confirmation of Lyme borreliosis (LB) in suspected cases, because the disease is protean in its clinical manifestations and can mimic several other fiseases. Moreover, in the case of LB the classical methods for confirming the diagnosis of a bacterial infection, i. e. isolation or direct visualisation of the causative agent, are not sensitive enough [1] and PCR assays, despite much promise for the future. still produce too many false-positive results at the moment [2]. Currently, the enzyme immunoassay (EIA) is the most reliable. sufficiently sensitive and readily available laboratory test for LB. However, false-positive reactions do occur because of crossreacting antibodies due to an infection with other microorganisms such as Treponema pallidum, or due to certain autoimmune diseases, such as rheumatoid arthritis. In the case of early Lyme borreliosis (ELB) (duration of a few weeks to 3 months) an IgM test is indicated. To improve specificity, a two-test protocol consisting of a screening of suspected LB patients with an ELA test followed by confirmation of positive cases with Western blot (WB) analysis, has been recommended by the CDC [3]. As no general European recommendations have been accepted, the American two-test protocol is commonly used in Europe. However, the antigenic variation of European Borrelia burgdor. feri sensu lato strains might cause a different immune response. To evaluate a recommended two-test protocol for patients with ELB, we tested the sera of confirmed EL.B patients, of healthy controls and of several groups of patients with diseases known to cause cross reactions in Lyme serology or with clinical symptoms mimicking Lyme borreliosis. All early Lyme patients had presented with erythema migrans and either had a recent tick bite, according their anamnesis, or B. burgdorferi was isolated from a skin lesion. All recovered after adequate antibiotic therapy and no relapses occurred. The healthy controls had neither a history of LB nor tick exposure. The patient control group consisted of 40 patients with infectious mononucleosis (positive according to the Paul and Bunell test and EBV IgM-EIA), 62 patients with acute cytomegalovirus (CMV) infection with a confirmed pp65 antigenemia, and a population of 92 other nonLyme patients: 24 patients with rheumatoid factor-positive rheumatoid arthritis, 24 patients with antinuclear antibodies, 23 patients with $T$. pallidum antibodies and 21 patients with HIVinfection. All samples in this study were tested in a commercially available EIA (Genzyme Virotech, Russelsheim, Germany) and in two WB assays (Genzyme Virotech and MRL, Los Angeles, CA, USA). The Genzyme Virotech Lyme IgM-EIA and IgM blot both contained the same antigen: genotype I strain 2591 (B. burgdorferi sensu stricto) and the MRL kit genotype II (Borrelia garinii). Tests were performed and interpreted according to the instructions of the manufacturers. An IgM blot was considered positive when OspC ( $24 \mathrm{kDa})$ and/or BmpA (39 $\mathrm{kDa}$ ) (both considered highly specific proteins) with or without flagellin $(41 \mathrm{kDa})$ reacted positive. No differences in results of the IgM-EIA-positive samples were observed between the WB test using the genotype I or genotype II strain. The results are shown in Table 1.

The sensitivity and specificity of the EIA test were $81 \%$ and $79 \%$, respectively, and of the two-step protocol $49 \%$ and $88 \%$. However, by omitting the infectious mononucleosis and CMV. infected patients the specificity of the EIA test increased to $97 \%$ and of the two-test protocol to $99 \%$. Approximately $60 \%$ of the Lyme IgM-EIA-positive sera from CMV and infectious mononucleosis patients reacted in the WB test with one of the two proteins considered highly specific. mainly OspC. All sera
Table 1: Serology results in the two-test protocol for early Lyme borreliosis.

\begin{tabular}{|c|c|c|c|c|c|}
\hline \multirow{2}{*}{\multicolumn{2}{|c|}{$\begin{array}{l}\text { Sera tested } \\
\text { Na }\end{array}$}} & \multicolumn{2}{|c|}{$\begin{array}{l}\text { Positive in } \\
\text { Lyme IgM-EIA }\end{array}$} & \multicolumn{2}{|c|}{$\begin{array}{l}\text { Positive in } \\
\text { Lyme IgM-EIA } \\
\text { and IgM WB }\end{array}$} \\
\hline & & $\mathrm{Na}$ & (8) & $\mathrm{Na}$ & $(\%)$ \\
\hline Early Lyme patient & 57 & 46 & (81) & 28 & (49) \\
\hline Healthy controls & 62 & 1 & (2) & 0 & (0) \\
\hline CMV patients & 62 & 23 & (37) & 13 & (21) \\
\hline \multicolumn{6}{|c|}{ Patients with infectious } \\
\hline mononucleosis & 40 & 21 & (53) & 14 & (35) \\
\hline $\begin{array}{l}\text { Other non-Lyme } \\
\text { patients }\end{array}$ & 92 & 7 & (8) & 3 & (3) \\
\hline
\end{tabular}

CMV = cytomegalovirus; EIA = enxyme immunoassay: WB $=$ Western blot; $\mathrm{No}=$ number of patients.

from ELB patients showed OspC and/or flagellin in the WB. however, and reacted negative in the CMV IgM and EBV IgMEIA.

Our findings contrast with those of Dressler et al. $[4]$ and Ledue et al. [5] that confirmation of positive EIA samples with a WB results in a specificity varying from $95-100 \%$. For the serological confirmation of ELB in suspected cases, we found that the exclusion of patients with infectious mononucleosis or CMV infection increased the specificity more than the recommended two-step protocol, without a significant loss in sensitivity of the Lyme IgM-EIA. As an EBV infection might clinically mimic Lyme borreliosis, confirmation of a positive Lyme IgM-EIA with an additional EBV test and, if indicated, a CMV test seems a better approach than performing a WB.

H. A. T. Goossens, M. K. E. Nohlmans, A. E. J. M. van den Bogaard

\section{References}

1. Nadelman, R. B., Pavia, C. S., Magnarelli, L. A., Wormser, G. P. Isolation of Borrelia burgdorferi from the blood of seven patients with Lyme disease. Am. J. Med. 88 (1990) 21-26.

2. Still, M. M., Ryan, M. E.: Pitfalls in diagnosis of Lyme disease. Postgrad. Med. 102 (1997) 65-72.

3. Centers for Disease Control and Prevention: Recommendations for test performance and interpretation from the Second National Conference on Serologic Diagnosis of Lyme Disease. MMWR 44 (1995) 590-591.

4. Dressler, F., Whelan, J. A., Reinhart, B. N., Steere, A. C. Western blotting in the serodiagnosis of Lyme disease. J. Infect. Dis. 167 (1993) $392-400$.

5. Ledue, T. B., Collins, M. F., Craig, W. Y.s New laboratory guidelines for serologic diagnosis of Lyme disease: evaluation of the two-test protocol. J. Clin. Microbiol. 34 (1996) 2343-2350.

Received: 9 September 1998/Revision accepted: 27 December 1998

H. A. T. Goossens, Dipl. Ing. A. E. J. M. van den Bogaard, D. V. M., D. T V. M. Dip. Bact. Dept. of Medical Microbiology, University of Maastricht, P. O. Box 616, NL-6200 MD Maastricht; M. K. E. Nohlmans. M. D., Ph. D., General Hospital Arnhem, Dept. of Medical Microbiology, P. O. Box 9025 , NL-6800 EG Arnhem, The Netherlands

Correspondence to: Dr. A. E. J. M. van den Bogaard 



\title{
Chapter IV
}

\section{SERODIAGNOSIS OF LYME BORRELIOSIS USING DETECTION OF DIFFERENT IMMUNOGLOBULIN (SUB)CLASSES BY ENZYME-LINKED IMMUNOSORBENT ASSAY AND WESTERN BLOTTING}

\author{
H.A.T. Goossens ${ }^{1}$, A.E. van den Bogaard', M.K.E. Nohlmans ${ }^{2}$ \\ ' Department of Medical Microbiology, University Maastricht; \\ ${ }^{2}$ Department of Medical Microbiology, General Hospital Arnhem, The Netherlands
}

Reprinted by permission Clin Lab (2001) 47:41-49 



\title{
Serodiagnosis of Lyme Borreliosis Using Detection of Different Immunoglobulin (Sub)classes by Enzyme-linked Immunosorbent Assay and Western Blotting
}

\author{
${ }^{1}$ H.A.T. GOOSSENS, ${ }^{1}$ A.E. VAN DEN BOGAARD, ${ }^{2}$ M.K.E. NOHLMANS \\ 'Department of Medical Microbiology. University of Maastricht, Maastricht, The Netherlands \\ ${ }^{2}$ Department of Medical Microbiology. General Hospital Arnhem, Armhem, The Netherlands
}

\begin{abstract}
SUMMARY
To improve the performance of enzyme-linked immunosorbent assays for the serodiagnosis of Lyme borreliosis, the prevalence of several immunoglobulin classes and subclasses against various antigens of Borrelia burgdorferi was investigated by Western blotting. The sera of 40 early Lyme borreliosis patients (ELB), 27 late Lyme borreliosis patients (LLB), 62 healthy controls and 140 non-Lyme borreliosis patients were used. Detection of $\operatorname{lgG}$ versus total IgG was found to be more sensitive in detecting Borrelia burgdorferi antigens, especially flagellin (41 kD) protein, but did not improve the performance of Western blotting. The use of IgG detection showed an increase in sensitivity and specificity for the early Lyme borreliosis patient group compared to the standard IgG and IgM detection method by enzyme immunoassays using purified Borrelia burgdorferi fagellum. However, in an enzyme immunoassay using a total sonicate, sensitivity in detecting early Lyme borreliosis and late Lyme borreliosis with $\mathrm{IgG}$ remained lower compared to the detection of early Lyme borreliosis by IgM antibodies and late Lyme borreliosis by total IgG antibodies. (Clin. Lab. 2001;47:41-49)
\end{abstract}

\section{KEY WORDS}

Borreliosis, Lyme disease, serodiagnosis, immunoglobulin subclasses, Western blot

\section{INTRODUCTION}

Lyme borreliosis (LB) $[1,2]$ is the most prevalent tickborne disease in Europe, North America, and other parts of the world with a temperate climate where lxodus ticks are prevalent [3-11]. LB is a multisystemic infectious disease with protean clinical manifestations that might involve the skin, joints, nervous system or heart and which can mimic several other disorders $[12,13]$. Therefore, serological confirmation of the clinical diagnosis of LB is important. Despite the occurrence of false-negative test results [13] and of cross-reacting antibodies resulting in false-positive findings $[14,15]$, the enzyme-linked immunosorbent assay (EIA) is currently the most commonly used laboratory test for LB.

Manuscript accepted September 11, 2000
During an immune response to an infection, different class- and subclass-specific antibodies are produced against the immunogenic components of the invader. It is known that certain antigens directly stimulate B cells, giving rise to a strong specific $\operatorname{lgM}$ response. Other antigens stimulate heavy chain isotype switching or elicit a selective increase in IgG antibodies of certain subclasses considering specified effector functions of the individual subclasses [16-30]. Since the half life of the different (sub)classes of antibodies is dissimilar, this might influence the levels and the subclasses of antibodies against certain epitopes present in serum at different stages of the disease [31-37]. The aim of this study was to test whether it would be possible to improve EIA tests for LB by detecting only one specific (sub)class: $\operatorname{Ig} A, \operatorname{Ig} M, \operatorname{IgG}, \operatorname{IgG}, \operatorname{IgG}_{2}, \operatorname{IgG}_{3}$ or $\operatorname{IgG}_{4}$ antibodies against Borrelia burgdorferi antigens. Therefore, in the first step of this study the prevalence of $\operatorname{IgA}, \lg M, \lg G$ and the different subclasses of $\mathrm{IgG}: \mathrm{IgG}_{-4}$ against the various antigens of Borrelia burgdorferi were investigated using Western blot (WB). In the second step the results obtained in WB were used to predict the effects of specific (sub)class detection in EIAs with different 
antigen composition. Compared to previous reports [15, $19,20,38-43$ ] a more diverse population of non-Lyme patients with disorders clinically mimicking LB and/or known to cause cross-reactivity in Lyme borreliosis serology and clinically defined early and late Lyme borreliosis patients were used in WB and EIA testing to expand the comprehension of sub(class) detection on sensitivity and specificity of the tests.

\section{MATERIALS AND METHODS}

\section{Serum Samples:}

Two hundred sixty-nine serum samples were collected in the Netherlands during a period of one year (1997). Based on clinical criteria, they were divided into two major groups according to their origin: the Lyme borreliosis group and the control group. The Lyme borreliosis group was subdivided in two groups: the early Lyme borreliosis (ELB) and the late Lyme borreliosis (LLB) group. The ELB group consisted of 40 patients who had presented themselves with an erythema migrans and had either a tick bite in the anamnesis and/or Borrelia burgdorferi was isolated from their skin lesions (ELBgroup). The LLB group consisted of ten patients with acrodermatitis chronica atrophicans and 17 with chronic neuroborreliosis. The control group consisted of two subgroups: the healthy control group and the non-Lyme control patient group. The healthy control group consisted of 62 healthy adult persons without any history of Lyme borreliosis and tick exposure. The non-Lyme control patient group consisted of 140 persons: 24 with acute Epstein-Barr virus (EBV) infection (positive in Paul and Bunell, internal house test and EBV-IgM EIA, Genzyme Virotech, Germany), 24 with acute cytomegalovirus (CMV) infection (positive in the CMV-M-test, Abbott, USA), 24 with rheumatoid factor-positive rheumatoid arthritis (RF) (positive in the RF-test, Eurogenetics, Belgium), 24 with antinuclear antibodies (ANA) (positive in IFA with Hep-2 cells, internal house test), 23 patients with Treponema pallidum infection (TP) (positive in the syphilis test, Fujirebio, Japan) and 21 patients who were seropositive for HIV (HIV) (positive in the HIV-test, Abbott, USA).

All Lyme borreliosis patients had negative test results for RF (Eurogenetics), ANA (IFA with Hep-2 cells, internal house test), EBV (Paul and Bunell, internal house test and EBV-IgM EIA, Genzyme Virotech), CMV (Abbott), HIV (Abbott) and specific syphilis antibodies (Fujirebio).

\section{IgG subclass EIA:}

To rule out low reactivity in WB caused by hypogammaglobulinaemic patients or patients with a subclass deficiency or low subclass concentration, the $\operatorname{lgG}_{\text {}}$, $I_{g} G_{2}, I g G_{3}$ and $I g G_{4}$ concentrations were quantified in all serum samples of all patient groups with a commercially available IgG subclass EIA (Genzyme Virotech). Patient samples with a reduced subclass concen- tration were less diluted in WB to obtain a minimum concentration considered normal for healthy individuals $[36,37]$. The $\operatorname{IgG}, \operatorname{IgG}_{2}$ and $\operatorname{IgG}_{3}$ serum levels of all patients tested, were in the range found in healthy individuals $[36,37]$. For $\operatorname{IgG}_{4}$ detection in $W B$, the following samples were less diluted: one serum sample of the HIV population, two srum samples of the EBV and ANA populations, four serum samples of the ELB, LLB and TP populations and eleven serum samples of the healthy controls.

\section{Electrophoresis:}

Sodium dodecylsulphate(SDS)-polyacrylamide gel electrophoresis (SDS-PAGE) was performed as described by Laemmli [44] with a vertical slab gel system (Novex, USA). Seventy micrograms (per $100 \mathrm{~mm}$ gel trough) of whole-cell sonicated Borrelia burgdorferi genotype I strain 2591, harvested in the log phase, were dissolved in sample buffer $(0.125 \mathrm{M}$ Tris- $\mathrm{HCl}, \mathrm{pH} 6.8,15 \%$ glycerol, $4 \%$ SDS, $5 \%$ B-mercaptoethanol, $0.005 \%$ bromophenol blue), heated for 5 minutes at $96{ }^{\circ} \mathrm{C}$ and electrophorated on a $1 \mathrm{~mm} \mathrm{12 \%}$ Tris-glycine gel (Novex). Electrophoresis was performed at room temperature in a Xcell-II (Novex) and 180V for approximately 80 minutes or until the dye front reached the bottom of the gel.

\section{Blotting Procedure:}

The spirochetal proteins separated by SDS-PAGE were transferred from the gel to a $0.45 \mu \mathrm{m}$-pore-size nitrocellulose membrane (BA 85; Schleicher and Schuell, Germany) in a graphite semidry electroblotter (CTI, Germany) containing two series of three pieces of GB3 filter paper (Schleicher and Schuell) prewetted in electroblot transfer buffer containing $0.05 \mathrm{M}$ Tris, $0.04 \mathrm{M}$ glycine, $0.015 \%$ SDS and $15 \%(\mathrm{vol} / \mathrm{vol})$ methanol. Transfer was carried out at $0.8 \mathrm{~mA} / \mathrm{cm}^{2}$ for two hours. The transfer was checked by a reversible Ponceau-red stain (Serva, Germany) and compared with an in-house standard. Blots with comparable staining intensity were subsequently washed in $0.2 \mathrm{M} \mathrm{NaOH}$ and doubly distilled water for one minute, blocked for two hours at room temperature in blocking buffer: $10 \%$ defatted milk powder (Nestlé, Belgium) in TBS (5 mM Tris, $150 \mathrm{mM}$ $\mathrm{NaCl}, 1 \mathrm{mM} \mathrm{MgCl} 2, \mathrm{pH} 8.0$ ) with the addition of $0.35 \%$ Tween-20, rinsed in doubly distilled water and dried at room temperature during the night. The nitrocellulose (NC) was fortified with PVC, cut into 20 strips of $3 \mathrm{~mm}$ and stored at $4{ }^{\circ} \mathrm{C}$ until further use. For blot standardization immunoreactivity was tested by a polyclonal human serum and band intensity analyzed (Gel analyzer Pro; Cybernetics, USA) and compared with an in-house reference blot; maximum deviation was set at $15 \%$. Proteins of Borrelia burgdorferi strain 2591: $83 \mathrm{kD}$, flagetlin, OspA, OspB, OspC, and $20 \mathrm{kD}$ were identified with monoclonal antibodies La 114.3, La 5.2, La 27.1.3, La 97.4 and La 7, respectively (kindly provided by Dr. Kramer, University of Heidelberg, Germany). 


\section{Immunoblotting Procedure:}

To prevent non-specific binding of antibodies to NC, the sera were diluted in blocking buffer, 1:100 for $\operatorname{lgM}$, $\lg A$, total $\lg G, \lg G, \lg _{3}$ and $1: 50$ for $\lg G_{2}$ and $\lg G_{4}$. NC-strips were incubated for 60 minutes at room temperature under constant rocking (Immunetics, USA). Sera with subclass concentrations lower than the minimum concentration found in the healthy control group were diluted accordingly to prevent possible falsenegative reactions in WB due to a lower concentration of subclasses found. Optimum concentrations for all immunoblot reagents had been determined in a series of preceding titration studies. After three five-minute washes with TBS with the addition of $0.001 \%$ Tween20 (TBS-T), the strips were incubated for 60 minutes at room temperature with $1 \mathrm{ml}$ of biotin-conjugated mouse anti-human $\mathrm{IgG}(1 / 250 ; \mathrm{ICN}$, USA), biotin-conjugated mouse anti-human $\operatorname{IgG}_{2}(1 / 375$; Calbiochem, USA), biotin-conjugated mouse anti-human $\operatorname{lgG}_{3}(1 / 1500$, Calbiochem) biotin-conjugated mouse anti-human $\mathrm{IgG}_{4}$ (1/375; Calbiochem) or 30 minutes at room temperature with $1 \mathrm{ml}$ of alkahine phosphatase-conjugated goat antihuman IgG (1/10000; KPL, USA). After three additional washes with TBS-T, the strips were incubated for 30 minutes at room temperature with $1 \mathrm{ml}$ Extravidine alkaline phosphatase conjugate (Sigma, USA) with a dilution of $1 / 3000,1 / 500,1 / 6000,1 / 1500$ for IgG, $\mathrm{IgG}_{2}, \mathrm{IgG}_{3}$ and $\mathrm{IgG}_{4}$ conjugates, respectively. The strips were washed three times with TBS-T. The alkaline phosphatase activity was visualized by incubation of the strips with a ready-to-use chromogenic substrate (5bromo-4-chloro3-indolylphosphate-4-nitroblue tetrazolium, Promega, USA). The reaction was stopped after 10 minutes by repeated washing in distilled water. The resulting protein band patterns were analyzed with a video system (Gel analyzer Pro, Cybernetics), which allows direct "on-screen" determination of molecular masses and intensity of reactive protein bands using a reference strip. As reference, a strip from the middle of the immunoblot was incubated with a serum reactive to p93/83, p41 (flagellin), p39 (BmpA), p34 (OspB), p31 (OspA) and p23 (OspC) antigens. The band intensities were classified into groups $1,2,3$ with a respective intensity range of $<50,50-100,>100$. Bands with an intensity range lower than 50 were found not to be reproducible and excluded for further WB interpretations. Proteins described as common antigens or heat shock proteins [45-51] in the range of $43 \mathrm{kD}-75 \mathrm{kD}$ and irrelevant for diagnostic purposes are not listed in Table 1.

\section{IgM, total IgG and IgG EIAs:}

All sera were tested by two commercially available EIAs (Dako, Denmark and Genzyme Virotech) and one prototype EIA (Genzyme Virotech) for the detection of human IgM and IgG antibodies against Borrelia burgdorferi according to the instructions of the manufacturer. For the detection of $\mathrm{IgG}_{\mathrm{I}}$ antibodies against Borrelia burgdorferi antigens, IgG test kits were used with a mouse anti-human IgG-POD conjugate (ICN) diluted (1/500) in conjugate dilution buffer (manufacturer specific) and standard running conditions according to the instructions of the manufacturers. Sensitivity and specificity of the tests were compared with results obtained from the same EIA-lot. The antigens used in the com mercial ElAs were purified Borrelia afzelii flagellum strain DK1 (Dako), total sonicated Borrelia burgdorferi sensu stricto strain 2591 (Genzyme Virotech) and for the prototype EIA, a flagellin degraded total sonicate Borrelia burgdorferi sensu stricto strain 2591 (Genzyme Virotech).

\section{Statistical Analysis:}

The diagnostic sensitivity and specificity of the total Borrelia burgdorferi sonic extract, flagellin degraded sonic extract and purified flagellum EIA were compared by using McNemar's test, assuming a binomial distribution of paired data. Non-paired data were compared by using the Chi-square test.

\section{RESULTS}

\section{IgM Immunoblotting:}

As displayed in Table 1, 35\% and $43 \%$ of the ELB patients showed an IgM response to the $41 \mathrm{kD}$ (flagellin) and $22 \mathrm{kD}(\mathrm{OspC})$ proteins, respectively, but this was not significantly different from the IgM responses in the LLB patients, which were $33 \%$ and $37 \%$, respectively. The healthy control group versus the ELB and LLB patient group showed a significantly lower response $(\mathrm{P}<0.05)$ to the $41 \mathrm{kD}(15 \%)$ and $22 \mathrm{kD}(2 \%)$ protein. Despite the significantly lower immune response to the $22 \mathrm{kD}$ protein in the control group, this was not the case for all patient groups in the non-Lyme control patient group. The EBV and CMV groups showed in respectively $38 \%$ and $42 \%$ of the patients a reaction to the $22 \mathrm{kD}$ protein, which was not significantly different from the ELB and LLB patients.

Based on the IgM response detected in WB, difficulties can be expected in discriminating LB patients from EBV and CMV patients in IgM-EIA testing, as we published before $(52,53)$.

\section{IgA Immunoblotting:}

The IgA immune response to Borrelia burgdorferi antigens in the ELB and LLB patient group was similar and modest. The immune reaction to the $41 \mathrm{kD}$ protein in $30 \%$ of the LLB patients was the only one in the LB group, higher than $15 \%$. The $\operatorname{IgA}$ response in the healthy and non-Lyme control patients was low, except for the CMV-patients who showed a significantly higher reaction $(\mathrm{P}<0.001)$ to the $41 \mathrm{kD}(83 \%)$ compared to the ELB (15\%) and LLB (30\%) patients. 


\section{CHAPTER IV}

Table 1: Frequency of different immunoglobulin classes to selected Borrelia burgdorferi proteins detected in Western blot.

\begin{tabular}{|c|c|c|c|c|c|c|c|}
\hline \multirow[b]{2}{*}{ Class } & \multirow[b]{2}{*}{ Protein } & \multicolumn{2}{|l|}{ Lyme group } & \multicolumn{4}{|l|}{ Control group } \\
\hline & & $\begin{array}{c}\text { ELB } \\
(N=40)\end{array}$ & $\begin{array}{c}\text { LLB } \\
(\mathrm{N}=27)\end{array}$ & $\begin{array}{c}\text { Healthy } \\
\text { control } \\
\text { patients } \\
(\mathrm{N}=62)\end{array}$ & $\begin{array}{c}\text { EBV } \\
(N=24)\end{array}$ & $\begin{array}{c}\text { CMV } \\
(N=24)\end{array}$ & $\begin{array}{l}\text { non-Lyme } \\
\text { control } \\
\text { patients } \\
(\mathrm{N}=140)\end{array}$ \\
\hline \multirow[t]{2}{*}{$\lg M$} & $41 \mathrm{kD}$ & 35 & 33 & 15 & 67 & 58 & 27 \\
\hline & $22 \mathrm{kD}$ & 43 & 37 & 2 & 38 & 42 & 14 \\
\hline \multirow[t]{2}{*}{$\lg A$} & $41 \mathrm{kD}$ & 15 & 30 & 2 & 17 & 83 & 7 \\
\hline & $22 \mathrm{kD}$ & 5 & 4 & $\cdot$ & $\cdot$ & 17 & 2 \\
\hline \multirow[t]{9}{*}{ lga total } & $83 \mathrm{kD}$ & 8 & 44 & 3 & $\cdot$ & $\cdot$ & 2 \\
\hline & $41 \mathrm{kD}$ & 33 & 67 & 36 & 18 & 42 & 37 \\
\hline & $39 \mathrm{kD}$ & 8 & 30 & 5 & $\cdot$ & $\cdot$ & 2 \\
\hline & $34 \mathrm{kD}$ & 10 & 15 & 3 & . & - & - \\
\hline & $31 \mathrm{kD}$ & 5 & 30 & 8 & - & - & 1 \\
\hline & $22 \mathrm{kD}$ & 10 & 15 & 6 & - & 17 & 2 \\
\hline & $20 \mathrm{kD}$ & 5 & 26 & 2 & - & $\cdot$ & 1 \\
\hline & $18 \mathrm{kD}$ & . & 15 & - & $\cdot$ & $\cdot$ & $\cdot$ \\
\hline & $<18 \mathrm{kD}$ & 8 & 19 & 6 & - & - & 2 \\
\hline \multirow[t]{9}{*}{ Iga1 } & $83 \mathrm{kD}$ & 8 & 48 & 5 & & & 2 \\
\hline & 4110 & 65 & 93 & 55 & 79 & 83 & 52 \\
\hline & 39 kD & 15 & 44 & 3 & $\cdot$ & $\cdot$ & 4 \\
\hline & $34 \mathrm{kD}$ & 15 & 26 & 5 & - & - & $\cdot$ \\
\hline & $31 \mathrm{kD}$ & 8 & 33 & 8 & - & $\cdot$ & 3 \\
\hline & $22 \mathrm{kD}$ & 25 & 26 & 3 & - & 17 & 2 \\
\hline & $20 \mathrm{kD}$ & 10 & 33 & 5 & - & • & 1 \\
\hline & $18 \mathrm{kD}$ & $\cdot$ & 15 & . & $\cdot$ & - & . \\
\hline & $<18 \mathrm{kD}$ & 18 & 41 & 8 & 21 & $\cdot$ & 5 \\
\hline \multirow[t]{2}{*}{$\operatorname{lgC2}$} & $41 \mathrm{kD}$ & 65 & 19 & 28 & 88 & . & 49 \\
\hline & $34 \mathrm{kD}$ & $\cdot$ & 11 & $\cdot$ & $\cdot$ & . & 1 \\
\hline \multirow[t]{2}{*}{$\lg 63$} & $41 \mathrm{kD}$ & 18 & 59 & 23 & 17 & - & 6 \\
\hline & $39 \mathrm{kD}$ & $\cdot$ & 26 & 6 & $\cdot$ & $\cdot$ & 2 \\
\hline $\lg 64$ & $41 \mathrm{kD}$ & - & - & . & 88 & 68 & 30 \\
\hline
\end{tabular}

$\because$ no distinct reactivity to protein bands

non-Lyme control patients: patients with acute Epstein-Barr virus infection (EBV), or acute cytomegalovirus infection (CMV), or rheumatold factor-positive rheumatold arthritis (RF), or with antinuclear antibodles (ANA), or with syphills (TP), or seropositive for HIV (HIV)

IgA-WB demonstrated a low value of IgA detection in future EIA test systems for the discrimination of LB patients.
Total IgG Subclass Immunoblotting:

As shown in Table 1, the LLB patients versus the ELB, healthy and non-Lyme control patients showed a significantly higher response $(\mathrm{P}<0.05)$ to the $41 \mathrm{kD}(67 \%)$ protein, followed by the $83 \mathrm{kD}(44 \%), 39 \mathrm{kD}$ and $31 \mathrm{kD}$ 
$(30 \%), 20 \mathrm{kD}(26 \%)$ and $18 \mathrm{kD}(15 \%)$ proteins. In contrast to the LLB patients, the immune response in ELB patients was not significantly different from that in healthy and non-Lyme control patients, except for the response to the $34 \mathrm{kD}$ protein, which only occurred in the ELB group and was completely absent in the nonLyme control patient group.

The more diverse IgG response to Borrelia burgdorferi antigens in the LLB patients, as shown in the total IgG WB, demonstrates the ability of discriminating LLB patients from the ELB, healthy and non-Lyme control patients in test systems using total IgG detection.

\section{IgG Subclass Immunoblotting:}

The main subclass responses in the ELB and LLB group were $\operatorname{lgG}, \operatorname{lgG}_{2}$ and $\operatorname{lgG}_{3}$. Among all subclasses detected, $\operatorname{IgG}$ showed the broadest response to the Borrelia burgdorferi proteins. The $\mathbf{g G}_{2}$ response in all patient groups was mainly directed to the $41 \mathrm{kD}$ protein. Of the non-Lyme control patient group, $88 \%$ of the EBV patients showed an $\operatorname{lgG}_{2}$ response to the $41 \mathrm{kD}$, which was significantly higher $(\mathrm{P}<0.05)$ compared to the ELB, LLB, healthy and other non-Lyme control patients. Although the $\mathrm{IgG}_{3}$ response to the $39 \mathrm{kD}$ protein was totally absent in ELB patients, $26 \%$ of LLB patients showed an immune reaction which was significantly higher $(\mathrm{P}<0.05)$ compared to the healthy control patients $(6 \%)$ and non-Lyme control patients $(2 \%)$. $\operatorname{lgG}_{4}$ immuire respomses to borretiá burgáorféri proteins were restricted to the $41 \mathrm{kD}$ (flagellin) protein and only occurred in the non-Lyme control group. Compared to the other non-Lyme control patients, the EBV and CMV patients showed a significantly $(\mathrm{P}<0.001)$ higher $\mathrm{IgG}_{4}$ response to the $41 \mathrm{kD}$ (flagellin) of $88 \%$ and $50 \%$, respectively.

Due to the response to a broader range of different Borrelia burgdorferi proteins, detection of $\mathrm{IgG}_{\mathrm{G}}$ seems to be more suitable than the detection of other IgG subclasses in future test systems for Lyme disease.

IgG subclasses versus total IgGWB. Compared to the subclass non-specific detection of human IgG (total-IgG WB), IgG testing showed a significant increase of $10 \%$ or more in detecting antibodies to the $41 \mathrm{kD}, 22 \mathrm{kD}$ and $<18 \mathrm{kD}$ borrelia proteins in the ELB group and to the 41 $\mathrm{kD}, 39 \mathrm{kD}, 34 \mathrm{kD}, 22 \mathrm{kD}, 20 \mathrm{kD}$, and $<18 \mathrm{kD}$ borrelia proteins in the LLB group. In all groups, only the detection of the $41 \mathrm{kD}$ protein was significantly higher $(P<0.05)$ wth $I g G$ versus total IgG antibody testing. $\mathrm{IgG}$ testing increased the sensitivity $(\mathrm{P}<0.05)$ of detecting the $41 \mathrm{kD}$ flagellin the most in the ELB group $(+32 \%)$, followed by the LLB group $(+26 \%)$, healthy control group $(+19 \%)$ and non-Lyme control group $(+15 \%)$. Of the non-Lyme control group, EBV and CMV patients showed an increased $41 \mathrm{kD}$ detection of $+61 \%$ and $+41 \%$, respectively, which was higher than that in the ELB $(+32 \%)$ and LLB $(+26 \%)$ group. An increased sensitivity in detecting the $41 \mathrm{kD}$ flagellin was also seen with $\lg G_{2}$ detection, but was limited to the ELB $(+32 \%)$ and EBV $(+70 \%)$ patients. IgG detection showed only in EBV cases a significantly $(P<0.001)$ higher sensitivity of detecting $41 \mathrm{kD}$ protein. ELB, LLB and healthy control patients showed no $\operatorname{lgG}_{4}$ response to the $41 \mathrm{kD}$ protein. In contrast to the ELB, LLB and healthy control group, the $\lg G$ response in the nonLyme control patients is also composed of $\mathrm{IgG}_{\mathrm{a}}$.

The use of IgG instead of total IgG detection could boost sensitivity of detecting $\mathrm{LB}$ patients in future test systems with specific parts of $41 \mathrm{kD}$ protein.

\section{IgG versus IgM-WB:}

Compared to $\lg M$ detection, $\lg G$ showed a more diverse immune response and a higher sensitivity $(\mathrm{P}<0.05)$ in detecting the $41 \mathrm{kD}$ protein in the ELB $(+30 \%)$, LLB $(+60 \%)$, healthy control $(+40 \%)$ and nonLyme control patients $(25 \%)$. IgG response to the $22 \mathrm{kD}(\mathrm{OspC})$ was lower in the CMV patients $(17 \%)$ and completely absent in the EBV patients compared to the $\operatorname{lgM}$ response, which was $42 \%$ and $38 \%$, respectively.

IgG detection could not only increase sensitivity but also specificity in the detection of ELB in test systems using a specific part of the $41 \mathrm{kD}$ protein.

\section{$\operatorname{Ig} M-\operatorname{IgG}-\operatorname{IgG}_{\text {ot }}$ EIAs for the detection of Antibodies to Borrelia burgdorferi:}

As listed in Table 2, the Genzyme Virotech EA using a total sonicate as antigen and IgM detection (GVI-IgM) showed the highest sensitivity $(80 \%)$ in detecting ELB patients compared to the other two IgM tests, which showed a sensitivity of $65 \%$. Specificity in all IgMEIAs was low in the EBV-patient goup and varied from $42 \%$ to $58 \%$. Compared to the other IgM-tests, in the CMV patient group the GVI-IgM-EIA showed a specificity of $67 \%$, which was significantly $(P<0.05)$ lower than the $92 \%$ found in the other IgM-EIAs tested. Of the EIAs using IgG detection, the EIA system using purified flagellum (Dako IgG) showed the highest sensitivity in detecting ELB (75\%) and LLB (76\%). When total IgG EIAs were used $\left(\operatorname{IgG}_{0 t}\right), 92 \%$ of the LLB patients were detected with the total sonicated antigen EIA (GV1) and flagellin reduced total sonicated antigen EIA (GV2), whereas only $76 \%$ of the LLB patients were detected with the flagellum EIA (Dako). For the EIAs using total IgG detection, the EIA using purified flagellum as antigen showed the highest specificity for the TP-patients ( $100 \%$ ) compared to the GV1 and GV2, which showed a specificity of $70 \%$ and $87 \%$, respectively. Reduction of flagellin showed a small improvement in specificity for TP-patients, as shown in the GV2 EIA. IgM versus IgG testing proved to be more sensitive $(\mathrm{P}<0.05)$ in detecting ELB in the EIA using a total sonicated antigen (GV1): $80 \%$ versus $30 \%$ $(\mathrm{GV} 1-\mathrm{IgG})$ and in the EIA using a flagellin degraded sonicated antigen $(\mathrm{GV} 2): 65 \%$ versus $30 \%\left(\mathrm{IgG}_{1}-\mathrm{GV}_{2}\right)$. However, in the EIA using purified flagellum, $\mathrm{IgG}_{\mathrm{H}}$ - 
Table 2: Sensitivity and specificity of nine EIAs for the detection of antibodies for Lyme borreliosis

\begin{tabular}{|c|c|c|c|c|c|c|c|}
\hline \multirow[b]{3}{*}{ EIA tests } & \multirow{2}{*}{\multicolumn{2}{|c|}{$\begin{array}{l}\text { Sensitivity (\%) } \\
\text { Lyme group }\end{array}$}} & \multicolumn{5}{|c|}{ Specifleity (\%) } \\
\hline & & & \multicolumn{5}{|c|}{ Control group } \\
\hline & $\begin{array}{c}E B \\
(N=40)\end{array}$ & $\begin{array}{c}\text { Uв } \\
(N=27)\end{array}$ & $\begin{array}{c}\text { Healthy } \\
\text { control } \\
\text { patients } \\
(\mathrm{N}=62)\end{array}$ & $\begin{array}{c}E B V \\
(N=24)\end{array}$ & $\begin{array}{c}\text { CMV } \\
(\mathrm{N}=24)\end{array}$ & $\begin{array}{c}T P \\
(N=23)\end{array}$ & $\begin{array}{c}\text { non-Lyme } \\
\text { control } \\
\text { patients } \\
(\mathrm{N}=140)\end{array}$ \\
\hline OV1 IgM & 80 & & 98 & 42 & 67 & 91 & 79 \\
\hline GV2 IgM & 65 & & 100 & 58 & 92 & 100 & 90 \\
\hline Dako IgM & 65 & & 95 & 46 & 92 & 100 & 89 \\
\hline av1 IgQ, & 30 & 60 & 94 & 100 & 100 & 91 & 97 \\
\hline GV2 IgQ, & 30 & 52 & 94 & 100 & 100 & 100 & 100 \\
\hline Dako lgG, & 75 & 76 & 97 & 100 & 92 & 100 & 98 \\
\hline GV1 IgGiot & & 92 & 94 & 96 & 100 & 70 & 92 \\
\hline QV2 IgCtot & & 92 & 94 & 100 & 100 & 87 & 97 \\
\hline Dako IgGtot & & 76 & 97 & 100 & 92 & 100 & 97 \\
\hline
\end{tabular}

QV1, Genxyme Virotech EIA (total sonicate); GV2, Genzyme Virotech EIA (flagellin degraded total sonicate); Dako (purifled flagellum); non-Lyme control patients: patients with acute Epstein-Barr virus Infection (EBV), or acute cytomegalovirus infection (CMV), or rheumatoid factor-positive rheumatoid arthritis (RF), or with antinuclear antibodies (ANA), or with syphilis (TP), or seropositive for HIV (HIV)

testing showed a higher sensitivity $(75 \%)$ in detecting ELB compared to IgM-testing (65\%). For EBV patients, IgM detection showed a low specificity in all EIAs tested. In contrast to the EIAs using sonicated antigen, the use of purified flagellum and $\mathrm{IgG}_{\mathrm{g}}$ detection improved specificity significantly $(\mathrm{P}<0.001)$ for the EBV patients: $46 \%(\operatorname{IgM})$ versus $100 \%(\mathrm{IgG})$ and even improved the sensitivity fom $65 \%$ to $75 \%$ for the detecting of ELB patients. Sensitivity of detecting ELB with the EIA using purified flagellum and $\mathrm{IgG}$ detection $(75 \%)$ was not significantly lower than the IgM-EIA showing the highest sensitivity in detecting ELB $(80 \%$, GV1-IgM). In contrast to the GV1 and GV2 ElA, the use of $\mathrm{IgG}_{4}$ detection instead of total IgG showed no loss in sensitivity for the detection of LLB patients with the flagellum EIA (Dako) and remained 76\%.

Compared to the IgG-tests, ElAs using a total sonicate as antigen in combination with the detection of all IgGs show the highest sensitivity in detecting LLB, but dis play a lower specificity in TP-patients.

EIA and Immunoblotting:

For the ten ELB sera that were additionally recognized in the $\lg G$-Dako test, two ELB patients showed a single but strong immune reaction directed to the $41 \mathrm{kD}$ protein in $\mathrm{IgG}_{\mathrm{H}}$-WB. Six patients showed a distinct immune reaction with two or more LB antigens in $\operatorname{IgM}$, IgG or total IgGWB and two patients showed a weak reaction directed to $41 \mathrm{kD}$ in IgM-WB (data not shown).

\section{DISCUSSION}

Again in this study, WB showed that IgM antibodies to the $41 \mathrm{kD}$ (flagellin) and $22 \mathrm{kD}$ (OspC) protein do not only occur in the sera of ELB and LLB patients but also in the sera of EBV and CMV patients. The fact that antibodies against the $22 \mathrm{kD}(\mathrm{OspC})$ protein are important for the serodiagnosis of LB [51], IgM antibodies to the $22 \mathrm{kD}(\mathrm{OspC})$ protein caused false positive results in patients with EBV or CMV infection. This study confirmed our previous finding [52,53]. The occurrence of IgA antibodies directed to different Borrelia burgdorferi antigens found in the ELB and LLB patient groups was limited to the $41 \mathrm{kD}$ and $22 \mathrm{kD}$ protein and too low to be of any interest for discriminating the LB patient sera from the control groups.

For the detection of IgG subclasses we found in accordance with the reports of Hechemy et al.[43], Olsson et 
al. [20], Seppala et al. [15] and Widhe et al. [19] that the distribution of $\mathrm{lgG}$ subclasses reactive with Borrelia burgdorferi antigens in the Lyme patient group was predominantly $\lg G_{1}$ and $\lg G_{3}$. However, the presence of $\mathrm{IgG}_{4}$ and $\mathrm{IgG}_{3}$ antibodies to Borrelia burgdorferi antigens was not limited to patients with Lyme disease but was also detected in healthy control subjects and in the non-Lyme control patients. Therefore the use of IgG subclass(es) specific detection in Western blotting did not improve the performance of Western blotting, but only indicated that $\mathrm{IgG}_{\mathrm{g}}$ antibodies were more sensitive in detecting the $41 \mathrm{kD}$ (flagellin), $39 \mathrm{kD}, 34 \mathrm{kD}, 22 \mathrm{kD}$, $20 \mathrm{kD}$, and $<18 \mathrm{kD}$ borrelia proteins. Although the 58 $\mathrm{kD}$ and $56 \mathrm{kD}$ proteins were described as specific antigens by Hauser et al. [39], we could not confirm this for the $\mathrm{IgG}$ response in the current study nor in the total IgG response in a previous study [52]. The fact that $\operatorname{lgG}_{3}$ gave poorer results than $\operatorname{lgG}$ was most likely due to the lower concentration of anti-Borrelia burgdorferi $\mathrm{IgG}_{3}$ present in the sera. This might be caused by the shorter half-life of $\operatorname{lgG}_{5}$ compared to $\operatorname{lgG}$ (one and three weeks, respectively) [37].

Therefore, we examined the effects of $\mathrm{IgG}$ detection on sensitivity and specificity in EIAs using different antigen preparations: a total sonicate, flagellin degraded total sonicate, and purified flagellum. The reason for including an EIA with purified flagellum was the higher sensitivity of test systems using purified flagellum instead of sonic extracts reported by Hansen et al. [54, 55] and the high $1 \mathrm{gG}$ response to the $41 \mathrm{kD}$ protein in LBpatients seen in our WB orientation study. In contrast to the results in WB, a decrease in sensitivity for detecting LLB with IgG antibodies to Borrelia burgdorferi antigen was observed in the EIAs using a total sonicate as well as in the EIAs using flagellin degraded sonicate. The use of $I g G$ detection in the EIA with purified flagellum improved the sensitivity significantly for ELB patients with $25 \%(\mathrm{P}<0.005)$ compared to the standard Dako IgG test, but remained constant for the detection of LLB patients. The discrepancy with the predictions based on our findings in WB that $\mathrm{IgG}$ detection should improve the detection of ELB as well as LLB could be explained by the following: for the EIAs using a total sonicate, antigens are the limiting factor. The lower IgG response to the $22 \mathrm{kD}$ protein could not be com pensated by the higher response to the $41 \mathrm{kD}$, resulting in a lower sensitivity in detecting ELB patients. For the EIA with purified flagellum, the $41 \mathrm{kD}$ protein would not be the limiting factor, and the higher $\mathrm{IgG}$ response should result in a higher sensitivity of detecting ELB patients as seen in our results. However, for the detection of LLB patients who show an IgG response to different Borrelia burgdorferi antigens, the use of an EIA test system with a single protein should result in a loss of sensitivity and not remain constant, and EIAs with a total sonicate should show an increase in detecting LLB patients. An explanation for these findings might be the influence of conformational changes of the proteins on the recognition of $\mathrm{IgG}$ antibodies which differs from
WB and EIA and the fact that a positive EIA result is the combination of the number and intensity of bands seen in WB. As in some cases, the new identified immune reactions in $\operatorname{lgG}$-WB showed a mediocre band intensity, which could explain the negative results of the $\operatorname{IgG}-$ EIA. However, the lower sensitivity in IgG-EIAs could not be related to a general lower band intensity in $\lg \mathrm{G}_{\mathrm{H}}-\mathrm{WB}$ compared to the band intensity seen in the total IgG-WB. Based on the findings in this study, detecting $\operatorname{lgG}$ antibodies directed to the $41 \mathrm{kD}$ (flagellin) could not only boost the sensitivity of detecting ELB but also improve specificity in case of EIAs using purified flagellum. However, sensitivity in detecting ELB and LLB with IgG remains lower compared to the detection of ELB by $\lg$ antibodies and LLB by $\lg G$ antibodies in an ElA system using a total sonicate. Nevertheless, the use of $\operatorname{lgG}$ detection could improve sensitivity and specificity in detecting ELB in EIAs using purified Borrelia burgdorferi flagellum.

\section{CONCLUSION}

In case of ELB, IgG detection in combination with purified flagellum $(41 \mathrm{kD})$ shows a higher specificity without a significant loss in sensitivity compared to other IgM tests. Further research is needed to investigate whether sensitivity and specificity are also im-

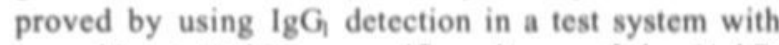
recombinant $41 \mathrm{kD}$ or specific epitopes of the $41 \mathrm{kD}$ protein as main antigen.

\section{References}

1) Burgdorfer W, Barbour AG, Hayes SF, Benach JL, Grunwald E, Davis JP. Lyme disease: a tickborne spirochetosis? Science 1982; $216: 1317-1319$.

2) Weber K, Schierz G, Wilske B, Preac Mursic V. European erythema migrans disease and related disorders. Yale J Biol Med $1984 ; 57: 463-471$.

3) Santino I, Dastoli F, Sessa R, Del Piano M. Geographical incidence of infection with Borrelia burgdorferi in Europe. Panminerva Med 1997; 39: 208-214.

4) Gustafson R, Jaenson TG, Gardulf A, Mejlon H, Svenungsson B. Prevalence of Borrelia burgdorferi sensu lato infection in Lxodes ricinus in Sweden. Scand J Infect Dis 1995; 27: 597-601.

5) Ikushima M, Kawahashi S, Okuyama Y, Matsui K, Arai T. [The survey of prevalence of Lyme borreliosis in forestry workers in Saitama prefecture]. Kansenshogaku Zasshi 1995; 69: 139-144.

6) Jochimsen E, Sikkink J, Marx JJ. The prevalence of Borrelia burgdorferi seropositivity in an area endemic for Lyme disease. Wis Med J 1990; 89:677-681.

7) Drgonova M, Rehacek J. Prevalence of Lyme borrelia in ticks in Bratislava, Slovak Republic. Cent Eur J Public Health 1995; 3 : 134-137. 
8) Lawrence CH, Botchlet R, Silberg SL, Flournoy DJ, Guthrie PJ. Prevalence of Lyme disease infection in Oklahoma. J Natl Med Assoc 1992; 84: 803-804.

9) Motiejunas L, Bunikis J, Barbour AG, Sadziene A. Lyme borreliosis in Lithuania. Scand J Infect Dis 1994; 26: 149-155.

10) Rumpel C, Jones JL. Lyme disease in South Carolina [see comments]. J S C Med Assoc 1991; 87: 420-423.

11) Smith HV, Gray JS, McKenzie G. A Lyme borreliosis human serosurvey of asymptomatic adults in Ireland. Int J Med Microbiol 1991; 275: 382-389.

12) Steere AC. Lyme disease. N Engl J Med 1989; 321: 586-596.

13) Rahn DW. Lyme disease: clinical manifestations, diagnosis, and treatment. Semin Arthritis Rheum 1991; 20: 201-218.

14) Raoult D, Hechemy KE, Baranton G. Cross-raction with Bomelia burgdorferi antigen of sera from patients with human im. munodeficiency virus infection, syphilis, and leptospirosis. J Clin Microbiol 1989; 27: 2152-2155.

15) Seppala IJ, Kroneld R, Schauman K, Forsen KO, Lassenius R. Diagnosis of Lyme borreliosis: non-specific serological reactions with Borrelia burgdorferi sonicate antigen caused by $\operatorname{lgG} 2$ antibodies. J Med Microbiol 1994; 40: 293-302.

16) Kaschka WP, Klein G, Hilgers R, Skvaril F. Humoral immune response in Epstein-Barr virus infections. I. Elevated serum concentration of the IgGI subclass in infectious mononucleosis and nasopharyngeal carcinoma. Clin Exp Immunol 1982; 49: 149 . 156.

17) Kaschka WP, Klein G, Hilgers R, Skvaril F. Humoral immune response in Epstein-Barr virus infections. II. IgG subelass distribution in African patients with Burkitt's lymphoma and nasopharyngeal carcinoma. Clin Exp Immunol 1984; 55: 14-22.

18) Shacks SJ, Heiner DC, Bahna SL, Horwitz CA. Increased serum IgG4 levels in acute Epstein-Barr viral mononucleosis. Ann Allergy 1985; 54: 284-288.

19) Widhe M, Ekerfelt C, Forsberg P, Bergstrom S, Emerudh J. IgG subclasses in Lyme borreliosis: a study of specific IgG subclass distribution in an interferon-gamma-predominated disease. Scand J Immunol 1998; 47; 575-581.

20) Olsson I, Hammarstrom L, Smith Cl, Hovmark A, Asbrink E. IgG subclasses of specific antibodies in Lxodes ricinus-borne borreliosis. Clin Exp Immunol 1987; 69: 618-623.

21) Siber GR, Schur PH, Aisenberg AC, Weitzman SA, Schiffman G. Correlation between serum IgG2 concentrations and the antibody response to bacterial polysaccharide antigens. New Engl J Med 1980; 303: 178-182.

22) Dreher R. Heterogeneity of antinuclear antibodies (ANA), immunoglobulin and complement levels in sera of patients with rheumatoid arthritis (RA). Immun Infekt 1977; 5: 11-22.

23) Baughn RE, Jorizzo JL, Adams CB, Musjer DM. Ig class and $\mathrm{IgG}$ subclass responses to Treponema pallidum in patients with syphilis. J Clin Immunol 1988; 8: 128-139.

24) van der Sluis JJ, van Reede EC, Boer M. Immunoglobulin G subclasses of fluorescent anti-Treponema pallidum antibodies: evidence for sequential development of specific anti-T. pallidem immunoglobulin $\mathrm{G}$ responses in patients with early syphilis. J Clin Mierobiol 1986; 24: 418-423.
25) Tanaka S, Suzuki T. Anti-Treponema pallidum IgM, IgA, and $\operatorname{lgG}$ subclass antibody responses after treatment in patients with syphilis at various stages: 1 . Assessments by enzyme-linked immunosorbent assay. Genitourin Medicine 1990; 66: 171-177.

26) Hamann A, Doerr HW. IgG subclass -specific antibodies to human cytomegalovirus (HCMV) - induced early antigens. Med Microbiol Immunol Berl 1991; 180: 193-204.

27) Mathiesen T, Sonnerborg A, von Sydow M, Gaines H, Wahren B. $\mathrm{IgG}$ subclass reactivity against human immunodeficiency virus (HIV) and cytomegalovirus in cerebrospinal fluid and serum from HIV-infected patients. J Med Virol 1988; 25: 17-26.

28) Sundqvist VA, Linde A, Kurth R, Werner A, Helm EB, Popovic $\mathrm{M}$, Gallo RC, Wahren B. Restricted IgG subclass responses to HTLV-III/LAV and to cytomegalovirus in patients with AIDS and lymphadenopathy syndrome. J Infect Dis 1986; 153: 970973.

29) Urban M, Winkler T, Landini MP, Britt W, Mach M. Epitopespecific distribution of $\mathrm{IgG}$ subclasses against antigenic domains on glycoproteins of human cytomegalovirus. J Infect Dis; 1994; 169: 83-90.

30) Elovaara I, Albert PS, Ranki A, Krohn K, Seppala I. HIV-1 specificity of cerebrospinal fluid and serum IgG, IgM, and IgG1 . G4 antibodies in relation to clinical disease. J Neurol Sci 1993; 117: 111-119.

31) Shakib F, Stanworth DR, Drew R, Catty D. A quantitative study of the distribution of $\mathrm{IgG}$ subclasses in a group of normal human sera. J Immunol Methods 1975; 8: 17-28.

32) Van Der Giessen $M$, Rossouw E, Van Veen TA, Van Loghem E, Zegers BJ, Sander PC. Quantification of IgG subclasses in sera of normal adults and healt hy children between 4 and 12 years of age. Clin Immunol Immunopathol 1975; 21 : (1975) 501-509.

33) Shakib F, Stanworth DR. Human IgG subclasses in health and disease. (A review). Part I Ric Clin Lab 1980; 10: 463-479.

34) Shakib F, Stanworth DR. Human IgG subclasses in health and disease. (A review). Part II Ric Clin Lab 1980; 10: 561-580.

35) French MAH, Harrison G. Serum IgG subclass concentrations in healthy adults: a study using monoclonal antisera. Clin Exp Immunol 1984; 56: 473-475.

36) Aucouturier $P$, Mounir $S$, P reudhomme JL. Distribution of $I g G$ subclass levels in normal adult sera as determined by a competitive enzyme immunoassay using monoclonal antibodies. Diag Immunol 1985; 3: 191-196.

37) Rich RR. Clinical immunology, principles and practice. 1996;1: 54.

38) Dressler F, Whalen JA, Reinhardt BN, Steere AC. Westem blotting in the serodiagnosis of Lyme disease [see comments]. J Infect Dis 1993; 167: 392-400.

39) Hauser U, Lehnert G, Lobentanzer R, Wilske B. Interpretation criteria for standardized Western blots for three European species of Borrelia burgdorferi sensu lato. J Clin Microbiol 1997; 35: 1433-1444.

40) Ledue TB, Collins MF, Craig WY. New laboratory guidelines for serologic diagnosis of Lyme disease evaluation of the twotest protocol. J Clin Microbiol 1996; 34: 2343-2350.

41) Zoller L, Cremer J, Faulde M. Western blot as a tool in the diagnosis of Lyme borreliosis. Electrophoresis 1993;14: 937944. 


\section{SERODIAGNOSIS OF LYME BORRELIOSIS}

42) Zoller L, Burkard S, Schafer H. Validity of Westem immunoblot band patterns in the serodiagnosis of Lyme borreliosis. J Clin Mierobiol 1991; 29: 174-182.

43) Hechemy KE, Harris HL, Duerr MJ, Benach JL, Reimer CB. Immunoglobulin G subclasses specific to Borrelia burgdorferi in patients with Lyme disease. : Ann N Y Acad Sci 1988; 539; 162-169.

44) Laemmli UK. Cleavage of structural proteins during the assemb. ly of the head of bacteriophage T4. Nature 1970; 227: 680-685.

45) Hansen K, Bangsborg JM, Fjordvang $H$, Pedersen NS, Hinders. son P. Immunochemical characterization - and isolation of the gene for a Borrelia burgdorferi immunodominant 60 -tiloduhon antigen common to a wide range of bacteria. Infect Immun 1988; 56: 2047-2053.

46) Luft BJ, Gorevic PD, Jiang W, Munoz P, Dattwyler RJ. Immunologic and structural characterization of the dominant 66-to 73-kDa antigens of Borrelia burgdorferi. J Immunol 1991; 146: 2776-2782.

47) Wallich R, Helmes C, Schaible UE, Lobet Y, Moter SE, Kramer MD, Simon MM. Evaluation of genetic divergence among Bor relia burgdorferi isolates by use of OspA, fla, HSP60, and HSP70 gene probes. Infect Immun 1992; 60 4856-4866.

48) Carreiro MM, Laux DC, Nelson DR. Characterization of the heat shock response and identification of heat shock protein antigens of Borrelia burgdorferi. Infect Immun 1990; 58: 21862191 .

49) Cluss RG, Goel AS, Rehm HL, Schoenecker JG, Boothby JT Coordinate synthesis and turnover of heat shock proteins in Borrelia burgdorferi degradation of DnaK during recovery from heat shock. Infect Immun 1996; 64: 1736-1743.

50) Shanafelt MC, Hindersson P, Soderberg C, Mensi N, Turck CW, Webb D, Yssel H, Peltz G. T cell and antibody reactivity with the Borrelia burgdorferi 60-kDa heat shock protein in Lyme arthritis. J Immunol 1991;146: 3985-3992.
51) Bruckbauer HR, Preac Mursic V, Fuchs R, Wilske B. Crossreactive proteins of Borrelia burgdorferi. Eur J Clin Microbiol Infect Dis 1992; 11: 224-232.

52) Goossens HAT, van den Bogaand AE, Nohlmans MKE. Ealantion of fifteen commercially available serological tests for diagnosis of Lyme borreliosis. Eur J Clin Microbiol Infect Dis 1999; 18: $551-560$.

53) Goossens HAT, van den Bogaard AE, Nohlmans MKE. EpsteinBarr vinus and cytomegalovinus infection cause false-positive rosults in IgM two-test protocol for early Lyme borreliosis. Infection 1999; 27:231.

54) Hansen K, Hindersson P, Pedersen NS. Measurement of antibodies to the Bomelia burgdorferi flagellum improves serodiagnosis in Lyme disease. J Clin Mierobiol 1988; 26: 338-346.

55) Hansen K, Asbrink E. Serodiagnosis of erythema migrans and acrodermatitis chronica atrophicans by the Bomla barydorfin flagellum enzyme-linked immunosorbent assay. J Clin Microbiol 1989; 27 : 545-551.

Correspondence: A.E. van den Bogaard

Department of Medical Microbiology, University of Maastricht, P. O. Box 616, NL-6200 MD Maastricht, The Netherlands

Tel.: 0031-43-3881015/16

Fax: 0031-43-3884161

E-mail: A.vandenBogaard@cpv.unimaas.nl 



\title{
Chapter V
}

\section{DOGS AS SENTINELS FOR HUMAN LYME BORRELIOSIS IN THE NETHERLANDS}

\author{
H.A.T. Goossens', A.E. van den Bogaard', M.K.E. Nohlmans ${ }^{2}$ \\ ' Department of Medical Microbiology, University Maastricht; \\ ${ }^{2}$ Department of Medical Microbiology, General Hospital Armhem, The Netherlands
}

Reprinted by permission J Clin Microbiol (2001) 39 (3) 844-848. 



\title{
Dogs as Sentinels for Human Lyme Borreliosis in The Netherlands
}

\author{
H. A. T. GOOSSENS, ${ }^{1}$ A. E. VAN DEN BOGAARD, ${ }^{1 *}$ AND M. K. E. NOHLMANS ${ }^{2}$ \\ Department of Medical Microbiology, University of Maastricht, NL-6200 MD Maastricht, ${ }^{2}$ and Department of \\ Medical Microbiology, General Hospital Amhem, 6800 EG Amhem, ${ }^{2}$ The Netherlands
}

Received 31 July 2000/Returned for modification 17 October 2000/Accepted 14 December 2000

\begin{abstract}
Serum samples from hunters $(n=440)$, their hunting dogs $(n=448$ ), and hunters without dog ownership $(n=53)$ were collected in The Netherlands at hunting dog trials and were tested for antibodies against Borrelia burgdorferi by a whole-cell enzyme-linked immunosorbent assay. Additionally, 75 healthy pet dogs were tested. The results of this study indicate that the seroprevalence among hunting dogs $(18 \%)$ was of the same order as the seroprevalence among pet dogs $(17 \%)$ and hunters $(15 \%)$. The seropositivity of a hunting dog was not a significant indicator of increased risk of Lyme borreliosis for its owner. No significant rise in seroprevalence was found in dogs older than $\mathbf{2 4}$ months. This indicated that seropositivity after an infection with $B$. burgdorferi in dogs is rather short, approximately 1 year. In humans this is considerably longer but is also not lifelong. Therefore, the incidence of $B$. burgdorferi infections among dogs was greater than that among hunters, despite a similar prevalence of seropositivity among hunters and their hunting dogs. Because no positive correlation was observed between the seropositivity of a hunter and the seropositivity of the hunter's dog, direct transfer of ticks between dog and hunter does not seem important and owning a dog should not be considered a risk factor for Lyme borreliosis.
\end{abstract}

Lyme borreliosis (LB) is a zoonotic disease caused by the spirochete Borrelia burgdorferi $(5,41)$. An animal reservoir of approximately 40 mammals and birds has been established (15) in Europe. The disease is transmitted primarily by ticks feeding on mammals and birds, with the most common vector in Europe being the tick Lxodes ricinus (1). In humans, LB in its early stages is characterized by influenza-like symptoms, followed in 60 to $80 \%$ of the cases by erythema migrans (40), a skin lesion that spreads outward from around the site of a tick bite. If untreated, the disease may proceed to a second or a third stage in which neurological disorders and arthritis are common symptoms (42). Much less is known about LB in animals than is known about the disease in humans. The most common symptom of LB in dogs is migratory arthritis (30) without divergent radiographic findings. Other but less common symptoms reported in dogs are carditis (25), glomerulonephritis (17), and neuritis (2; B. M. Feder, R. J. Joseph, S. D. Moroff, et al., Abstr. Proc. 9th ACVIM, p. 892, 1991). B. bungdorferi infections or serologic evidence of $B$. burgdorferi infections have been reported in dogs in the United States $(3,7,26,29$, $30)$. In Europe, relatively few reports exist on LB in animals. In Sweden (13), Denmark (18), Germany (20, 21, 35, 45, 47), The Netherlands (19), the United Kingdom (32), Belgium (33), France $(9,11,12,14)$, Switzerland (37), Slovakia (43), Slovenia (34), and Spain (10), antibodies to B. burgdorferi and/or clinical symptoms of LB have been found in dogs. However, in Europe, the use of dogs as sentinel animals for the estimation of the risk of Lyme borreliosis for humans in that region has not been examined. Moreover, it has been suggested that in the United States pet ownership increases the risk of getting Lyme disease (K. L. Curran and D. Fish, Letter, N. Engl. J. Med. 320:183,

- Corresponding author. Mailing address: Department of Medical Microbiology, University of Maastricht, P.O. Box 616, NL-6200 MD Maastricht, The Netherlands. Phone: 31.(0)43.388.10.15. Fax: 31.(0)43.388.41.61. E-mail: A.vandenBogaard@cpv.unimaas.nl.
1989), yet in Europe the relationship of dog ownership and an increased risk of Lyme disease for the dog owners has not been studied.

People recreating or working in tick-infested areas like forests show an increased prevalence of antibodies to $B$. burgdor. feri compared to that for controls $(22,23,36)$. Parallel to the findings for people with high levels of outdoor activity, a higher seroprevalence of antibodies $B$. burgdorferi could be expected for hunting dogs compared to that for controls. As dogs could be an intermediary source for human tick infestation, the risk of human Lyme disease could be increased by dog ownership. The aims of the study described here were to evaluate if high levels of outdoor activity can be related to an increased prev. alence of antibodies to $B$. burgdorferi in both hunter and hunting dog populations, to search if dogs in an area of endemicity for LB pose a risk factor for LB for their owners, and to investigate if in The Netherlands the risk for LB in humans can be deduced from the seroprevalence of antibodies against B. burgdorferi among the dog population in the same area.

\section{MATRRIALS AND METHODS}

In the autumn of 1989 at trials for hunting dogs, blood samples were collected from hunters $(n=440)$ and their dogs $(n=448)$. Blood samples from an additional group of hunters who did not own a $\operatorname{dog}(n=53)$ were also included. All participants in the study were asked to fill in a questionnaire about age, tick infestations, and clinical symptoms of LB for both the hunter and the dog. The ages of the 448 hunting dogs ranged from 4 to 120 months, with a mean age of 38 months, and the dogs were of various breeds. In the same year of the trial, blood samples were collected from 75 healthy dogs of various breeds that lived in the countryside, that had no clinical signs of Lyme disease, and that presented at veterinary clinics for their regular vaccinations. The ages of the 75 dogs ranged from 6 to 97 months, with a mean age of 35 months. None of the animals included in this study were vaccinated against $L B$. No vaccine against $L B$ is available in The Netherlands. All sera were stored at $-70{ }^{\circ} \mathrm{C}$ until assayed. Serological testing was used to determine the prevalence of Lyme antibodies in the hunters, hunting dogs, and nonhunting dogs. To exclude differences related to test technology, both human and dog sera were tested in an enryme immunoassay (EIA) system by using the same antigen batch. 
ELISA for human and canine sera. The sera of the hunters were retested for immunoglobulin $G\left(I_{g} G\right)$ antibodies to $B$. burgdorferi, and the results were compared to the previously reported results (36). For the in-house enzymelinked immunosorbent assay (ELISA), the B. burgdorferi B31 strain (ATCC 35210) was used as an antigen. The human and dog sera were tested in an ELISA as described by Craft et al. (8), with minor modifications. Briefly, the spirochetes were grown for 5 to 7 days at $35^{\circ} \mathrm{C}$ in BSK-II medium (modified BarbourStoenner-Kelly medium). The culture was centrifuged $\left(10,000 \times \mathrm{g}, 30 \mathrm{~min}, 4^{\circ} \mathrm{C}\right)$, and the pellets were washed twice in phosphate-buffered saline (PBS; pH 7.2) with $0.005 \mathrm{M} \mathrm{MgCl}_{2}\left(10,000 \times \mathrm{g}, 30 \mathrm{~min}, 4^{\circ} \mathrm{C}\right)$, resuspended in PBS, and sonicated 20 times for $15 \mathrm{~s}$ each time on ice water in a Branson sonicator. ultrasonic processor at the maximum microtip setting. The sonic extract was centrifuged $\left(10,000 \times \mathrm{g}, 30 \mathrm{~min}, 4^{\circ} \mathrm{C}\right)$, and the protein content of the supernatant was determined by a protein assay (Bio-Rad Laboratories, Munich, Germany). The supernatant was divided into aliquots and was kept at $-70^{\circ} \mathrm{C}$. Immunoplates (Polysorp; Nunc, Roskilde, Denmark) were coated with $100 \mu \mathrm{l}$ of sonicated antigen $(2 \mu \mathrm{g} / \mathrm{ml})$ that was diluted in $0.05 \mathrm{M}$ carbonate buffer $(\mathrm{pH} 9.6)$ (15 h, $4^{\circ} \mathrm{C}$ ). Nonspecific binding was blocked with $200 \mu \mathrm{l}$ of $1 \%$ fish gelatin (Sigma, St. Louis, Mo.) in PBS $\left(1 \mathrm{~h}, 22^{\circ} \mathrm{C}\right)$. Test and control sera were diluted 1:100 and 1:250 in PBS with $0.05 \%$ Tween 20 and in $0.5 \%$ fish gelatin for human and canine sera, respectively, and were tested in duplicate $(100 \mu \mathrm{l}$ per well). After $1 \mathrm{~h}$ of incubation at $37 \mathrm{C}, 100-\mu \mathrm{l}$ volumes of peroxidase-conjugated goat anti-human IgG (Kirkegaard \& Perry Laboratories, Ine., Gaithenburg, Md.) and peroxidaseconjugated protein $G$ (Sigma) were added at a dilution of 1:8,000 (in PBS-Tween 20) for human sera and a dilution of 1:10,000 (in PBS-Tween 20) for canine sera, respectively, and the solutions were incubated at $37 \mathrm{CC}$ for $30 \mathrm{~min}$. Between all steps, the plates were washed in a Microplate washer (Flow Laboratories, Glasgow, Scotland) on a three-wash cycle with PBS-Tween 20 used as a washing buffer. As a substrate, $100 \mu \mathrm{l}$ of ready-to-use tetramethylbenzidine (D-tek, Mons, Belgium) was used. The optical density (OD) at $405 \mathrm{~nm}$ was read in a Titertek Multiskan apparatus (ICN Pharmaceuticals Inc., Irvine, Calif.). The time of the substrate reaction was set to 15 min and was stopped with tetramethylbenzidine stop solution (D-tek)

Standardization of the human and canine Lyme disease E.A. For the human Lyme disease EIA, 25 serum samples from patients with clinically defined late Lyme disease, 100 serum samples from blood donors, and 100 serum samples from patients with diseases that clinically mimic Lyme disease were used to determine the cutoff, which was 0.300 OD unit. For the canine Lyme disease EIA, sera from 105 dogs from an experimental animal facility that had never been exposed to ticks ( 5 of which, however, had been hyperimmunized against leptospirosis) were used to determine the cutoff for a positive reaction. A mean OD and standard deviation (SD) of the mean were calculated for the 105 negative canine serum samples and were used to determine the cutoff value, which was $0.250 \mathrm{OD}$ unit. In the B. bundorferi EL.ISAs, commonly 2 times (8) or 3 times (28) the SD above the mean for a group of negative controls is used as a cutoff value (31). This might, however, vary between laboratories. To determine the cutoff levels for a positive canine Lyme disease test result, a mean OD ratio and SD of the mean were calculated for the 105 negative serum samples which had the same serum dilution as the test sera. To ensure the reproducibility of the test, all the sera included in the serosurvey were tested with the same batch of antigen. The best reproducibility was obtained when 3 SDs was used as the cutoff, because $98 \%$ of the canine serum samples were consistently either positive or negative by both tests. If, on the other hand, a 2-SD cutoff was used, only $86 \%$ of the canine serum samples were repeatedly positive or negative. Of the canine sera, which additionally became positive when the cutoff was lowered, $82 \%$ were borderline sera: i.e., when the same sera were tested repeatedly, they gave various results, either positive or negative. This led to a much poorer reproducibility of the test. On the basis of these results, the cutoff between a positive test result and a negative test result was set at $3 \mathrm{SD}$ above the mean $O D$ for the negative canine control serum samples, and a seropositive animal was defined as one that had an OD ratio above this calculated cutof value.

Control sera. For the human Lyme disease EIA, sera with negative, cutoff, and positive values were tested in duplicate on each plate. For the canine Lyme disease EIA, a pool of sera from three dogs hyperimmunized with sonicated B. burydorferi ATCC 35210 antigen was used as a positive control. These dogs had been immunized subcutaneously with L.B antigen in an adjuvant mixture of water in the mineral oil Specol (4) (ID-DLO, Zelystad, The Netherlands) and were boostered after 4 weeks with $B$. bundorferi antigen in PBS. The antibody response against L.B was confirmed by Western blotting. One week after the last immunization, blood was collected from the animals and the serum was stored at $-70^{\circ} \mathrm{C}$ until it was assayed. The immunized animals had an antibody titer of 51,200 (reciprocal dilution) in the ELISA and were pooled for use as positive control serum. No background reaction was observed for the positive control
TABLE 1. Prevalence of $\mathrm{IgG}$ antibodies to $B$. burgdorferi in hunters, by age, with or without ownership of hunting dogs

\begin{tabular}{crcccc}
\hline & \multicolumn{4}{c}{ No. (\%) of hunters } \\
\cline { 2 - 3 } Age $(y r)$ & \multicolumn{2}{c}{$\begin{array}{c}\text { Hunters with } \\
\text { hunting dogs }\end{array}$} & & \multicolumn{2}{c}{$\begin{array}{c}\text { Hunters without } \\
\text { hunting dogs }\end{array}$} \\
\cline { 2 - 3 } \cline { 5 - 7 } & Total & Seropositive & & Total & Seropositive \\
\hline $9-30$ & 86 & $6(7)$ & & 16 & $1(6)$ \\
$31-40$ & 145 & $18(12)$ & & 10 & $1(10)$ \\
$41-50$ & 128 & $26(20)$ & & 11 & $2(18)$ \\
$>50$ & 81 & $18(22)$ & & 16 & $3(19)$ \\
& & & & & \\
Total & 440 & $68(15)$ & & 53 & $7(13)$ \\
\hline
\end{tabular}

serum in control wells, which were blocked with 1\% fish gelatin (Sigma) in PBS. Sera taken before and after immunization of these dogs were also tested for antibodies against Leptospina intemogans serovar hardjo (macroscopic agglutination test, internal house test) and $L$. internogans serovar icterohaemorrhagiac (macroscopic agglutination test, internal house test) and for Treponema pallidum antibodies (Fujirebio, Tokyo, Japan); all sera were negative.

A pool of sera from 10 experimental dogs negative for $B$. burgdorferi antibodies (Vet Lyme Borreliosis EIA; Genxyme-Virotech, Ruesselsheim, Germany) was used as a negative control.

To eliminate plate-to-plate variation, the ELISA result was expressed as an $O D$ ratio, i.e., the ratio of the mean $O D$ for a test serum sample to the mean $O D$ for the serum sample with the cutoff value on the same plate. While testing the dog sera these positive and negative samples and a diluted positive control serum sample with the predefined cutof value were tested on each plate. The mean $O D$ value was calculated for each duplicate serum sample. Human or canine sera were retested if the OD values for the duplicates differed by more than $10 \%$ from the mean.

Statistical Analysis. Paired data were compared by McNemar's test, assuming a binomial distribution of the data. Nonpaired data were compared by using the chi-square test.

\section{RESULTS}

The results of the testing of the hunters, as previously described by Nohlmans et al. (36), showed no significant differences compared to those of the current tests. Briefly, the prevalence of IgG antibodies against $B$. burgdorferi among owners of working hunting dogs $(n=440)$ was significantly higher $(15 \%)$ than that among healthy blood donors $(n=1,052)$ matched for the same age ( $9 \%$ ). In both groups the prevalence of seropositivity increased with age, but in hunters older than 40 years it remained relatively constant, as shown in Table 1. Only $3 \%$ of the hunting dog owners could recall having had symptoms most likely to be due to LB. Of the $68 \%$ seropositive hunters, $64(94 \%)$ were asymptomatic. As shown in Table 1, the rate of seropositivity among the hunters increased with increasing age: from $7 \%$ for those $<31$ years of age to $20 \%$ for those $>40$ years of age $(P<0.005)$. Among the hunters older than 40 years, the seroprevalence no longer rose significantly and remained constant at approximately $20 \%$.

As listed in Table 2, antibodies against B. burgdorferi were detected in $18 \%$ ( $95 \%$ confidence interval, 14.4 to 21.4 ) of the hunting dogs and $17 \%$ (95\% confidence interval, 8.5 to 25.5 ) of the pet dogs. Hunting dogs older than 24 months appeared to have a greater risk of being exposed $(22 \%)$ than younger hunting dogs $(9$ to $11 \%)(P<0.05)$, but the seroprevalence among hunting dogs remained stable at approximately $22 \%$ among animals over 24 months of age (Table 2). In a comparison of the age distribution of seropositive hunting dogs and the total hunting dog population, no significant differences were ob- 
TABLE 2. Prevalence of antibodies to $B$. burgdorferi among hunting and nonhunting dogs, by age

\begin{tabular}{|c|c|c|c|c|}
\hline \multirow{3}{*}{$A_{\theta e}(\mathrm{mo})$} & \multicolumn{4}{|c|}{$\mathrm{Na}$ (\%) of dogs } \\
\hline & \multicolumn{2}{|c|}{ Hunting dops } & \multicolumn{2}{|c|}{ Nonhunting dog } \\
\hline & Total & Seropositive & Total & Seropositive \\
\hline $6-12$ & 56 & $5(9)$ & 11 & $1(9)$ \\
\hline $13-24$ & 125 & 15 (11) & 19 & $3(16)$ \\
\hline $25-36$ & 85 & $19(22)$ & 11 & $2(18)$ \\
\hline $37-48$ & 73 & $16(22)$ & 15 & $3(20)$ \\
\hline $49-120$ & 109 & $25(23)$ & 19 & $4(21)$ \\
\hline Total & 448 & $80(18)$ & 75 & $13(17)$ \\
\hline
\end{tabular}

served except among the hunting dogs ages 60 to 70 months and younger than 12 months $(P<0.05)$.

When we compared the seroprevalence of antibodies against B. burgdorferi for the hunting dog population with that for the nonhunting dog population, no significant differences were seen for all age groups listed. Eleven $(14 \%)$ of the 80 seropositive hunting dogs showed signs of lameness and were older than 24 months, with a mean age of 46 months. Eight $(72 \%)$ of the 11 hunting dogs that had been suffering from migratory lameness had a history of regular tick infestations, whereas ticks had seldom been spotted on the other three dogs by their owners. Ticks had regularly been removed from $53(66 \%)$ of the 80 seropositive hunting dogs and $217(59 \%)$ seronegative hunting dogs. Most of the seropositive hunting dogs $(86 \%)$ had not shown any clinical symptoms that could be attributable to LB, and only $11(14 \%)$ had recently suffered from intermittent lameness, a clinical symptom that could be attributed to LB. Of the 217 seronegative hunting dogs, $36(17 \%)$ had recently shown signs of lameness. All seropositive pet dogs were healthy, without any clinical signs pointing to LB. As shown in Tables 1 and 2, the prevalences of seropositive hunters (15\%; $95 \%$ confidence interval, 11.7 to 18.3 ) and hunting dogs (18\%; $95 \%$ confidence interval, 14.4 to 21.4 ) were not significantly different. However, if the results of the EIAs were matched between the dog and the dog owner, the prevalence of seropositivity among the hunters was significantly different $(P<$ $0.001)$ from the prevalence of seropositivity among their hunting dogs. In only $12 \%$ of the hunter-dog pairs was a match of seropositivity observed. The seroprevalence among hunters with or without dog ownership was not significantly different.

\section{DISCUSSION}

Outdoor activity as a risk factor for Lyme disease? The seroprevalence of antibodies against B. burgdorferi among hunting dogs and hunters in this study is higher than that among healthy blood donors $(9 \%)$ in The Netherlands but is of the same order as the seroprevalence among Dutch forestry workers ( 20 to $24 \%$ ), as described by Kuiper et al. (22). In contrast, a significantly lower seroprevalence in Dutch soldiers $(0.9 \%)$ conducting predominantly outdoor activities in areas of endemicity for ticks has been reported (44). The most likely explanation for the lower seroprevalence among Dutch soldiers is the fact that soldiers must wear a special uniform during field training: long sleeves, long pants, and high boots. This uniform is different from and much more protective against tick infestations than the clothes worn by most other people involved in recreational or occupational outdoor activities, especially during warm weather conditions. However, despite the observed similar seroprevalence among dogs and hunters in this study, the hypothesis of Eng et al. (T. R. Eng, M. L. Wilson, A. Spielman, and C. C. Lastavica, Letter, J. Infect. Dis. 158:1410-1411, 1988) that dogs have a greater risk of $B$. burg. dorferi infection than people is endorsed by the results of this study, as dogs stay seropositive for a much shorter period of time after an infection with $B$. bungdorferi. Because seropositivity seemed to last for only approximately 1 year, the seroprevalence in dogs in fact is more or less identical to the yearly incidence of infections with $B$. bungdorferi in dogs. Surprisingly, although it was supposed that hunting dogs have an increased risk of tick infestation compared to the risk for other dogs, no significant differences in seroprevalences between the hunting dog and the pet dog populations were found. These findings are in contrast to the seroprevalence among hunting dogs $(40 \%)$ in the Slovak Republic (43), which was significantly higher than the seroprevalence among service dogs $(12 \%)$. The lower seroprevalence among Slovakian service dogs could be explained by the residence of watchdogs in more strictly home environments and the rate of outdoor walking compared to the rate of outdoor walking of house dogs in The Netherlands, where it is higher. The breed of dog supposed as a proxy for occupational or recreational exposure did not influence the seroprevalence in our study, as the biotopes for the dog populations examined could be considered the same.

Dynamic of antibody response to $B$. burgdorferi in humans and dogs. Age as a proxy for the cumulative duration of exposure was demonstrated in this study by the increasing rate of seropositivity with the increasing age of the dogs, but after an age of 24 months no significant increase in age-specific seropositivity was found, although a continuous risk of exposure to $B$. burgdorferi exists. In contrast to the human immunological response, in whom IgG antibodies to $B$. burgdorferi can persist for several years, the findings of the present study are in concordance with previous findings that the seroprevalence in dogs remains relatively stable after 2 years of age $(27,38)$. Our study also strengthens the view of Hovius et al. (19) that a yearly reinfection is necessary to maintain seropositivity. Also in humans, seropositivity is certainly not lifelong, as shown by the incidence rates in hunters of different age groups. Because the period of seropositivity in humans after an infection with $B$. burgdorferi is much longer than that in dogs, the incidence of infection of the dogs in this study is certainly higher than that in humans, as was to be expected. Furthermore, these findings could be considered the same for test systems with isolates other than B31. The use of isolates representative of B. burgdorferi sensu lato in European Lyme disease serology showed no improvement of test performance but indicated only a predictive value for human clinical cases $(6,16,46)$.

Dogs and their validity as sentinel animals. The dog has been proposed for use as a sentinel animal for detection of the risk of $B$. burgdorferi infection in humans. Dogs exposed to infected ticks develop antibodies to the spirochete, and dogs are more likely than people to be exposed to infected ticks because their behavior brings them into direct and closer contact with tick habitats like brush. Moreover, ticks can easily hide in the hair coats of dogs and dogs are not protected 
against tick infestation by clothing like hunters are. Although it was expected that dogs were frequently bitten by ticks more often than hunters were, the seroprevalence of antibodies against $\boldsymbol{B}$. burgdorferi in hunters and hunting dogs was of the same order in the present study. This indicated that estimates of seroprevalence among hunting dogs are predictive of the risk of LB in humans. This finding was supported not only by the overall seroprevalence but also by the fact that no significant variation was seen when the seroprevalences for hunters and hunting dogs from the same regions were compared (data not shown). The use of dog sera to detect and quantify the risk of Lyme disease for humans in a certain region is more sensitive than the use of reports of incident human clinical cases but is not more sensitive than the use of seroprevalence in humans. The use of dog sera, however, has the advantage that the seroprevalence among dogs is more likely to reflect the actual environmental risk of Lyme disease because of the short halflife of canine antibodies against B. burgdorferi. This study shows that the risk factors identified for dogs may directly or indirectly illuminate certain aspects of the epidemiology of human Lyme disease. Nonetheless, one should be aware that it is very difficult to standardize canine Lyme disease tests due to the lack of indisputable clinically defined cases of Lyme disease. Most studies use panels of canine sera reactive by other tests as a reference, but this is not a real "gold standard." A serum sample can be regarded as a gold standard when clinically it is indisputably related to Lyme disease and when the presence of $B$. burgdorferi has been demonstrated. Therefore, to circumvent the problem of disputable reference sera, this study used the sera of dogs vaccinated with $B$. burgdorferi for the tuning of the linear response range of the test. For the cutoff determination, the mean OD for a dog population considered negative for Lyme disease and a population considered possibly cross-reactive to Lyme disease (hyperimmunized against leptospirosis) was used. Although this method is acceptable for seroepidemiological studies, this is not the ideal way and panels of an acceptable number of indisputably defined sera from dogs with Lyme disease should be made available for future test development. Parallel to the findings for human Lyme disease serology, that exclusion of diseases that mimic Lyme disease is a better approach than confirmation of Lyme disease by Western blotting (16), such an approach should be taken into consideration for future multiple test approaches for canine Lyme disease serology.

Dog ownership as a risk factor for Lyme disease? In contrast to a single publication that cat ownership (two case reports) seemed to increase the risk of Lyme disease (Curran and Fish, letter, 1989), the seropositivity of the hunting dogs was not an indicator for an increased risk of $B$. burgdorferi infection for their owners. Only $12 \%$ of the seropositive hunters had hunting dogs which were also seropositive. Moreover, hunters without dog ownership showed no significantly lower rates of seropositivity. Therefore, on the basis of the findings of our study, ownership of dogs with increased risk of infection could not be associated with a higher risk of human Lyme disease, as described for dogs living in regions of endemicity by Eng et al. (Eng et al., letter, 1988) and Cimmino et al. (M. A. Cimmino and D. Fumarola, Letter, JAMA 262:2997-2998, 1989). Humans and dogs seem to be independently infected.
Conclusion. The evolution of a Lyme disease focus might occur quickly $(24,39)$, which causes the need for a surveillance method capable of detecting changes in exposure to the pathogen. Dog serum samples can be used for this purpose, but they are not more sensitive than those of people with comparable exposures, such as hunters and forestry workers. However, because of the shorter period of seropositivity after infection, the seroprevalence among dogs is more indicative of recent exposure than the observed prevalence among humans. Dog ownership causes no increased risk for human Lyme disease.

\section{REFERENCES}

1. Ackermann, R., J. Kabatzki, H. P. Boisten, A. C. Steere, R. L. Grodxicki, S. Hartung. and U. Runne. 1984. Ixodes ricinus spirochete and European erythema chronicum migrans disease. Yale J. Biol. Med. 57:573-580.

2. Aruma, Y., K. Kawamura, H. Isogai, and E. Isogai. 1993. Neurologic abnormalities in two dogs suspected Lyme discase. Microbiol. Immunol. 37:325329.

3. Barthold, S. W., S. A. Levy, E. Fikrie. L K. Bockenstedt, and A. L. Smith. 1995. Serologic responses of dogs naturally exposed to or vaccinated against Borrelia burgdorferi infection. J. Am. Vet. Med. Assoc. 207:1435-1440.

4. Bokhout, B. A., C. Van Gaalen, and P. J. Van der Hejjen. 1981. A selected water-in-oil emulsion: composition and usefulness as an immunological adjuvant. Vet. Immunol. Immunopathol. 2:491-500.

5. Burgderfer, W., A. G. Barbour, S. F. Hayes, J. L. Benach, E. Grunwaldt, and J. P. Davis. 1982. Lyme disease: a tickborne spirochetosis? Science 216: 1317-1319.

6. Busch, U., C. Hizoteufel, R. Boehmer, V. Fingerle, H. Nitschko, B. Wilske, and V. Preacmursic. 1996. Three species of Bomelia burgdorferi sensu late ( $\boldsymbol{B}$. burgdorferi sensu stricto, $\boldsymbol{B}$. afzelii, and $\boldsymbol{B}$. garinii) identified from cerebrospinal fluid isolates by pulsed-field gel electrophoresis and PCR. J. Clin. Microbiol. 34:1072-1078.

7. Coben, N. D. C. N. Carter, M. A. Themas, Jr., A. B. Angulo, and A. K. Eugster. 1990. Clinical and epizootiologic characteristics of dogs seropositive for Borrelia burgdorferi in Texas: 110 cases (1988). J. Am. Vet. Med. Assoc. 197:893-898.

8. Craft, J. E., R. L. Grodzicki, and A. C. Steere. 1984. Antibody response in Lyme disease: evaluation of diagnostic tests. J. Infect. Dis. 149:789-795.

9. Davoust, B., and M. Boni. 1998. Lyme-disease in dogs-seroepidemiological survey in the south-east of France. Med. Mal. Infect. 28:408-409.

10. Delgado, S., and P. Carmenes. 1995. Seroepidemiological survey for Borrelia burgdorferi (Lyme disease) in dogs from northwestern of Spain. Eur. J. Epidemiol. 11:321-324.

11. Doby, D. M., S. Chevrier, and A. Couatarmanach. 1988. Tickborne Borrelia burgdorferi infection in dogs in western France. Systematic serological survey of 806 hunting dogs and 88 military dogs in 14 departments. Rec. Med. Vet. 164:367-374.

12. Doby, J., S. Chevrier, and A. Couatarmanach. 1988. La spirochetose a tiques par Borrelia burgdorferi chez les chiens dans louest de la France. Rec. Med. Vet. 164:367-374.

13. Egenvall, A., B. N. Bonnett, A. Gunnarsson, A. Hedhammar, M. Shoukri, S. Bornstein, and K. Artursson. Sero-prevalence of granulocytic Ehrlichia spp. and Borrelia burgdorferi sensu lato in Swedish dogs 1991-94. Scand. J. Infect. Dis. 32:19-25.

14. Euxeby, J. P., and A. Raff. 1988. Demonstration of antibodies to Borrelia burgdorferi in dogs: epidemiologica survey in the central Pyrenees region. Rev. Med. Vet. 139:589-593.

15. Gern, L., A. Estrada-Pena, F. Frandsen, J. Gray, T. Jaenson, F. Jongejan, O. Kahl, E. Kerenberg, R. Mehl, and P. Nuttall. 1998. European reservoir hosts of Borrelia burgdorferi sensu lato. Zentbl. Bakteriol. Parasitenkd. Infektkrankh. Hyg. Abt. 1 Orig. 287:196-204.

16. Geossens, H. A. T., A. E. van den Bogaard, and M. K. E. Nohlmans. 1999. Evaluation of fifteen commercially available serological tests for diagnosis of Lyme borreliosis. Eur. J. Clin. Microbiol. Infect. Dis. 18:551-560.

17. Grauer, G. F., E. C. Burgess, A. J. Cooley, and J. H. Hagee. 1988, Renal lesions associated with Borrelia burgdorferi infection in a dog. J. Am. Vet. Med. Assoc. 193:237-239.

18. Hansen, $\mathbf{K}$., and $\mathbf{H}$. Dietz. 1997. Serosurvey for antibodies to Borrelia burgdorferi in Danish dogs. APMIS 97:281-285.

19. Hevius, K. E., S. G. Rijpkema, P. Westers, B. A. M. van der Zejist, F. J. A. M. van Asten, and D. J. Houwers. 1999. A serological study of cohorts of young dogs naturally exposed to Lodes ricinus ticks, indicates seasonal reinfection by Borrelia burgdorferi sensu lato. Vet. Q. 21:16-20.

20. Kasbohrer, A., G. Liebisch, A. Schonbere, and A. Liebisch. 1994. Serodiagnosis of Lyme borreliosis development and evaluation of a test system for epidemiological studies in the dog. DTW. Dtsch. Tierarzt. Wochenschr. 101: 476-481.

21. Kasbohrer, A. and A. Schonbere. 1990 . Serologic studies of the occurrence 
of Borrelia burgdorferi in domestic animals in Berlin (West). Bert. Munch. Tierarat. Wochenschr. 163:374-378.

22. Kuiper, H. B. M. de Jongh, A. P. Nauta, H. Heuweling, L. G. Wiessing, A. W. van Charante, and L. Spanjaard. 1991. Lyme borrelioxis in Dutch forestry worken. 1. Infect. $23.279-286$.

23. Kuiper, H., A. P. van Dam, A. W. Mell van Charante, N. P. Nauta, and 1. Dankert. 1993. One year follow-up study to assess the prevalence and incidence of Lyme borreliosis among Dutch forestry workers. Eur. J. Clin Microbiol. Infect. Dis 12:413-418.

24. Lastavica, C. C. M. L. Wilson, V. P. Berardi, A. Spielman, and R. D. Deblinger. 1989. Rapid emergence of a focal epidemic of Lyme disease in coastal Massachusetts N. Engl. J. Med. 320:133-137.

25. Ley, S. A, and P. H. Duray. 1988. Complete heart block in a dog seropos. itive for Borrelia burgdorferi. Similarity to human Lyme carditis. J. Vet. Intern. Med. 2:138-144.

26. Len, S. A., and L A. Magnarelli. 1992. Relationship between development of antibodies to Borrelia burgdorferi in dog and the subsequent develop. ment of limbjoint borreliosis J. Am. Vet. Med. Assoc. 200:344-34t

27. Lindenmayer, J. M. D. Marshall, and A. B. Onderdenk. 1991. Dogs as sentinels for Lyme discase in Massachusetts. Am. J. Public Health 81:14481455.

28. Magnarelli, L A, and J. F. Anderson. 1989. Class-specific and polyvalent enryme-linked immunosorbent assays for detection of antibodies to Borrelia burgdorferi in equids. J. Am. Vet. Med. Assoc. 195:1365-1368.

29. Magnarelli, L A., J. F. Andersen, A. F. Kaufmann, L. L. Lieberman, and G. D. Whitne, 1985. Borreliosis in dogs from southem Connecticut. J. Am. Vet. Med. Assoc. 186:-955-959.

30. Magnarelli, L. A. J. F. Anderson, A. B. Schreier, and C. M. Ficke. 1987. Clinical and serologic studies of canine borreliosis. J. Am. Vet. Med. Assoc. 191:1089-1094.

31. Magnarelli, L. A., J. M. Meegan, J. F. Andersen, and W. A. Chappell. 1984. Comparison of an indirect fluorescent-antibody test with an enryme-linked immunosorbent assay for serological studies of Lyme disease. J. Clin. Mi. crobiol. 20:181-184.

32 May, C., S. Carter, A. Barnes, S. Bell, and D. Bennett. 1991. Serodiagnosis of Lyme discase in U. K. dogs. J. Small Anim. Pract. 32:170-174.

33. MeKenna, P. J. Clement, D. Van Dück, M. Lauwerys, D. Carey, T. Van den Bogaard, and G. Bizaignen. 1995. Canine Lyme discase in Belgium. Vet. Rec. 136:244-247.

34. Mehle, J. 1996. Lyme borreliosis in animals. Vet. Nov. 22:179-183,
35. Muller, E. 1994. Borreliosis bei Hunden Klinische und serologische Befunde. Kleintierpraxis 39:375-380.

36. Nohtmans, M. K., A. E. vas den Bogaard, A. A. Blaauw, and C. P. van Boren. 1991. Prevalence of Lyme borreliosis in The Netherlands Ned. Tijdschr. Geneeskd. 135:2285-2202.

37. Ptister, K. B. Bigler, J. Neswadba, L. Gern, and A. Aeschlimana. 1980. Borrelia buredorferi infections of dogs in Switzerland. Zentbl. Bakteriol. Parasitenkd. Infektkrankh. Hye, Abc. 1 Orie. 18:26-31.

38. Schutes, T. L., E. M. Bosler, J. K. Shisler, L. C. Ware, M. F. Lakat, and W. E. Parkin. 1986. Prevalence of canine Lyme discase from an endemic area as determined by seroservey. Zenthl. Bakteriol. Parasitenkd. Infektkrankh. He. Abt 1 Orie. Reihe A 260:427-434.

39. Schulte, T. L., J. K. Stister, E. M. Besler, M. F. Lakat, and W. E. Parkin. 1986. Evolution of a focus of Lyme discase. Zentbl. Bakteriol. Parasitenkd. Infektikrankh. Hyg. Abt. 1 Orieg, Reihe A 263:65-71.

40. Steere, A. C. 1980. Lyme discase. N. Engl. J. Med. 321:586-596,

41. Steere, A. C., R. L. Grodzicki, A. N. Kernblatt, J. E. Craf, A. G. Barbeur, W. Burgderfer, G. Schmid, E. Johnsee, and S. E. Malawista. 1983. The spirochetal etiology of Lyme discase. N. Enel. J. Med. 308:730-739.

42. Steere, A. C., S. E. Malawista, N. I. Bartenhagen, P. N. Spieler, J. II Newman, D. W. Rahn, G. J. Hutchinson, J. Green, D. R. Snydman, and E. Tayler. 1984. The dinical spectrum and treatment of Lyme disease. Yale J. Biol. Med. 57,453-464.

43. Stefancikeva, A., L. Skardeva, B. Pet'ka, D. Janevska, and V. Cypricheva. 1996. IgG antibodies to Borrelia in dogs in the area of Kosice. Vet. Med Praha 41:83-86.

44. Vos, K., A. P. Van Dam, H. Kuiper, I. Bruins, L. Spanjaard, and J. Dankert. 1994. Seroconversion for Lyme borreliosis among Dutch military. Scand. J. Infect. Dis 26:427-434.

45. Weber, A., U, Beim, and R. Schafer, 1091, Incidence of antibodies to Bor relia burgdorferi in dog in small animal practice in North Bavaria. Bert. Munch. Tierarzt. Wochenschr. 1042384-386.

46. Wilske, B., U, Busch, H. Eiffert, V. Fingerle, II. W. Phster, D. Rossler, and v. Preacuursic. 1996. Divensity of OspA and OepC among cerebrospinal fluid isolates of Borrelia burgdorferi sensu lato from patients with neurobor reliosis in Germany. Med. Microbiol. Immunol. 184:195-201

47. Wittenbrink, M. M., K. Failing, and II. Krauss. 1906. Enryme-tinked immunosorbent assay and immunoblot analysis for detection of antibodies to Borrelia burgdorferi in dogs. The impact of serum absorption with homologous and heterologous bacteria. Vet. Microbiol. 48:257-268. 



\section{Chapter VI}

\section{DEVELOPMENT OF A SPECIES INDEPENDENT EIA FOR THE ESTIMATION OF THE PREVALENCE OF ANTIBODIES AGAINST B. BURGDORFERI IN DUTCH DOGS.}

H.A.T. Goossens, J.H.J Maes, A.E. van den Bogaard

Department of Medical Microbiology, University Maastricht

Accepted for Nederlands Tijdschrift voor Diergeneeskunde 2002 



\title{
Development of a species independent EIA for the estimation of the prevalence of antibodies against $B$. burgdorferi in Dutch dogs.
}

\author{
H.A.T. Goossens, J.H.J. Maes, A.E. van den Bogaard (*) \\ Department of Medical Microbiology, University of Maastricht, \\ NL-6200 MD Maastricht, The Netherlands \\ Accepted for publication, Nederlands Tijdschrift voor Diergeneeskunde 2002
}

\begin{abstract}
Five serological tests for the detection of IgM and IgG antibodies to Borrelia burgdorferi sensu stricto were compared in 1177 sera from Dutch dogs: 401 healthy working hunting dogs, 100 healthy city pet dogs, 629 city dogs with various clinical symptoms and 47 hunting dogs with lameness. The results of the in-house species independent enzyme immunoassay (i.e. an EIA which can be used to test serum samples from different animal species) showed a strong agreement (kappa: 0.78-0.81) with the experimental and commercially available enzyme immunoassay (Genzyme -Virotech, Germany) for the detection of canine IgG antibodies to Borrelia burgdorferi and could be very useful in seroepidemiological studies for detecting antibodies in various animal species. Furthermore, sensitivity of the in-house enzyme immunoassays for the detection of antibodies to Borrelia burgdorferi showed to be independent of the antigen used. Serological diagnosis of Lyme borreliosis in Dutch dogs with lameness $(n=60)$, neurological $(n=60)$ and skin disorders $(n=52)$ was not affected by the antigenic heterogeneity. The indirect hemagglutination assay (Diagast, France) proved to be an interesting tool for the detection of an acute Lyme infection in dogs because of its high sensitivity for $\mathrm{IgM}$ antibodies. Dog sera with a high $\mathrm{IgM}$ response to Borrelia burgdorferi were identified in $96 \%$ of the cases by the indirect hemagglutination assay. However, in this study a positive serological result could not be linked to any clinical symptom that has been related to Lyme disease; neither for dogs at high risk or at low risk of a Borrelia burgdorferi infection. Therefore the use of serodiagnostic tests to support the clinical diagnosis of Lyme disease in dogs might be of limited value. Nevertheless the species independent enzyme immunoassay could be valuable in seroepidemiological studies where sera of several different animal species have to be tested.
\end{abstract}

Lyme borreliosis (LB) is a bacterial infection that affects both man and animals and that is transmitted by hard ticks of the genus Ixodidae. Steere showed that an epidemic of "Lyme arthritis" in children from the township Old Lyme in Connecticut, USA was caused by tick bites. In 1981, the causative micro-organism, the spirochete Borrelia burgdorferi, was discovered in Lxodes scapularis ticks by Burgdorfer $(1,2)$. Subsequent investigations revealed that the illness had been present for many years before its recognition and that it is world-wide in its distribution. Serologic surveys indicated that many animal species, including dogs, have antibodies to $B$. burgdorferi (3). Although surveys detected antibodies against B. burgdorferi in up to $90 \%$ of dog sera in endemic areas in the USA (4-15) and up to $27 \%$ in

- Corresponding author. Mailing address: Department of Medical Microbiology, University of Maastricht, P.O. Box 616, NL-6200 MD Maastricht. The Netherlands. Phone: $+31 .(0) 43.388 .10 .15$. Fax: +31.(0)43.388.41.61. E-mail: A.vandenBogaard@cpv.unimaas.nl
Europe (16-24), only approximately $5 \%$ of these animals were suspected to suffer from LB.

As with the CDC criteria for the diagnosis of LB in humans (25) a putative diagnosis of LB can be obtained by applying inclusion and exclusion criteria: 1. the presence of typical clinical symptoms, 2. exclusion of other diseases in the differential diagnosis of these symptoms, 3. tick infestation in the anamnesis, 4. residence in an endemic area, 5. the presence of specific antibodies to $B$. burgdorferi and 6. a positive clinical response to an adequate antibiotic therapy.

In dogs lameness combined with malaise is considered the most prevalent clinical symptom of LB $(26,27)$. The lameness is often intermittent and either an extreme claudication with localisable swollen painful joints without any abnormalities on radiographs or a stiff gait without a clear localisation of the pain $(28,29)$. The malaise may be caused by fever resulting in listlessness or inappetance (27). In the USA Lyme-nephritis, a proliferative glomerulonephritis with tubulonecrosis and lymphoplasmatic infiltration, has been described $(30,31)$. 
Other clinical manifestations in the dog attributed to LB are lethargy, lymphadenopathy, and heart block (28, 32, 33). Genetic susceptibility, immune complex reactions, or repeated exposures to the agent via tick bites may all be factors that determine whether a dog will develop clinical signs. In humans, skin biopsies from the border of the erythema migrans lesion are nearly always culture positive for $B$. burgdorferi (34). Unfortunately such a clear pathognomonic clinical symptom as erythema migrans is lacking or very hard to identify in dogs, which makes it more difficult to isolate $B$. burgdorferi. Furthermore culturing $B$. burgdorferi is a cumbersome technique not readily available in most clinical situations.

LB is a difficult disease to diagnose, which is complicated by several factors inherent to tests intended to detect specific serum antibodies or DNA fragments of B. burgdorferi. Detection of the causative micro-organism with PCR is more sensitive than culturing and is $100 \%$ specific after experimental infections. However PCR lacks the necessary sensitivity for diagnostic purposes because of sample bias resulting from the uneven distribution of Borrelia throughout biopsy specimens (35. 36) and it does not only detect vital infecting organisms, but also DNA leftovers of the causative spirochetes in recovered subjects (37), Still, in human cases, PCR has demonstrated the link between the different clinical manifestations of LB to infections with certain species. The genospecies found to predominate early and late skin borreliosis was $B$. afzelii, while $B$. garinii, predominated in neuroborreliosis. However in Europe, B. burgdorferi sensu lato strains causing Lyme arthritis in humans are very heterogeneous $(38,39)$. Nonetheless more recently published studies demonstrated a preponderance of $\boldsymbol{B}$. burgdorferi sensu stricto DNA in joint samples from Dutch human Lyme arthritis patients (40). It was also demonstrated that European Lyme arthritis in humans is preferentially, but not exclusively caused by $B$. burgdorferi sensu stricto (41). In how far these findings could be taken for dogs is unknown.

Serological diagnosis is always a balance between sensitivity and specificity of the assays, which depend on the choice of cut-off level. In analogy to the guidelines of the European Union Concerted Action on human Lyme Borreliosis (42), a minimum specificity of at least $90 \%$ should be aimed at for screening tests. The cut-off level giving such a specificity should be established in at least 100 serum samples from healthy patients. A complete evaluation of the assay should include validation of the recommended cut-off level in the population where the assay is to be used and performance of the assay should be investigated with samples of patients with diseases known to cross-react with LB or disorders known to cause false positive reactions. Serodiagnosis in canine LB may be hampered by other spirochetal organisms, e.g. Leptospira internogans or Escherichia coli $(43,44)$. However the assumption that leptospires cross-react in conventional EIA's for antibodies to B. burgdorferi have not been substantiated in the published literature and disorders like periodontal disease caused by Treponema spp (45) which could cause false positive results are very uncommon in Dutch dogs. Furthermore in dogs there is only little knowledge about the normal background level of naturally occurring cross-reacting antibodies to $B$. burgdorferi. The facts that in the Netherlands only a few clinical confirmed cases of canine LB have been reported and that most seropositive dogs are asymptomatic makes it difficult to specify the performance of the test, even impossible to estimate the positive and negative predictive value of the test results. Despite these shortcomings, the whole cell enzyme immunoassay (EIA) is the test most commonly used for the detection of antibodies against $\boldsymbol{B}$. burgdorferi in animals and man, and has a sensitivity of $100 \%$ after experimental infection. In epidemiological studies the sensitivity of this test is lower, but has been enhanced by enrichment of the cell lysate with flagellin or surface proteins specific for LB (46-48). In several studies the sensitivity of EIA tests was shown to be comparable or even superior to immunofluorescent assays (IFA) (49-51). The indirect hemagglutination antibody assay (IHA) is a polyvalent test able to detect B. burgdorferi antibodies of both IgM and IgG isotypes in virtually any mammalian species. In human LB serology, IHA could be considered as a first-step test analogous to the current EIA and IFA detection systems. Compared to the EIA, IHA shows a slightly better sensitivity for the detection of antibodies to B. burgdorferi in early LB patients (52). This is because the IHA is much more sensitive for IgM than for IgG. Therefore the overall performance of the IHA in human LB is variable. In a comparative study it was shown by our group (53), that the IHA had a considerable lower sensitivity compared to EIA for detection of IgG in sera, that consisted mainly of late lyme borreliosis patients. Immunoblotting, a technique where antibodies to single $B$. burgdorferi antigens can be identified, is often used as confirmation of serological reactivity. However the interpretation of immunoblot patterns is an area of controversy with many different schemes available, resulting in discrepant sensitivity and specificity in human serology. No interpretation criteria for immunoblots of canine sera have been published. To date, no generally accepted test is able to differentiate between past or subclinical infection and active disease in humans or dogs. Recently a few publications in which the detection of borreliacidal-antibodies correlated with active clinical disease in humans and dogs have been published (54-56). However these results have to be evaluated and this test is difficult to perform and not readily available in most clinical situations.

Because of their ease of performance and low production and analysis costs, the EIA test is the laboratory test most used for the serodiagnosis of LB and for epidemiological surveys. In comparison of performance of assays for detecting human antibodies against LB, EIA was shown to be the best test in most cases. $(36,49-51,57,58)$. Many reports using EIA to confirm the clinical diagnosis of LB and the prevalence of antibodies against $\mathrm{Bb}$ in dogs have been published. However in most of these studies the used EIA have not been been validated for canine sera, for sensitivity and specificity or only a limited number of control sera have been used. Validation of EIA test for dogs is severely hampered by the lack of availability of sera of confirmed clinical cases of canine LB.

The aim of the study was to determine the prevalence of antibodies to B. burgdorferi in Dutch healthy dog populations with different risks for LB and in Dutch dogs presented with clinical symptoms in veterinary clinics: patient control group. This patient control group was split up in sera from dogs with symptoms, which could have been caused by LB: "high suspect 
LB" patient control group and a "low suspect LB" patient control group with symptoms that are not directly related to LB in dogs. The healthy control group consisted of a high risk group: working hunting dogs and a low risk control group: healthy city dogs. Before the analysis of the prevalence, the in house EIAs were validated by using sera of; dogs never exposed to ticks. dogs experimentally infected with $\boldsymbol{B}$. burgdorferi and dogs hyperimmunised with leptospirosis. Results were compared with a commercially available EIA and an IHA for detection of $\mathrm{Bb}$ antibodies in dogs. The in house ElAs were the (SI-IgG-EIA) for the detection of $\mathrm{IgG}$ antibodies against B. burgdorferi which can be used with serum samples from various animal species and an EIA for the detection of IgG (IgG-EIA) and IgM (IgMEIA) antibodies against $B$. burgdorferi in canine serum samples. Furthermore, initially the influence of antigenic heterogeneity on the test performance was studied using dogs with clinical manifestations linked to a specific strain in human LB.

\section{MATERIALS AND METHODS}

The importance of antigenic heterogeneity in the serological diagnosis of Lyme borreliosis in Dutch dogs was evaluated with the sera of dogs highly suspected of LB with affected organ systems or clinical symptoms which could be attributed to LB; dogs with lameness $(\mathrm{n}=60)$, dogs with neurological disorders $(\mathrm{n}=60)$ and dogs with skin disorders. In addition, the SI-IgG-, IgG- and IgM-EIA were compared with two commercially available tests: an $\mathrm{EIA}$ for the detection of $\mathrm{Ig} G$ antibodies against $B$. burgdorferi in canine sera and an IHA test for the detection of antibodies against $B$. burgdorferi.

The prevalence of $\operatorname{Ig} \mathrm{M}$ and $\operatorname{Ig} \mathrm{G}$ antibodies to $\boldsymbol{B}$. burgdorferi in Dutch dogs in was studied in a "healthy control group" and a "patient control group" with the S1-IgG-, IgG- and IgM-EIA. The healthy control group was subdivided into a "high risk group" and a "low risk group". For the high risk group of the healthy controls, blood samples from 401 healthy Dutch working dogs were collected. For the low risk group of the healthy controls, blood samples were taken from 100 healthy dogs presented for their yearly vaccination at veterinary clinics. The patient control group consisted of 629 city dogs presented to veterinary clinics with various clinical symptoms and 47 hunting dogs with lameness, all highly suspected for LB.

To study the correlation between clinic and LB in dogs, antibodies to $B$. burgdorferi were analysed in 629 diseased city pet dogs presented at veterinary clinics. Sera were split in two groups: clinical symptoms or affected organ systems "attributed to LB" (lameness, uveitis, renal, neurological, liver and cardial disease) and "ambiguously attributed to LB"(fever, anorexia, myositis, dermatological and urogenital disease).

Sera. 105 laboratory dogs (Beagles) which had never been exposed to ticks. but of which five had been subcutaneously hyperimmunized against leptospirosis, were used to determine the cut-off values for positive reaction of the in-house developed EIA tests. A pool of these sera was used as a negative control serum during the study in all tests. In addition three Beagle dogs, 2-4 years old, which were negative for $\mathrm{IgM}$ and $\mathrm{IgG}$ antibodies to $B$. burgdorferi, were infected subcutaneously with $10^{9} \mathrm{~B}$. burgdorferi (ATCC 35210) organisms suspended in one $\mathrm{ml}$ adjuvant (Specol ${ }^{\mathrm{m}}$; ID-DLO, Lelystad, the Netherlands). Serum samples were collected every three days and the dogs were boostered after 28 days with $10^{9} \mathrm{~B}$. burgdorferi organisms suspended in one ml PBS. Sera were collected until 32 days after the booster. At day 60 blood was collected from the animals and these sera were pooled and used as a positive control serum.All sera were stored at $-70^{\circ} \mathrm{C}$ until assayed. Data on age, history of tick infestations and clinical symptoms of all sera were collected. None of the 1177 animals included in this study were vaccinated against L.B, since no canine L.B-vaccine has been licensed in the Netherlands.

Experimental in-house EIAs. Three experimental ElAs for the detection of canine IgG (IgG-EIA-I, IgG-EIA-II, IgG-EIA-III), canine IgM (IgM-EIA) and species independent IgG (SI-IgG-EIA) antibodies to $B$. burgdorferi were developed and tested as previously described (59) with minor modifications. The reference strains used were B. burgdorferi sensu stricto B31 (ATCC 35210) for the IgG-EIA-I, IgM-ElA and SI-IgG-EIA, B. garinii (ATCC 51383) for the IgGElA-II and and B. afzelii (strain: PKo) for the IgG-ElA-III. The conjugates used were peroxidase-conjugated goat anti-dog lgG diluted 1/8000 (KPL USA) for the IgG-ELA-1, IgG-ELA-II and IgG-ElA-III, peroxidase-conjugated Protein-G with a dilution of $1 / 10.000$ (Sigma, USA) for the SI-IgG-EIA and peroxidase-conjugated goat anti-dog $\lg$ M with a dilution of $1 / 2000$ (Jackson Immunoresearch, USA) for the IgM-EIA. All conjugates were diluted in RTU conjugate stabilising matrix (D-tek, Belgium).

Standardisation. Cat-ef vahe $(\mathrm{CO})$ determination. For the experimental in-house ElAs, the mean OD-values $\approx$ SD of the 105 negative canine samples were 0.127 (SD, 0.058), 0.090 (SD, 0.056), 0.088 (SD, 0.056), 0.198 (SD, 0.085) and 0.075 (SD, 0.057), respectively for the IgG-EIA-1, IgO-EIA-II. IgG-EIA-III. IgM-E1A and SI-IgG-EIA. All 105 canine samples taken for the CO determination in the experimental EIAs were also found negative in the Virotech-IgG-EIA and IHA test. The best reproducibility of the experimental EIAs was obtained when the mean +3 SD was used as a CO, because $98 \%$ of the canine serum samples were consistently either positive or negative in all experimental E1As. The cut-of value (mean + 3SD) for the IgO-EIA-1, IgG-EIA-II, IgO-EIA-III. IgM-EIA and SI-IgG-EIA was respectively set at $0.300,0.250,0.250,0.450$ and $0.250 \mathrm{OD}$. If. on the other hand, the mean OD-value +2 SD was used for $\mathrm{CO}$, the canine serum samples were repeatedly positive or negative in only $87 \%, 85 \%, 85 \%, 84 \%$ and $88 \%$ of respectively the IgG-EIA-I. IgG-EIA-II, IgG-EIA-III. IgM-EIA and SI-IgG-EIA tests. Of the canine sera, which additionally became positive when the $\mathrm{CO}$ was lowered, most sera were borderline sera. When the same sera were tested repeatedly, they gave various results, either positive or negative which led to a much poorer reproducibility of the test. The cut-off value of the experimental ElAs and the commercial EIA were located in the linear range of the tests (data not shown). The intra-assay precision of the experimental EIAs was 97\%, 95\%, 95\%. $93 \%$ and $96 \%$ respectively for the Ig G-EIA-I, IgC-EIA-II, IgG-EIA-III. Ig M-FIA and SI-IgG-EIA. The Virotech-IgO-EIA showed an intra-assay precision of 95 which was not significantly different from the experimental $\lg \mathrm{G}-\mathrm{ELA}$ and $\mathrm{SI}-\mathrm{IgO}$. EIA $(P>0.05)$. The inter-assay precision of all EAs was $>90 \%$

To assure the reproducibility of the test, the standardisation and all the sera included in the serosurvey were tested with the same batch of antigen. A seropositive animal was defined as one that had an $O D$ ratio above this calculated cut-off value. No background reaction was observed for the positive control serum in control wells. which were blocked with $1 \%$ fish gelatin (Sigma, USA) in PBS. Canine sera taken before and after immunisation were also tested for antibodies against Leptospira

TABLE 1 Seroprevalence of antibodies to B. burgdorferi sensu stricto, B. garinii and B. afzelii in Dutch dogs highly suspected for LB with clinical symptoms which could be attributed to LB

Clinical

No. $(\%)$ of Seropositives

symptoms or

affected organ

systems

Total

IgG-
EIA-I' $\quad \begin{aligned} & \text { IgG- } \\ & \text { EIA-II' }\end{aligned}$

IgG-

Lameness

60

$10(17)$

9(15)

Neurological

disease

Dermatological

disease ': strain B31, B. burgdorferi sensu stricto, ${ }^{2}$ : strain B. garinii
${ }^{3}$ : strain B. afzelii

interrogans serovar hardjo (macroscopic agglutination test, internal house test), $L$ interrogans serovar icterohacmorrhagiae (macroscopic agglutination test, internal house test) and Treponema pallidum antibodies (Fujirebio, Japan); all sera were negative. To eliminate plate-to-plate variation, the EIA results were expressed as an $O D$ ratio, i.e. the ratio of the mean $O D$ of a test serum sample to the mean OD of the cut-off serum sample on the same plate. In every run a negative and a diluted positive control serum with the predefined cut-off value $(\mathrm{CO})$ were tested on each plate. All serum samples were tested in duplicate and the mean OD value was taken for further evaluation. Canine sera were retested if the OD value of the duplicates differed by more than $10 \%$ from the mean. 
Commercial assays. A commercially available EIA for the detection of canine IgG (GenzymeVirotech, Ruesselsheim, Germany) to B. burgdorferi Genotype $I$ (strain 2591) (Virotech-IgG-EIA) and a commercial available IHA (Diagast, France) were used according to the instructions of the manufacturers. To exclude test related differences, all dog sera were tested in test systems which were lot consistent. The cut-off of the IHA test was set at 2. For the calculation of the inter and intra-assay precision in all tests used in this study, the deviation of the duplicate values within $25 \%$ of the mean base line was used $(60)$.

Statistical Analysis. Paired data were compared using McNemar's test, assuming a binomial distribution of the data. The Chi-square test was used to compare nonpaired data. The kappa value was calculated to indicate the agreement between the tests used. Interpretation of kappa values; kappa < 0.4 : poor agreement, $0.4<$ kappa 6.75 ; good agreement, kappa > 0.75 : strong agreement (61).

\section{RESULTS}

Comparison SI-IgG-EIA, IgG-EIA-I, IgG-EIA-II and IgG-EIA-III. As shown in Table 1, the results of the SI-IgGEIA and IgG-EIA-I were identical in the dog population with lameness, neurological and dermatological disease. For dogs with lameness the SI-IgG-EIA and IgG-EIA-I showed the highest sensitivity $(17 \%$ versus $15 \%)$ compared to the IgGEIA-II and IgG-EIA-III but was not significantly higher. The IgG-EIA-II showed the highest sensitivity (13\%) in the dog population with neurological disorders, but was not significantly higher compared to the results of the SI-IgG-EIA, IgG-EIA-I or IgG-EIA-III. For dogs with dermatological disorders, IgG-EIAIII and IgG-EIA-I, SI-IgG-EIA showed a sensitivity of $17 \%$ but were not significantly higher than IgG-EIA-II. The kappa values of the SI-IgG-EIA, IgG-EIA-I, IgG-EIA-II and IgG-EIA-III for dogs with lameness, neurological and dermatological disorders were higher than 0.9 , showing a strong agreement of the results. Data showed no significant improvement of sensitivity by the use of a specific strain.

Comparison IgG-EIA-I, IgM-EIA, SI-IgG-EIA, VirotechIgG-EIA and IHA. All the 1177 canine sera were tested in five different serological tests. Because of the strong agreement between the results of IgG-EIA-I -II and-III, shown in Table 1,

TABLE 2 Level of agreement between 5 serological tests for the detection of antibodies to B. burgdorferi in Dutch healthy dogs at high and low risk for Lyme disease and Dutch dogs with various clinical symptoms (kappa-value)

\begin{tabular}{|c|c|c|c|c|c|c|c|}
\hline & $\begin{array}{l}\text { IHA } \\
\text { CO } \\
=1\end{array}$ & $\begin{array}{l}\text { IHA } \\
\text { CO } \\
\geq 2\end{array}$ & $\begin{array}{l}\text { IHA } \\
\text { CO } \\
\geq 3\end{array}$ & $\begin{array}{l}\text { IgM. } \\
\text { EAA }\end{array}$ & $\begin{array}{c}\text { S1- } \\
\text { ggG- } \\
\text { EIA }\end{array}$ & $\begin{array}{l}\text { IgG- } \\
\text { EIA }\end{array}$ & $\begin{array}{l}\mathrm{VT}^{1} . \\
\operatorname{lgg} \text {. } \\
\text { EAA }\end{array}$ \\
\hline IgM-EIA & $<0.4$ & $<0.4$ & $<0.4$ & 1 & $<0.4$ & $<0.4$ & $<0.4$ \\
\hline $\begin{array}{l}\text { S1-lga- } \\
\text { EiA }\end{array}$ & $<0.4$ & 0.43 & $<0.4$ & $<0.4$ & 1 & 0.81 & 0.78 \\
\hline IgG-EIA & $<0.4$ & 0.48 & $<0.4$ & $<0.4$ & 0.81 & 1 & 0.79 \\
\hline $\begin{array}{l}V T^{1} . \\
\text { IgG-EIA }\end{array}$ & $<0.4$ & 0.53 & $<0.4$ & $<0.4$ & 0.78 & 0.79 & 1 \\
\hline
\end{tabular}

1: Virotech-IgG-ElA

Interpretation of kappa values; kappa $<0.4$ : poor agreement, $0.4<$ kappa $<0.75$ : good agreement, kappa $>0.75$ : strong agreement

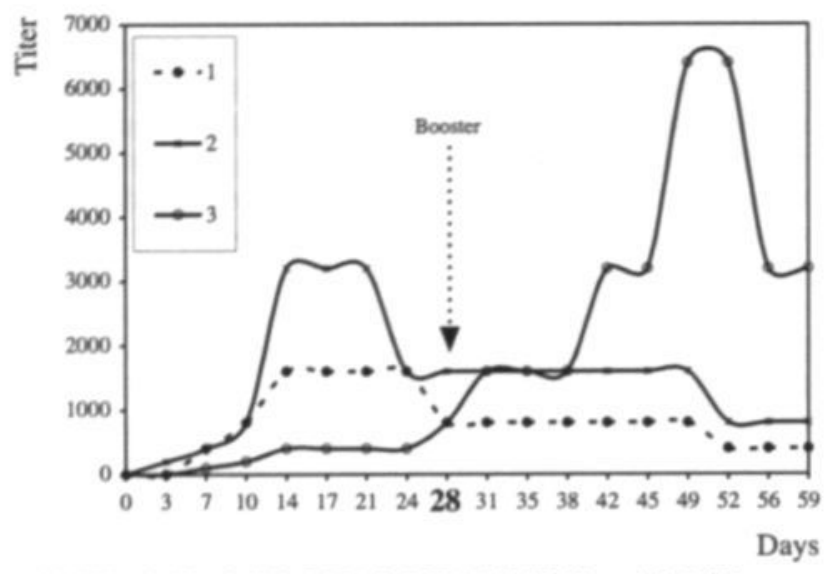

1: IgM-EIA, 2: IHA, 3: SI-IgG-EIA, IgG-EIA-1,-II,-III, Virotech-IgG-EIA

FIGURE I Mean antibody response to Borrelia burgdorferi of three dogs inoculated subcutaneously with $10^{5}$ Borrelia burgdorferi spirochetes,

the IgG-EIA-I was taken for further comparison studies. As shown in Table 2, the IgG-EIA-I, SI-IgG-EIA and VirotechIgG-EIA showed a strong agreement (kappa: $0.78-0.81$ ) The IHA with a $\mathrm{CO}$ of 2 (inter- intra- assay precision; $96 \%$ ) gave the best correlation (kappa: $0.43-0.53$ ) with the IgG-EIA-I, SIIgG-EIA and Virotech-IgG-EIA. However, the IHA $(\mathrm{CO}=2)$ antibodies to $B$. burgdorferi showed in only $156(13 \%)$ of the 1177 dogs, which was significantly lower than the percentage found in the IgG-EIA-I (16\%), SI-IgG-EIA (18\%) and VirotechIgG-EIA (16\%). For the IgM-EIA, the agreement with the IgG-EIA-I, SI-IgG-EIA and Virotech-IgG-EIA proved to be very low (kappa: $<0.4$ ) as could be expected because of the different immuneglobulines detected. However in case of the IHA, which is a polyvalent assay, the agreement was also lower than 0.4. Still, of the 25 animals positive in the IgM-EIA, 24 were also positive in the IHA $(\mathrm{CO}=2)$ of which 19 showed a strong reaction in the IHA $(\mathrm{CO}=3)$ and were nonreactive in SIIgG-EIA, IgG-EIA-I or Virotech-IgG-EIA. The high reactivity displayed in IHA for IgM positive sera denoted a high affinity for the detection of IgM antibodies to B. burgdorferi, as shown by the antibody response in the three experimentally infected beagles with $B$. burgdorferi (Figure I). The IgG-EIA-I, SI-IgGEIA and Virotech-IgG-EIA showed comparable results and displayed a higher sensitivity $18 \%$ versus $13 \%$ in detecting IgG antibodies to $B$. burgdorferi compared to the IHA. Although the sensitivity of the IHA was lower, $96 \%$ of the sera found positive in the IgM-EIA were recognised. The SI-IgG-EIA was used as the representative for the EIAs detecting IgG antibodies to $B$. burgdorferi because IgG-EIA-I, IgG-EIA-II and IgG-EIA-III showed no significantly different results and a high level of agreement for the IgG-EIA-I, Virotech-IgG-EIA and the SIIgG-EIA was shown as listed respectively in Tablel and Table 2. Furthermore the SI-IgG-EIA was taken for further evaluation because of its potency of detecting antibodies to $B$. burgdorferi in various animal species. The IgM-EIA and IHA were further used for the detection of IgM antibodies. 
TABLE 3 Seroprevalence of antibodies to B. burgdorferi in healthy dogs at high and low risk for Lyme disease and diseased dogs with various clinical symptoms.

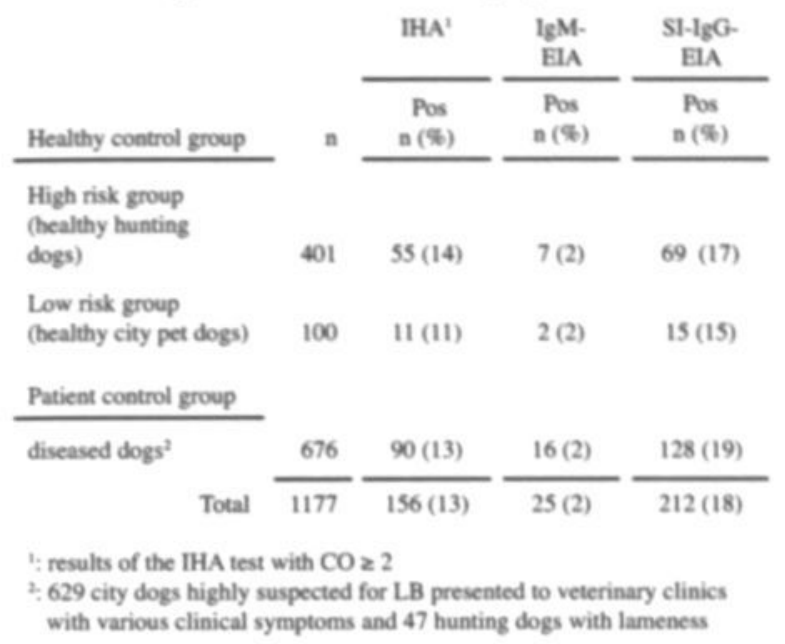

Antibody titer development in experimentally infected dogs. As shown in Figure I, a titre notation was taken to compare the results found in IgG-EIA-I,-II,-III, IgM-EIA, SI-IgG-EIA, Virotech-IgG-EIA and IHA. The test results of the IgG-EIAI,-II,-III, SI-IgG-EIA and Virotech-IgG-EIA were practically identical for the IgG immune response in the consecutive serum pools of the three dogs inoculated with $B$. burgdorferi are visualised as one plot. As displayed in Figure I, the IgM immune response to $B$. burgdorferi detected by the IgM-EIA reached its maximum level 15 days after inoculation and remained at its maximum level for 9 consecutive days. At the point of boosting (day 28 ), the IgM immune response dropped to half of its maximum and remained constant for 21 days. After 49 days the IgM titre dropped to $0.25 \%$ of its maximum and remained constant till day 60 after the inoculation. Compared to the IgMEIA, the IHA test showed a higher sensitivity in detecting the IgM immune response, but failed to detect the boosting effect. The IgG response, as measured with the IgG-EIA-I,-II,-III, SIIgG-EIA and Virotech-IgG-EIA showed only a moderate rise $(100-400)$ until 28 days after the inoculation where it climbed to its maximum (6400) 21 days after the booster, whereas the IgM response dropped to 400 . The IgG response remained at its maximum for three days and stayed at half of its maximum until day 60 after the first inoculation.

Seroprevalence of antibodies to $B$. burgdorferi in healthy dogs at high and low risk for Lyme disease and dogs with various clinical symptoms. As presented in Table 3, the healthy hunting dog population and the healthy city pet dog population versus the diseased dog population showed no significant difference in the seroprevalence of antibodies to $B$. burgdorferi in the IHA, IgM-EIA or SI-IgG-EIA. The seroprevalence of IgM (IgM-EIA, 2\%) versus IgG antibodies (SI-IgG-EIA, 18\%) to $B$. burgdorferi was significant lower $(\mathrm{P}<0.001)$ for all dog populations tested. However, the IHA, which is able to detect IgM as well as IgG antibodies, showed a significant lower
TABLE 4 Lyme ElA ${ }^{1}$ results in 629 diseased city pet dogs

\begin{tabular}{lccccc}
$\begin{array}{l}\text { Clinical symptoms or affected } \\
\text { organ systems }\end{array}$ & \multicolumn{2}{c}{$\begin{array}{c}\text { Seropositive } \\
\text { dogs }(\mathrm{n}=117)\end{array}$} & & \multicolumn{2}{c}{$\begin{array}{c}\text { Seronegative } \\
\text { dogs (n=512) }\end{array}$} \\
attributed to LB & $\mathrm{n}$ & $(\%)$ & & $\mathrm{n}$ & (\%) \\
\cline { 2 - 3 } \cline { 5 - 6 } Lameness & $10 / 117$ & $(9)$ & & $50 / 512$ & $(10)$ \\
Uveitis & $4 / 117$ & $(3)$ & & $13 / 512$ & $(3)$ \\
Renal disease & $7 / 117$ & $(6)$ & $59 / 512$ & $(12)$ \\
Neurological disease & $7 / 117$ & $(6)$ & $53 / 512$ & (10) \\
Liver disease & $17 / 117$ & (15) & $98 / 512$ & (19) \\
Cardial disease & $17 / 117$ & (15) & $68 / 512$ & (13)
\end{tabular}

ambiguously attributed to LB

$\begin{array}{lcccc}\text { Dermatological disease } & 9 / 117 & (8) & 43 / 512 & (8) \\ \text { Fever } & 14 / 117 & (12) & 45 / 512 & (9) \\ \text { Urogenital disease } & 18 / 117 & (15) & 66 / 512 & (13) \\ \text { Anorexia } & 9 / 117 & (8) & 36 / 512 & (7) \\ \text { Myositis } & 18 / 117 & (15) & 109 / 512 & (21)\end{array}$

1: SI-IgG-EIA for the detection of IgG antibodies to B. burgdorferi

prevalence in the diseased dog population of $13 \%$ versus $19 \%$ in the SI-IgG-EIA $(\mathrm{P}<0.01)$. Nevertheless the IHA detected 24 of the 25 IgM-EIA positive sera. Of the 24 animals positive in IHA and IgM-EIA, nine dogs displayed an infection of the liver, three dogs were diagnosed with urogenital infections, three dogs showed a gastrointestinal infection and one dog had symptoms of a renal infection.

Comparison of symptomatic and asymptomatic dogs seropositive in SI-IgG-EIA. As shown in Table 4, none of the listed clinical symptoms was significantly more present in the seropositive city pet dogs than in the seronegative city pet dog population. However, in the $\mathbf{4 4 8}$ hunting dogs lameness was the only clinical symptom present. Eleven (14\%) of the 80 seropositive hunting dogs suffered from intermittent lameness, but this was not significant higher than the $36(10 \%)$ of the 368 seronegative hunting dogs showing lameness which might also be attributed to LB. All healthy city pet dogs listed in Table 3 which were presented at veterinary clinics for their yearly vaccination were healthy without clinical signs pointing to LB.

\section{DISCUSSION}

Assay development for canine LB serology, an arduous task ? Ideally the performance of a new diagnostic test is evaluated by comparing results from healthy individuals, individuals in which the disease under study has been clinically confirmed in $100 \%$ of the cases, and sera from a group of patients suffering from diseases that may mimic the symptoms of disease under study. However, such criteria are not available for LB in dogs since LB is not a commonly diagnosed disease in dogs in the Netherlands. Only very few cases of dogs with LB in 
the Netherlands have been published $(62,63)$. Another method for the evaluation of a new test is to compare the results with a generally accepted assay, which is supposed to determine the true disease state unambiguously and to use these results as a gold standard. Unfortunately no such tests have been developed for LB yet. The true disease state in practice is rarely known because perfect results may be difficult or impossible to obtain. In dogs a clearly defined and typical clinical symptom for LB such as erythema migrans in humans is missing. Furthermore, the fact that $B$. burgdorferi has also been cultured from clinically healthy dogs in natural and experimental conditions $(4,64)$ and that antibodies against $B$. burgdorferi are found in healthy dogs (27) makes it very difficult or even impossible to establish a "golden standard". For now a consensus on how to interpret antibody titres which can be taken as a diagnostic of an active LB infection in dogs has not been reached. In canine LB serology, some investigators consider only a high single titre $(30,65)$ whereas others suggest a fourfold rise in titre over two to four weeks as a confirmation of an active infection (7). It has been claimed, however, that a high antibody titre is suggestive of a recent exposure and is not indicative for a clinical infection (8). The fact that various interpretations exist and that most veterinary laboratories use different commercial tests or their own unique test, contributes to the diagnostic confusion. Problems with interpretation and the absence of standardisation has also the topic of several articles dealing with human LB serology (66-68). Since a real golden standard is lacking for LB in dogs, this study favoured the commonly accepted method of cut-off determination over the use of canine sera reactive in other tests as a reference. The mean OD of a dog population considered negative for Lyme and a population considered possibly cross-reactive to Lyme (dogs hyperimmunized against leptospirosis) were taken for the $\mathrm{CO}$ calculation combined with the SD resulting in the best reproducible findings. Furthermore the linear response range of the tests were fine-tuned with the help of consecutive serum samples from dogs vaccinated with B. burgdorferi.

Characteristics and value of the searched tests used for the detection of antibodies to $\boldsymbol{B}$. burgdorferi. In contrast to the findings in human cases (69), the sensitivity in detecting antibodies to $B$. burgdorferi in Dutch dogs did not improve by the use of $B$. burgdorferi sensu stricto, nor $B$. garinii or B. afzelii for dogs with clinical symptoms which have been proven in human cases to be predominated by certain $B$. burgdorferi strains. Based on the results obtained in this study, the antigenic source, B. burgdorferi sensu stricto was choosen for the commercial as well as the in-house EIAs. Furthermore for further evaluation an acceptable population consisting of 1177 dogs was used. Based on the results obtained in this study the use of a species independent EIA for the detection of antibodies to B. burgdorferi proved to be comparable to selfdeveloped and commercially available EIA for the detection of canine IgG antibodies to $B$. burgdorferi. The IHA displayed a somewhat lower sensitivity compared to the EIAs detecting $\mathrm{IgG}$, but proved to be more sensitive in tracing IgM antibodies as indicated by Figure I and the fact that the IHA detected $96 \%$ of the sera which were positive in the IgM-EIA. Although in human LB, IgM serology is used for confirming early disease, only total Ig or IgG antibodies are checked in dogs suspected of $\mathrm{LB}$ and $\mathrm{IgM}$ responses are rarely reported. The fact that IgM EIAs are difficult to standardise probably can be responsible for the low reporting. As sera with a high IgM response were confirmed by IHA and not detected by the IgG-EIAs, makes the IHA test a useful tool for the detection of an acute Lyme infection in dogs and possibly in other species, including human. Still, in this study neither a positive serological result or a high OD value could be linked to a clinical symptom related to Lyme disease for dogs at high or low risk for the disease which is in concordance with a previous report where the seroprevalence of hunting dogs was searched (59).

Conclusion. As positive serological results in this study do not prove to be significantly linked to clinical symptoms, the use of current diagnostic tests to support the diagnosis for Lyme disease are of limited value. As compared to humans, antibodies against $\boldsymbol{B}$. burgdorferi in dogs persist only for a relatively short time, i.e. less than one year. Regular reinfections are needed to maintain seropositivity in dogs $(59,63)$. Therefore, the use of IHA and EIA for the detection of antibodies to $B$. burgdorferi in dogs remains useful for seroepidemiological studies since dogs have proven to be good sentinel animals in endemic areas $(59,70)$. Even more in EIA, the use of species independent IgG detection has proven its value in serological surveillance of LB in sera of wild animals $(71,72)$ and could be used for a large number of other species, including dogs as demonstrated in this study. The application of a species independent EIA could facilitate studying the seroprevalence of $\mathrm{IgG}$ antibodies to $B$. burgdorferi in a variety of animals residing in an endemic or increasing endemic area. The overall impression of this study is that despite the common occurrence of infections by $B$. burgdorferi in Dutch dogs, this causes very seldom clinical symptoms of LB in infected dogs in the Netherlands.

\section{REFERENCES}

1. Burgdorfer W, Barbour AG, Hayes SF, Benach JL, Grunwaldt E, Davis JP. Lyme disease :a tick-borne spirochetose? Science 1982:216:1317-19.

2. Steere AC. Lyme disease. N Engl J Med 1989;321(9):586-96.

3. Magnarelli LA, Anderson JF, Burgdorfer W, Chappell WA. Parsitism by Lxodes dammini (Acari : Ixodidae) and antibodies to spirochetes in mammals at Lyme disease foci in Connecticut USA. J Med Entomol 1984;21(1):52-7.

4. Burgess EC. Natural exposure of Wisconsin dogs to the Lyme disease spirochete (Borrelia burgdorferi). Lab Anim Sci 1986;36(3): 288-90.

5. Teitler J, Madigan J, DeRock E, Petersen N, Carpenter T, Franti C. Prevalence of Borrelia burgdorferi antibodies in dogs in Northern California, risk factors and zoonotic implications. Ann NY Acad Sci 1986:500-3.

6. Bosler EM, Cohen DP, Schulze TL, Olsen C, Bernard W, Lissman B. Host responses to Borrelia burgdorferi in dogs and horses. Ann NY Acad Sci 1988:539:221-34.

7. Eng TR, Wilson ML, Spielman A, Lastavica CC. Greater risk of Borrelia burgdorferi infection in dogs than in people [letter]. J Infect Dis 1988;158(6):1410-1.

8. Greene RT, Levine JF, Breitschwerdt EB, Walker RL, Berkhoff HA, Cullen J, et al. Clinical and serologic evaluations of induced Borrelia burgdorferi infection in dogs. Am J Vet Res 1988;49(6):752-7. 
9. Magnarelli LA, Anderson JF, Schreier AB. Persistence of antibodies to Borrelia burgdorferi in dogs of New York and Connecticut. J Am Vet Med Assoc 1990;196(7): 1064-8.

10. Rand PW, Smith RPJ, Lacombe EH. Canine seroprevalence and the distribution of Lxodes dammini in an area of emerging Lyme disease. Am J Public Health 1991;81(10):1331-4.

11. Levy SA, Magnarelli LA. Relationship between development of antibodies to Borrelia burgdorferi in dogs and the subsequent development of limb/joint borreliosis. J Am Vet Med Assoc 1992;200(3): 344-7.

12. Mukolowe S, Kocan A, Wyckoff J. Serological survey for Lyme disease in domestic dogs and white-tailed deer from Oklahoma. Ann NY Acad Sci 1992;16:172-77.

13. Daniels TD, Fish D, Levine J, Greco M. Eaton A, Padget P, et al. Canine exposure to Borrelia burgdorferi and prevalence of Lodes dammini (Acari: Lxodidae) on deer as a measure of Lyme disease risk on the Northeastern United States. J Med Entomol 1993:30: 171-8.

14. Falco RC, Smith HA, Fish D, Mojica BA, Bellinger MA, Harris HL. et al. The Distribution of Canine Exposure to Borrelia-Burgdorferi in a Lyme-Disease Endemic Area. Am J Public Health 1993;83(9): 1305-10.

15. Wright JC, Chambers M, Mullen GR, Swango LJ, Dandrea GH, Boyce AJ. Seroprevalence of Borrelia burgdorferi in Dogs in Alabama, USA. Prev Vet Med 1997;31(1-2):127-31.

16. Doby JM, Chevrier S, Couatarmanac'h A. Tickborne Borrelia burg. dorferi infection in dogs in western France. Systematic serological survey of 806 hunting dogs and 88 military dogs in 14 Departments [La spirochetose a tiques par Borrelia burgdorferi chez les chiens dans l'ouest de la France. Examens serologiques systematiques de 806 chiens de meute et 88 chiens militaires de 14 departements]. Rec Med Vet 1988;164(5):367-74; 15 ref.

17. Hansen K, Dietz HH. Serosurvey for antibodies to Borrelia burg dorferi in Danish dogs. APMIS 1989;97(3):281-5.

18. Pfister K, Bigler B, Neswadba J, Gern L, Aeschlimann A. Borrelia burgdorferi infections of dogs in Switserland. Zentralbl Bakteriol 1989;18(18):26-31.

19. Kasbohrer A, Schonberg A. [Serologic studies of the occurrence of Borrelia burgdorferi in domestic animals in Berlin (West)] Serologische Untersuchungen zum Vorkommen von Borrelia burgdorferi bei Haustieren in Berlin (West). Berl Munch Tierarztl Wochenschr 1990;103(11):374-8

20. May C, Carter SD, Barnes A, Bell S, Bennett D. Serodiagnosis of Lyme disease in UK dogs. J Small Anim Pract 1991;32:170-74.

21. Delgado S, Carmenes P. Seroepidemiological survey for Borrelia burgdorferi (Lyme disease) in dogs from northwestern of Spain. Eur J Epidemiol 1995;11(3):321-4.

22. Mehle J. Lyme borreliosis in animals. Vet Nov 1996:22(179-83).

23. Stefancikova A, Skardova I, Petko B, Janovska D, Cyprichova V. Antibodies IgG to Borrelia burgdorferi in Dogs from Kosice Region. Vet Med (Praha) 1996;41(3):83-6.

24. Wittenbrink MM, Failing K, Krauss H. Enzyme-linked immunosorbent assay and immunoblot analysis for detection of antibodies to Borrelia burgdorferi in dogs - The impact of serum absorption with homologous and heterologous bacteriae. Vet Microbiol 1996:48(3-4):257-68.

25. CDC. Recommendations for test performance and interpretation from the Second National Conference on Serologic Diagnosis of Lyme disease. Morb Mortal Wkly Rep 1995:44:590-1.

26. Greene RT. An update on the serodiagnosis of canine Lyme borreliosis. J Vet Intern Med 1990;4(3): 167-71.

27. Jacobson RH, Chang YF, Shin SJ. Lyme disease laboratory diagnosis of infected and vaccinated symptomatic dogs. Semin Vet Med Surg (Small Anim.) 1996:11(3): 172-82.

28. Magnarelli LA, Anderson JF, Schreier AB, Ficke CM. Clinical and serologic studies of canine borreliosis. J Am Vet Med Assoc 1987;191(9): 1089-94.

29. Magnarelli LA, Anderson JF, Kaufmann AF, Lieberman LL, Whitney GD. Borreliosis in dogs from southem Connecticut. J Am Vet Med Assoc 1985;186(9):955-9.

30. Grauer GF, Burgess EC, Cooley AJ, Hagee JH. Renal lesions associated with Borrelia burgdorferi infection in a dog. J Am Vet Med Assoc 1988;193(2):237-9.

31. Dambach DM, Smith CA, Lewis RM, Vanwinkle TJ. Morphologic, immunohistochemical, and ultrastructural characterization of a distinctive renal lesion in dogs putatively associated with Borrelia burgdorferi infection: 49 cases (1987-1992). Vet Pathol 1997:34(2): 85-96.

32. Komblatt AN, Urband PH, C. SA. Arthritis caused by Borrelia burgdorferi in dogs. J Am Vet Med Assoc 1985;186(9):960-4.

33. Levy SA, Duray PH. Complete heart block in a dog seropositive for Borrelia burgdorferi. Similarity to human Lyme carditis. J Vet Intern Med 1988;2(3):138-44.

34. Berger BW, Johnson RC, Kodner C, Coleman L. Cultivation of Borrelia burgdorferi from erythema migrans lesions and perile sional skin. J Clin Microbiol 1992;30(2):359-61.

35. Picken M, Picken R, Han D. A two year prospective study to com. pare culture and polymerase chain reaction amplification for the detection and diagnosis of Lyme borreliosis. Mol Pathol 1997:50: 186-193.

36. Schmidt BL. PCR in laboratory diagnosis of human Borrelia burg. dorferi infections. Clin Microbiol Rev 1997:10(1):185.

37. Straubinger RK, Straubinger AF, Summers BA, Jacobson RH. Status of Borrelia burgdorferi infection after antibiotic treatment and the effects of corticosteroids: An experimental study, 2000;181(3): 1069-81.

38. Eiffert H, Karsten A, Thomssen R, Christen HJ. Characterization of Borrelia burgdorferi strains in Lyme arthritis. Scand J Infect Dis 1998:30(3):265-8.

39. Vasiliu V, Herzer P, Rossler D, Lehnert G, Wilske B. Heterogeneity of Borrelia burgdorferi sensu lato demonstrated by an ospA-type. specific PCR in synovial fluid from patients with Lyme arthritis. Med Microbiol Immunol (Berl) 1998:187(2):97-102.

40. van der Heijden IM, Wilbrink B, Rijpkema SG, Schouls LM, Heymans PH, van Embden JD, et al. Detection of Borrelia burgdorferi sensu stricto by reverse line blot in the joints of Dutch patients with Lyme arthritis. Arthritis Rheum 1999;42(7):1473-80.

41. Lunemann JD, Zarmas S, Priem S, Franz J, Zschenderlein R, Ab erer E, et al. Rapid typing of Borrelia burgdorferi sensu lato species in specimens from patients with different manifestations of Lyme borreliosis. J Clin Microbiol 2001;39(3):1130-3

42. EUCALB. Diagnosis: Serology: Minimum Standards. [cited 2000 Okt 30 one screen]. Available from: URL: http: Uwww.dis.strath.ac.uk/vie/LymeEU/diagnosis_serology. minstandards.html

43. Shin SJ, Chang YF, Jacobson RH, Shaw E, Lauderdale TL, Appel MJ, et al. Cross-reactivity between B. burgdorferi and other spirochetes affects specificity of serotests for detection of antibodies to the Lyme disease agent in dogs. 1993:36(1-2):161-74.

44. Fawcett PT, Rose CD, Gibney KM. Comparative evaluation of adsorption with E. coli on ELISA tests for Lyme borreliosis. 1995;22(4):684-8.

45. Schillhorn van Veen TW, Murphy AJ, Colmery B. False positive Borrelia burgdorferi antibody titres associated with periodontal disease in dogs. 1993;132(20):512.

46. Hansen K. Hindersson P. Pedersen NS. Measurement of antibodies to the Borrelia burgdorferi flagellum improves serodiagnosis in Lyme disease. J Clin Microbiol 1988;26(2):338-46.

47. Grodzicki RI, Steere AC. Comparison of immunoblotting and 


\section{CHAPTER VI}

indirect enzyme-linked immunosorbent assay using different antigen preparations for diagnosing early Lyme disease. J Infect Dis 1988;157(4):790-7.

48. Magnarelli LA, Anderson JF, Barbour AG. Enzyme-linked immunosorbent assays for Lyme disease: reactivity of subunits of Borrelia burgdorferi. J Infect Dis 1989;159(1):43-9.

49. Lindenmayer J, Weber M, Bryant J, Marquez E, Onderdonk A. Comparison of indirect immunofluorescent-antibody assay, enzyme-linked immunosorbent assay, and Western immunoblot for the diagnosis of Lyme disease in dogs. J Clin Microbiol 1990;28(1): 92-6.

50. Greene RT, Walker RL, Nicholson WL, F. LJ. Comparison of an enzyme-linked immunosorbent assay to an indirect immunofluorescence assay for the detection of antibodies to Borrelia burgdorferi in the dog. Vet Microbiol 1991;26(1-2):179-90.

51. Artsob H, Barker IK, Fister R, Sephton G, Dick D, Lynch JA, et al. Serological Studies on the Infection of Dogs in Ontario with Borrelia-Burgdorferi, the Etiologic Agent of Lyme-Disease. Can Vet J 1993:34(9):543-8.

52. Pavia CS, Wormser GP, Bittker S, Cooper D. An indirect hemagglutination antibody test to detect antibodies to Borrelia burgdorferi in patients with Lyme disease. J Microbiol Meth 2000;40:163-173.

53. Nohlmans MKE, Blaauw AAM, van den Bogaard AE, Vanboven CPA. Evaluation of nine serological tests for diagnosis of lyme borreliosis. Eur J Clin Microbiol Inf Dis 1994;13(5):394-400.

54. Callister SM, Jobe DA, Schell RF, Pavia CS, Lovrich SD. Sensitivity and specificity of the borreliacidal antibody test during early Lyme disease: a "gold standard"? Clin Diagn Lab Immunol 1996:Jul 3(4):399-402.

55. Callister SM, Jobe DA, Schell RF, Lovrich SD, Onheiber KL, Korshus JB. Detection of borreliacidal antibodies in dogs after challenge with Borrelia burgdorferi-infected ixodes scapularis ticks. J Clin Microbiol 2000;38(10):3670-4.

56. Hovius JW, Hovius KE, Oei A, Houwers DJ, van Dam AP. Antibodies against specific proteins of and immobilizing activity against three strains of Borrelia burgdorferi sensu lato can be found in symptomatic but not in infected asymptomatic dogs. J Clin Microbiol 2000;38(7):2611-21.

57. Berg D, Abson KG, Prose NS. The laboratory diagnosis of Lyme disease. Arch Dermatol 1991:127(6):866-70.

58. Goossens HAT, van den Bogaard AE, Nohlmans MKE. Evaluation of fifteen commercially available serological tests for diagnosis of lyme borreliosis. Eur J Clin Microbiol Infect Dis 1999;18(8):55160 .

59. Goossens HAT, van den Bogaard AE, Nohlmans MKE. Dogs as sentinels for human borreliosis in the Netherlands. J Clin Microbiol 2001(Mar.):844-48.

60. Chan DW. Immunoassay. A practical guide. 1987:53-5.

61. Fleiss FL. Statistical Methods for Rates and Proportions. New York: Wiley; 1981.

62. van den Bogaard AEJM, Nohlmans MKE. Lyme borreliosis in domestic animals; the situation in the Netherlands. Vet Q 1990:56-8.

63. Hovius KE, Rijpkema SG, Westers P, vander Zeijst BAM, van Asten FJAM, Houwers DJ. A serological study of cohorts of young dogs, naturally exposed to Ixodes ricinus ticks, indicates seasonal reinfection by Borrelia burgdorferi sensu lato. Vet Q 2000;21(1): 16-20.

64. Straubinger RK, Straubinger AF, Harter L, Jacobson RH, Chang YF, Summers BA, et al. Borrelia burgdorferi migrates into joint capsules and causes an up-regulation of interleukin- 8 in synovial membranes of dogs experimentally infected with ticks. Infect Immun 1997;65(4): 1273-85.

65. Burgess EC. Borreliosis (Lyme disease) Manual of Small Animal Infectious Disease. New York: Churchill Livingstone; 1988.

66. Wilkinson HW, Russell H, Sampson JS. Caveats on using nonstand- ardized serologic tests for Lyme disease [letter]. J Clin Microbiol 1985:21(2):291-2.

67. Hedberg CW, Osterholm MT, MacDonald KL, White KE. An interlaboratory study of antibody to Borrelia burgdorferi. J Infect Dis 1987;155(6):1325-7.

68. Barbour AG. The diagnosis of Lyme disease: rewards and perils. Ann Intern Med 1989;110(7):501-2.

69. Hauser U, Krahl H, Peters H, Fingerle V, Wilske B. Impact of strain heterogeneity on Lyme disease serology in Europe: comparison of enzyme-linked immunosorbent assays using different species of Borrelia burgdorferi sensu lato. J Clin Microbiol 1998;36(2):42736.

70. Lindenmayer JM, Marshall D, Onderdonk AB. Dogs as sentinels for Lyme disease in Massachusetts. Am J Public Health 1991;81(11): 1448-1455.

71. Deruaz D, Eid P, Deruaz J, Sempere A, Bourgouin C, Rodhain F, et al. Use of enzyme-labelled protein $G$ assay for the detection of anti Borrelia burgdorferi antibodies in wild animal sera. Eur J Epidemiol 1996;12(5):515-9.

72. Sugiyama Y, Minamoto N, Kinjo T. Serological surveillance of Lyme borreliosis in wild Japanese serows (Capricornis crispus). J Vet Med Sci 1998;60(6):745-47. 




\section{Chapter VII}

\section{PREVALENCE OF ANTIBODIES TO BORRELIA BURGDORFERI IN HUMANS AND DOMESTIC ANIMALS IN THE NETHERLANDS}

H.A.T. Goossens, J.H.J Maes, A.E. van den Bogaard

Department of Medical Microbiology, University Maastricht; 



\title{
Prevalence of antibodies to Borrelia burgdorferi in humans and domestic animals in the Netherlands
}

\author{
H.A.T. Goossens, J.H.J. Maes, A.E. van den Bogaard (*) \\ Department of Medical Micnobiology, University of Maastricht, \\ NL-6200 MD Maastricht, The Netherlands
}

\begin{abstract}
The prevalence of antibodies to Borrelia burgdorferi in sera of 1052 healthy persons, 1177 dogs, 3919 dairy cows and 2288 sheep from 12 regions of the Netherlands was investigated. The results showed that in all regions of the Netherlands humans and animals are exposed to $B$. burgdorferi-infections and are therefore at risk to develop Lyme borreliosis. In the western regions, healthy persons showed a higher prevalence $(13-17 \%)$ compared to the eastern regions $(2-6 \%)$ of the Netherlands. The prevalence found in dogs did not differ significantly within the regions studied $(15-23 \%)$. Cattle showed the highest prevalence in the eastern regions $(11-20 \%)$ and lowest in the western regions $(2-8 \%)$. Sheep showed the highest prevalence in the western regions $(15-17 \%)$, whereas unexpectedly in the eastern regions the prevalence (4-8\%) was significantly lower $(\mathrm{P}<\mathbf{0 . 0 0 1})$. The differences found in antibody prevalence to $B$. burgdorferi in the different regions could be explained by the differences in biotopes that are favorable for Ixodes ricinus ticks and the frequencies by which humans, dogs, cattle and sheep come in contact with these biotopes.
\end{abstract}

In the eighties Burgdorfer and Barbour isolated B. burgdorferi from Ixodes ticks and human patients and identified it as the causative agent of Lyme borreliosis (LB) [1, 2]. Since then, LB has been increasingly recognized and is now the most frequently diagnosed tick-borne illness in humans in Europe and North America. In the Netherlands, Borrelia spirochetes were isolated for the first time from patients in 1986 [3]. In the following years, clinical LB was regularly diagnosed in the Netherlands. However, most infections of humans with $B$. burgdorferi in the Netherlands appear to be asymptomatic [4].

In animals, the first observations of $B$. burgdorferi infections have probably been reported from Norway [5] and the Netherlands [6]. In 1969, spirochetes, observed in blood smears from febrile yearling cattle pastured on the island of Ameland (the Netherlands) were presumptively identified as Borrelia theileri despite the absence of any known tick vector species on this island or in the Netherlands. It is most likely that the observed spirochetes were $B$. burgdorferi because $B$. theileri infections never have been diagnosed in cattle from the Netherlands. Furthermore, Lxodes ricinus ticks that are abundantly present on all the Dutch North Sea islands are heavily infected with $B$. burgdorferi.

In contrast to human LB, where the clinical picture is multifaceted but relatively well defined [7, 8], clinical symptoms of LB in animals are not clearly characterized and reports of clinical LB in animals are much less common and

- Corresponding author. Mailing address: Department of Medical Microbiology, University of Maastricht, P.O. Box 616, NL-6200 MD Maastricht. The Netherlands. Phone: $+31 .(0) 43.388 .10 .15$. Fax: +31.(0)43.388.41.61. E-mail: A.vandenBogaard@cpv.unimaas.nl often controversial. However, in endemic regions serologic evidence of infection with $\boldsymbol{B}$. burgdorferi is commonly observed in farm animals like cattle and sheep, as well as horses, cats, dogs and wildlife [9-17]. In addition B. burgdorferi has been isolated from organs of these animals [18-23] but also from cow milk and from the urine of dogs, cattle and mice $[20,24$ 29]. To what extent cattle are susceptible to an infection with $B$. burgdorferi is largely unknown. Although $B$. burgdorferi has been detected and isolated from ovine and bovine foetuses and blood of adult animals, attempts to reproduce clinical symptoms in sheep and cattle by experimental inoculation with European or American B. burgdorferi strains have been unsuccessful so far $[23,30]$. In contrast to the absence of clinical symptoms all inoculated animals developed antibodies against $B$. burgdorferi $[23,31]$. Also cattle residing in endemic areas and seropositive for $\boldsymbol{B}$. burgdorferi seldom show clinical disease but seroconvert readily like humans and dogs [25]. However, a variety of clinical symptoms in cattle have been attributed to infections with $B$. burgdorferi. Fever, lameness, single or multiple swollen joints, arthritis, weight loss and diminished milk production are the clinical symptoms in cattle most commonly attributed to a B. burgdorferi-infection $[17,25,32,33]$. A warm hypersensitive hyperemic skin lesion resembling the erythema migrans rash of humans has also been observed on the udders of infected cows [33]. Moreover B. burgdorferi-infections have also be blamed for the occurrence of chronic weight loss, laminitis and abortions in cattle herds [34]. In sheep the clinical symptoms attributed to LB are similar to those described in cattle [10. 35-38]. In dogs the most typical clinical symptom of LB is considered lameness combined with malaise [39, 40]. The lameness is often intermittent and either an extreme claudication with localizable swollen painful joints without any abnormalities on $\mathrm{X}$-ray photographs or a stiff gait without a clear localization 
of the pain $[22,41]$ are reported. The malaise may be caused by fever resulting in listlessness and/or lack of appetite [40]. Experimental infestations of dogs with B. burgdorferi-infected ticks caused, apart from an antibody response, fever and lameness in one or more legs within 210 days after challenge in all exposed animals [42]. Other clinical manifestations in the dog attributed to LB are lethargy, lymphadenopathy, and heart block $[22,43,44]$. In addition a proliferative glomerulonephritis with tubulonecrosis and lymfoplasmatic infiltration caused by a $B$. burgdorferi infection has been described $[20,45]$ and spirochetes have also been observed in silver stained liver coupes from dogs with chronic active hepatitis [46]. Despite the absence of serum titers against leptospires in affected animals, these were presumptively identified as leptospires, but might have been $B$. burgdorgferi.

As for the Netherlands no data about the occurrence and prevalence of clinical LB in most domestic animals are available, the aim of this study was to estimate the risk in different regions in the Netherlands that humans and animals become infected with B. burgdorferi. Therefore the prevalence of antibodies against $B$. burgdorferi in sera of humans, dogs, cattle and sheep from different regions in the Netherlands was determined.

\section{MATERIALS AND METHODS}

Sera. Serum samples of 3919 dairy cows, 2288 sheep, collected for regularly annual disease surveillance programs, and sera of 1177 healthy dogs, that were presented to veterinary surgeons for their yearly vaccinations, were tested for IgG antibodies to $B$. burgdorferi by a species independent EIA as described previously [47]. In addition results of sera of 1052 healthy humans (blood donors). that have been described elsewhere $[4]$ were used for this study. The sera were collected in 12 different regions. Unfortunately, the sera of the 2288 sheep were not all separated per region. Apart from the regions Noord-Brabant, Gelderland and Overijssel the other sheep sera were separated into two groups; the northern area of the Netherlands consisting of the combined regions: Friesland, Groningen and Drenthe and the western area consisting of the regions: Noord-Holland, ZuidHolland and Utrecht. Sheep sera obtained from the western area originated mainly from the island of Texel. All sera tested in this and previous studies were collected during the same time span. No human sera from the regions Drenthe and Utrecht were obtained.

The EIA-test for the detection of antibodies to B. burgdorferi in human and dog sera has been described previously [47] and was slightly adapted for testing cattle and sheep sera. The cut-off values for sheep and cattle sera were determined using positive and negative sera of the respective species.

For negative control, sera of 50 cows from a non-Lyme endemic area (Zimbabwe. kindly provided by Dr. F. Jongejan, Veterinary Faculty of Utrecht University. The Netherlands) and sera of $\mathbf{5 0}$ three months old Dutch lambs kept indoors, were pooled. Positive control sera were produced by infecting three B. burgdorferi seronegative cows and sheep intracutaneously with $10^{\prime} \mathrm{B}$. burgdorferi (ATCC 35210) organisms suspended in $1 \mathrm{ml}$ adjuvant: Specol ${ }^{\mathrm{m}}$ (ID-DLO. Lelystad, the Netherlands). Blood samples of the infected animals were collected every three days. At day 48, sera of the respective species were pooled for positive control. All sera were stored at $-70{ }^{\circ} \mathrm{C}$ until assayed. None of the animals included in this study were vaccinated against L.B. To this date no L.B-vaccine has been licensed in the Netherlands.

EIA. A species independent EIA for the detection of $\lg G$ antibodies to B. burgdorferi was used as described previously for dogs [47]. A checkerboard titration of three day consecutive serum samples of the experimentally infected cattle and sheep was used to determine the optimal dilution of sample and conjugate for testing sheep and cattle sera. Dilution of test and control sera for both cattle and sheep samples were set at 1:250 in PBS with 0.05\% Tween 20 . $0.5 \%$ fish gelatine (Sigma, St. Louis, Mo.). All sera were tested in duplicate ( 100 $\mu \mathrm{l}$ per well). After I hour incubation at $37^{\circ} \mathrm{C}$, a $100 \mu \mathrm{l}$ volume of peroxidaseconjugated Protein-G (Sigma) were added in a dilution of $1 / 80.000$ in ready to use conjugate stabilising matrix (D-tek, Mons, Belgium) for both cattle and sheep sera. The solutions were incubated at $37^{\circ} \mathrm{C}$ for 30 minutes. Between all steps, the plates were washed in a microplate washer (Flow Laboratories, Glasgow, UK) on a three-wash cycle with PBS, $0.05 \%$ Tween 20 used as a washing buffer. As substrate, $100 \mu 1$ ready to use TMB (D-tek) was used. The optical density (OD) at $405 \mathrm{~nm}$ was determined in a Titertek Multiskan apparatus (ICN Pharmaceuticals Inc., Irvine, Calif.). The substrate reaction was set at 15 minutes and was stopped with TMB stop solution (D-tek).

Standardisation. For the determination of the cut-off value, the mean $O D$ and standard deviation (SD) of the mean were calculated for the 50 negative cattle and sheep serum samples. The cut-off value for cattle and sheep sera was set at an $\mathrm{OD}$ of respectively 0.500 and 0.250 . To assure the reproducibility of the test, the standardisation and all the sera included in the serosurvey were tested with the same batch of antigen. The cut-off between a positive and a negative test result was set at 3 SDs above the mean OD of the negative control serum samples. A seropositive animal was defined as one that had an OD ratio above this calculated cut-off value. No background reaction was observed for the positive control sera in control wells, which were blocked with 1\% fish gelatine (Sigma) in PBS. Cattle and sheep sera taken before and after immunisation were also tested for antibodies against Leptospira interrogans serovar hardjo (macroscopic agglutination test, in-house test), $L$ interrogans serovar icterohaemornhagiae (macroscopic agglutination test, in-house test) and Treponema pallidum antibodies (Fujirebio. Japan); all sera were negative.

To eliminate plate-to-plate variation, the EIA results were expressed as an OD ratio, i.e. the ratio of the mean $O D$ of a test serum sample to the mean $O D$ of the cut-off serum sample on the same plate. Additionally in every run a negative and a positive control serum with a high and borderline titer were tested on each plate. All serum samples were tested in duplicate and the mean OD value was taken for further evaluation. Sera were retested if the OD value of the duplicates differed by more than $10 \%$ from the mean.

Statistical Analysis. Chi-square test was used to compare non-paired data.

\section{RESULTS}

The prevalence of $\mathrm{IgG}$ antibodies to $B$. burgdorferi in healthy humans, dogs and cattle in the different regions is shown in Figure I.

Humans. The highest prevalence of IgG antibodies to B. burgdorferi was found in Zuid-Holland (17\%) along with the regions Noord-Holland (15\%), Friesland $(15 \%)$ and NoordBrabant (13\%). The prevalences found in Limburg, Gelderland, Overijssel and Groningen varied from $2 \%-6 \%$ and were significantly lower $(\mathrm{P}<0.001)$ compared to the other regions. In the Netherlands the overall prevalence of antibodies to B. burgdorferi was $9 \%(91 / 1052)$

Dogs. The prevalence found in dogs varied from $23 \%$ (Friesland) to $15 \%$ (Noord-Brabant). However, no region showed a significant higher or lower prevalence. A total of $18 \%(212 / 1177)$ of all dogs tested in the Netherlands showed antibodies against $B$. burgdorferi.

Cattle. The highest prevalence in cattle was found in Overijssel $(20 \%)$ which was significantly higher $(\mathrm{P}<0.001)$ compared to all other regions except Drenthe $(15 \%)$ and Groningen (13\%). Noord-Holland, Utrecht and Noord-Brabant displayed a prevalence of respectively $3 \%, 2 \%$ and $4 \%$ which was significantly lower $(\mathrm{P}<0.05)$ compared to the rest of the Netherlands where the prevalence varied from $20 \%$ to $7 \%$ between the different regions. Of all tested cattle sera, $9 \%$ (369/ 3919 ) of the sera showed antibodies to B. burgdorferi.

Sheep. Because the blood samples of the 2288 sheep were not identified for each region of the Netherlands, prevalence data for sheep were not listed in Figure I. In sheep, the highest prevalence was found in the western area of the Netherlands $(17 \%)$ and Noord-Brabant $(15 \%)$ which was significantly $(\mathrm{P}<0.001)$ higher compared to the northern area and eastern area of the Netherlands $(4 \%)$. Overijssel and Gelderland 


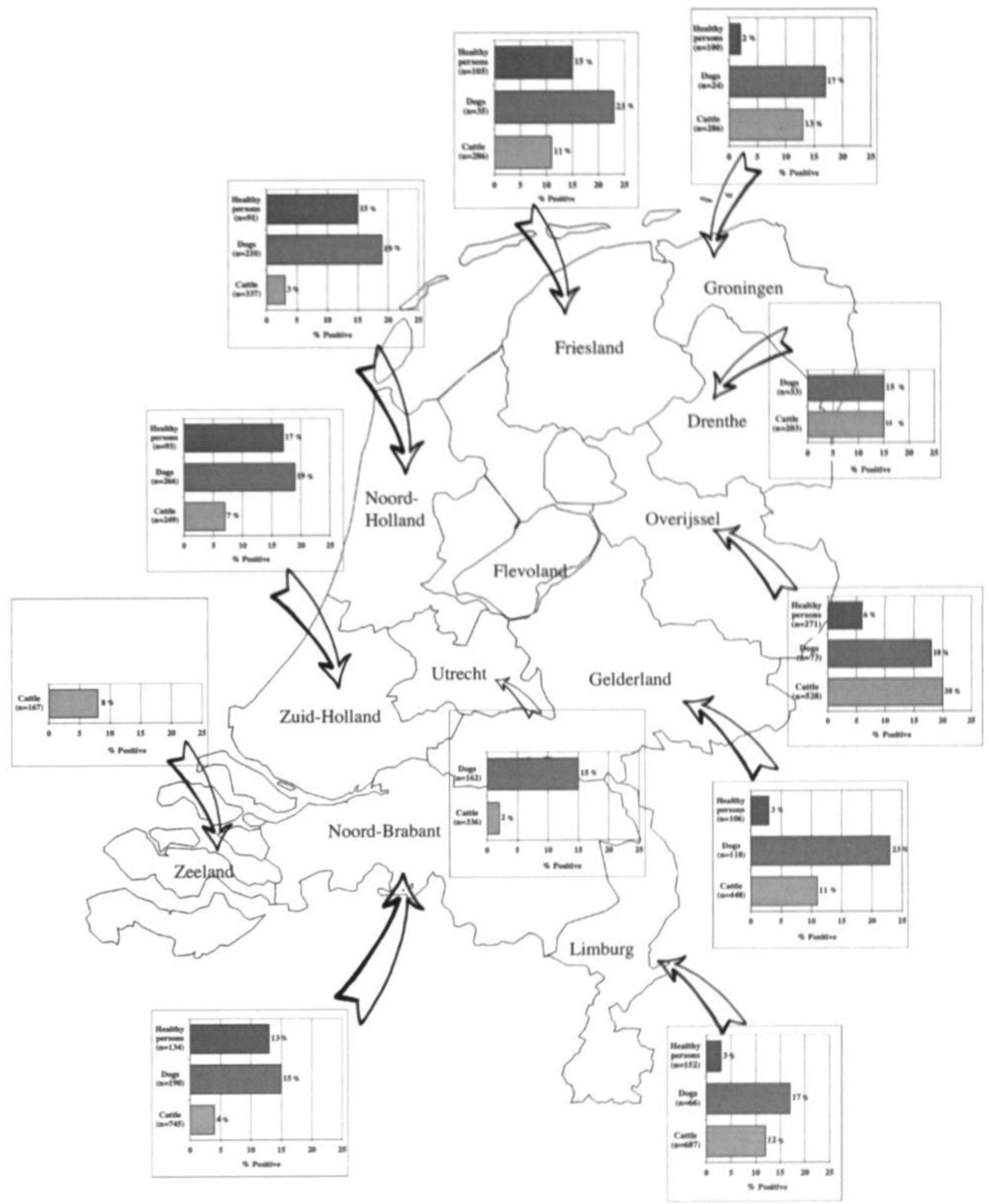

Figure I. The Netherlands: prevalence of antibodies to Borrelia burgdorferi in healthy persons, dogs and cattle in different regions. 
showed both a prevalence of $8 \%$ which was significantly lower $(P<0.001)$ than the western area of the Netherlands $(17 \%)$ but higher than the northern area (4\%) of the Netherlands $(\mathrm{P}<0.05)$. Of all sheep studied $10 \%(235 / 2288)$ proved positive for antibodies against $\boldsymbol{B}$. burgdorferi.

\section{DISCUSSION}

In this study a species independent EIA was used for all sera tested which has not only facilitated the testing of these large numbers, but also made comparison of the results of different animal populations more reliable. Currently, enzyme immuno assays (EIA) are the most frequently used tests for determination of antibodies to B. burgdorferi in humans as well as in animals. To aid clinical diagnosis the major drawback of these tests is that they cannot differentiate between a past (sub)clinical infection or overt disease. This is, however, of no importance for the study of infection incidence and the prevalence of antibodies to B. burgdorferi in populations.

In human serology, specificity in early LB is mainly hampered by Epstein-Barr virus and cytomegalovirus infections whereas in late LB, loss in specificity caused by well-defined infections mimicking LB were less explicit [48, 49]. Therefore, when studying the seroprevalence of $\mathrm{IgG}$ antibodies to $\boldsymbol{B}$. burgdorferi in humans, the influence of infections by cross-reacting microorganisms on the specificity of the test can assumed to be minimal.

In cattle, other Borrelia species like B. theileri, and $B$. coriaceae are known to cause infections: theileriosis and epizootic bovine abortion respectively $B$. theileri and $B$. coriaceae share epitopes with $B$. burgdorferi sensu lato and could cause false positive reactions in LB serology [50-52]. However cross-reaction of B. theileri and B. coriaceae has only been described in immunofluorescence tests and has never been observed in EIA tests [53]. Furthermore as B. theileri and $B$. coriaceae do not occur in the Netherlands, no cross-reactions caused by infections with these micro-organisms are to be expected in the Netherlands. However spirochetes other than Borrelia spp. are involved in a common occurring infection in Dutch cattle herds: digital dermatitis [54, 55]. Although a low seropositive response to the $41-\mathrm{kD}$ flagellin protein of $B$. burgdorferi has been reported from herds with digital dermatitis $[56,57]$, it is unlikely that a single response to the 41 $\mathrm{kD}$ protein elicits a high response in EIA systems using whole cell antigens. Therefore, false positive outcomes as the result of digital dermatitis is expected to be limited.

In dogs, serodiagnosis may be hampered by other spirochetal as well as non-spirochetal organisms, e.g. Leptospira interrogans or Escherichia coli [58-60]. As in the Netherlands most dogs are yearly vaccinated against leptospirosis, a high prevalence of antibodies against leptospires might be expected. Antibodies to leptospires have been assumed to cross-react in conventional EIA's for antibodies to B. burgdorferi and therefore, theoretically might cause false positive reactions in tests for B. burgdorferi antibodies. However this is not substantiated in the published litterature $[22,61,62]$ and could not be confirmed in this or previous study [47] as sera of dogs hypervaccinated against leptospirosis used for potency testing of a leptospiral vaccine, were negative for antibodies to B. burgdorferi. This is in accordance with the results of others [63]. In addition Treponema spp. involved in severe periodontal disease of dogs [60] could theoretically cause false positive results in B. burgdorferi serology, but as this disease is very uncommon in Dutch dogs, this seems unimportant for the results in this study. Based on the facts that either micro-organisms known to cause cross-reactivity do not occur in the Netherlands, or cross-reactivity has only been found in test systems other than EIA, it can be assumed that cross-reactivity has not influenced the results of the EIA test in this study.

In all regions studied, B. burgdorferi was endemic, which was to be expected as the vector ticks: Lxodes ricinus are to be found in all the regions studied. In Sweden it has been shown that $B$. burgdorferi infections only occurred in the South of the country, were Lxodes ricinus ticks can thrive, but not in the north of Sweden, where it is too cold during the winter for Lxodes ticks to survive [64].

Data of Lyme disease seroprevalence has been published for various European countries or areas [65]. The range of antibodies to $\boldsymbol{B}$. burgdorferi in blood donors or control subjects shows the highest prevalence in Ireland $(15 \%)$ and the lowest in Austria $(8 \%)$ and Germany $(6 \%)$. In southern Europe the highest prevalence was found in Croatia (43\%) while Greece (1\%) showed the lowest prevalence. In Italy the range of antibodies to B. burgdorferi in blood donors varied from $2 \%$ in Lazio to $11 \%$ on the island Sicily. In France 10\% of the blooddonors coming from central France showed antibodies to B. burgdorferi. In Switzerland $11 \%$ of the healthy blooddonors showed IgG antibodies to $B$. burgdorferi [66]. For the USA no figures are available about the prevalence of antibodies to $B$. burgdorferi in healthy blood donors, but a Lyme disease cases surveillance performed by CDC from 1992-1998 showed temporal as well as geographic trends [67]. For dogs, antibodies to B. burgdorferi have been reported from Denmark (16\%) [68], Germany (2- 61\%) [69-72], Switzerland (11\%) [73], Slovakia (18-71\%) $[74,75]$, Spain $(21 \%)[76]$, France $(6-27 \%)[35,77,78]$ and the UK $(21 \%)$ [79]. In the USA prevalence of antibodies to B. burgdorferi in dogs varied from $2 \%$ to $70 \%[41,44,80]$. Serologic surveys for antibodies to B. burgdorferi in sheep showed a prevalence of $14 \%$ in Italy [36], ranged from $0 \%$ to $20 \%$ in Norway [37] and varied from $38 \%-53 \%$ in France [35]. Seroepidemiological reports of $B$. burgdorferi exposure of cattle showed prevalences in various ranges; $25 \%-33 \%$ in Germany $[69,81], 5 \%-53 \%$ in France [35] and $7 \%-17 \%$ in the state of Wisconsin, USA. [11].

The most likely explanation for the various prevalences found between the species and regions studied is the exposure to Ixodes-ticks. However the prevalence of $\boldsymbol{B}$. burgdorferi in ticks could also have influenced the observed differences in antibody prevalence between the regions. For people and dogs recreating in the same habitat an agreement in the prevalence of antibodies to $B$. burgdorferi has been reported [47] and are consistent with the findings for the western regions studied in the Netherlands.

The foundings that dogs have the highest prevalence of antibodies against B. burgdorferi is likely to be explained by the fact that dogs and ticks favor the same habitats and 
that dogs are not protected by clothing like humans. In the western regions of the Netherlands, a high prevalence of antibodies to $\boldsymbol{B}$. burgdorferi was found in humans and dogs whereas the prevalence found in cattle showed to be significant lower $(\mathrm{P}<0.05)$. The coastal areas of the Netherlands exist of sand dunes which are a favored habitat by ticks with a high prevalence of $\boldsymbol{B}$. burgdorferi [82] and are intensely used for recreation by people with or without their pet dog. Due to the nature of this recreation, people are often less protected from tick-bites by their minimal clothing, resulting in a higher risk for tick bites which is comparable to that for dogs. In contrast in the western regions of the Netherlands, cattle is grazed on low lands behind the dunes, which are often below sea level. This wet land is not a suitable biotope for ticks and therefore cattle is not exposed to $B$. burgdorferi. This hypothesis which explains the high prevalence in the western coastal areas among humans and dogs and the significantly lower prevalence among cattle in the same regions, is also supported by the observation in the north of the Netherlands for sheep. In the northern area, the observed prevalence in sheep was significantly lower $(P<0.001)$ compared to the prevalence found in cattle. In the northern regions, sheep are kept in wet pastures surrounded by ditches because this is cheap and effective fencing, whereas cattle are also grazed on dry land close to forests. The high prevalence observed in sheep from the western regions is probably due to the fact that a disproportional larger part of the sheep sera were collected on the Dutch North Sea islands where not only sheep farming is very common, but which are also heavily infested with Lxodes-ticks with a high infection rate with $B$. burgdorferi [82].

In the east of the Netherlands, the lower prevalence in the healthy persons versus the higher prevalence in dogs also could be explained by the nature of recreation. In this region thickly wooded areas or forest are favored recreational areas. People wandering in these areas mostly stick to the roads and wear outfits which provide good protection against tick-bites. Therefore they have a considerably lower risk of becoming infected compared to dogs which walk more into the bushes, resulting in a lower prevalence of antibodies. The significant lower prevalence in sheep $(\mathrm{P}<0.001)$ versus cattle found in the eastern regions, could be accounted by the fact that sheep are grazed on short grassland close to farms, which is less infested by Lxodes ticks and that especially young cattle is often put in pastures in the woods. It has also been proven that the risk of tick infestation progressively decreases from the fence line into the pasture [83].

Conclusion. In all regions of the Netherlands humans and animals can be infested by Ixodes ricinus ticks and exposed to a $\boldsymbol{B}$. burgdorferi-infection and are therefore at risk for LB. The differences found in antibody prevalence to $B$. burgdorferi in the different regions can be explained by the differences in biotopes that are favorable for Lodes ricinus ticks and the accessibility of ticks to humans and the animal species studied. The prevalence of $\boldsymbol{B}$. burgdorferi antibodies in dogs is a better indication for the risks of a B. burgdorferi-infection in humans compared to cattle or sheep, as dogs and humans share more commonly the same biotopes.

\section{REFERENCES}

1. Barbour AG: Isolation and cultivation of Lyme disease spirochetes. Yale Journal of Biology and Medicine (1984) 57: 521-525

2. Burgdorfer W, Barbour AG, Hayes SF, Benach J, Grunwaldt E, Davis JP: Lyme disease: a tick-borne spirochetose? Science (1982) 216: $1317-1319$

3. De Koning J, Bosma RB, Hoogkamp Korstanje JA: Demonstration of spirochaetes in patients with Lyme disease with a modified silver stain. Journal of Medical Microbiology (1987) 23: 261-267

4. Nohlmans MK, van den Bogaard AE, Blaauw AA, van Boven CP: [Prevalence of Lyme borreliosis in The Netherlands [Prevalentie van Lyme-borreliose in Nederland.]. Nederlands Tujdschrift Voor Geneeskunde (1991) 135: 2288-2292

5. Hjelle A: Borrelia-like organisms in the urine of lambs suffering from eczema facialis. Nature (1966) 212: 856-857

6. Schillhorn TW, Leyendekkers GJ: Borrelia theilerii (Laveran 1903) in cattle in the netherlands. Tjjschrif Voor Diergeneeskunde (1971) 96: 1028-1031

7. Nadelman RB, Wormser GP! Lyme borreliosis. Lancet (1998) 352: 557.565

8. Stanek G, O'Connell S, Cimmino M, al. et European Union concerted action on risk assessment in Lyme borreliosis: clinical case definition for Lyme borreliosis. Wiener Klinische Wochenschrif (1996) 108: 741-747

9. Cohen D, Bosler EM, Bemard W, Meirs D, Eisner R, Schulze TL: Epidemiologic studies of Lyme disease in horses and their public health significance. Annals of the New York Academy of Sciences (1988) 539: 244-257

10. Hovmark A, Asbrink E, Schwan O, Hederstedt B, Christensson D: Antibodies to Borrelia spirochetes in sera from Swedish cattle and sheep. Acta Veterinaria Scandinavica (1986) 27: 479-485

11. Ji BX, Collins MT: Seroepidemiologic survey of Borrelia burgdorferi exposure of dairy cattle in Wisconsin. American Journal of Veterinary Research (1994) 55: 1228-1231

12. Lindenmayer JM, Marshall D, Onderdonk AB: Dogs as sentinels for Lyme disease in Massachusetts. American Journal of Public Health (1991) 81: 1448-1455

13. Magnarelli LA, Anderson JF, Schreier AB: Persistence of antibodies to Borrelia burgdorferi in dogs of New York and Connecticut. Journal of the American Veterinary Medical Association (1990) 196: 1064-1068

14. Muhlemann MF, Wright DJ, Black C: Serology of Lyme disease [letter]. Lancet (1986) 1: 553-554

15. Parker JL, White KK: Lyme borreliosis in cattle and horses: a review of the literature. Comell Veterinarian (1992) 82: 253-274

16. Ubico SR, McLean RG, Cooksey LM: Susceptibility of Selected Rodent Species from Colorado to Borrelia burgdorferi. Journal of Wildlife Diseases (1996) 32: 293-299

17. Wells SJ, Trent AM, Robinson RA, Knutson KS, Bey RF: Association between clinical lameness and Borrelia burgdorferi antibody in dairy cows. American Journal of Veterinary Research (1993) 54: 398-405

18. Bosler EM, Evans RD, Schneider EM: Biopsy of canine ear tissue for detection of Borrelia burgdorferi following Ixodes dammini feeding. FEMS Microbiology Letters (1992) 78: 317-319

19. Burgess EC: Experimentally induced infection of cats with Borrelia burgdorferi. American Journal of Veterinary Research (1992) 53: 1507-1511

20. Grauer GF, Burgess EC, Cooley AJ, Hagee JH: Renal lesions associated with Borrelia burgdorferi infection in a dog. Journal of the American Veterinary Medical Association (1988) 193: 237-239 
21. Kurtenbach K, Carey D, Hoodless AN, Nuttall PA, Randolph SE: Competence of Pheasants as Reservoirs for Lyme-Disease Spirochetes. Journal of Medical Entomology (1998) 35: 77-81

22. Magnarelli LA, Anderson JF, Schreier AB, Ficke CM: Clinical and serologic studies of canine borreliosis. Journal of the American Veterinary Medical Association (1987) 191: 1089-1094

23. Stuen S, Fridriksdottir V: Experimental inoculation of sheep with Borrelia burgdorferi. Veterinary Record (1991) 129: 315

24. Bauerfeind R, Kreis U, Weiss R, Wieler LH, Baljer G: Detection of Borrelia burgdorferi in Urine Specimens from Dogs by a Nested Polymerase-Chain-Reaction. Zentralblatt für Bakteriologie (1998) 287: $347-361$

25. Burgess EC: Borrelia burgdorferi infection in Wisconsin horses and cows. Annals of the New York Academy of Sciences (1988) 539: 235-243

26. Burgess EC, Wachal MD, Cleven TD: Borrelia burgdorferi Infection in Dairy-Cows, Rodents, and Birds from 4 Wisconsin Dairy Farms. Veterinary Microbiology (1993) 35: 61-77

27. Dorward DW, Schwan TG, Garon CF: Immune capture and detection of Borrelia burgdorferi antigens in urine, blood, or tissues from infected ticks, mice, dogs, and humans. Journal of Clinical Microbiology (1991) 29: 1162-1170

28. Hyde FW, Johnson RC, White TJ, Shelburne CE: Detection of antigens in urine of mice and humans infected with Borrelia burgdorferi, etiologic agent of Lyme disease. Journal of Clinical Microbiology (1989) 27: 58-61

29. Manion TB, Khan MI, Dinger J, Bushmich SL: Viable Borrelia burgdorferi in the Urine of 2 Clinically Normal Horses. Journal of Veterinary Diagnostic Investigation (1998) 10: 196-199

30. Tuomi J, Rantamaki LK. Tanskanen R: Experimental infection of cattle with several Borrelia burgdorferi sensu lato strains; immunological heterogenity of strains as revealed in serological tests. Veterinary Microbiology (1998) 60: 27-43

31. Ellis WW: Proceedings of a Lyme Disease Workshop. (1991) Aberdeen:

32. Burgess EC, Gendron Fitzpatrick A, Wright WO: Arthritis and systemic disease caused by Borrelia burgdorferi infection in a cow. Journal of the American Veterinary Medical Association (1987) 191: $1468-1470$

33. Lischer CJ, Leutenegger CM, Braun U, Lutz H: Diagnosis of Lyme disease in two cows by the detection of Borrelia burgdorferi DNA Veterinary Record (2000) 146: 497-499

34. Carlomagno G, Luksa V, Candussi G, Rizzi GM, Trevisan G: Lyme Borrelia positive serology associated with spontaneous abortion in an endemic Italian area. Acta Europaea Fertilitatis (1988) 19: 279 . 281

35. Cabannes A, Hernandez JC, Lucchese F, Appriou M, Tribouleyduret $\mathrm{J}$ : Epidemiology of Lyme-Disease in Cattle and Sheep, in Gironde (France). Médecine et Maladies infectieuses (1997) 27: 878-883

36. Ciceroni L, Simeoni J, Pacetti AI, Ciarrocchi S, Cacciapuoti B: Antibodies to Borrelia burgdorferi in sheep and goats. Alto AdigeSouth Tyrol, Italy. The new microbiologica (1996) 19: 171-174

37. Fridriksdottir V, Nesse LL, Gudding R: Seroepidemiological studies of Borrelia burgdorferi infection in sheep in Norway. Journal of Clinical Microbiology (1992) 30: 1271-1277

38. Mitchell GBB, Smith IW: Lyme-Disease in Scotland - Results of a Serological Study in Sheep. Veterinary Record (1993) 133: 66-67

39. Greene RT: An update on the serodiagnosis of canine Lyme borreliosis. Journal of Veterinary Internal Medicine (1990) 4:167. 171

40. Jacobson RH, Chang YF, Shin SJ: Lyme-Disease - Laboratory Diagnosis of Infected and Vaccinated Symptomatic Dogs. Seminars in Veterinary Medicine and Surgery of Small Animals (1996) 11: 172-182

41. Magnarelli LA, Anderson JF, Kaufmann AF, Lieberman LL,
Whitney GD: Borreliosis in dogs from southern Connecticut. Journal of the American Veterinary Medical Association (1985) 186: 955-959

42. Callister SM, Jobe DA, Schell RF, Lovrich SD, Onheiber KL, Korshus JB: Detection of borreliacidal antibodies in dogs after challenge with Borrelia burgdorferi-infected Ixodes scapularis ticks. Journal of Clinical Microbiology (2000) 38: 3670-3674

43. Komblatt AN, Urband PH, C. SA: Arthritis caused by Borrelia burgdorferi in dogs. Journal of the American Veterinary Medical Association (1985) 186: 960-964

44. Levy SA, Magnarelli LA: Relationship between development of antibodies to Borrelia burgdorferi in dogs and the subsequent development of limb/joint borreliosis. Journal of the American Veterinary Medical Association (1992) 200: 344-347

45. Dambach DM, Smith CA, Lewis RM, Vanwinkle TJ: Morphologic, immunohistochemical, and ultrastructural characterization of a distinctive renal lesion in dogs putatively associated with Borrelia burgdorferi infection: 49 cases (1987-1992). Veterinary Pathology (1997) 34: 85-96

46. Bishop L, Strandberg JD, Adams RJ, Brownstein DG, Patterson R: Chronic active hepatitis in dogs associated with leptospires. American Journal of Veterinary Research (1979) 40: 839-844

47. Goossens HAT, van den Bogaard AE, Nohlmans MKE: Dogs as sentinels for human Lyme borreliosis in The Netherlands. Journal of Clinical Microbiology (2001) 39: 844-848

48. Goossens HAT, Nohlmans MKE, van den Bogaard A: Epstein-Barr virus and cytomegalovirus infections cause false-positive results in IgM two-test protocol for early Lyme borreliosis. Infection (1999) 27: 231

49. Goossens HAT, van den Bogaard AE, Nohlmans MKE: Evaluation of fifteen commercially available serological tests for diagnosis of lyme borreliosis. European Journal of Clinical Microbiology and Infectious Diseases (1999) 18: 551-560

50. Johnson RC, Burgdorfer W, Lane RS, Barbour AG, Hayes SF, Hyde FW: Borrelia coriaceae sp. nov.:Putative agent of epizootic bovine abortion. International Journal of Systematic Bacteriology (1987) 37: $72-74$

51. Osebold JW, Osburn BI, Spezialetti R, Bushnell RB, Stott JL: Histopathologic changes in bovine fetuses after repeated reintroduction of a spirochete-like agent into pregnant heifers: association with epizootic bovine abortion. American Journal of Veterinary Research (1987) 48: 627-633

52. Osebold JW, Spezialetti R, Jennings MB, Pritchett RF, Bushnel RB: Congenital spirochetosis in calves: association with epizootic bovine abortion. Journal of the American Veterinary Medical Association (1986) 188: 371-376

53. Rogers AB, Smith RD, Kakoma I: Serologic cross-reactivity of antibodies against Borrelia theileri, Borrelia burgdorferi, and Borrelia coriaceae in cattle. American Journal of Veterinary Research (1999) 60: 694-697

54. Choi BK, Nattermann H, Grund S, Haider W, Goebel UB: Spirochetes from digital dermatis lesions in cattle are closely related to treponemes associated with human periodontitis. International Journal of Systematic Bacteriology (1997) 47: 175-181

55. Rijpkema SGT, David GP, Hughes SL, Woodward MJ: Partial identification of spirochaetes from two dairy cows with digital dermatitis by polymerase chain reaction analysis of the $16 \mathrm{~S}$ ribosomal RNA gene. Veterinary Record (1997) 140: 257-259

56. Blowey RW, Carter SD, White AG, Barnes A: Borrelia burgdorferi infections in UK cattle: a possible association with digital dermatitis. Veterinary Record (1994) 135: ??

57. Demirkan I, Walker RL, Murray RD, Blowey RW, Carter SD: Serological Evidence of Spirochaetal Infections Associated with Digital Dermatitis in Dairy Cattle. Veterinary Journal (1999) 157: 
$69-77$

58. Fawcett PT, Rose CD, Gibney KM: Comparative evaluation of adsorption with E.coli on ELISA tests for lyme borreliosis. Journal of Rheumatology (1995) 22: 684-688

59. Shin SJ. Chang YF, Jacobson RH, Shaw E, Lauderdale TL, Appel MU, Lein DH: Cross-reactivity between $B$. burgdorferi and other spirochetes affects specificity of serotests for detection of antibodies to the lyme disease agent in dogs. Veterinary Microbiology (1993) 36: 161-174

60. Vanveen TWS, Murphy AJ, Colmery B: False-Positive Borrelia burgdorferi Antibody-Titers Associated with Periodontal-Disease in Dogs. Veterinary Record (1993) 132: 512

61. Kasbohrer A, Liebisch G, Schonberg A, Liebisch A: Serological Diagnosis of Lyme Borreliosis - Development and Validation of a Test System for Epidemiologic Investigations in Dogs. Deutsche Tierarztliche Wochenschrift (1994) 101:476-481

62. Liebisch A, Liebisch G, Kasbohrer A: Diagnosis of Lyme-Disease in the Dog. Praktische Tierarzt (1994) 75: 381

63. Keller LS, Molstad SM, Levy SA: The incidence of leptospirosis cross-reactivity in Borrelia burgdorferi ELISA testing. Abstract Laboratory Animals Medical Poster Presentations (1992) AVMA Convention:

64. Jaenson TGT, Talleklint L, Lundqvist L, Olsen B, Chirico J, Mejlon H: Geographical-Distribution, Host Associations, and Vector Roles of Ticks (Acari, Ixodidae, Argasidae) in Sweden. Journal of Medical Entomology (1994) 31: 240-256

65. Santino I. Dastoli F, Sessa R, DelPiano M: Geographical incidence of infection with Borrelia burgdorferi in Europe. Panminerva Medica (1997) 39: 208-214

66. Altpeter ES, Meier C: [Epidemiological aspects of neurological complications of Lyme borreliosis in Switzerland. A casecontrol study] [Epidemiologische Aspekte der neurologischen Komplikationen der Lyme-Borreliose in der Schweiz.Eine FallKontrollstudie. ]. Schweizerische Medizinische Wochenschrift. Journal Suisse de Medecine (1992) 122: 22-26

67. CDC: Surveillance for Lyme Disease - United States, 1992 - 1998. MMWR (2000) 49: 1-12

68. Hansen K, Dietz HH: Serosurvey for antibodies to Borrelia burgdorferi in Danish dogs. APMIS (1989) 97: 281-285

69. Kasbohrer A, Schonberg A: [Serologic studies of the occurrence of Borrelia burgdorferi in domestic animals in Berlin (West)] Serologische Untersuchungen zum Vorkommen von Borrelia burgdorferi bei Haustieren in Berlin (West). Berliner und Munchener Tierarztliche Wochenschrift (1990) 103: 374-378

70. Liebisch A, Liebisch G: Lyme-Borreliosis in Dogs - Bibliographical Review and Findings from Northern Germany. Monatshefte Fur Veterinarmedizin (1993) 48: 479-487

71. Liebisch G, Liebisch A: Lyme-borreliosis in dogs: Risk of infection. interpretation of laboratory diagnosis and vaccination. Praktische Tierarzt (1999) 80: 404-409

72. Wittenbrink MM, Failing K, Krauss H: Enzyme-linked immunosorbent assay and immunoblot analysis for detection of antibodies to Borrelia burgdorferi in dogs - The impact of serum absorption with homologous and heterologous bacteriae. Veterinary Microbiology (1996) 48: 257-268

73. Pfister K, Bigler B, Nesvadba J, Green L, al, e: Borrelia burgdorferi in dogs in Switzerland. Zentralbl Bakteriol (1989) 18: 26-31

74. Stefancikova A, Skardova I, Petko B, Janovska D, Cyprichova V: Antibodies IgG to Borrelia burgdorferi in Dogs from Kosice Region. Veterinarni Medicina (1996) 41: 83-86

75. Stefancikova A. Tresova G. Pet'ko B. Skardova I. Sesztakova E: Elisa comparison of three whole-cell antigens of Borrelia burgdorferi sensu lato in serological study of dogs from area of Kosice, eastern Slovakia. Annals of Agricultural and Environmental Medicine (1998) 5: 25-30
76. Delgado S, Carmenes P: Seroepidemiological survey for Borrelia burgdorferi (Lyme disease) in dogs from northwestern of Spain. European Joumal of Epidemiology (1995) 11: $321-324$

77. Davoust B, Boni M: Lyme-Disease in Dogs - Seroepidemiological Survey in the South-Bast of France. Médecine et Maladies infectieuses (1998) 28: 408-409

78. Doby JM, Chevrier S, Couatarmanac'h A: Tickborne Borrelia burgdorferi infection in dogs in westem France. Systematic serological survey of 806 hunting dogs and 88 military dogs in 14 Departments [La spirochetose a tiques par Borrelia burgdorferi chez les chiens dans l'ouest de la France. Examens serologiques systematiques de 806 chiens de meute et 88 chiens militaires de 14 departements.]. Recueil de Medecine Veterinaire (1988) 164: 367. 374

79. May C, Carter SD, Barnes A, Bell S, Bennett D: Serodiagnosis of Lyme disease in UK dogs. Journal of Small Animal Practice (1991) 32: $170-174$

80. Schulze TI, Bosler EM, Shisler JK, Ware IC, Lakat MF, Parkin WE: Prevalence of canine Lyme disease from an endemic area as determined by serosurvey. Zentralblatt fur Bakteriologie Mikrobiologie und Hygiene Series A (1986) 263: 427-434

81. Krampitz HE, Bark S: [Epidemiology of Ixodes-Borreliosis in Southern Germany] Zur Epidemiologie der Ixodes-Borreliose in Suddeutschland. Immunitat und Infektion (1987) 15: 141-145

82. Nohlmans MK, de Boer R, van den Bogaard AE, Blaauw AA, P. vBC: [Occurrence of Borrelia burgdorferi in Ixodes ricinus in The Netherlands] Voorkomen van Borrelia burgdorferi in Ixodes ricinus in Nederland. Nederlands Tijdschrif Voor Geneeskunde (1990) 134: 1300-1303

83. Schmidtmann ET, Carroll JF, Potts WJE: Host-Seeking of Blacklegged Tick (Acari, Ixodidae) Nymphs and Adults at the Woods Pasture Interface. Journal of Medical Entomology (1994) 31: 291-296 



\section{General discussion}

Immunoserological assays for the diagnosis of Lyme borreliosis (LB) were developed immediately after isolation of the causative micro-organism. They are now commonly used for laboratory confirmation of this disease. High demand undoubtedly has provided a potent stimulus for the development and marketing of these assays. World-wide, first-step assays, including enzymelinked immunosorbent assays (EIAs), immunofluorescent assays (IFAs), or immunodot techniques, and second-step (supplemental) Western immunoblot assays (WB) are used in clinical laboratories. In view of the large interest in these tests, it is important for physicians and other health care professionals to be aware of the strengths and limitations of these tests so that they are used and interpreted correctly. In 1989, Magnarelli wrote an editorial in the Journal of American Medical Association about the quality of immunoserological laboratory tests for LB. Most of the commercial and in-house tests at that time available, did not meet the desired performance standards. Especially the lack of test specificity resulted in lingering misconceptions about the protean clinical nature of LB. Because of common false positive test results, virtually any constellation of symptoms was attributed to B.burgdorferi infections. This in turn, caused an inappropriate demand for more serological testing and was a vicious cycle that resulted in more false positive results.

In the 90's the tide turned slowly. In 1995, the Centers for Disease Control and Prevention (CDC) in Atlanta, in conjunction with the Association of State and Territorial Public Health Laboratory Directors, initiated a fundamental change in immunoserological testing for LB. A conditional two-step serological testing system was recommended. A serum specimen with a positive or equivocal first-step result should be further tested with a WB test. The serum should only be considered positive if the results of both tests had been positive. In addition, evidence based recommendations for WB interpretations were suggested. However, concerns have been raised about the performance of individual test kits. Another important item of the same testing recommendations is that in patients with an illness of longer than 30 days. the IgG immunoblot for LB should be positive. This recommendation reflects the natural antibody respons and the low specificity of the IgM immunoblot. Unfortunately this recommendation is often neglected. Careful selection of patients to be tested for LB has been reported to improve the specificity of immunoserological tests for LB.

The meaning of the words 'diagnostic testing' and 'laboratory diagnosis' have changed into 'laboratory confirmation 'to show the limitations of immunoserological testing. None of the immunoserological tests for LB actually should be defined as "screening" tests, because all tests lack sufficient sensitivity to be used alone for this purpose. Immunoblotting should be considered rather a "supplementary" test than a "confirmatory" assay for first-step tests. Since it shares the same antigens, it is not an independent test. Moreover it lacks the specificity that may be expected for confirmatory tests as shown in patients with Epstein-Barr virus or cytomegalovirus infections where a false positive LB reaction was found. Therefore in case of testing for early LB, preferably the exclusion of these infections should be considered.

A major step forward in the evaluation and standardization of serodiagnostics for LB would be the establishment of a reference laboratory that could supply a well defined and sufficiently large panel of serum specimens to be used for evaluating LB test kits. Such a panel should not only consist of sera from LB patients in the various stages of the disease, healthy volunteers from endemic and non-endemic areas, but also contain sera of patients with other infections that cross-react in LB serology, and with diseases clinically mimicking LB. Ideally such a reference laboratory should not only make sera available, but also control and update these serum panels. It could also take a key position in performance testing of new test kits and making the results public available. This approach would improve the quality and validity of performance testing considerably. Further, this would also enable laboratories to make an informed choice from the many available tests for $\mathrm{LB}$ and provide clinicians with information on the predictive value of test results in the clinical situation. However, this is not likely to be realized in the near future. In the USA manufacturers of kits for immunoserological tests for LB are recommended 
to evaluate their tests using a CDC-generated panel of circa 40 serum specimens of LB patients but a non-Lyme patient group is not included. However, use of this serum panel has shown, as reported in several papers, that test performance varies substantially among the evaluated testkits. In Europe no such service is available. This makes it very difficult to evaluate available test kits and to compare their performance. Therefore, for the evaluation of tests, a large number of well defined serum samples should be used which allow a meaningful assessment of sensitivity, specificity and precision. These sera should be tested blind and in duplo in order to make it feasible to evaluate intra- as well as inter-test reproducibility of the assays. It is generally accepted that to achieve realistic performance data of a test, the number of sera in the patient and control groups should reflect the regional clinical laboratory situation, i.e. the numbers of sera in the non-Lyme patient control groups should be circa 5 times larger than in the LB patient group. However this is, mostly neglected as was shown in chapter 3. Especially increasing the number of non-Lyme patient sera, would considerably improve the value of performance testing of LB laboratory tests.

In addition, much confusion about serological tests for LB is caused by the failure to accept the general limitations of immunoserological tests. A positive result of a serological test for LB means that the patient has antibodies against B. burgdorferi. This increases the probability that a particular patient has LB. A negative result implies that the probability is decreased. These probabilities both increase and decrease by a factor that is a function of the sensitivity and specificity of the used test kit. Whether that probability reaches an appropriate threshold to initiate therapy depends on the prevalence of LB being present before the test was done. When this pretest prevalence of LB is low, positive testing will result in more false-positive than true-positive results.

In addition to the optimalisation of serodiagnosis, increased attention should be paid to standardizing methods of quantifying the probability of infection before serum samples of suspected patients are tested, as this very strongly influences the positive predictive value of test results. Therefore, in addition to these guidelines patients with only aspecific symptoms of LB such as myalgia, fatigue, and arthralgias (pre-test probability < 0.20 ) should not be tested or treated for LB. This is very important since a positive test result of these patients does not increase the probability of LB above the decision threshold for initiation of therapy. Neglecting the pre-test prevalence in the selection of patients to be tested for LB results inevitably in many false positive results. Unjustified antibiotic treatment of these patients increases not only the costs of health services but also the occurrence of unwanted side effects of antibiotics in patients and in the community, i.e. emergence of antibiotic resistance. Moreover, a wrong diagnosis causes a delay before the correct diagnosis is made and consequently in appropriate treatment. Testing is indicated for patients with more than one indication highly suggestive for LB (e.g. a swollen knee and a history of a recent tick bite). For these patients, the available immunoserological tests are sufficiently sensitive and specific, provided testing is ordered in accordance to the stage of the disease, i.e. IgM tests for early LB and IgG for the late stages of the disease. As has been demonstrated in chapter 3, combined IgM and IgG testing irrespective of the stage of LB is not to be recommended, because this causes a significant drop in specificity of the tests results. The development of EIA for the detection of specific $\mathrm{IgG}_{1}$ in combination with purified flagellum proteins as antigen could improve the sensitivity of testing for early LB patients without any loss of specificity. However, for testing late LB patients this test system appears to be less sensitive. The development of EIAs for $\mathrm{IgG}_{1}$ detection using purified flagellum proteins in combination with purified proteins highly specific for B. burgdorferi, like ospC, ospC fragments or ospC peptides might result in a single test that can be used with an acceptable sensitivity and specificity in all stages of LB. In case of a proper patient and test selection, serodiagnosis is a valuable help in the diagnosis of LB in humans. The use of EIA tests for the diagnosis of LB in dogs remains questionable, as a positive serological result could not be linked to any clinical symptom that has been related to LB in dogs. The observed high sensitivity for IgM antibodies in dog sera of a commercially available IHA (indirect haemagglutination assay) and its better performance than the tested IgM EIAs, warrants further research into its performance using sera of human patients with early LB. Furthermore, it has been shown that after an infection with B.burgdorferi, dogs become seropositive fast, but in contrast to the findings in humans, this seropositivity lasts only for a relatively short time. This observation makes dogs valuable sentinel animals for estimating the risk for LB in humans. It was also shown that dog ownership per se does not increase the risk for B. burgdorferi infections in humans. The developed species independent EIA, which can be used to test serum samples from different animal species, could simplify sero-epidemiological studies where the prevalence of antibodies to $B$. burgdorferi in various 
animals is investigated. EIA tests are very well suited for this type of studies because sensitivity is more important than specificity in epidemiological studies and large numbers of sera can be processed easily. Analysis of the results of sero-epidemiological studies in humans and domestic animals in different regions in the Netherlands showed that in humans, cattle, sheep and dogs, the risk for a $\boldsymbol{B}$. burgdorferi infection was not correlated with residence in a specific region of the Netherlands, but with the extent of time being spend in specific tick infested biotopes.

It should be kept in mind that EIA, IFA and WB tests always indicate an infection, but cannot differentiate between past infection, subclinical infection or active disease. However to evaluate and compare the performance of tests, serum panels with sufficient sera of LB patients, non-LB patients and healthy volunteers are needed.

It is unlikely that simple immunological tests will be able to differentiate between infection and active disease. Most likely, other types of confirmatory tests have to be developed for that purpose. Therefore research laboratories and manufacturers of diagnostic tests are still in search of "the holy grail". 



\section{Summary}

Lyme borreliosis (LB) is an infectious disease that is caused by the bacterium $B$. burgdorferi and affects humans and domestic animals. The causative organism belongs to the Spirochaetaceae, a family of relatively long, slender, helically shaped bacteria and is transmitted via the bite of ticks of the genus Lxodes, who are found in all parts of the world with a temperate climate. In some parts of the USA more than $50 \%$ of the Ixodes scapularis ticks have been shown to be infected with $B$. burgdorferi. These ticks transmit $B$. burgdorferi among wildlife, that forms the main reservoir. Therefore LB is a zoonosis. Mice are the main hosts for lxodes ticks and are also the main reservoir of B. burgdorferi. The wood-mouse Apodemus sylvaticus and the bank vole Clethrionomys glareolus are probably the most important reservoir of $B$. burgdorferi in Belgium and the Netherlands and the sheep tick Lxodes ricinus the most important vector. In Europe a reservoir function for approximately 40 mammals and birds has been established and infection rates of 1 . ricinus ticks ranged from $5 \%$ to $34 \%$ for nymphs and from $11 \%$ to $34 \%$ for adult ticks. The risk of acquiring clinical LB after the bite of an infected tick has been estimated to be $1-4 \%$.

Infections with $B$. burgdorferi might result in a plethora of symptoms involving several organ systems. Despite the fact that most of the symptoms of LB have been known, and some associated with tick bites in Europe for more than a century, it was not until 1981 that in the USA the causative organism was isolated, cultured and shown to be the etiological agent. In 1992, B. burgdorferi sensu lato has been split up into several genomic species of which B. burgdorferi sensu stricto, B. garinii and B. afzelii are associated with clinical disease. In Europe all this three genomic species are endemic, but in the USA B. burgdorferi sensu stricto is the only species found so far. There are indications that the different genomic species account for differences in the clinical course of an infection. $B$. afzelii has been associated with cutaneous disorders, B.garinii with neurological symptoms and B. burgdorferi sensu stricto with arthritis, what is indemick in the USA, apart from erythema migrans, the most pathognomonic symptom of LB. Neurological symptoms of LB are rarely seen in the USA.

In humans, an early and a late stage of LB can be recognised. The early stage consists of a localised infection of the skin with as most typical clinical symptom a ring-shaped and usually peripherally expanding rash with central clearing: erythema migrans. This rash occurs at the site of the tick bite and might be followed by a disseminated infection. During the early LB (ELB) numerous spirochetes can be found at the site of the lesion or in case of disseminated ELB in the blood. General malaise and fever might be the only symptoms of disseminated ELB. Arthralgia and myalgia, which are typical intermittent, are the most frequently seen theumatological symptoms of LB and lymphadenosis benigna cutis is a cutaneous manifestation that is mainly seen in children. Furthermore, there is a broad range of neurological symptoms associated with early disseminated LB of which meningoradiculoneuritis (Bannwarths syndrome) is the most frequently occurring. Cardiac involvement is less common and the most common abnormalities are rhythm and conduction disturbances.

Late LB (LLB) marks a persistent infection and may occur month to years after the primary infection. Very few spirochetes are present in the lesions and the disease symptoms might be caused by an (over)reaction of the host. Late Lyme arthritis is typically mono- or oligoarticular and mainly affects large joints, especially the knees. Acrodermatitis chronica atrophicans a late skin disorder of LB, is characterised by atrophy of the skin especially at the site of the causative tick bite.

The clinical symptoms of LB in domestic animals are less well defined. With exception of the cutaneous lesions all other symptoms found in man, have been described in animals with in addition glomerulonephritis and abortion. Lameness combined with malaise is, however, the most important described symptom in animals.

Laboratory methods for the diagnosis of LB either intend to isolate or detect the presence of the causative micro-organism or to measure a specific immune response against it. Detection of B. burgdorferi is possible by means of direct microscopy, antigen detection, isolation and molecular microbiological methods e.g. PCR. However, these methods are not (yet) useful in routine clinical practice because they have a too low sensitivity, 
are laborious and time consuming, require tissue biopsies and/or are not commercially available.

Therefore, at present measuring antibodies against B. burgdorferi is the most used method for laboratory confirmation of a clinical diagnosis of LB. However, several problems are encountered with Lyme serology. The antibody response to B. burgdorferi is variable, sometimes even absent, and slow. The primary immune response is directed against the $41 \mathrm{kD}$ flagellin protein. In the course of the infection, antibodies against a broad range of other B. burgdorferi proteins either specific or non specific are produced. IgM antibodies may not appear until 6 weeks after infection and IgG antibodies may not peak before the onset of the disease and may persist for years, at least in humans. Apart from LB patients that do not develop any measurable antibody response to LB, effective antibiotic therapy early in the course of an infection may prevent a humoral immune response. False positive results can be due to cross-reactivity of B. burgdorferi with other bacteria, mainly other Borrelia. spp., treponemata, virusses or auto-immune diseases. In addition, a large number of people and animals have (had) asymptomatic B. burgdorferi infections causing "false" positive results. This is common especially in humans and animals that are regularly exposed to ticks.

The most commonly used serological tests for LB are the immunofluorescent antibody assay (IFA), enzyme immunoassay (EIA) and Western immunoblot (WB). An indirect haemagglutination assay (IHA) has also been developed and marketed, but has never been widely used. IFA has the advantage that, when performed by experienced personnel, false positive results may be distinguished because of an abnormal fluorescence pattern. Testing of large numbers of samples is, however, time consuming and tiring. With EIA, large numbers of samples can be handled and the results read colorimetrically which not only circumvents the problem of subjectivity, but also made automation of the test feasible. This is important especially when large numbers of samples have to be tested for epidemiological surveys. To increase specificity and sensitivity of EIA and IFA, pre-adsorbtion of serum samples and/or use of selected enriched and/or purified antigens is being practised. WB has the theoretical advantage of detecting antibodies against individual and specific B. burgdorferi proteins. It is however a more complicated test and therefore only recommended as an additional test for samples that are positive in an EIA test to increase specificity without loss of sensitivity.

The main problems with all immunoassays for LB is lack of standardisation and the heterogeneity of the genospecies complex of $B$. burgdorferi and the variability of immune response among infected individuals. Moreover, as these tests cannot differentiate between active disease, recovery and subclinical infections, false positive and false negative results occur. The predictive accuracy of a positive or negative serological result depends on the pre-test likelyhood of LB being present. Therefore requests for LB immunoassays should only be made to confirm LB diagnosis in cases of clinical and epidemiological evidence.

The diagnosis of LB in animals is even more difficult than in humans. Animals lack a pathognomonic marker like EM in human LB. In man, isolation of $B$. burgdorferi from a skin biopsy of this skin lesion is considered as the "golden standard". Asymptomatic infections seem to be even more common in animals. Not only high incidences of seropositivity in healthy animals from endemic areas have been reported, but also the causative micro-organism B. burgdorferi itself has been isolated from healthy dogs. However, only in animals living in LB endemic regions, sero-positivity is found.

In chapter II a summary is presented of the literature published between 1990-2002 concerning the performance of EIA- and WB-tests for the laboratory confirmation of the clinical diagnosis of LB in humans. In total 59 articles are listed. In addition, the information on test characteristics and determination of test performance were evaluated. To estimate the methodological quality of testing, a scoring method was developed for ranking the literature. Various factors were taken into account: the type of antigen(s) used, description of how the tests were performed, the method(s) of performance evaluation, the choice of composition and numbers of positive and negative control sera including the applied clinical definitions. The total score was subdivided into 6 scoring groups. The systematic evaluation of the performance testing of serodiagnostic test for LB in humans shows clearly that the choice and number of patient groups and control groups is not a reflection of the real laboratory situation. In future studies, the expansion of the nonLyme patient control group could help the design of better evaluations and the ability to perform a meta-analysis on the accuracy of these diagnostic tests.

In chapter III the the performance of 11 commercially available EIAs and four WB tests for the detection of IgM and IgG antibodies against B. burgdorferi were compared. A total of 229 serum specimens were used: 
26 from patients with ELB, 13 from patients with LLB, 62 from healthy controls and 128 from patients with disorders clinically mimicking LB and/or known to cause cross-reactivity in LB serological tests (patient control group). In specimens from patients with ELB, the sensitivity of the individual tests ranged from $35 \%$ to $81 \%$ for detection of IgM. In LLB, sensitivity of the tests ranged from $46 \%$ to $92 \%$. In healthy controls the specificity of the tests ranged from $89 \%$ to $100 \%$ and from $82 \%$ to $97 \%$ for IgM and IgG tests, respectively. In the patient control group, specificity of the tests ranged from $75 \%$ to $90 \%$ for IgM and from $84 \%$ to $100 \%$ for IgG. The Behring (Germany) and Genzyme Virotech (Germany) IgM-EIAs showed the best performance in detecting ELB. For the detection of LLB, the Dako (Denmark) IgG test was the best despite its low sensitivity. The maximum sensitivity of Western blotting for detecting IgM in patients with ELB and IgG in patients with LLB was $50 \%$ and $46 \%$, respectively.

When the use of an EIA-WB two-test protocol was applied, an improvement of the specificity and positive predictive values of the EIA results were observed. However, the use of the EIA-WB two-test protocol also caused a significant loss in sensitivity. Patients with Epstein-Barr virus or cytomegalovirus infections who had a positive reaction in the IgM-EIA could not be discriminated from patients with ELB with WB. Hence, positive and negative predictive values in combination with sensitivity and specificity indicated that the exclusion of these infections was more relevant than the confirmation of a positive IgM-EIA with WB.

Furthermore, some laboratories prefer polyvalent EIAs or routinely use IgM- and IgG-EIAs regardless of the stage of the disease or the clinical symptoms observed. Therefore, the performance of combined IgM and IgG testing in our serum pannel was evaluated. The only polyvalent EIA that was tested in chapter II performed poorly in comparison with the monovalent assays. The use of combined IgM and IgG testing significantly improved the sensitivity but, due to cross-reacting IgG and IgM antibodies (mostly non-paired), a significant decrease in specificity was found when compared to IgM and $\mathrm{IgG}$ test results.

In chapter IV the prevalence of IgA, IgM, total IgG and subclasses $\mathrm{IgG}_{14}$ antibodies against $B$. burgdorferi was examined by WB. The sera of 40 ELB patients, 27 LLB patients, 62 healthy controls and 140 non-LB patients were used. Detection of $\mathrm{IgG}_{1}$ versus total IgG showed to be more sensitive in detecting $B$. burgdorferi antigens, especially flagellin $(41 \mathrm{kD})$ protein, but did not improve the performance of WB. The use of $\mathrm{IgG}_{1}$ detection showed an increase in sensitivity and specificity for the ELB patient group compared to the standard IgG and IgM detection method by enzyme immunoassays using purified B. burgdorferi flagellum antigen. However, in an enzyme immunoassay using a total sonicate, sensitivity in detecting ELB and LLB with $\operatorname{IgG}_{1}$ remained lower compared to the detection of ELB by IgM antibodies and LLB by total IgG antibodies. It was concluded that only the use of purified flagella in combination with $\mathrm{IgG}_{1}$ detection might enhance the performance of EIAs for the detection of LB in ELB patients.

In chapter $\mathbf{V}$ the risk of outdoor activity and dog ownership for acquiring LB, the dynamics of antibody response in humans and dogs and the validity of dogs as sentinel animals for the risk at LB in humans was studied. Serum samples from hunters $(\mathrm{n}=440)$, their working dogs $(n=448)$ and hunters without a dog $(n=53)$ were collected in the Netherlands at hunting dog trials and tested for antibodies against B. burgdorferi with a whole-cell EIA. Additionally, 75 healthy city pet dogs were tested. Results of this study indicate that the seroprevalence among active hunting dogs $(18 \%)$ was in the same size of order as the seroprevalence in pet dogs $(17 \%)$ and in hunters $(15 \%)$. Seropositivity of a dog was not a significant indicator of increased risk of LB infection for their owners. No significant rise in seroprevalence was found in dogs older than 24 months. This indicated that seropositivity after an infection with $B$. burgdorferi in dogs is rather short, approximately one year. In humans this is considerably longer but also not life long. Therefore the incidence of B. burgdorferi infections in dogs was larger than in hunters, despite a similar prevalence of seropositivity in hunters and their dogs. Because no positive correlation was observed between seropositivity of the hunter and seropositivity of his dog, direct transfer of ticks between dog and hunter does not seem important and owning a dog should not be considered a risk for LB.

In chapter VI five serological tests for the detection of $\mathrm{IgM}$ and $\mathrm{IgG}$ antibodies against B. burgdorferi sensu stricto were compared in 1177 sera from Dutch dogs: 401 healthy hunting dogs, 100 healthy city dogs, 629 city dogs with various clinical symptoms and 47 huntingdogs with lameness. The results of the in-house species independent EIA (i.e. an EIA which can be used to test serum samples from different animal species) showed a strong agreement (kappa: 0.78-0.81) with the 
experimental and commercially available EIA (Genzyme -Virotech, Germany) for the detection of canine IgG antibodies to B.burgdorferi and could be very useful in seroepidemiological studies for detecting antibodies in various animal species. Furthermore, sensitivity of the in-house EIAs for the detection of antibodies against B. burgdorferi showed to be independent of the antigen used. Serological diagnosis of LB in Dutch dogs with lameness $(n=60)$, neurological $(n=60)$ and skin disorders $(n=52)$ was not affected by the antigenic heterogeneity. The IHA (Diagast@, France) proved to be an interesting tool for the detection of an acute Lyme infection in dogs because of its high sensitivity for IgM antibodies. Dog sera with a high IgM response against B. burgdorferi were identified in $96 \%$ of the cases by the IHA. However, in this study a positive serological result could not be linked to any clinical symptom that has been related to Lyme disease; neither for dogs at high or low risk of a B. burgdorferi infection. Therefore the use of serodiagnostic tests to support the clinical diagnosis of Lyme disease in dogs might be of limited value. Nevertheless the species independent EIA could be valuable in seroepidemiological studies where sera of several different animal species must be tested. Compared to the IgM-EIAs, the IHA showed a higher sensitivity and a better performance in detecting IgM antibodies. This might also be expected in human serum samples and warrants further research with sera of ELB patients.

In chapter VII the prevalence of antibodies to B. burgdorferi in sera of 1052 healthy persons, 1177 dogs, 3919 dairy cows and 2288 sheep from 12 regions of the Netherlands was investigated. The results showed that in all regions of the Netherlands, humans and animals are exposed to B.burgdorferi-infections and are therefore at risk to develop LB. In the western regions, healthy persons showed a higher prevalence $(13 \%-17 \%)$ compared to the eastern regions $(2 \%-6 \%)$ of the Netherlands. The prevalence found in dogs did not differ significantly within the regions studied $(15 \%$ $23 \%$ ). Cattle showed the highest prevalence in the eastern regions $(11 \%-20 \%)$ and lowest in the western regions $(2 \%-8 \%)$. Sheep showed the highest prevalence in the western regions (15-17\%), whereas unexpectedly in the eastern regions the prevalence $(4 \%-8 \%)$ was significantly lower $(\mathrm{P}<0.001)$.

The differences found in the prevalence of the antibodies against $\boldsymbol{B}$. burgdorferi between the regions examined, could be explained by the differences in biotopes that are favorable for Ixodes ricinus ticks and the frequencies by which humans, dogs, cattle and sheep come into contact with these biotopes.

\section{IN CONCLUSION}

A sensitivity and specificity of $100 \%$ will never be reached for any serological test for LB. The fact that in some LB patients a specific antibody response is lacking and asymptomatic infections and cross-reacting antibodies can occur, makes the development of new tests very hard if not impossible. Still, other laboratory tests might be made commercially available, but these are likely to be more costly and laborious. Therefore, at this time and in the near future, the EIA remains the most important test for the laboratory confirmation of the clinical diagnosis of LB . In addition the EIA is an important tool for the study of the epidemiology of B. burgdorferi infections.

In our hands confirmation of a positive EIA test result by WB did not improve the overall results. However for the detection of IgM antibodies in ELB patients, IHA might be another valuable test, as was proven in dogs. Still, its value for the laboratory confirmation of ELB in humans has still to be elucidated.

Despite the observed high prevalence and incidence of B. burgdorferi infections in dogs, clinical LB in dogs seems to be very rare. In human medicine, clinicians should also be aware that the diagnosis LB is primary made on clinical symptoms and that laboratory testing is only recommended in patients whose pretest probability of LB is $\geq 0.20$. If the pretest probability is less, testing will result in more false positive than true positive results. 




\section{Samenvatting}

Lyme borreliose (LB) is een infectieziekte bij mens en dier veroorzaakt door de bacterie Borrelia burgdorferi. Deze bacterie behoort tot de Spirochaetaceae, een familie van lange slanke spiraalvormige bacteriën, die overgedragen worden via de beet van harde teken behorende tot het genus lxodes. Deze teken komen in alle delen van de wereld met een gematigd klimaat voor. LB is een zoönose. Muizen vormen het hoofdreservoir van $B$. burgdorferi en zijn bovendien de belangrijkste gastheren voor Lxodes teken. In België en Nederland is de schapenteek Lxodes ricinus de belangrijkste vector van B. burgdorferien vormen de bosmuis Apodemus sylvaticus en de rosse woelmuis Clethrionomys glareolus het belangrijkste reservoir. In sommige delen van de USA komt het voor dat meer dan $50 \%$ van de Ixodes scapularis teken besmet zijn met $B$. burgdorferi. In Europa varieert de besmettingsgraad van nimfen tussen de $5 \%$ en $34 \%$ en van volwassen teken tussen de $11 \%$ en $34 \%$. Verder is angetoond dat meer dan 40 verschillende vogel- en zoogdiersoorten symptoomloos drager kunnen zijn van B. burgdorferi. Het risico voor de mens op LB na een tekenbeet wordt geschat op $1 \%$ tot $4 \%$.

Een infectie met $B$. burgdorferi kan resulteren in een breed scala van symptomen. Dit veelvoud aan symptomatologie wordt veroorzaakt door het infecterende genospecies, de weerstand van de gastheer, het stadium van de ziekte en het aangetaste orgaansysteem. De meeste ziektebeelden van LB waren in het begin van de vorige eeuw al in Europa bekend en enkele werden geassocieerd met tekenbeten. Toch heeft het tot 1981 geduurd voordat de oorzakelijke bacterie van LB werd geïsoleerd. In 1992 is deze bacterie met de species naam $B$. burgdorferi sensu lato opgesplitst in verschillende genospecies.

B. burgdorferi sensu stricto, B. garinii, en B. afzelii zijn de pathogene genospecies, en zijn in Europa endemisch. Infecties door deze drie genospecies veroorzaken koorts, algehele malaise en erythema migrans (EM). Ze worden daarnaast met verschillende klinische symptomen geassocieerd: B. afzelii met huidaandoeningen in het late stadium van de ziekte, $B$. garinii met neurologische af wijkingen en $B$. burgdorferi sensu stricto met arthritis. In de USA, waar alleen B. burgdorferi sensu stricto voorkomt, zijn dan ook EM en arthritis de meest voorkomende ziektebeelden. Neurologische symptomen en acrodermatitis atroficans worden zelden gezien in de USA.

Bij LB bij de mens wordt een vroeg en een laat stadium van de ziekte onderscheiden.

Het vroege stadium bestaat uit een gelokaliseerde infectie van de huid met als meest typisch klinisch symptoom een ringvormige erythemateuze laesie, die zich cirkelvormig uitbreidt en centraal ophelderd: EM. Gedurende het vroege stadium van LB kunnen talrijke spirocheten op de plaats van de huiduitslag en in geval van een systemische infectic in het bloed aangetoond worden. Deze huiduitslag die ontstaat op de plaats van de tekenbeet geneest veelal spontaan, maar kan ook gevolgd worden door een systemische infectie met griepachtige symptomen zoals algemene malaise met koorts en soms spier- en gewrichtspijnen. Typisch is dat deze arthralgieën en myalgiěn intermitterend voorkomen en dat verschillende gewrichten aangetast kunnen worden. Een andere huidafwijking bij LB: lymphadenosis benigna cutis, komt voornamelijk voor bij kinderen. Het meest frequent voorkomende neurologische symptoom, geassocieerd met het vroege stadium van een gedissemineerde LB, is meningoradiculoneuritis (Bannwarth's syndrome). Myocarditis met ritme- en geleidingsstoornissen als gevolg van een $B$. burgdorferi infectie wordt zelden gezien.

Het late stadium van LB wordt veroorzaakt door een persisterende infectie met B. burgdorferi. Symptomen kunnen pas maanden tot zelfs jaren na de primaire infectie optreden. In het late stadium worden weinig spirocheten in de aangetaste orgaansystemen gevonden en de symptomen worden waarschijnlijk veroorzaakt door een overreactie van het afweersysteem. Late Lyme arthritis is typisch mono- of oligoarticulair en betreft vooral de grote gewrichten, in het bijzonder de knic. Acrodermatitis chronica atrophicans is een late manifestatie van LB en wordt gekenmerkt door atrofie van de huid in het gebied van de oorzakelijke tekenbeet.

De klinische symptomen van LB bij huisdieren zijn minder duidelijk gedefinieerd. Met uitzondering van huidlaesies zijn alle andere bij de mens voorkomende symptomen ook bij dieren beschreven met als aanvulling 
glomerulonephritis en abortus. Kreupelheid in combinatie met malaise is echter het meest beschreven symptoom bij dieren.

De meest gebruikte laboratorium methoden voor LB diagnose berusten op het isoleren of aantonen van de verwekker of het meten van een specifieke immuunrespons gericht tegen B.burgdorferi. De detectie van $B$. burgdorferi is mogelijk door middel van microscopie, het aantonen van specifieke antigenen, isolatie of met behulp van moleculair microbiologische methoden zoals de polymerase chain reactie (PCR). Deze methoden worden echter niet routinematig gebruikt. De redenen hiervoor zijn de lage sensitiviteit en/of grote bewerkelijkheid gepaard met een lange analysetijd. Bovendien zijn weefselbiopten nodig en zijn geen commercięle testkits beschikbaar. Ondanks dat LB serologie een aantal problemen kent is het aantonen van antilichamen tegen $B$. burgdorferi de meest gebruikte laboratorium methode voor de bevestiging van een klinische diagnose van LB.

Een belangrijk gegeven is dat de ontwikkeling van antistoffen tegen $B$. burgdorferi traag kan verlopen en soms geheel kan ontbreken. De eerste antilichamen zijn meestal gericht tegen het $41 \mathrm{kD}$ flagelline eiwit. Later in het verloop van de infectie worden antilichamen gevormd die gericht zijn tegen een groot aantal zowel specifieke als aspecifieke eiwitten van B. burgdorferi. Een IgM respons blijft bij mensen soms uit tot 6 weken na infectie, terwijl IgG antilichamen vaak pas aangetoond kunnen worden als de patient al enige tijd ziek is. $\mathrm{Ze}$ kunnen echter jarenlang na herstel persisteren. Een effectieve behandeling met antibiotica in het vroege stadium van de ziekte kan de immuunrespons afbreken en antilichaamvorming voorkomen. Fout positieve test resultaten komen voor als gevolg van kruisreactiviteit met andere bacteriën, hoofdzakelijk andere Borrelia spp., treponemata maar ook door virus-infecties of autoimmuun ziekten. Daarnaast kunnen ook bij mensen en dieren die eerder een asymptomatische B.burgdorferi infectie hebben doorgemaakt, antilichamen tegen $B$. burgdorferi aangetoond worden terwijl ze niet aan LB lijden. Dit komt vooral voor in populaties van mensen en dieren, die regelmatig met teken in contact komen.

De meest gebruikelijke serologische testen voor LB zijn de immunofluorescent antibody assay (IFA), de enzyme immunoassay (EIA) en de Western immunoblot (WB). De indirect haemagglutination assay (IHA) wordt weing gebruikt. De IFA heeft het voordeel, indien uitgevoerd door ervaren personeel, dat fout positieve resultaten herkend kunnen worden aan de hand van een afwijkend fluorescentie patroon. De test is echter tijdrovend en vooral het correct aflezen van de fluorescentie is bij grote aantallen sera erg bewerkelijk en belastend voor laboratorium medewerkers. De EIA is gemakkelijk uit te voeren en te standardizeren. Bovendien kunnen door automatiseren grote aantallen serummonsters snel getest worden. Dit is vooral belangrijk bij epidemiologische onderzoek. Om de specificiteit van de EIA en de IFA te verhogen wordt meestal gebruik gemaakt van gezuiverde, verrijkte en/of geadsorbeerde antigenen. De WB heeft het theoretische voordeel dat antilichamen tegen individuele en specifieke $\boldsymbol{B}$. burgdorferi antigenen aangetoond worden. Door de complexiteit en relatief hoge kosten van een WB test wordt het gebruik enkel aanbevolen ter bevestiging van een positief EIA resultaat. Hierdoor zou de specificiteit verhoogd worden zonder verlies aan sensitiviteit.

De voornaamste problemen met immunologische testen voor LB zijn: het gebrek aan standaardisatie, de heterogeniteit van het genospecies complex B. burgdorferi sensu lato en de variabiliteit van het immuun antwoord bij geïnfecteerden. Fout positieve resultaten worden bovendien veroorzaakt doordat testen niet differentiëren tussen acute, chronische en convalescente stadia van de ziekte. Bovendien zijn er veel gezonde personen die een asymptomatische infectie hebben doorgemaakt, maar wel een positieve serumtiter hebben ontwikkeld. Omdat de voorspellende waarde van positieve en negatieve serologische testresultaten sterk afhangt van de kans dat de patiënten LB hebben, is een goede klinische preselectie noodzakelijk. Er moeten dus alleen LB testen worden aangevraagd voor patiënten met duidelijk klinische symptomen van LB en waarbij een $B$. burgdorferi infectie op epidemiologische gronden aannemelijk is; dus van patiënten die door een teek zijn gebeten of uit een endemisch gebied komen en een of meerdere symptomen hebben typisch voor LB.

Door het ontbreken van een duidelijk pathognomonisch kenmerk zoals EM, het diffuse ziektebeeld en de grote hoeveelheid symptomen die met een B.burgdorferi infectie worden geassocieerd, is de diagnose van LB bij dieren nog gecompliceerder dan bij de mens. In geval van een $B$. burgdorferi infectie bij de mens kan in een groot percentage van de gevallen de bacterie uit de rand van de huidlaesie met behulp van een biopt geïsoleerd worden. Sera van patiënten met een positieve $B$. burgdorferi kweek, worden in dit geval als de "gouden standaard" beschouwd en gebruikt voor het evalueren van serologische testen voor LB bij de mens. EM komt echter bij dieren niet voor en bovendien is ook bij gezonde dieren de isolatie van 
B. burgdorferi beschreven. Daarom ontbreekt bij dieren een dergelijke "gouden standaard". Ook seropositiviteit als gevolg van asymptomatisch verlopen infecties lijkt bij dieren meer voor te komen dan bij mensen, wat verklaard kan worden door de grotere kans op tekenbeten. Wel is bij dieren seropositiviteit alleen beschreven in gebieden waar LB endemisch is.

In hoofdstuk II is een analyse uitgevoerd van de beschreven prestaties van EIA's en WB's voor de bevestiging van de klinische diagnose van LB bij mensen. In totaal werden 59 artikelen, die verschenen zijn tussen 1990 en 2002 in internationale engelstalige wetenschappelijke tijdschriften, gerangschikt volgens de kwaliteit van de methodiek waarmee de prestaties van deze testen werden beschreven. Met behulp van een score systeem dat opgebouwd was uit 6 scoregroepen werd rekening gehouden met verschillende faktoren zoals: de keuze, samenstelling en aantal positieve en negatieve controle sera, de gebruikte klinische definitie. beschrijving van de testuitvoering. gebruikte antigenen en beschrijving van de evaluatie methodiek. Uit deze systematische evaluatie werd duidelijk dat de keuze en aantallen van de patientengroepen en controle groepen niet overeenstemmen met de daadwerkelijke laboratoriumsituatie. De voornaamste conclusie was dat voor de evaluatie van de prestaties van een test in de klinische situatie naast een aantal sera van klinisch goed gedefinieerde LB patiënten een controle groep bestaande uit sera van niet-Lyme patiënten getest moet worden. Het aantal sera in deze laatste groep dient circa een faktor 5 groter te zijn dan het aantal geteste Lyme sera.

In hoofdstuk III zijn op klinische microbiologische laboratoria veel gebruikte commercieel verkrijgbare EIA's en WB's voor het testen van sera op de aanwezigheid van antilichamen tegen B. burgdorferi onderzocht. De prestaties van 11 EIA's en 4 WB's, die IgM en IgG antilichamen detecteren tegen $B$. burgdorferi werden vergeleken. Hiervoor werd een panel bestaande uit 229 serummonsters gebruikt. Deze sera waren afkomstig van 26 patiënten in het vroege stadium van LB (de vroege LB groep), 13 patiënten in het late stadium van LB (de late LB groep), 62 gezonde vrijwilligers (gezonde controle groep) en een controle groep bestaande uit 128 sera afkomstig van patiënten met ziektebeelden, waarvan de symptomen met die van LB overeenkomen, of die aspecifieke antilichamen tegen $B$. burgdorferi kunnen hebben (kruisreactie): de niet-Lyme patienten groep. In de vroege $\mathrm{LB}$ groep varieerde de sensitiviteit voor alle testen die IgM antilichamen tegen B. burgdorferi detecteren van $35 \%$ tot $81 \%$. In de late Lyme groep varieerde de sensitiviteit van $46 \%$ tot $92 \%$. In de groep met gezonde vrijwilligers varieerde de specificiteit voor alle testen die IgM en IgG detecteren respectievelijk van $89 \%$ tot $100 \%$ en van $82 \%$ tot $97 \%$. In de controle groep varieerde de specificiteit voor alle $\operatorname{IgM}$ en IgG testen respectievelijk van $75 \%$ tot $95 \%$ en van $84 \%$ tot $100 \%$. De testen van Behring (Duitsland) en Genzyme Virotech (Duitsland) gaven de beste resultaten voor wat betreft de detectie van IgM antilichamen tegen B. burgdorferi in de vroege LB groep. Ondanks de lagere sensitiviteit voor de detectie van $\mathrm{IgG}$ antilichamen tegen $B$. burgdorferi behaalde de Dako (Denemarken) testkit de beste resultaten in de groep patiènten met late LB.

Het gebruik van een ElA-WB twee-stappen protocol verbeterde de specificiteit en de positief voorspellende waarde van het onderzoek. Dit ging echter ten koste van de sensitiviteit, die significant daalde. Epstein-Barr virus of cytomegalovirus infecties veroorzaakten een fout positief resultaat in de IgM-EIA en WB testen. Daarom lijkt bij een positieve IgM-EIA test uitslag, uitsluiting van deze infecties meer relevant dan bevestiging met een WBtest.

De enige polyvalente EIA die geëvalueerd werd gaf beduidend slechtere resultaten dan de geteste monovalente EIA's. Omdat sommige laboratoria het gebruik van polyvalente EIA's prefereren of routinematig altijd een IgM en een IgG EIA gebruiken werden ook de resultaten van de gecombineerde IgM en IgG testresultaten geëvalueerd. Hieruit bleek dat het gebruik van gecombineerde IgM en IgG testen de sensitiviteit weliswaar significant verhoogde, maar door de aanwezigheid van kruisreagerende IgM of IgG antilichamen was de specificiteit significant lager.

In hoofdstuk IV worden de resultaten beschreven van een onderzoek naar de prevalentic van IgA, IgM, totaal $\mathrm{IgG}$ en subklassen van $\mathrm{IgG}\left(\mathrm{IgG}_{1-4}\right)$ antilichamen tegen B. burgdorferi. Verder werd onderzocht of met deze informatie de prestaties van de EIA of WB zou kunnen worden verbeterd. Hiervoor werden sera van 40 patiënten met vroege LB, 27 patiënten met late LB, 62 gezonde patiènten en 140 patiènten met andere infecties dan LB gebruikt. In vergelijking met de totale IgG detectie vertoonde $\mathrm{IgG}_{1}$ een hogere sensitiviteit voor de detectie van antilichamen tegen $B$. burdorferi antigenen en wel in het bijzonder tegen het $41 \mathrm{kD}$ flagelline eiwit. De prestatie van WB testen werd door de detectie van $\mathrm{IgG}_{1}$ antilichamen echter niet verbeterd. In het geval van 
$\mathrm{IgG}_{1}$ detectie in met flagelline verrijkte EIA's werd bij patiënten met vroege $\mathrm{LB}$ echter wel een verhoging van sensitiviteit en specificiteit waargenomen. Vergeleken met EIA's, die als antigeen een gekweekte $B$. burgdorferi stam gebruiken, was in geval van $\mathrm{IgG}_{1}$ detectie de sensitiviteit lager dan wanneer IgM of totaal IgG gedetecteerd werd. $\mathrm{Bij}$ vroege $\mathrm{LB}$ patiënten konden tegen flagelline, in tegenstelling tot andere specifieke antigenen, eerder IgG $_{4}$ antilichamen aangetoond worden. Geconcludeerd werd dat de prestaties voor het opsporen van patiënten met vroege LB verbeterd zouden kunnen worden wanneer in met flagelline verrijkte EIA's gebruik gemaakt wordt van $\mathrm{IgG}_{1}$ detectie.

In hoofdstuk $\mathbf{V}$ wordt onderzocht of het bezit van een hond als huisdier of het frequent vertoeven in bos en veld, de kans op een B. burgdorferi infectie vergroot. Bovendien werd het verloop van de antilichaam respons bij mens en hond vergeleken. Ook werd de voorspellende waarde onderzocht van de prevalentie van antilichamen tegen $B$. burgdorferi bij honden voor de kans op LB bij mensen in hetzelfde gebied. Hiervoor werden sera van 53 jagers zonder hond, 440 jagers met hun voor de jacht gebruikte hond(en) ( $\mathrm{n}=448)$ en 75 gezonde stadshonden getest op antilichamen tegen $B$. burgdorferi met behulp van een EIA-test. De seroprevalentie was bij alle groepen vergelijkbaar; bij jachthonden $18 \%$, bij stadshonden $17 \%$ en bij jagers $15 \%$. De seropositiviteit bij jachthonden was geen relevante indicator voor een verhoogd risico op LB bij de eigenaar. Omdat bij honden die ouder waren dan 24 maanden de seroprevalentie constant bleef, werd geconcludeerd, dat de persistentie van specifieke antilichamen tegen $\boldsymbol{B}$. burgdorferi na een infectie relatief kort is: circa een jaar. Bij mensen duurt deze seropositiviteit veel langer, maar is zeker niet levenslang. Geconcludeerd werd, dat ondanks een vergelijkbare seroprevalentie, de incidentie van B. burgdorferi infecties bij honden aanzienlijk hoger geweest moet zijn dan bij jagers. Er bestond geen correlatie tussen seropositiviteit van een jager en die van zijn/haar hond en daarom lijkt overdracht van (besmette) teken van hond naar mens geen rol van betekenis te spelen in de epidemiologie van LB bij de mens. Hieruit kan geconcludeerd worden dat hondenbezit op zich geen risico vormt voor de mens met betrekking tot LB.

In hoofdstuk VI worden voor de toepassing in seroepidemiologische studies 5 serologische testen voor de detectie van IgM en IgG antilichamen tegen B. burgdorferi sensu stricto bij honden met elkaar vergeleken. Als antigeen werden in deze testen verschillende genotypen van $B$. burgdorferi gebruikt. Hiervoor werden 1177 sera getest afkomstig van $\mathbf{4 0 1}$ gezonde voor de jacht gebruikte jachthonden, 100 gezonde stadshonden, 47 jachthonden met kreupelheid en 629 stadshonden waarvoor een dierenarts geconsulteerd was vanwege uiteenlopende ziekteverschijnselen. De 5 gebruikte testen waren eerst geijkt en geëvalueerd met sera van experimenteel geïnfecteerde honden en laboratorium honden die nooit met teken in contact konden zijn geweest. De resultaten van de 5 EIA's, waaronder een commerciële testkit (Genzyme-Virotech, Duitsland) kwamen sterk overeen (kappa: 0.78-081). Ook de resultaten van een zelf ontwikkelde species onafhankelijke EIA (dit is een EIA die kan gebruikt worden voor het testen van serummonsters van verschillende diersoorten) kwamen goed overeen met die van de 4 andere testen voor het aantonen van IgG tegen B. burgdorferi bij honden. Deze zelf ontwikkelde test lijkt daarom bruikbaar voor sero-epidemiologische studies waarbij men sera van verschillende diersoorten wil onderzoeken. Aan de hand van de sera van honden met diverse ziekteverschijnselen zoals: verlammingsverchijnselen $(n=60)$, neurologische afwijkingen $(n=60)$ en huidafwijkingen $(n=52)$ is aangetoond dat de sensitiviteit van de zelf opgezette EIAs onafhankelijk is van de gebruikte B. burgdorferi stam. Bovendien bleek uit de resultaten van de sera van experimenteel geïnfecteerde honden dat voor de detectie van acute LB, de indirecte haemagglutinatietest (Diagast $\circledast$, Frankrijk) een waardevolle test zou kunnen zijn. Met deze test werd een hoge sensitiviteit voor IgM antilichamen aangetoond. Echter noch bij honden met een hoog, noch bij honden met een laag risico op een infectie met $B$. burgdorferi kon een positief serologisch resultaat gecorreleerd worden met klinische symptomen. De ondersteunende waarde aan serologisch onderzoek lijkt daarom voor de diagnose van LB bij honden beperkt. De waargenomen hoge sensitiviteit van de indirecte haemagglutinatietest voor de detectie van IgM antilichamen tegen $B$. burgdorferi bij honden, nodigt uit tot verder onderzoek met deze test bij de mens.

In hoofdstuk VII wordt het regionale risico op LB in Nederland onderzocht door de prevalentie van antilichamen tegen $\boldsymbol{B}$. burgdorferi bij gezonde personen $(n=1052)$, honden $(n=1177)$, runderen $(n=3919)$ en schapen $(n=2288)$ uit 12 verschillende gebieden in Nederland in kaart te brengen. In alle gebieden werden seropositieve mensen en dieren gevonden en bestaat dus het risico op LB. Bij gezonde personen uit de kuststreken 
werd een hogere prevalentie $(13 \%-17 \%)$ waargenomen dan bij mensen uit het Noorden, Zuiden en Oosten van Nederland $(2 \%-6 \%)$. Bij honden werd geen verschil in prevalentie (15\%-23\%) tussen de diverse gebieden waargenomen. $\mathrm{Bij}$ runderen was de hoogste prevalentie $(11 \%-20 \%)$ in de oostelijke gebieden en de laagste prevalentie $(2 \%-8 \%)$ in de kustgebieden. Bij schapen echter was de prevalentie het hoogst (15\%-17\%) in de kustgebieden en significant lager (4\%-8\%) in het Oosten van Nederland $(P<0,001)$. De waargenomen prevalenties verschilden in de diverse onderzochte gebieden en varieerden tussen de onderzochte diersoorten. Dit kon verklaard worden door de geschiktheid van de aanwezige biotopen voor Lxodes ricinus teken in de betreffende gebieden en de frequentie waarmee mensen, honden, runderen en schapen uit die gebieden met deze biotopen en dus met teken in contact komen.

\section{CONCLUSIES}

Door het gebrek aan een specifieke antilichaamrespons in sommige LB patiënten, het frequent voorkomen van asymptomatische infecties en aanwezigheid van kruisreagerende antilichamen, kan bij geen enkele serologische LB test een sensitiviteit en specificiteit van $100 \%$ bereikt worden. Van alle gebruikte laboratoriumtesten voor serologisch onderzoek van LB bleek de EIA de meest geschikte test te zijn. Deze test moet echter gebruikt worden voor de laboratoriumconfirmatie van een duidelijk klinische verdenking op LB. Het bevestigen van een positief EIA resultaat met een WB-test verhoogde de specificiteit ten koste van de sensitiviteit. Het uitsluiten van een Epstein-Barr virus infectie of CMV infectie bleek effectiever. Daarnaast is de EIA een waardevol hulpmiddel bij epidemiologische studies naar B. burgdorferi infecties.

Zoals bewezen bij honden zou voor de detectie van IgM antilichamen bij Lyme patiënten in het vroege stadium van de ziekte, de indirecte haemagglutinatie test van waarde kunnen zijn. Nader onderzoek hiernaar is wenselijk.

Ondanks een hoge prevalentie en incidentie van B. burgdorferi infecties bij honden en andere huisdieren in Nederland, lijkt klinische LB bij huisdieren zelden voor te komen.

$\mathrm{Bij}$ de mens is het van groot belang dat artsen zich realiseren dat de diagnose LB voornamelijk een klinische diagnose is die gebaseerd is op gegevens uit de anamnese en de klinische symptomen. De diagnose van LB kan enkel door serologisch onderzoek bij patiënten bevestigd worden waarvan de waarschijnlijkheid dat de patient lijdt aan LB groter is dan 20\%. Een lagere waarschijnlijkheid heeft tot gevolg dat laboratoriumbevestiging resulteert in meer foute dan correcte uitslagen.

Bij huisdieren lijkt LB, ondanks de grote besmettingsgraad zelden klinische verschijnselen te veroorzaken. 



\section{Acknowledgments}

This thesis would not have been possible without the help and support from many inidividuals. I would like to take this opportunity to express my sincere gratitude and appreciation to:

Dr. A. van den Bogaard for offering me the opportunity to work in the laboratory of the Centralised Animal Facilities, for your continuous guidance, support and encouragement throughout this study. Ton, especially thanks for your expertise and preparation of the articles.

Prof. Dr. C. Bruggeman for being my promotor and for the interest shown in my work and help with the preparation of this thesis.

Dr. A. Ramon for the initial stimulation to start my PhD-study.

Dr. L. Nohlmans for providing clinical defined sera.

Jacqueline Maes for her technical advice and support and for creating a pleasant working atmosphere.

Math Hazen for his expertise on software.

Petra Vandervoort and Ann Neve for their practical assistance.

Peter Kessler, for giving me the opportunity of combining my PhD-study and work at Genzyme Virotech.

Andreas Strubel, for allowing me to arrange my work ad libido.

Anne-Marie Salupo, for the nice cd-rom version of this dissertation and Java-programming.

Valerie van den Bogaard, for her hospitality and her enchanting cooking creations during my stay in Eysden.

Furthermore, I wish to express my gratitude to my family members, my parents and parents-in-law for their encouragement. My wife for marrying me, her loving care and her ultimate present on 11 september 2001, our daughter Leonie.

My dog Zita for her persistent willpower to take me outside regardless of the weather condition during the weekends.

Last but not least, I want to thank all, who are not mentioned by name, but who contributed to this dissertation. 



\title{
Curriculum Vitae
}

\author{
H.A.T. Goossens
}

The author of this disseration was born in Gent, Belgium on June 9, 1969. After obtaining his diploma VSO-Latin/ Mathematics he finished his study of graduate in bio-chemistry at the higher institute Sint-Lieven, Belgium, in 1992. At the Polytechnical Faculty West-Brabant, the Netherlands, he got his degree of Ing. in bio-chemistry in 1993. During his military service as noncommissioned officer he worked at the laboratoria of immunology and bacteriology of the military hospital Köln, Germany (head Dr. Ramon). From 1994 to present he is a research associate in the "Department of Research \& Business Development" at Genzyme Virotech, Rüsselsheim, Germany. From 1996 to 2002 he worked at this thesis in the Centralised Animal Facilities of the Maastricht University, Maastricht, the Netherlands (head Dr. van den Bogaard). 



\section{List of publications}

1. Goossens, H. A., A. E. van den Bogaard, and M. K. Nohlmans. 1999. Evaluation of fifteen commercially available serological tests for diagnosis of Lyme borreliosis. Eur J Clin Microbiol Infect Dis 18:551-60.

2. Goossens, H. A., A. E. van den Bogaard, and M. K. Nohlmans. 2000. Reduced specificity of combined IgM and IgG enzyme immunoassay testing for lyme borreliosis. Eur J Clin Microbiol Infect Dis 19:400-2.

3. Goossens, H. A., M. K. Nohlmans, and A. E. van den Bogaard. 1999. Epstein-Barr virus and cytomegalovirus infections cause false-positive results in IgM two-test protocol for early Lyme borreliosis. Infection 27:231.

4. Goossens, H. A., A. E. van den Bogaard, and M. K. Nohlmans. 2001. Serodiagnosis of Lyme borreliosis using detection of different immunoglobulin (sub)classes by enzyme-linked immunosorbent assay and Western blotting. Clin Lab 47:41-9.

5. Goossens, H. A., A. E. van den Bogaard, and M. K. Nohlmans. 2001. Dogs as sentinels for human Lyme borreliosis in The Netherlands. J Clin Microbiol 39:844-8.

6. Goossens, H. A., J.H. Maes, A. E. van den Bogaard. 2002. Development of a species independent EIA for the estimation of the prevalence of antibodies against B. burgdorferi in dutch dogs. Accepted, Nederlands Tijdschrift voor diergeneeskunde. 
\}
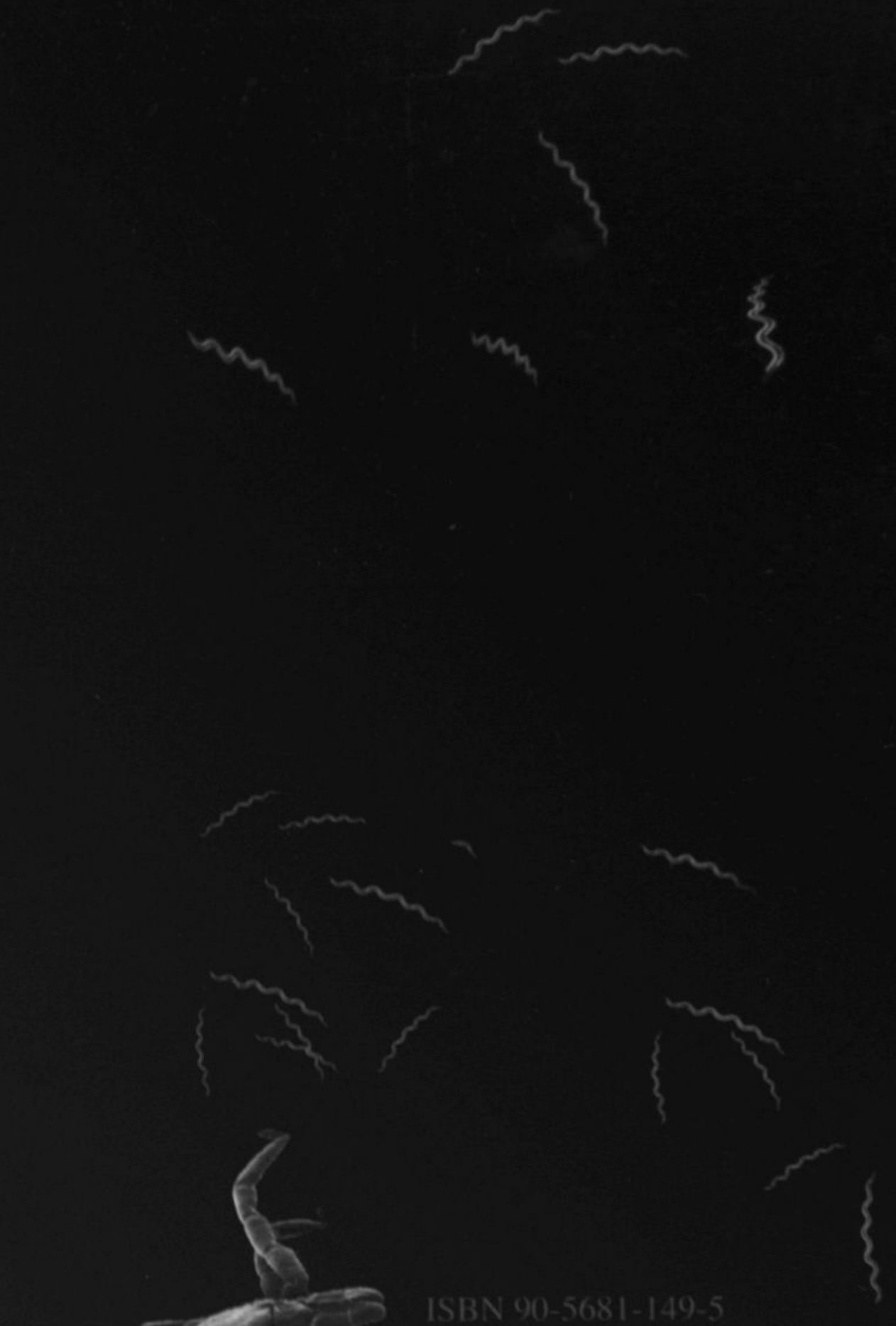